Florida International University FIU Digital Commons

6-15-1990

\title{
An assessment of the effectiveness of the Polanyi equilibrium theory at predicting adsorption isotherms
}

James D. Burkhart

Florida International University

DOI: $10.25148 /$ etd.FI14051885

Follow this and additional works at: https://digitalcommons.fiu.edu/etd

\section{Recommended Citation}

Burkhart, James D., "An assessment of the effectiveness of the Polanyi equilibrium theory at predicting adsorption isotherms" (1990). FIU Electronic Theses and Dissertations. 1891.

https://digitalcommons.fiu.edu/etd/1891 
ABSTRACT

AN ASSESSMENT OF THE EFFECTIVENESS OF THE POLANYI EQUILIBRIUM

THEORY AT PREDICTING ADSORPTION ISOTHERMS

by

James D. Burkhart, B.A.

The Polanyi Equilibrium Theory proposes that a characteristic curve exist which can, after the application of certain abscissa scale factors, describe the adsorption of all compounds on a given carbon. A study was undertaken, using published data from several sources on a variety of compounds and carbons to challenge the most fundamental aspects of the Polanyi Adsorption Equilibrium Theory. Its effectiveness as a predictive model was tested by constructing characteristic curves and comparing the observed isotherm data to the Polanyi predictions.

The results support the existence of the characteristic curve. However, in several instances, experimental data was required to accurately determine the required scale factors. Data from several compounds indicates that these scale factors can be estimated from a single data point. A comparison of predicted to observed scale factors indicates that polarizability is effective in providing only an approximation of the true abscissa scale factors.

An additional adjustment for adsorbate density is required to correct for the theorized inefficient packing of the solids in the carbon pores. However, after these empirically determined scale factors are applied, an accurate depiction of the data results. 
AN ASSESSMENT OF THE EFFECTIVENESS OF THE POLANYI EQUILIBRIUM THEORY AT PREDICTING ADSORPTION ISOTHERMS

by James D. Burkhart, B.A.

A Thesis submitted in partial fulfillment of the requirements for the degree of MASTER OF SCIENCE

in

ENVIRONMENTAL ENGINEERING

at

FLORIDA INTERNATIONAL UNIVERSITY

Committee in charge:

Assistant Professor Roberto M. Narbaitz Chairperson

Assistant Professor Jeffrey H. Greenfield

Assistant Professor Robert J. Fennema

June 1990 
To Assistant Professors Roberto M. Narbaitz

Jeffrey H. Greenfield

Robert J . Fennema

This thesis, having been approved in respect to form and mechanical

execution, is referred to you for judgment upon its substantial merit.

Gordon R. Aopkins, Dean

College of Engineering

and Applied Sciences

The thesis of James D. Burkhart is approved.

Professor

"Proffessor

Májor Professox

Date of Examination:

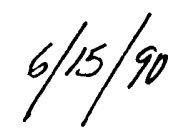


AN ASSESSMENT OF THE EFFECTIVENESS OF THE POLANYI EQUILIBRIUM THEORY AT PREDICTING ADSORPTION ISOTHERMS

by

James D. Burkhart, B.A.

A Thesis submitted in partial fulfillment of the requirements for the degree of

MASTER OF SCIENCE

in

ENVIRONMENTAL ENGINEERING

at

FLORIDA INTERNATIONAL UNIVERSITY

1990 
First, I wish to thank my advisor, Dr. Roberto Narbaitz, for his encouragement and direction throughout this research project. His knowledge and advice led me to a greater understanding of the subject.

I would also like to thank Dr. Jeffrey H. Greenfield and Dr. Robert J. Fennema for reviewing my thesis and offering constructive suggestions on its improvement.

Additionally, I wish to thank Stanley and Kathleen M. Glaser for their financial assistance.

Finally, I would like to thank my wife Lori and my children Kimmie, Sarah and Jimmy. Without their understanding and support this thesis would not have been possible. 


\section{TABLE OF CONTENTS}

Chapter

Page

LIST OF FIGURES. vii

NOMENCLATURE .

$x i$

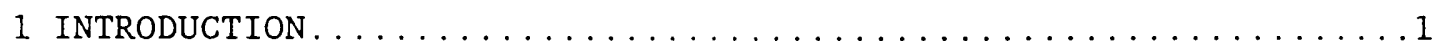

2 LITERATURE REVIEW...........................

2.1 Activated Carbon and Adsorption Mechanisms...........

2.2 Single Solute Isotherms.................

2.3 Predictive Single Solute Isotherms..............

2.4 Polanyi Model for Single Solute Adsorption...........11

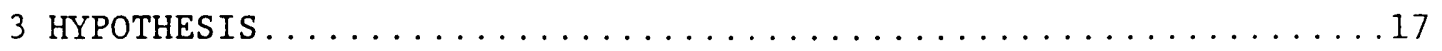

4 OBJECTIVES ............................. 18

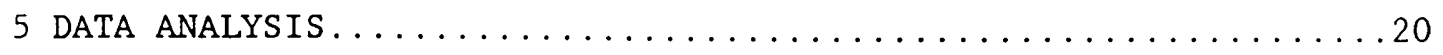


6 EVALUATION OF THE POLANYI MODEL FOR SINGLE SOLUTE ISOTHERMS . . . 23

6.I Evaluation of the Polanyi Model for Speth's Data......23

6.1 .1 Basic Characteristic Curve...............26

6.1.2 Theoretically Predicted Characteristic Curves..... 30

6.1.3 Regression Base Characteristic Curves............ 34

6.1 .4 Summary of Analysis of Speth's Data...........49

6.2 Evaluation of the Polanyi Model for Fukuchi's Data.....51

6.2 .1 Basic Characteristic Curve..................54

6.1.2 Theoretically Predicted Characteristic Curves.....56

6.2.3 Density Adjustments for Solids............60

6.1.3 Regression Base Characteristic Curves...........64

6.2 .4 Summary of Analysis of Fukuchi's Data..........79

6.3 Evaluation of the Polanyi Model for Luft's Data.......80

6.3 .1 Basic Characteristic Curve................ 82

6.1.2 Theoretically Predicted Characteristic Curves.....86

6.1 .3 Regression Base Characteristic Curves...........89

6.3.4 Comparison Between Different Activated Carbons.....89 
6.3.5 Summary of Analysis of Luft's Data.............101

6.4 Evaluation of the Polanyi Model for van Vliet's Data...103

6.4 .1 Basic Characteristic Curves.............. . . . 104

6.4.2 Between Carbon Comparison of Scale Factors........104

6.4.3 Summary of Analysis of van Vliet's Data........111

6.5 Evaluation of the Polanyi Model for Kong's Data.......112

6.5.1 Basic Characteristic Curves.................113

6.1.2 Theoretically Predicted Characteristic Curves.....113

6.1.3 Regression Base Characteristic Curves..........116

6.5 .4 Summary of Analysis of Kong's Data............121

6.6 Evaluation of the Polanyi Model for Narbaitz's Data....122

6.6.1 Basic Characteristic Curves.................... 23

6.1.2 Theoretically Predicted Characteristic Curves.....123

6.1.3 Regression Base Characteristic Curves...........126

6.6.4 Summary of Analysis of Narbaitz's Data..........130

6.7 Summary of Evaluations..................... 131 


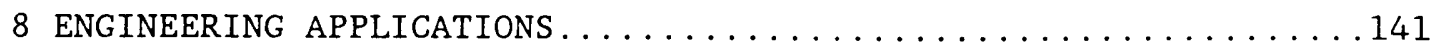

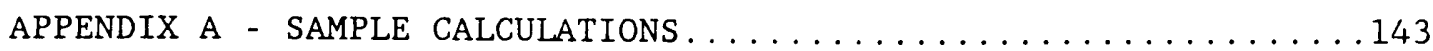

APPENDIX B - ADSORPTION ISOTHERM DATA............... 146

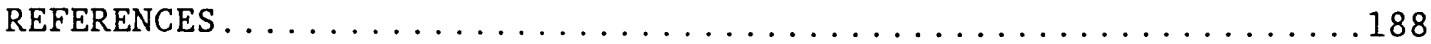


6.1. Characteristic Curve of Speth's Raw Data.............27

6.2. Speth's data fit with an exponential...............29

6.3. Speth's data fit with an exponential with constant.......29

6.4. Speth's data - observed vs TDASFprediction for:

a) bromoform, b) CDBM, c) chloroform, d) cis-DCE.........31

6.5. Speth's data - observed vs TDASF prediction for: a) DBE,

b) ethylbenzene, c) m-xylene, d) o-xylene...............

6.6. Speth's data - observed vs TDASF prediction for: a) PCE,

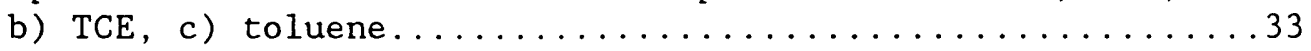

6.7. Correlation Curve of Speth's data - adjusted

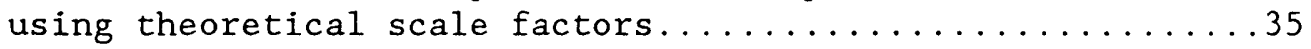

6.8. Speth's data - best fit for: a) bromoform, b) CDBM,
c) chloroform,
d) cis-DCE.

6.9. Speth's data - best fit for: a) DBE, b) ethylbenzene,

c) m-xylene, d) o-xylene.

6.10. Speth's data - best fit for: a) PCE, b) TCE,

c) toluene.

6.11. Correlation Curve of Speth's data - adjusted using EDASF (exponential) ...................

6.12. Correlation Curve of Speth's data - adjusted using EDASF (exponential w/constant).

6.13. Speth's bromoform data - worst case results using single point EDASF (exp) $\ldots \ldots \ldots \ldots \ldots \ldots 4$

6.14. Speth's bromoform data - worst case results using single point EDASF ( $\exp w /$ constant) $\ldots \ldots \ldots \ldots \ldots$

6.15. Speth's PCE data - worst case results using single point EDASF (exp) .............44

6.16. Speth's PCE data - worst case results using single point EDASF (exp w/constant) ............44

6.17. Characteristic Curve of Fukuchi's Raw Data............55

6.18. Characteristic Curve of Fukuchi's vinyl acetate data - best fit reference curve................. 57 
6.19. Fukuchi's data - observed vs TDASF prediction for:

a) acetone, b) n-butanol, c) MEK, d) pyridine..........58

6.20. Fukuchi's 2-propanol data - observed vs TDASF prediction ...59

6.21. Fukuchi's propionitrile data - observed

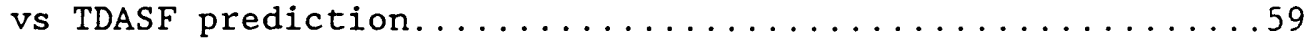

6.22. Fukuchi's benzoic acid data (no density adjustment)

- observed vs TDASF prediction ..................61

6.23. Fukuchi's benzoic acid data (ordinate density adjustment) - observed vs TDASF prediction...........61

6.24. Fukuchi's p-chlorophenol data (no density adjustment) - observed vs TDASF prediction...........62

6.25. Fukuchi's p-chlorophenol data (ordinate density adjustment) - observed vs TDASF prediction...........62

6.26. Fukuchi's phenol data (no density adjustment)

- observed vs TDASF prediction..................663

6.27. Fukuchi's phenol data (ordinate density adjustment)

- observed vs TDASF prediction.................63

6.28. Fukuchi's data (ordinate and abscissa adjustment)

- observed vs TDASF prediction for a) benzoic acid,

b) $\mathrm{p}$-chlorophenol, c) phenol ................65

6.29. Fukuchi's data - best fit for: a) acetone,

b) $\mathrm{n}$-butanol, c) MEK, d) pyridine..............67

6.30. Fukuchi's 2 -propanol data - best fit.............68

6.31. Fukuchi's propionitrile data - best fit...........68

6.32. Fukuchi's benzoic acid data - best fit: no density adjustment, b) ordinate density adjustment, c) ordinate

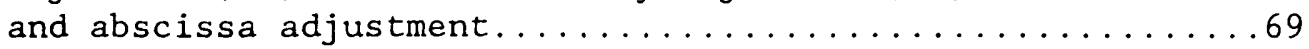

6.33. Fukuchi's p-chlorophenol data - best fit: no density adjustment, b) ordinate density adjustment, c) ordinate and abscissa adjustment...............

6.34. Fukuchi's phenol data - best fit: no density adjustment, b) ordinate density adjustment, c) ordinate and abscissa adjustment................... 71

6.35. Correlation Curve of Fukuchi's data - adjusted using TDASF............................... 75

6.36. Correlation Curve of Fukuchi's data - adjusted 
6.37. Fukuchi's MEK data - worst case

results using single point EDASF $\ldots \ldots \ldots \ldots \ldots \ldots \ldots$

6.38. Fukuchi's 2-propanol data - worst case

results using single point EDASF...............78

6.39. Characteristic curves of Luft's raw data on:

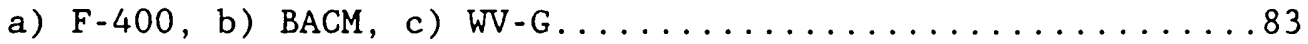

6.40. Reference characteristic curves of Luft's raw

data on: a) F-400, b) BACM, c) WV-G.............. 85

6.41. Luft's chloroform data - observed vs TDASF prediction

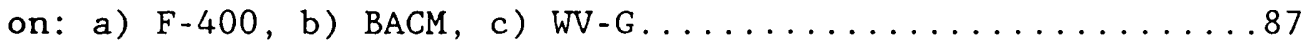

6.42. Luft's TCE data - observed vs TDASF prediction

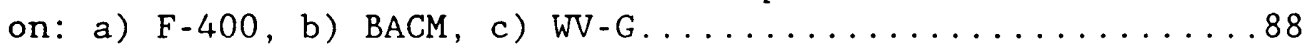

6.43. Luft's chloroform data - best fit

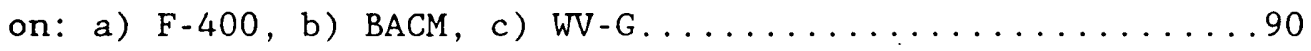

6.44. Luft's TCE data - best fit

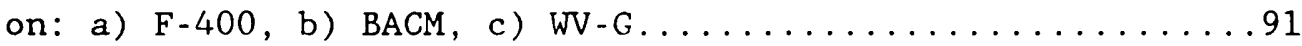

6.45. Luft's data using F-400 scale factors: a) chloroform

on HD-3000, b) chloroform on WV-G, c) TCE on HD-3000,

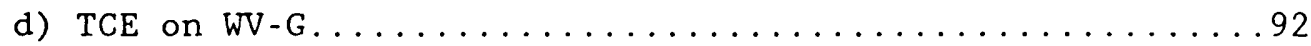

6.46. Correlation Curves of Luft's data using TDASF

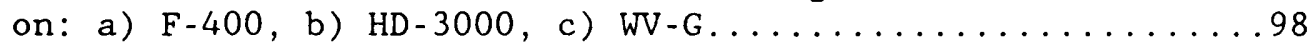

6.47. Correlation Curves of Luft's data using EDASF

(exponential) on: a) F-400, b) HD-3000, c) WV-G.........99

6.48. Correlation Curves of Luft's data using EDASF (exponential

w/constant) on: a) F-400, b) HD-3000, c) WV-G.........100

6.49. Characteristic curves of unadjusted data:

a) van Vliet's F-400, b) van Vliet's BACM,

c) Fukuchi's F-400

6.50. Characteristic curve of van Vliet's phenol

data - best fit $F-400$ reference curve..............106

6.51. Characteristic curve of van Vliet's phenol

data - best fit BACM reference curve...............106

6.52. Van Vliet's PCP data - observed vs predicted on:

a) F-400 using theoretical scale factor, b) BACM using theoretical scale factor, c) F-400 using Fukuchi's scale factor, d) BACM using Fukuchi's scale factor............108 
6.53. Correlation curves of van Vliet's data: a) F-400 using theoretical scale factor, b) BACM using theoretical scale factor, c) F-400 using Fukuchi's scale factor,

d) BACM using Fukuchi's scale factor................110

6.54. Characteristic curve - Kong's raw data.............114

6.55. Characteristic curve of Kong's PCE data best fit reference curve......................114

6.56. Kong's carbon tetrachloride data - observed

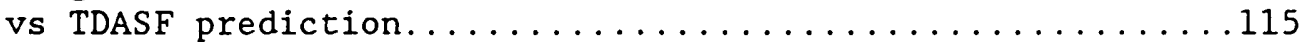

6.57. Kong's TCE data - observed vs TDASF prediction........115

6.58. Kong's data - best fit: a) carbon tetrachloride, b) TCE, c) TCE using Speth's scale factor.............117

6.59. Correlation curve of Kong's data - adjusted

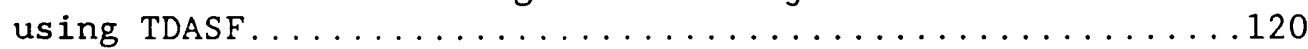

6.60. Correlation curve of Kong's data - adjusted

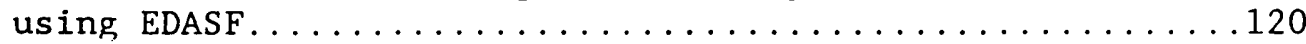

6.61. Characteristic curve - Narbaitz's raw data............124

6.62. Narbaitz's TCE data -

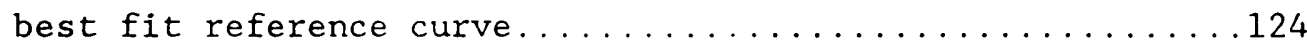

6.63 Narbaitz's carbon tetrachloride data: a) observed vs TDASF prediction, b) best fit, c) using Kong's EDASF....125

6.64. Correlation curve of Narbaitz's data - adjusted

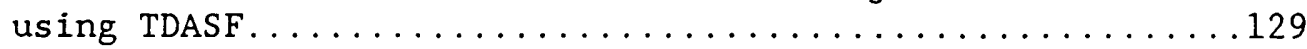

6.65. Correlation curve of Narbaitz's data - adjusted

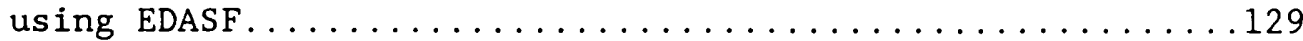




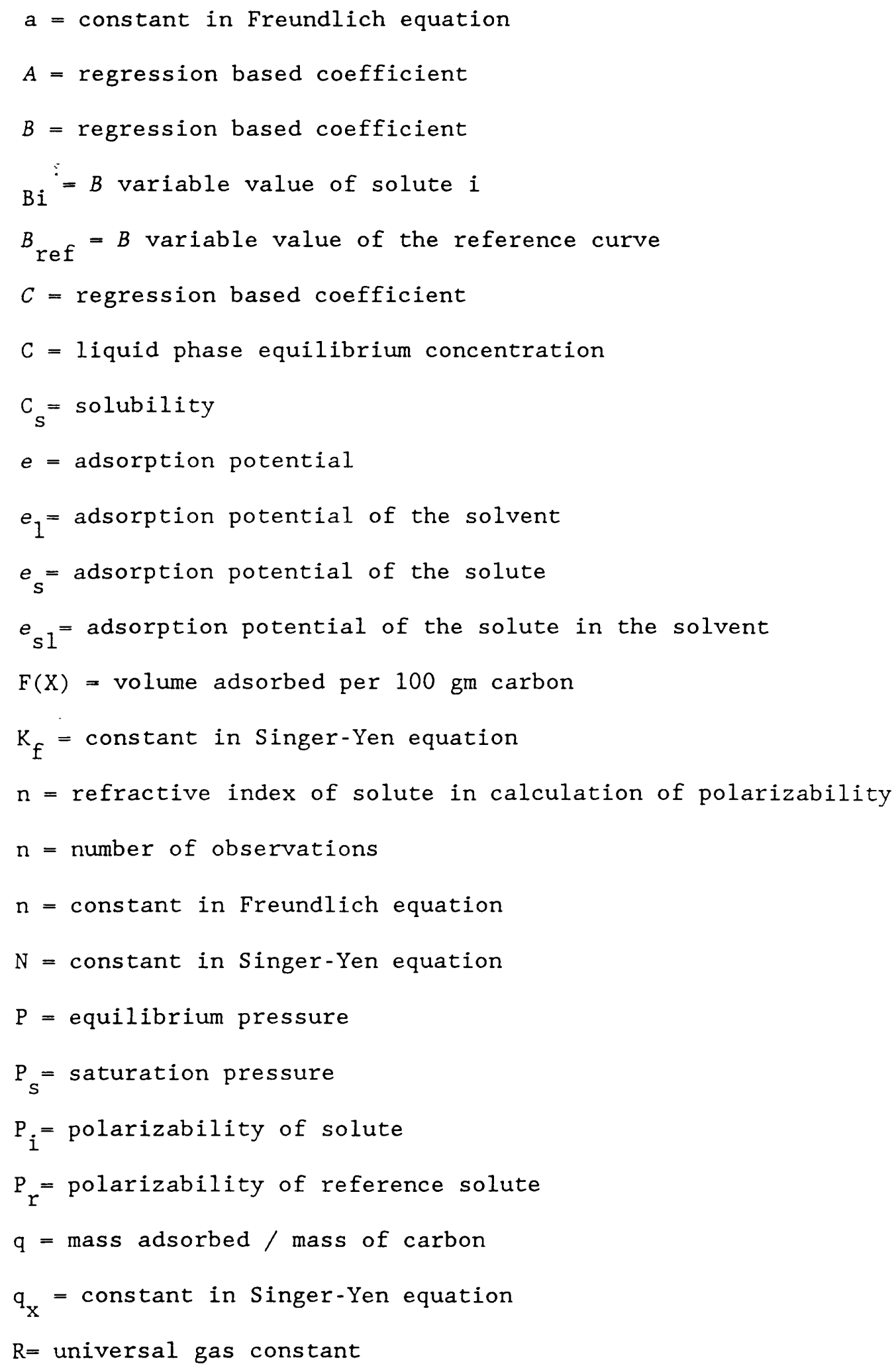


$\mathrm{T}=$ absolute temperature

TDASF $=$ Theoretically Determined Abscissa Scale Factor

$\mathrm{V}=$ Molar Volume (molecular weight / density)

$\mathrm{W}=$ weighting factor, $1 / \mathrm{Y}_{\mathrm{ob}}$

$\mathrm{X}=(\mathrm{T} / \mathrm{V}) \log \left(\mathrm{C}_{\mathrm{s}} / \mathrm{C}\right)$

$\mathrm{Y}_{\mathrm{ob}}=$ observed dependent variable value

$\mathrm{Y}_{\text {pred }}=$ predicted dependent variable value

$\mathrm{Y}_{\mathrm{wt}}=$ weighted dependent variable value

$Z$ = correction factor for polarizability 
CHAPTER 1

INTRODUCTION

As groundwater is the United States' major source of drinking water, there has been an increasing concern about the potential deleterious health effects of groundwater contamination by hazardous chemicals. This type of problem is becoming fairly common as indicated by an eight state survey conducted by the EPA which found that $28 \%$ of the wells tested positive for trichloroethylene (EPA, 1980). Currently, a number of alternatives are available to deal with a polluted aquifer. Choices which should be given first consideration are those which can be grouped as "management techniques". Eliminating the pollution source, finding a different water supply or blending the polluted water with clean water are examples (Dyksen and Hess, 1982). If these options are not practical, decontamination methods such as air stripping or in-situ bioreclamation should be considered. Another method which has proven to be both economical and successful in restoring water to very high quality levels is activated carbon adsorption (O'Brian and Fisher, 1983). Recent amendments to the Safe Drinking Water Act (EPA, 1986), which list activated carbon as the best available technology for treating synthetic organic chemicals, should further increase interest in activated carbon adsorption.

Determining the effectiveness of granular activated carbon, GAC, for treating a particular water requires testing of the actual wastestream. At a minimum, this testing should consist of laboratory batch equilibrium experiments which are called isotherms as they are conducted at constant temperature. Batch adsorption equilibrium studies 
define the relationship between the quantity adsorbed and the quantity in solution at equilibrium and measure the maximum capacity of an adsorbent, the carbon, for an adsorbate, the contaminant (Schuliger, 1978). Although this maximum capacity is often unattained in practice, knowledge of true equilibrium is critical since it is the main driving force of an adsorption treatment system. However, the work required in defining these isotherms is delicate, costly and quite time consuming. Fortunately, there are models available which can, if not totally eliminate, reduce considerably the amount of laboratory testing required. One of these models, based on the Polanyi Adsorption Theory, seems to be well suited for predicting isotherms (Polanyi, 1916). The purpose of this thesis is to verify the applicability of the Polanyi theory in single solute cases. 
CHAPTER 2

\section{LITERATURE REVIEW}

The importance of activated carbon as a treatment method for the removal of trace organics is reflected by the large number of articles and books published on the subject in recent years. For convenience, these publications are divided into several subtopics: 1) activated carbon and adsorption mechanisms, 2) single solute isotherms, 3) predictive single solute isotherms and 4) the Polanyi model for single solute adsorption.

2.1 Activated Carbon and Adsorption Mechanisms

Activated carbon is the name given to a variety of organic materials which, after undergoing a controlled process of dehydration, carbonization and oxidation, develop a porous structure yielding surface areas on the order of $1000 \mathrm{~m}^{3}$ per gram (Lyman, 1978). This large surface area to mass ratio is primarily responsible for activated carbon's excellent adsorptive properties. Other important characteristics of an adsorbent are its pore size distribution and surface chemistry. The physical conditions under which the aforementioned activation process occurs, as well as the raw material used, strongly influence each of these physical characteristics (Mattson, 1978).

During the carbonization step high temperatures (up to $600^{\circ} \mathrm{C}$ ) are used to remove impurities from the carbon. What remains is a highly concentrated carbon but with little of the micropore structure required 
for a high surface area and effective adsorption. These pores are created by activating the carbon at high temperatures in the presence of oxidizing materials such as oxygen, steam or carbon dioxide. Although a highly porous product, consisting of numerous parallel planes of carbon, results, functional groups, composed of various combinations of oxygen, hydrogen and carbon, are frequently formed at the edges of these planes (Cookson, 1978). These groups form strong chemical bonds with certain solutes and chemical adsorption results.

However, the great majority of adsorption occurs within the basal planes of the carbon. This adsorption, which is due to van der Waals forces, is referred to as physical adsorption (Belfort, 1980). Although the adsorptive bonds formed are not as strong as in chemical adsorption, the number of such bonds vastly outweighs those resulting from chemisorption.

Adsorption thus occurs when a substance, due to physical or chemical forces, accumulates at the interface of two phases (Montgomery, 1985). The degree of adsorption is dependent, not only on the properties of the adsorbent, but also upon the properties of the adsorbate and the environmental conditions.

Although the adsorption process is quite complex and there are many exceptions, a few rules generally apply. For example, highly soluble compounds are difficult to adsorb since more energy is required to remove the solute from the solvent. Also, polar compounds are prone to form hydrogen bonds with the water thus decreasing their adsorption. This effect may be offset by a polar compound's tendency to form bonds with some functional groups. In general, nonpolar compounds are more easily adsorbed on nonpolar adsorbents (such as activated carbon). The 
temperature at which the isotherm is conducted will also affect results. In general, higher temperatures will decrease physical while increasing chemical adsorption capacity. Finally, the pH of the liquid affects adsorption in that favorable adsorption conditions correspond to the $\mathrm{pH}$ which results in minimum ionization (Lyman, 1978).

Therefore, due to the complexities involved in the treatment process, it must be demonstrated that the contaminated wastestream is amiable to carbon treatment. Once the wastestream is characterized, the decision can be made how to treat it. Many compounds, such as benzene, phenol, TCE and most other organic compounds, as well as some heavy metals are effectively removed by carbon; others compounds are not (Stover and Kincannon, 1983).

\subsection{Single Solute Isotherms}

To determine if activated carbon adsorption is feasible in a particular situation, batch adsorption isotherms are performed. In this procedure a specific concentration of the pollutant is measured into several bottles containing increasing amounts of carbon. These bottles are then rotated until an equilibrium state between the compound existing in the liquid and solid (on the carbon) phases is attained. The time required to reach this equilibrium varies with the carbon and the contaminant and true equilibrium may, in some instances, never be reached (Sontheimer, Crittenden and Summers, 1988).

The equilibrium concentration of the solute remaining in the liquid is then measured for each isotherm bottle. The amount of solute adsorbed onto the carbon is determined as the difference between the 
initial and the equilibrium concentrations within the solvent. Graphical depiction of this data is normally obtained by using the equilibrium concentration as the abscissa and the amount adsorbed per mass of carbon as the ordinate. These graphs are also referred to as isotherms.

Many different approaches have been used to describe the equilibrium conditions defined by these isotherms. These models can be placed into either of two broad categories - regressive or predictive.

In describing single solute adsorption one of the most widely used regressive models is the Langmuir adsorption isotherm (Langmuir, 1918). Derived from the well known Gibb's equation, this two parameter model assumes that adsorption occurs in a single layer on a homogeneous energy surface with no interaction between adsorption sites (Fritz and Schlunder, 1981). Although the validity of these assumptions is doubtful, the Langmuir isotherm is simple to use and often fits observed data quite well. A multilayer extension of the Langmuir equation was made by Brunauer, Emmit and Teller (Braunauer et al, 1938).

Most liquid phase adsorption data can best be described by regressing it to the Freundlich isotherm model (Freundlich, 1906).

$$
q=a c^{1 / n}
$$

$$
\text { where } \begin{aligned}
\mathrm{q} & =\text { mass adsorbed / carbon mass used } \\
\mathrm{a}, \mathrm{n} & =\text { constants } \\
\mathrm{C} & =\text { liquid phase equilibrium concentration }
\end{aligned}
$$

A log-log plot of the Freundlich equation is linear. Although this model was originally derived empirically, it was later shown to describe an exponential distribution of adsorption energies within the carbon 
(Fritz and Schunder, 1981). Its main drawback is that at infinite dilution it does not conform to Henry's Law which requires that solute adsorbed be directly proportional to solute concentration.

Several multiparameter models have been proposed to overcome the limitations of the Langmuir and Freundlich equations in describing single solute adsorption. An example is the Singer-Yen model, (Singer and Yen, 1980) which, although derived from the Freundlich equation, is valid at low concentrations:

$$
\begin{aligned}
& \ln (\mathrm{C})=\ln \left(\mathrm{q} / \mathrm{q}_{\mathrm{x}}\right)-((1 / \mathrm{N})-1)\left(1-\left(\mathrm{q} / \mathrm{q}_{\mathrm{x}}\right)\right)+(1 / \mathrm{N}) \ln \left(\mathrm{q}_{\mathrm{x}} / \mathrm{K}_{\mathrm{f}}\right) \\
& \text { where } \mathrm{C}=\text { equilibrium concentration } \\
& \mathrm{q}=\text { mass adsorbed / mass of carbon } \\
& \mathrm{q}_{\mathrm{x}}, \mathrm{K}_{\mathrm{f}}, \mathrm{N}=\text { constants }
\end{aligned}
$$

When $q>q_{x}$ the fit is the same as the Freundlich; however, when $q<q_{x}$ the fit conforms to Henry's Law. Also, the Redlich-Peterson equation (Redlich and Peterson, 1959) approaches the Freundlich at higher levels and is also consistent with Henry's Law. An adaptation of the Langmuir equation for heterogeneous surfaces, the Toth equation (Toth, 1962), has demonstrated good fit to data and is thermodynamically sound (Jossens et al., 1978). Other models, consisting of three and five parameters have also been used (Radke, 1972). Usually the data base isn't large enough to justify the use of a five parameter model. When using any of these models it should be remembered that the goal is to be as simple and accurate as possible. 


\subsection{Predictive Single Solute Isotherms}

Regressive models are useful because they arrange isotherm data into a format which allows for easy analysis. For example, the proper choice of activated carbon can be made by comparing adsorption data from different carbons using one of the above mentioned equations. Predictive models, however, offer the added benefit of eliminating much of the required laboratory testing. In contrast to the numerous regressive models, relatively few models have also been proposed to predict single solute sorptive behavior in lieu of testing.

The Polanyi equilibrium model is a predictive model which explains adsorption in terms of physical forces (Polanyi, 1916). As a solute particle approaches the carbon surface, van der Walls forces attract it to the surface. Although the required adsorption energy is solute dependent, the attraction exerted by the carbon is independent of either solute or temperature. Thus, once the isotherm of one solute is determined on a carbon and plotted in a particular form, isotherms of all other solutes can be derived by using certain abscissa scale factors. These scale factors, which can be estimated from a compound's molar volume and refractive index, are a function of a solute's adsorbability. For a particular contaminant, the scale factors are the same on all carbons. Although application of this model has been restricted to only a few researchers (Manes, 1980 Speth, 1986 and Kuennen, 1989), their results seem quite encouraging.

The Theory of Correspondence is another predictive model which is derived from Polanyi's (Myers and Sinclair, 1983). In this model, the aforementioned abscissa scale factors are replaced with thermodynamically derived $\mathrm{K}$ functions. Application of these $\mathrm{K}$ functions 
should force isotherms of various compounds to coincide. Knowledge of the saturation capacity of the carbon and the free energy of immersion of the absorbent in the solute are required to estimate $\mathrm{K}$ (Myers and Sincar, 1983). Although the saturation capacity and free energy of similar compounds can be estimated, the free energy of dissimilar compounds must be derived from experimental data (isotherms). Since the data manipulation in this model is more cumbersome, Polanyi's theory would seem more practical.

Another predictive model is the Calculated Net Adsorption Energy Concept (McGuire and Suffet, 1980). This model recognizes the fact that adsorption requires that the solute be removed from the solvent before it can displace solvent on the carbon. The net adsorption energy is equal to the energy of attraction between the solute and the carbon, minus the energy of affinity between the solvent and the carbon, minus the energy of attraction between the solute and the solvent. According to this model there is a relationship between adsorption and the net adsorption energy of a solute. These energies can be calculated using solubility theory and a total solubility parameter. This parameter is calculated based on estimates of a compound's hydrogen bonding and polar characteristics and the dispersive characteristic of the carbon. As is the case of all of the predictive models, testing of its effectiveness has been quite limited. Reported results indicate that the theory is useful when comparing compounds within a limited size and solubility range (Faust and Aly 1987). Molar volume and refractive index, two of the main Polanyi correlations, figure prominently in the calculations. However, compared to the Polanyi model, the calculations are more elaborate and, there is a reliance on estimated parameters. 
The Solvophobic Interaction Theory is a predictive model which combines aspects of solubility theory while considering other physical interactions to predict, like the Net Adsorption Energy theory, preferential adsorption without the necessity of generating isotherms (Belfort, 1979). Parameters considered are the cavity formation, van der walls and electrostatic forces, mixing effects and entropy. Although some reported data indicates that the theory is effective, others disagree (Arbuckle 1980).

While both the Solvophobic and the Net Adsorption models are useful for comparing various solutes and solvents, differences between carbons are not considered. Effects of pore size and functional groups are often only determined via experimentation. By comparison, the calculations for the Polanyi model are simpler while still considering solubility effects and the properties of the carbon by using an experimentally generated characteristic curve for the chosen carbon. Both the Solvophobic Net Adsorption theories would likely benefit from a similar consideration of actual laboratory data.

Several empirical approaches to adsorption have also been proposed. One group contribution method (Chitra and Govind, 1986) expands the basic Polanyi model to account for the structural and group contributions of the chemical groups present on a molecule. Experimental data is required to determine several of the required parameters and the resulting model is applicable only to the particular carbon tested. A simplification of the Solvophobic model has also been proposed (Nirmalakhandan and Speece, 1990). In this model a function was determined by regressing experimental data using a group contribution parameter, connectivity, and a correction for 
polarizability. In applying the Polanyi model the effects of the various molecular groups are incorporated into the solubility term. The effects of a compound's polarizability are also taken into consideration.

\subsection{POLANYI MODEL FOR SINGLE SOLUTE ADSORPTION}

In Polanyi's initial development of his adsorption equilibrium theory (Polanyi, 1916) he postulated that, in the vicinity of a carbon's surface, there exist an adsorption potential, e. This attractive force, which is inversely proportional the distance from the surface, acts to reduce the potential energy of nearby gas molecules with a resulting increase in the gas concentration. When the concentration reaches saturation the gas liquifies and adsorption occurs. The adsorption potential is calculated using the following equation:

$$
e=R T \ln \left(\mathrm{P}_{\mathrm{s}} / \mathrm{P}\right)
$$

$$
\begin{aligned}
& \text { where } e=\text { adsorption potential } \\
& \qquad \begin{array}{r}
\mathrm{R}=\text { universal gas constant } \\
\mathrm{T}=\text { absolute temperature } \\
\mathrm{P}_{\mathrm{S}}=\text { saturation pressure } \\
\mathrm{P}=\text { equilibrium pressure }
\end{array}
\end{aligned}
$$

Given an adsorption isotherm, equation 2.3 can be utilized to create a characteristic curve which describes the adsorption of all compounds on a given carbon. 
In a later article (Polanyi, 1920) the theory was extended to include the adsorption of solid solutes from liquids. In this case, adsorption occurs when the solute concentration increases until precipitation occurs. The adsorption potential is now defined as:

$$
e=R T \ln \left(C_{s} / C\right)
$$

$$
\begin{aligned}
& \text { where } e=\text { adsorption potential } \\
& \qquad \begin{aligned}
\mathrm{R} & =\text { gas constant } \\
\mathrm{T} & =\text { absolute temperature } \\
\mathrm{C}_{\mathrm{S}} & =\text { solubility } \\
\mathrm{C} & =\text { equilibrium concentration }
\end{aligned}
\end{aligned}
$$

Polanyi further theorized that adsorption of a solute occurs with a corresponding desorption of the solvent:

$$
e_{s 1}=e_{s}-e_{1}
$$

where $e_{s 1}=$ adsorption potential of the solute in the solvent

$$
\begin{aligned}
& e_{s}=\text { adsorption potential of the solute } \\
& e_{1}=\text { adsorption potential of the solvent }
\end{aligned}
$$

Equation 2.5 indicates that adsorption will be greatest from solvents which are themselves poorly adsorbed.

The Polanyi theory was generalized to include completely miscible solutions by Hansen and Fackler (1953). In this treatment the solute concentration increases throughout the adsorption space but no phase 
change occurs. Vapor phase isotherms of water, propanol and butanol on Spheron- 6 carbon were used to calculate isotherms from solution. The results produced an approximate agreement with the theory, although the butanol-water system underestimated adsorption in the low concentrations.

The Polanyi model was again applied to the adsorption of solutions by Manes and Hofer (1968). Seeking to establish the link between gas and liquid phase adsorption, they tested the adsorption of solids Sudan III and p-dimethylaminoazobenzene onto Calgon Grade CAL activated carbon from a variety of solvents: methanol, acetonitrile, acetone, 2-propanol, cyclohexane, benzene, carbon tetrachloride and carbon disulfide. Manes attempted to fit these adsorption curves onto a gas phase characteristic curve. Although the curves had the same general shape, a single curve could not describe the adsorption of all of these compounds when they were plotted as adsorption potential vs volume adsorbed. However, dividing the abscissa by molar volume caused several of these curves to collapse to a gas phase curve in the low concentrations. Because of this correlation of molar volume, $V$, with adsorption, and to facilitate calculations, the abscissa term was changed from $R T \ln \left(C_{s} / C\right)$ to $(\mathrm{T} / \mathrm{V}) \log \left(\mathrm{C}_{\mathrm{S}} / \mathrm{C}\right)$ in the characteristic plots. Manes then theorized that if chemical's refractive indexes differ significantly, each abscissa point must be divided by an additional correction factor to make the curves coincide. For solutes this factor is calculated as follows :

$$
Z=P_{r} / P_{i}
$$


where, $Z$ = correction factor for polarizability

$$
\begin{aligned}
& P_{r}=\text { polarizability of reference solute } \\
& P_{i}=\text { polarizability of solute }
\end{aligned}
$$

The polarizability term, $\mathrm{P}$, is approximated by the Lorentz-Lorenz equation:

$$
P=\left(n^{2}-1\right) /\left(n^{2}+2\right)
$$

where $\mathrm{n}=$ refractive index of solute

Application of these scale factors did seem to create a single curve for most compounds, although the limiting adsorbate volume, the $\mathrm{Y}$ intercept, was significantly lower than that of the gas phase characteristic curve. Steric effects were proposed to account for anomalies in the adsorption from carbon tetrachloride and, to a lesser degree, carbon disulfide and cyclohexane.

The adsorption from aqueous solutions of partially miscible organics was then applied to the Polanyi model (Wohleber and Manes, 1970). The solutes tested included: 1,2-dichloroethane, diethyl ether, ethyl acetate, methylene chloride and propionitrile. Calgon grade CAL was again used in this, and all future, testing by Manes and his coworkers. Polarizability proved to be an effective indicator of adsorption of the organics and application of this scale factor provided an excellent fit to the gas phase correlation curve. It was also discovered that water adsorbs significantly less than indicated by its polarizability. 
Testing of the Polanyi model was then extended to include the adsorption from water of the miscible organics acetic acid, acetone, acetonitrile, dimethylformamide, isopropyl alcohol, n-propyl alcohol, p-dioxane and pyridine (Wohleber and Manes, 1971). Analysis of these isotherms demonstrated general agreement with the curves predicted by applying the correction for polarizability to a gas phase correlation curve previously determined on the same carbon (CAL). The lower than expected adsorption of $p$-dioxane was, as in the previous cases of cyclohexane, carbon disulfide and carbon tetrachloride, attributed to steric affects.

Because of the anomalously low adsorption of these compounds a study was then undertaken to determine the effects of molecular orientation on adsorption (Chiou and Manes, 1972). The degree of adsorption of planar copper, platinum and palladium acetylacetonates was significantly greater than that of the octahedral iron, aluminum and cobalt acetylacetonates indicating that the inability to closely approach the carbon surface can affect the ability of the Polanyi model to predict adsorption. Similar results on carbon black proved that this effect was not caused by the octahedral complexes inability to penetrate the carbon pores. All of the acetylacetonates exist as solids at the isotherm temperature and, as before, the limiting adsorbate volume was much lower than the gas phase correlation curve.

Chiou and Manes (1973) then compared aqueous isotherms of several solid compounds which were performed at temperatures both above and below their melting points. The solids tested were: $0, m$ and p-nitrophenol, p-bromophenol, 2,5-dichlorophenol, coumarin, phthalide, 5-dichlorophenol, m-acetotoluidide, m-chloroacetanilide and 
2,2-bipyridine. Adsorption below the melting points was significantly less than expected from the gas correlation curve; however, the isotherms conducted at higher temperatures matched the gas correlation curve. Chiou and Manes theorized that inefficient packing of the solid particles was the cause of the poor adsorption below the melting point.

In a later article, (Rosene, 1976) it was reported that adjusting the density of a solid compound to raise its limiting adsorbate volume to the level of the gas correlation curves results in isotherms which, in the cases of acetamide, acetone oximide, acrylamide, formamidoxime, 1,2,4-triazole and urethane, adhere to the Polanyi predictions. Other solids tested, including alanine, methionine, thiouurea and valine, required empirical scale factors to collapse their data to a single curve. For single solute adsorption the density adjustment applies only to the ordinate. The density term in the abscissa, incorporated in the molar volume, remains unchanged.

The Rosene article was the last in a series published by Manes and his graduate students concerning single solute adsorption. Thomas Speth (1986) incorporated the Freundlich equation into the Polanyi model and effectively converted isotherms determined at one temperature to another. More recently, (Kuennen et al, 1989) Speth's adaptation of the Polanyi model was again effectively used to correct for temperature changes. Kuennen also attempted to correlate 14 different compounds using the Polanyi model with moderate success; however, molar volume was the only scale factor utilized. 


\section{CHAPTER 3}

\section{HYPOTHESIS}

Using the Polanyi Adsorption Theory, adsorption isotherms for organic compounds can be accurately predicted from adsorption data of a single solute from the same solvent. In addition, the isotherms of various solutes will, when plotted as characteristic curves, collapse into a single correlation curve after certain correction factors are applied. These scale factors can be estimated from the compounds polarizability. 
CHAPTER 4

OBJECTIVES

The cornerstone of the Polanyi theory is the existence of a characteristic curve which, after abscissa scale factors are applied, describes the adsorption of all compounds on a carbon. The main objective of this thesis is to validate the existence of such a curve.

First, the theory's predictive abilities will be tested using theoretically determined scale factors. The model will be used along with adsorption data from a single solute on a carbon to generate a characteristic curve for that carbon. From this curve isotherms of several other solutes on the same carbon will be created using abscissa scale factors which are theoretically determined from a compounds polarizability. The predicted isotherms will then be compared to the raw data. The accuracy of these predictions will be quantified using the average error equation described in the data analysis section.

Second, the theory's modeling capabilities will be tested using abscissa scale factors determined by regressing the experimental data. Since at least one data point from each solute is required to calculate the scale factors, more testing is required than if the theoretically determined scale factors are used. However, if the experimentally determined scale factors produce a significantly better fit than those determined theoretically, the extra effort may be necessary. So, another objective of this project will be to compare the correction factors derived theoretically to those obtained experimentally. In addition, the ordinate correction factors, which are required for compounds which exist as solids at the isotherm temperature, will also be examined. 
The process will be repeated on a variety of solutes using several different carbons. A determination will be made concerning this model's effectiveness based on the quality of the data simulations for the various carbons and solutes. 
CHAPTER 5

DATA ANALYSIS

This thesis will compare the Polanyi model predictions for single solute isotherms to experimental data reported in published literature. Raw data has been obtained from such noted researchers as Crittenden and coworkers, Fukuchi and coworkers, Kong, van Vliet and Narbaitz. This data includes isotherms for many different types of compounds obtained using several different activated carbons. This isotherm data will be used to generate characteristic curves. Of the data required to create these curves only solubility is not readily available from experimental conditions or reference sources. An chemical estimation method, which is derived from the universal quasi-chemical (UNIQUAC) equation will be used to calculate solubility. This method, UNIFAC (UNIQUAC Functional-group Activity Coefficients), uses chemical structure and functional groups to estimate a compound's physical properties (Fredenslund et al, 1975).

As mentioned, the cornerstone of the Polanyi theory is the existence of a single characteristic curve which, after certain abscissa scale factors have been applied, describes the adsorption of all compounds. In determining this characteristic curve, the isotherm of a single solute must be chosen to serve as the reference. The curve chosen as this reference will be the one whose data points cover the widest range.

First, RS/1 (BBN Software, Cambrige, Ma.) a statistical analysis software package, will be used to nonlinearly regress the data for the reference solute, to determine the best fitting characteristic curve. In performing this regression RS/1 uses an iterative search procedure, 
the Marquardt's compromise, which combines features of the Gauss-Newton method and the method of steepest descent. To avoid problems caused by overemphasis of data in the high range, all curves will be weighted so that each data point is given the same value in determining the curves fit. This is accomplished by applying the following equation to each data point during the error minimization routine:

$$
\mathrm{Y}_{\mathrm{wt}}=\mathrm{W} *\left(\mathrm{Y}_{\mathrm{obs}}-\mathrm{Y}_{\mathrm{pred}}\right)^{2}
$$

$$
\begin{aligned}
& \text { where } \begin{aligned}
Y_{w t} & =\text { weighted value } \\
W & =\text { weighting factor, } 1 / Y_{o b} \\
Y_{o b} & =\text { observed value } \\
Y_{\text {pred }} & =\text { predicted value }
\end{aligned}
\end{aligned}
$$

Second, this reference characteristic curve will then be used to create the curves of the other solutes. As previously mentioned, the abscissa scale factors needed can be estimated by the polarizability of the various solutes. Third, after these theoretically determined abscissa scale factors, TDASF, have been applied, the goodness of fit of the raw data points for each solute to these predicted curves will be determined using the following equation for average error:

$$
\text { AVERAGE ERROR }=\frac{1}{n} \sum_{i=1}^{n}\left|\frac{\left(Y_{\text {obs }}-Y_{\text {pred }}\right)}{Y_{\text {obs }}}\right|
$$

This equation is basically the average of the normalized differences between predicted and observed. Since this equation places the same weight on each data point, goodness of fit is not distorted by $Y$ values 
in the higher ranges. This equation is also well suited for making comparisons between different curves since, unlike sum of the squares and other statistics, the average error is not related to the shape of the curve or the values of the individual data points.

Fourth, the best fit curves of each solute, based upon the reference curve, will be determined by using RS/1. Fifth, the experimentally determined abscissa scale factors, EDASF, for each compound are obtained by determining the abscissa adjustments required to make the characteristic curves of the individual solutes coincide. It is therefore imperative that, for a given carbon, all characteristic curves be described by the same type of function (exponential, 2nd degree polynomial, etc). Otherwise, the characteristic curves will have different shapes and a single scale factor will not apply over the entire range of interest.

The above data analysis should help define the Polanyi theory's usefulness at predicting single solute isotherms by quantifying the model's predictive capabilities. 
CHAPTER 6

EVALUATION OF THE POLANYI MODEL FOR

SINGLE SOLUTE ISOTHERMS

In this chapter adsorption isotherm data from various sources is plotted as characteristic curves, to test the predictive ability of the Polanyi theory. To avoid potential problems associated with differences in experimental technique, data analysis will begin by separating the results according to the source of the data. These include thesis and research articles reported by Speth, Fukuchi, Luft, van Vliet, Kong and Narbaitz. For compounds tested by several different scientist, isotherm data will be compared with the Polanyi predictions in later sections of this chapter.

\subsection{EVALUATION OF THE POLANYI MODEL FOR SPETH'S DATA}

The Polanyi equilibrium theory was applied to adsorption isotherm data obtained from the Master's thesis of Thomas F. Speth (1986). This data, which was generated at the Michigan Technological University, was obtained under the guidance of $\mathrm{Dr}$. John C. Crittenden using the bottle point isotherm method.

In this method increasing amounts of precisely weighed pulverized carbon, $200 \times 400$ mesh, which has been rinsed and dryed to remove fines, are added to $300 \mathrm{~mL}$ bottles which have been meticulously cleaned to remove all trace organics. A large reservoir containing a specified concentration of the solute in a buffered milli-Q water matrix is then used to fill each of these bottles.

A floating teflon top is used in 
the reservoir to assure no loss of volatile compounds during the filling procedure. The bottles were then capped and rotated for the equilibration period. Before testing, the samples were centrifuged to separate the carbon.

Speth tested Filtrasorb F-400 carbon (Calgon Corp, Pittsburgh, Pa). Data was obtained on the following solutes: bromoform, chlorodibromomethane (CDBM), chloroform, cis-dichloroethene (DCE), 1,2 dibromoethane (DBE), ethylbenzene, m-xylene, o-xylene, tetrachloroethane $(\mathrm{PCE})$, trichloroethene (TCE) and toluene. Experimental conditions are described in Table 6.1.

TABLE 6.1 EXPERIMENTAL CONDITIONS (Speth)

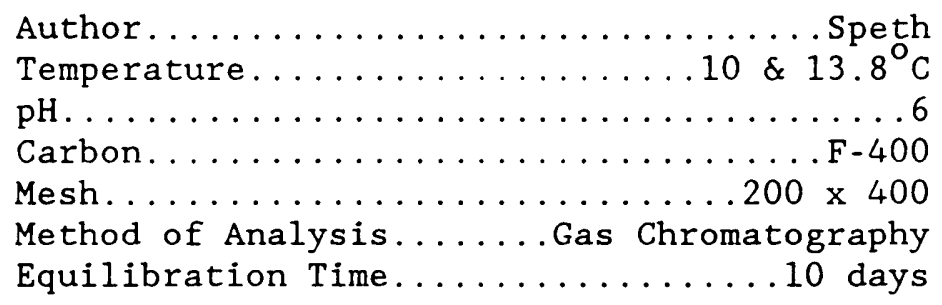

Relevant information on each of the solutes is listed in Table 6.2. At the isotherm temperature all of the solutes exist as liquids; so, molar volume and polarizability should be the only scale factors which apply. Further, the spread in polarizability is relatively small with al1 compounds except for bromoform, chloroform and DCE. 
TABLE 6.2 CHARACTERISTICS OF SOLUTES (Speth)

$\begin{array}{lrrrrrc}\text { COMPOUND } & \text { MOL WT } & \begin{array}{r}\text { DEN } \\ (\mathrm{g} / \mathrm{mL})\end{array} & \begin{array}{r}\text { SOL } \\ (\mathrm{mg} / \mathrm{L})\end{array} & \begin{array}{r}\text { MP } \\ (\mathrm{C})\end{array} & \text { INDEX } & \text { P } \\ & & & & & & \\ \text { Bromoform } & 252.77 & 2.894 & 6934 & 7 & 1.5960 & 0.3403 \\ \text { CDBM } & 208.29 & 2.451 & 13969 & -22 & 1.5465 & 0.3169 \\ \text { Chloroform } & 119.39 & 1.500 & 6460 & -63 & 1.4460 & 0.2667 \\ \text { cis-DCE } & 96.95 & 1.284 & 1921 & -81 & 1.4481 & 0.2678 \\ \text { DBE } & 187.88 & 2.180 & 10140 & 9 & 1.5385 & 0.3130 \\ \text { Ethylbenzene(13.8) } & 106.16 & 0.867 & 145 & -95 & 1.4952 & 0.2917 \\ \text { m-Xylene (13.8) } & 106.16 & 0.870 & 86 & -47 & 1.4970 & 0.2926 \\ \text { o-Xylene (13.8) } & 106.16 & 0.868 & 86 & -25 & 1.5048 & 0.2965 \\ \text { PCE } & 165.85 & 1.623 & 322 & -22 & 1.5056 & 0.2969 \\ \text { PCE (13.8) } & & & 347 & & & \\ \text { TCE } & 131.40 & 1.464 & 837 & -85 & 1.4755 & 0.2818 \\ \text { TCE (13.8) } & & & 891 & & & \\ \text { Toluene (13.8) } & 92.13 & 0.867 & 360 & -95 & 1.4968 & 0.2925\end{array}$

Note: MOL WT = molecular weight; $\mathrm{DEN}=$ density; $\mathrm{SOL}=$ solubility; $\mathrm{MP}=$ melting point; INDEX = refractive index; $\mathrm{P}=$ polarizability (eq 2.7) 


\subsubsection{Basic Characteristic Curve}

As Figure 6.1 demonstrates, simply plotting solute volume adsorbed vs $(\mathrm{T} / \mathrm{V}) \log \left(\mathrm{C}_{\mathrm{s}} / \mathrm{C}\right)$ does indeed create a reasonably good fit of a single curve indicating that, in this instance, molar volume is the only scale factor required to approximate the adsorption of all these solutes.

The fit can, however, be improved. Before scale factors can be applied, one solute must first be chosen to serve as the reference. The ideal reference solute would be well defined with data points covering the entire adsorption range. This will result in a characteristic curve whose shape is defined over the entire range of interest. Unfortunately, in the case of this data, there are no good candidates to serve as the reference solute. Although the curve of all of the solutes covers a very wide range, testing of the individual compounds was restricted to limited ranges.

This problem was overcome by using the overall curve as the reference curve. Bromoform, CDBM, chloroform and DBE were excluded in the regression of this curve because of their poor fit, relative to the other compounds. RS/1 (BBN Software, Cambridge, Ma.), using nonlinear regression, was used to determine the function which best describes this curve. After testing numerous polynomial and exponential functions, it was determined that the best fit of this data is obtained using exponential functions.

An example of an exponential function which yields a good fit to the data is:

$$
\mathrm{F}(\mathrm{X})=A * \exp (B * \mathrm{X})
$$




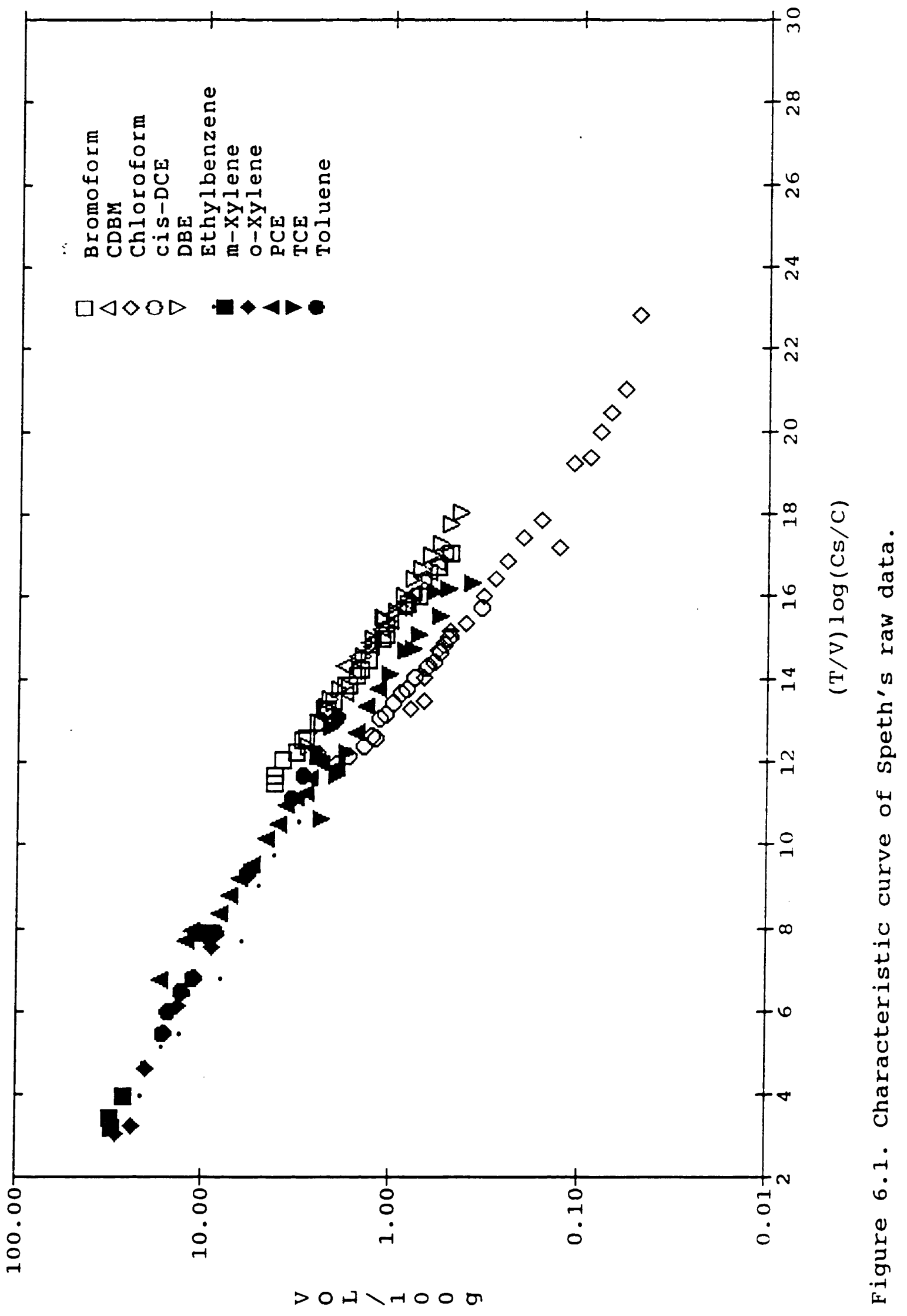


where $F(X)=$ volume adsorbed per 100 gm carbon

$$
\begin{aligned}
\mathrm{X} & =(\mathrm{T} / \mathrm{V}) \log \left(\mathrm{C}_{\mathrm{S}} / \mathrm{C}\right) \\
A, B & =\text { regression based coefficients }
\end{aligned}
$$

In this function, the value of $A$ defines the $Y$ intercept of the curve, while the $B$ term, since a characteristic curve is a log-linear plot, describes its slope. For example, Figure 6.2 demonstrates the result obtained using this exponential to fit Speth's data (excluding bromoform, CDBM, chloroform and DBE). In this particular case, the function which best fits the data is:

$$
F(X)=78.25 * \exp (-.303969 * X)
$$

For this data, the best fit of the experimental data yields a graph with a $Y$ intercept of 78.25 and a slope of -0.303969 .

Another function which provided a good representation of the overall curve was an exponential function with a constant:

$$
\mathrm{F}(\mathrm{X})=A * \exp (B * \mathrm{X})+C
$$

where $C=$ regression based coefficient

Interpretation of the graphical meaning of coefficients $A$ and $B$ is the same as for the simple exponential function ( $A=\mathrm{Y}$ intercept, $B=$ slope) except that each point is adjusted by an amount equal to $C$. The best fit result is:

$$
F(X)=64.9 * \exp (-.2560 * X)-0.853701
$$




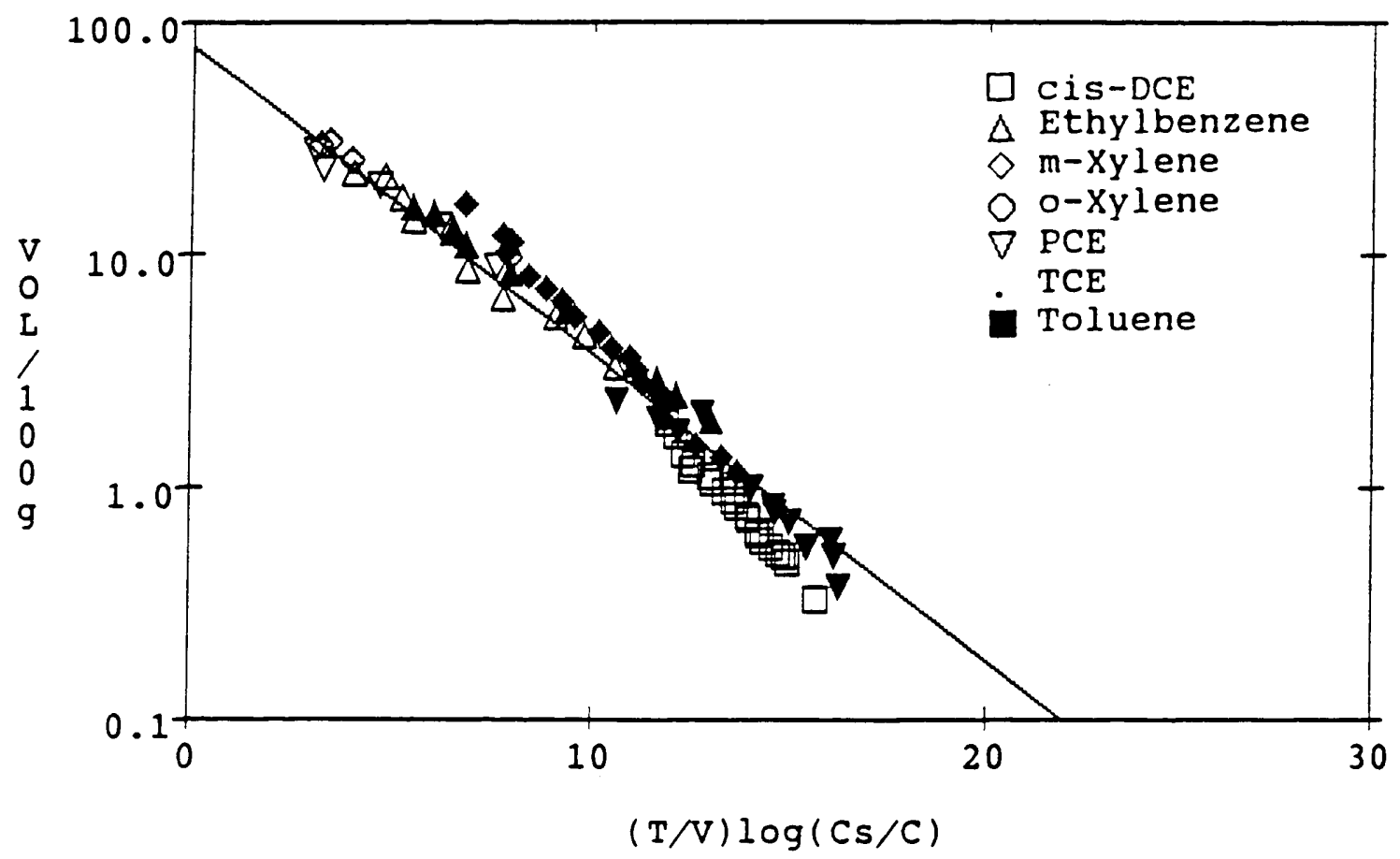

FIGURE 6.2. SEETH'S DATA FIT WITH AN EXPONENTIAL FUNCTION.

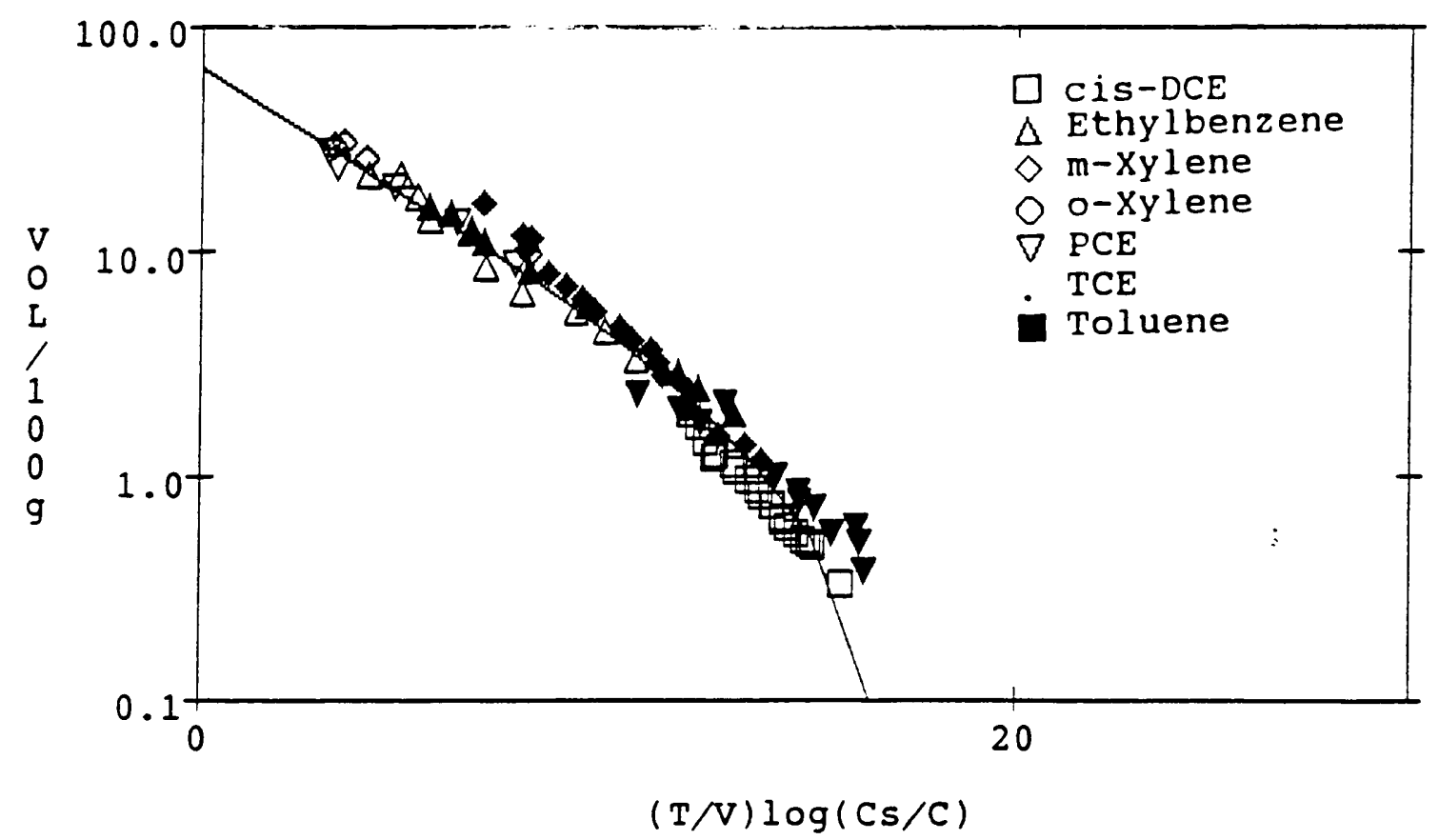

FIGURE 6.3. SPETH'S DATA FIT WITH AN EXPONENTIAL WITH CONSTANT FUNCTION. 
The shape of the curve, as Figures 6.2 and 6.3 demonstrate, will depend upon the function used to describe it. Although both functions accurately depict the data, the exponential with a constant (sum of squares $=32.74)$ produces a better fit of the reference curve than the simple exponential (sum of squares $=41.04$ ). Results obtained using both equations will be compared in the data analysis of the individual compounds to determine if use of the additional coefficient is warranted.

\subsubsection{Theoretically Predicted Characteristic Curves}

Using the graphs of the overall curve to determine the shape of the characteristic curve, theoretically determined abscissa scale factors, TDASF, were then determined by applying equations 2.6 and 2.7. (Refer to Appendix A for sample calculations.) To predict the characteristic curves of the individual compounds from the overall correlation curve the $B$ value (if, as in this case, the function is an exponential) of the reference curve is multiplied by this scale factor. Normally, a single reference compound provides both the shape of the characteristic curve and the reference polarizability value needed to calculate the abscissa scale factors. However, because several compounds were used in describing the shape of the reference curve a compound must be chosen to provide a reference polarizability. Cis-DCE will serve in this capacity although any of the compounds tested could have been used.

Figures 6.4 thru 6.6 demonstrate the differences between observed and predicted data for each compound using both an exponential and an 

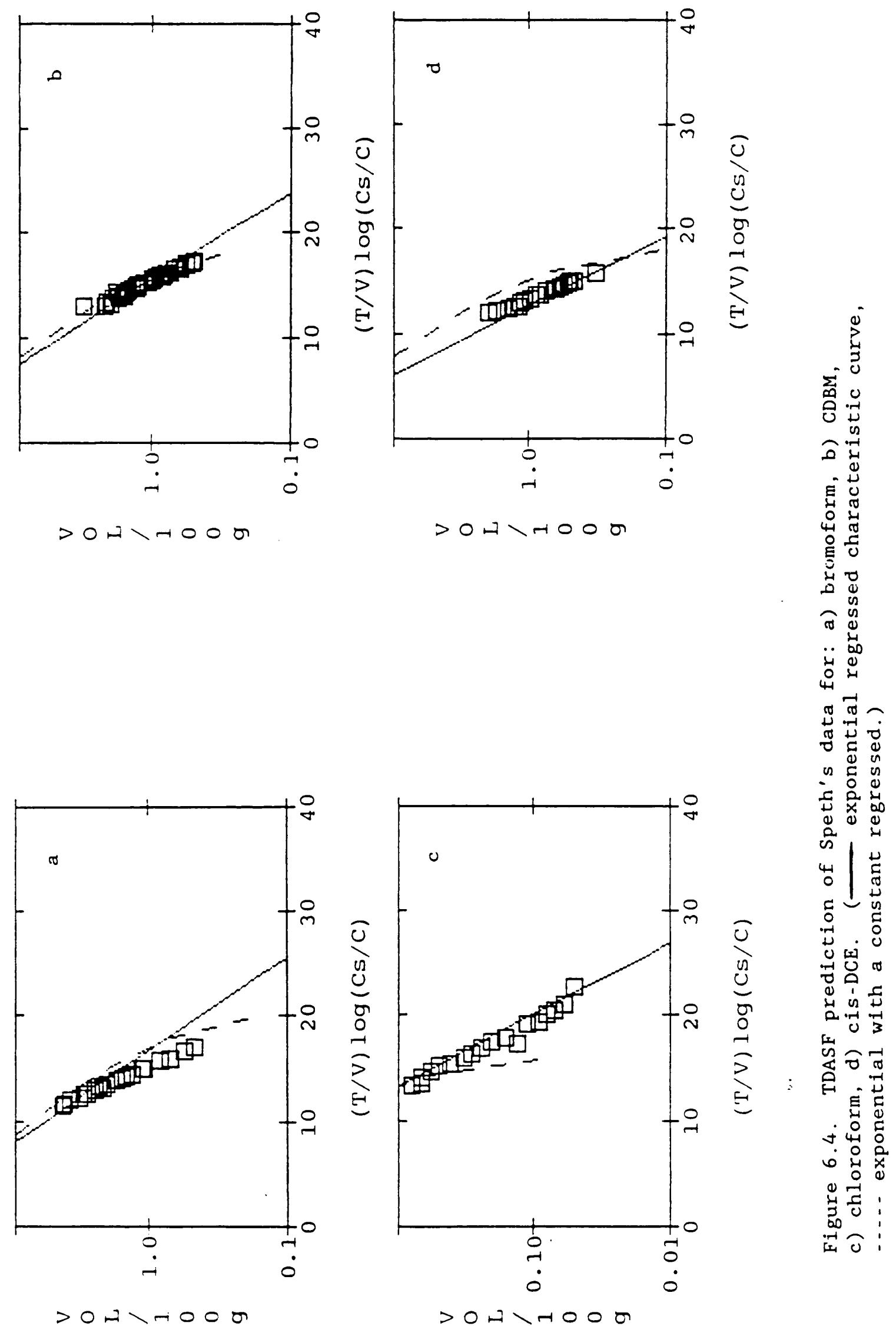

$>0$ \

$>0$ म $>$ - 0 व 
exponential with a constant to define the shape of the characteristic curve. These figures indicate the predictions work well for CDBM, DBE, ethylbenzene, m-xylene, o-xylene, PCE, TCE and toluene (worst case average error, $\mathrm{AE}=.26)$; however, although the exponential model is effective, chloroform $(A E=3.76)$ and cis-DCE $(A E=1.09)$ are not wel1 depicted by the exponential with a constant. The prediction for bromoform, using the exponential with a constant, is also poor ( $\mathrm{AE}=$ $0.60)$

A good indication of the overall effectiveness of the TDASF at predicting adsorption can be obtained by plotting the raw data of each compound adjusted by the theoretical scale factor. If this adjustment, which consist of multiplying the abscissa value of each point by the scale factor, is effective, all the data should collapse to a single curve. Figure 6.7 shows the resulting curve using DCE as the reference compound. The data is close to a single curve with a limited amount of scatter and indicates that, in this instance, theoretically determined scale factors would, in general, provide a satisfactory prediction of the isotherm data.

\subsubsection{Regression Based Characteristic Curves}

TDASF offer the advantage of requiring isotherm data on only the reference compound. Experimentally determined abscissa scale factors, EDASF, require, in addition to a well defined reference characteristic curve, that at least one data point be determined for each compound. However, if an improved fit results, the extra effort may be worthwhile. Also, the extra testing on each compound may make the engineer a bit 

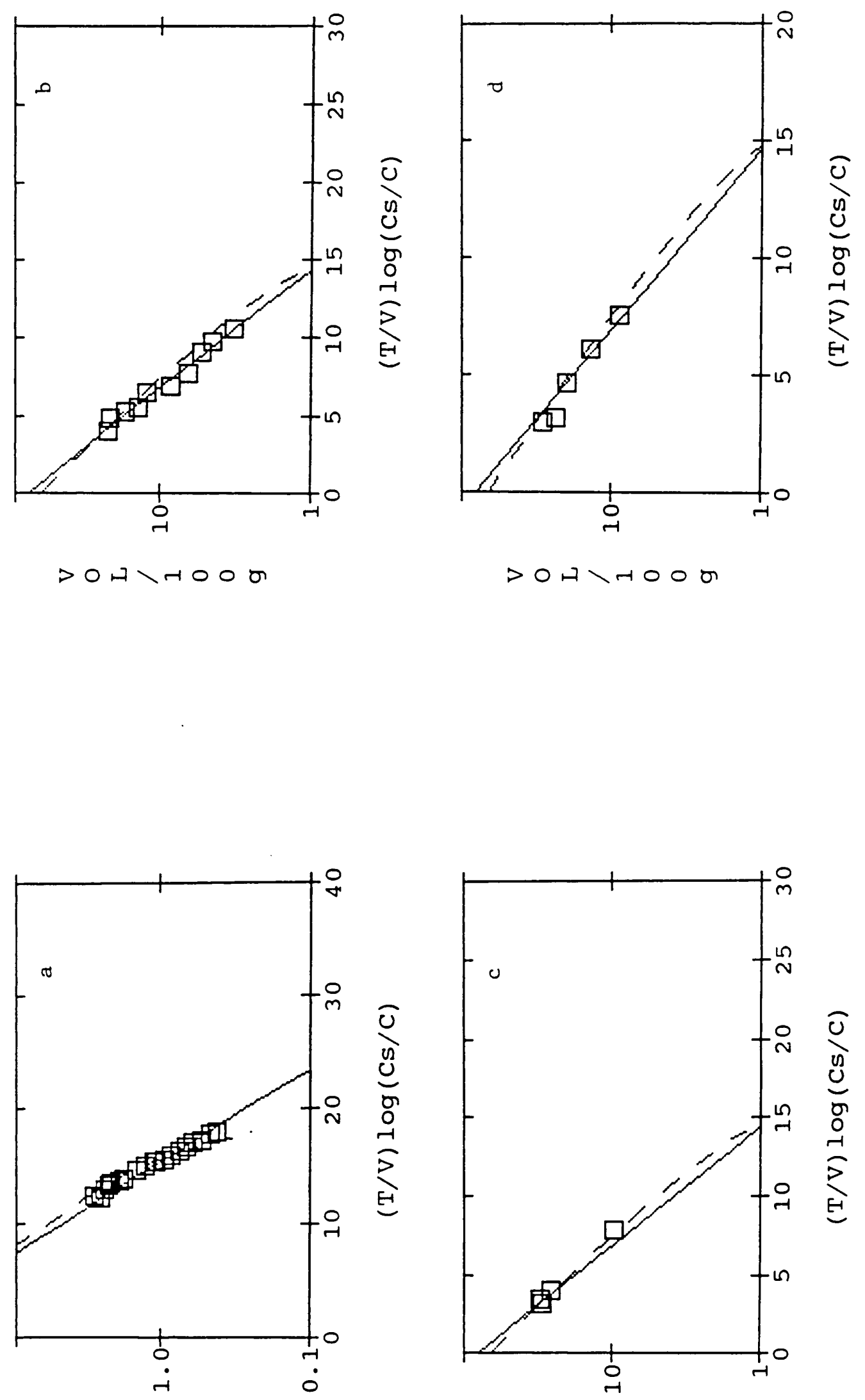

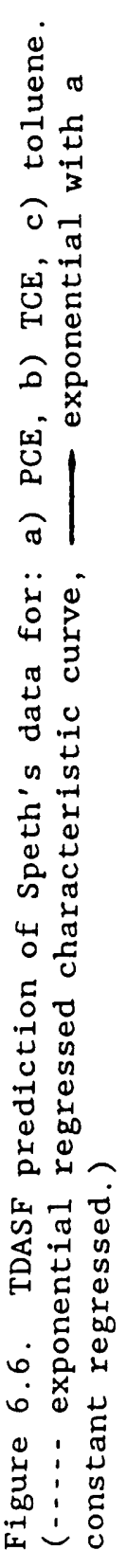

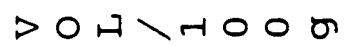

$>0$ म $>$ म० O 

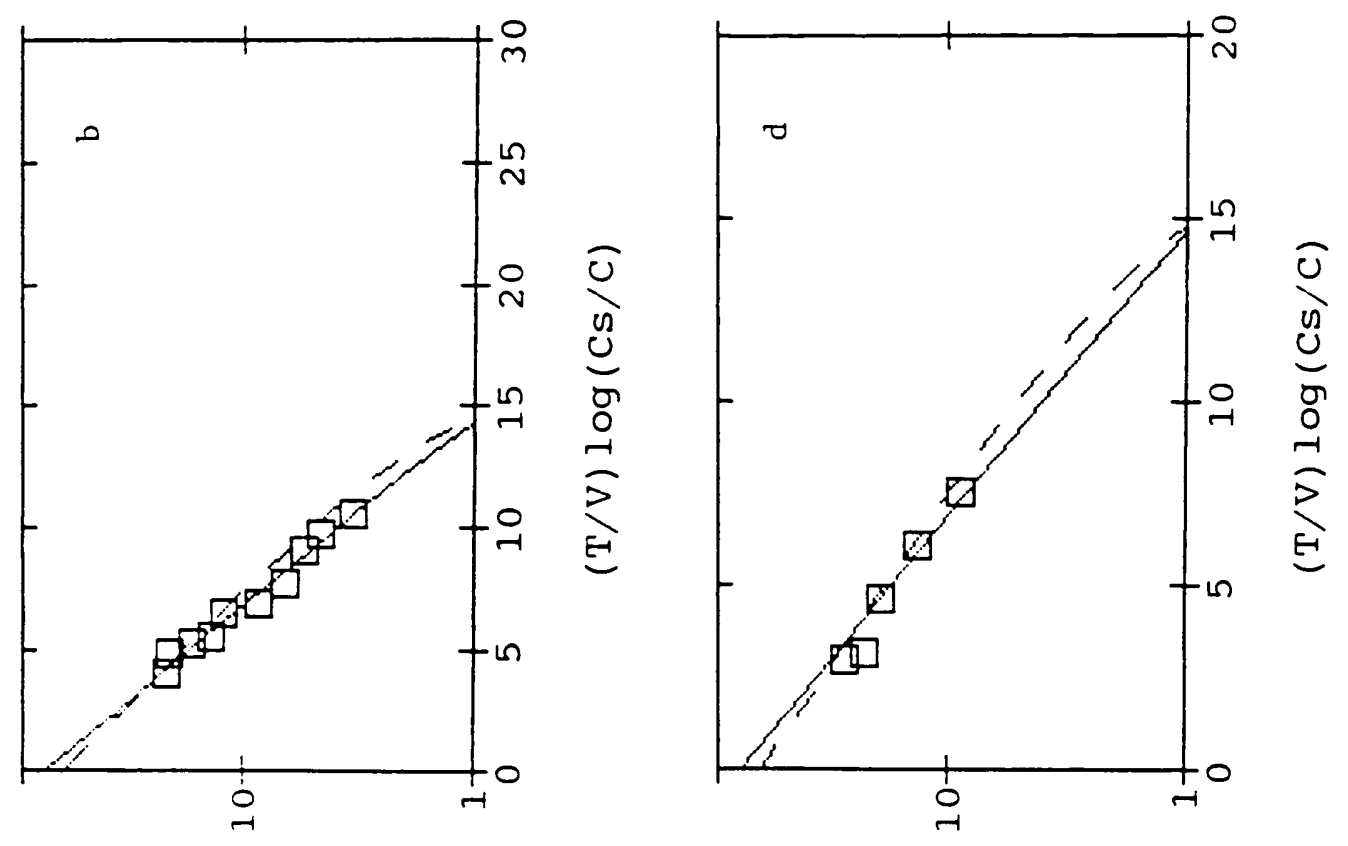

> ON\400 O
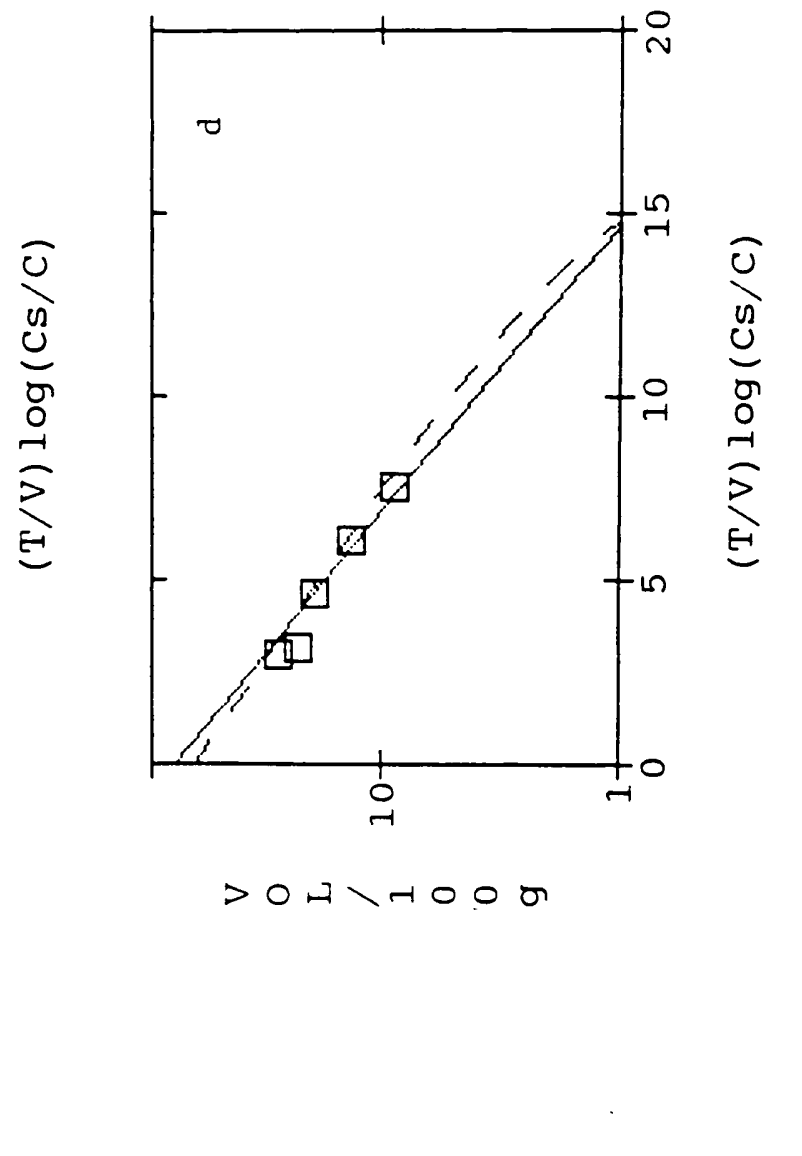

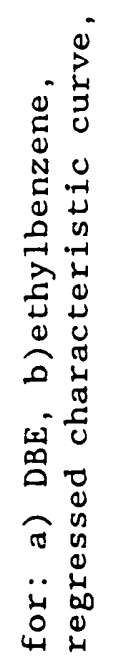
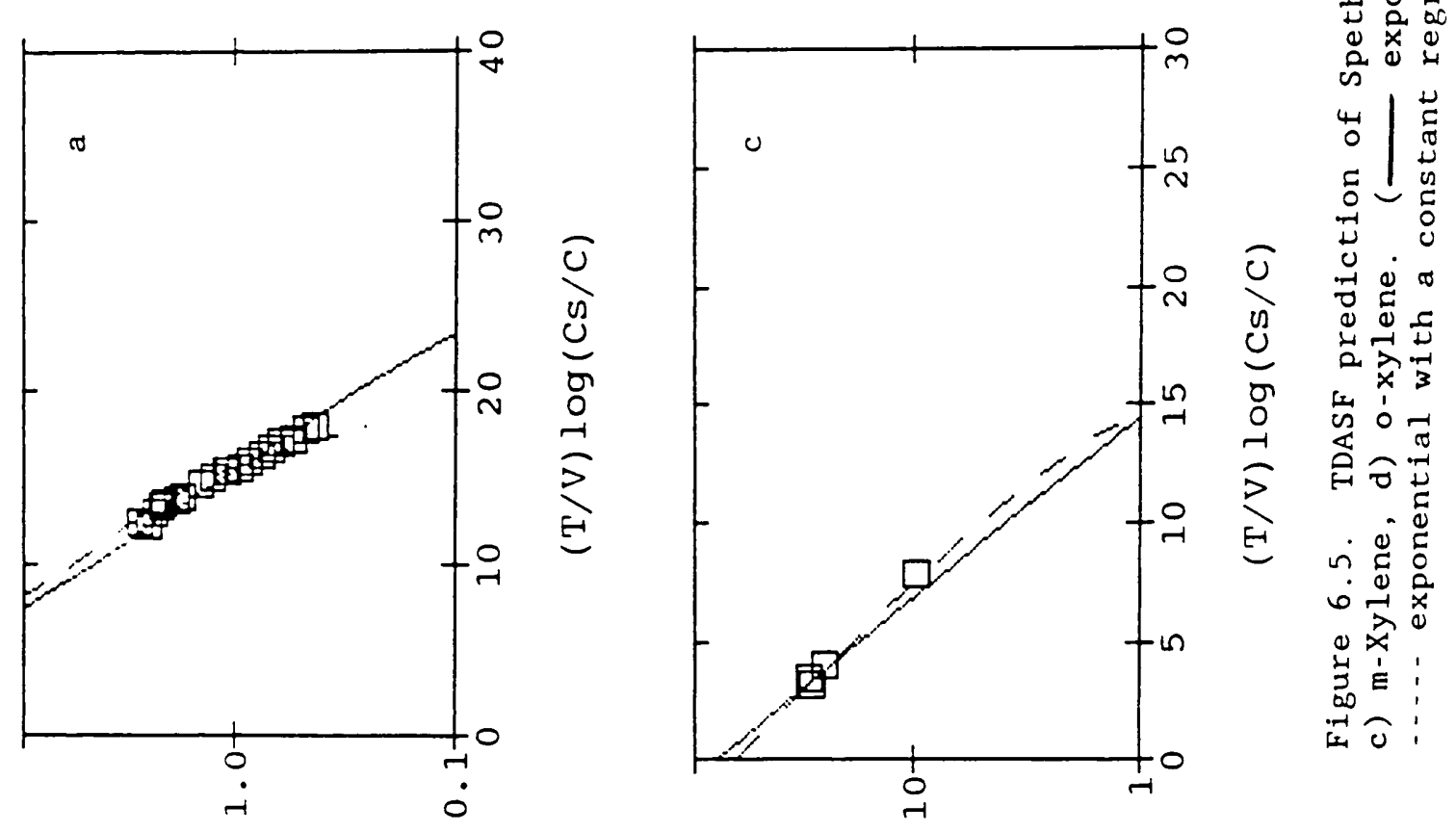

>OA > OA\HOO O 


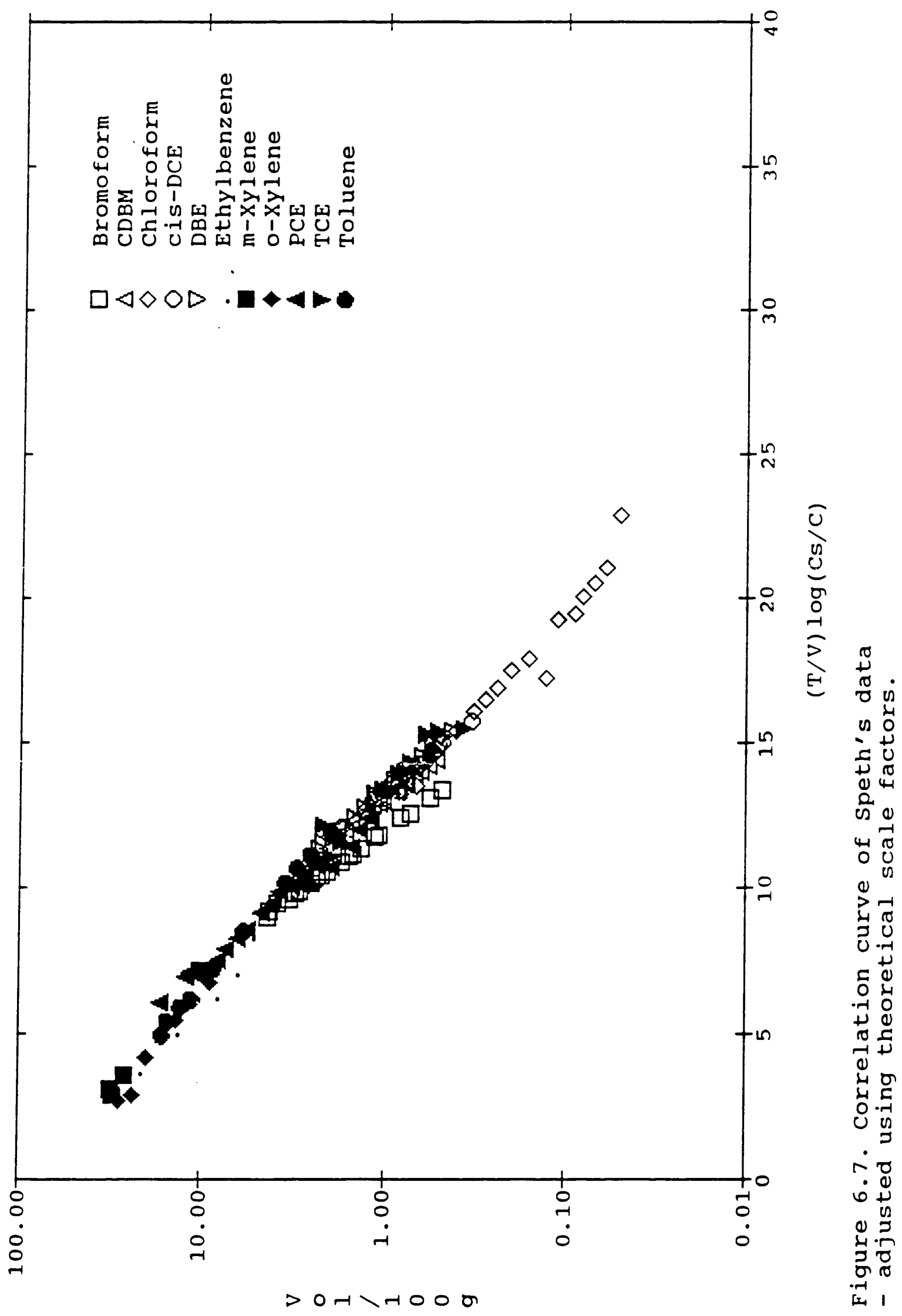


more confident in his, or her, design.

As in the case of TDASF, one compound must first be chosen to serve as a reference. This compound, since it defines the shape of the characteristic curve, requires sufficient points across the concentration range. As before, since none of the individual solutes $\vdots$
tested met this criteria, the reference curve was determined to be the best fit of the overall curve of all compounds (excluding bromoform, CDBM, chloroform and DBE).

Also, as before, the shape of this reference curve will depend on the function used to describe it. If the simple exponential function, $F(x)=78.25 * \exp (-0.303969 * X)$, is used to describe the curve, then it will result in a straight line, since its a log-linear plot. If, on the other hand, the exponential with a constant model is used, the best fit value of $B$ is determined from the reference equation $F(X)=64.9 * \exp (-0.2560 * X)-0.853701$, which has a curved shape

For the simple exponential model to describe all the individual solutes the value of the variable $A$ must be the same for all compounds. This means that the $Y$ intercept, which is equal to $A$, must be equal for the characteristic curves of all the compounds; otherwise, ordinate as well as abscissa scale factors would be required to force the curves to collapse. The value of $B$, which defines the slope of the curve, will vary and the amount of variance defines the experimentally determined abscissa scale factor, EDASF. In this case, for the curves of the individual solutes to collapse to this curve they must all have a Y intercept of 78.25. RS/1 was then used, for each solute, to determine the best fitting value of $B$ in the equation $F(X)=78.25 * \exp (B * X)$. Using the exponential with a constant function to define the reference 
characteristic curve, the graphs of the individual solutes were determined by fixing the values of $A$ and $C$ to 64.9 and -0.853701 and determining the value of $B$ which results in the best fit. Figures 6.8 thru 6.10 present these simulations of the individual compounds using the two different models.

A comparison of the fit of the individual solutes shows that some are more accurately described by the theory than others. Figure 6.8c demonstrates that chloroform data is not accurately described by an exponential with a constant $(A E=2.64)$. The chloroform isotherm data does not fit on a characteristic curve defined by this equation.

Regardless of which function is used to describe the reference curve, the experimentally determined abscissa scale factor is defined as:

$$
\operatorname{EDASF}=B_{i} / B_{\text {ref }}
$$

where $\operatorname{EDASF}=$ Experimentally Determined Abscissa Scale Factor

$$
\begin{aligned}
B_{i} & =B \text { variable value of solute } i \\
B_{\text {ref }} & =B \text { variable value of the reference curve }
\end{aligned}
$$

To force the characteristic curves of the individual compounds to collapse to one correlation curve, each abscissa point is multiplied by it's scale factor while the ordinate values are left unadjusted. Figures 6.11 and 6.12 demonstrate the curves obtained when all compounds, including bromoform, CDBM, chloroform and DBE, are plotted after applying EDASF using the two exponential equations tested.

As Figures 6.11 and, to a lesser extent, 6.12 demonstrate, EDASF do 

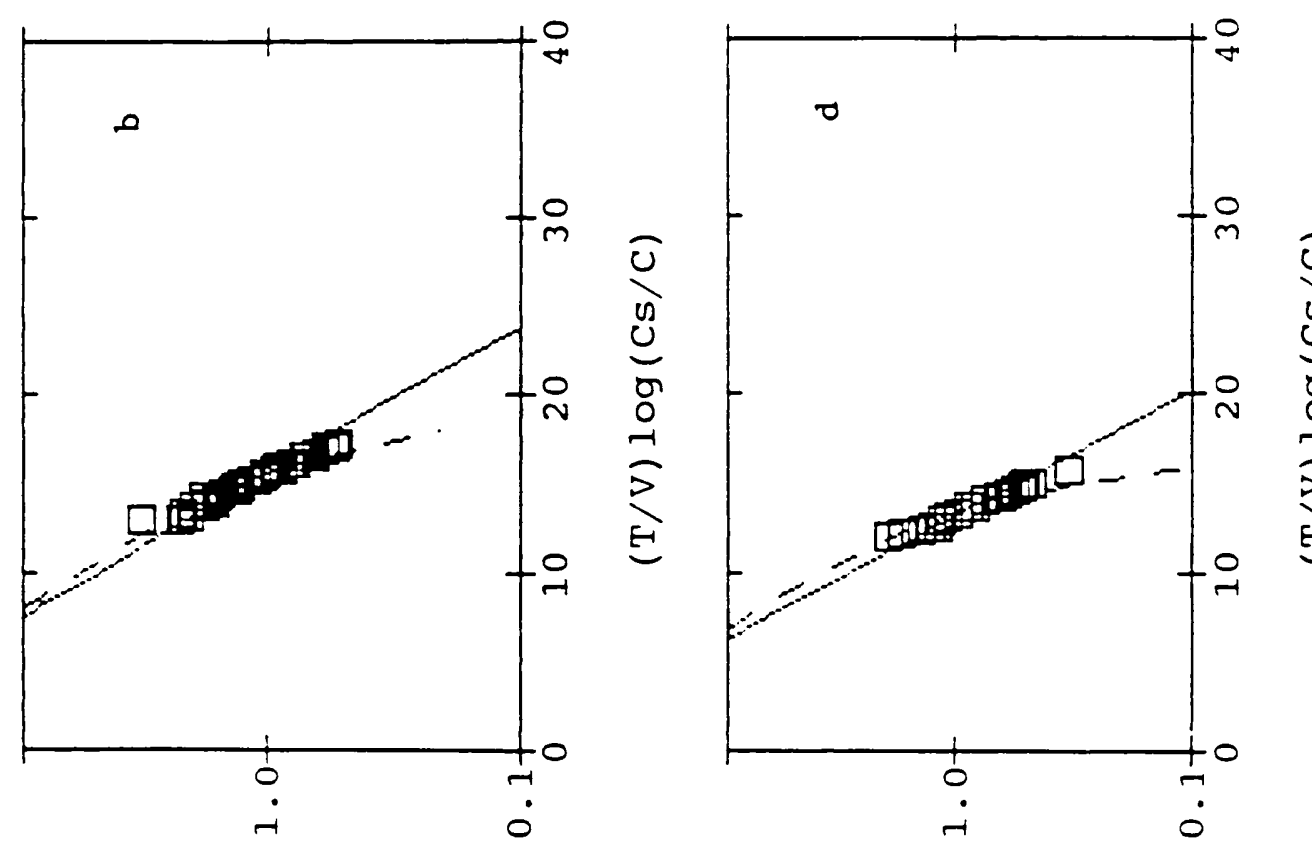

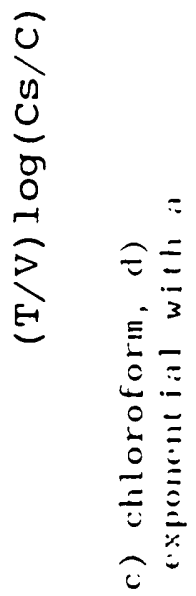

$>0$ >

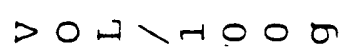

㐫

อิ

E

ㄴ.

$4=$

ํํㅇ -

ㄴ.

ชิ

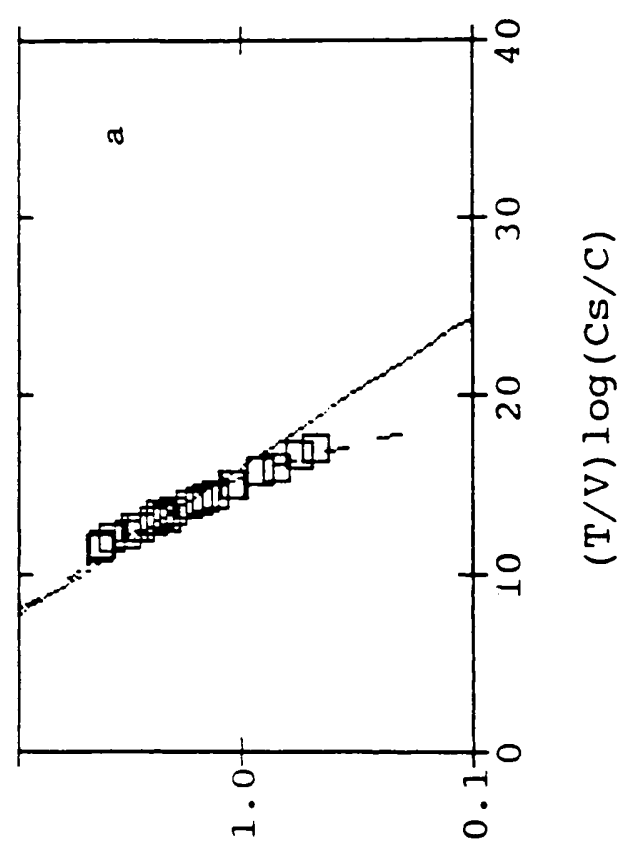

$>0$ I $>$ - 000

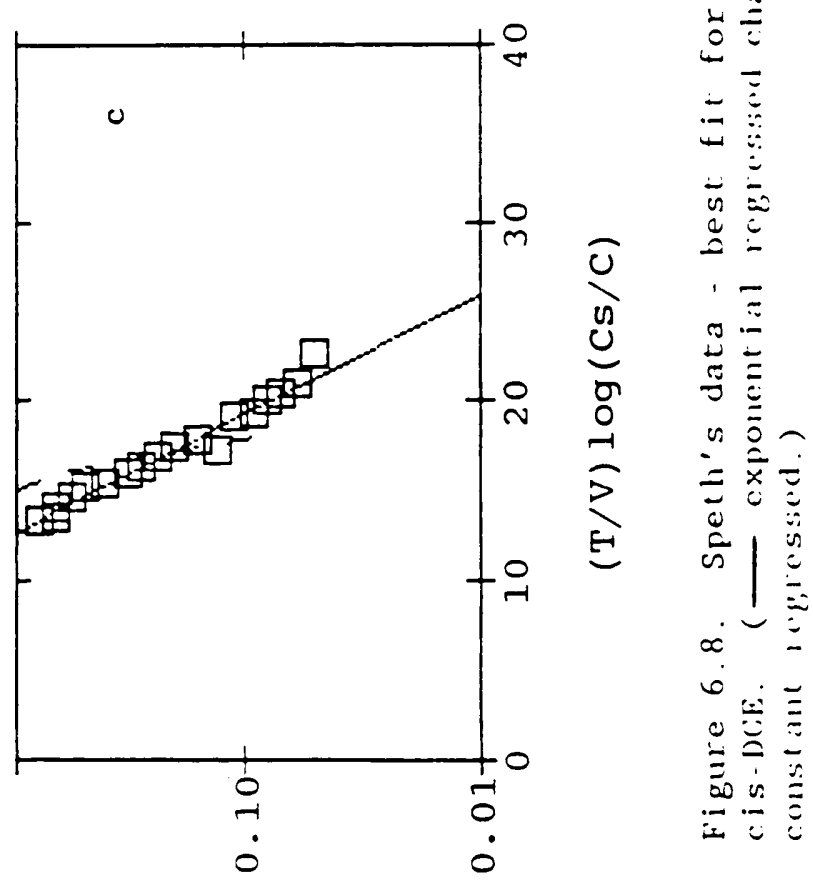

$>0$ 月र⿵冂卄 

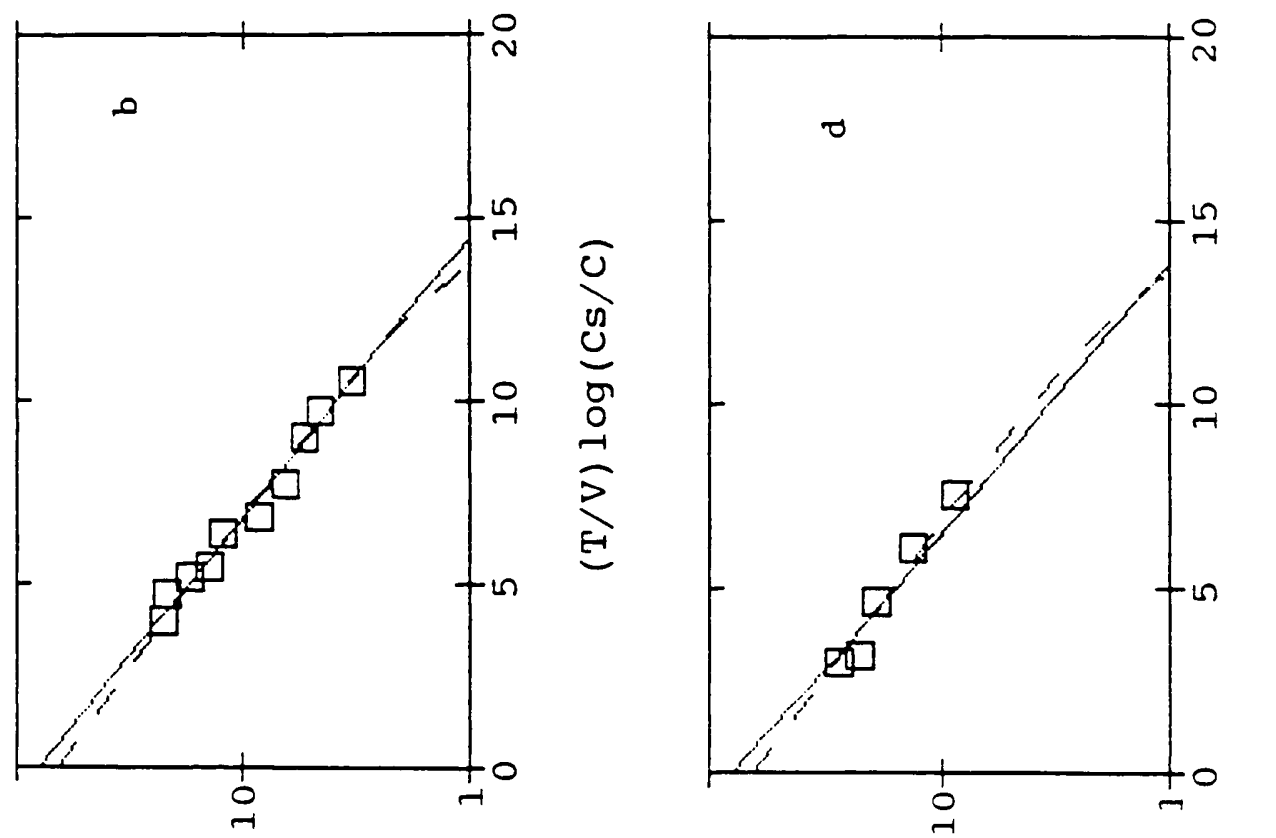

$>0$ >
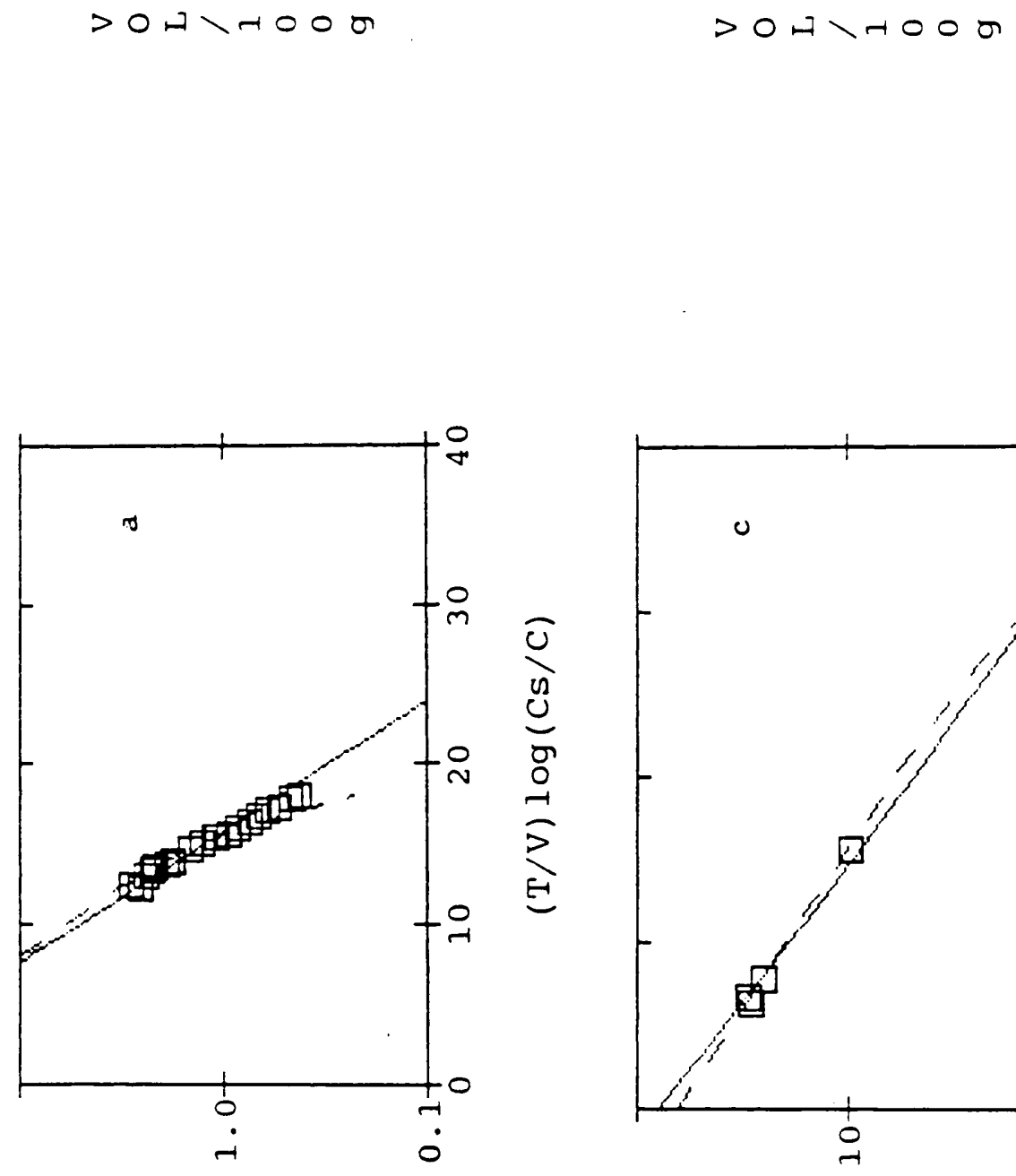

$>0$ $>$ - 000

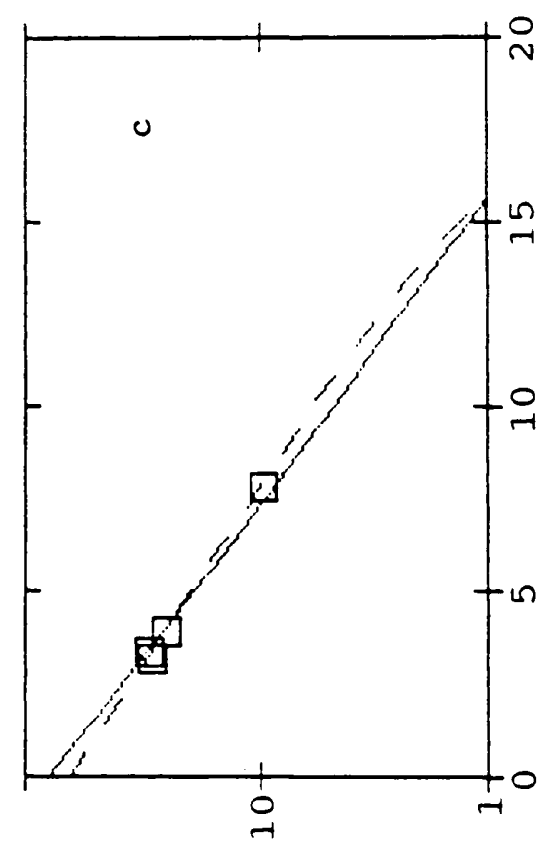

>0ロ入 


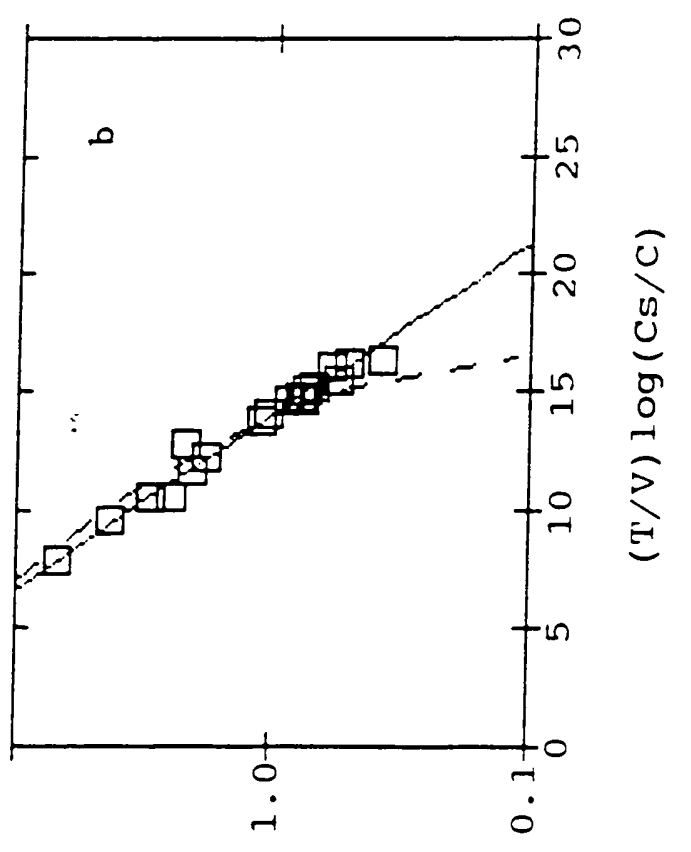

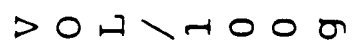
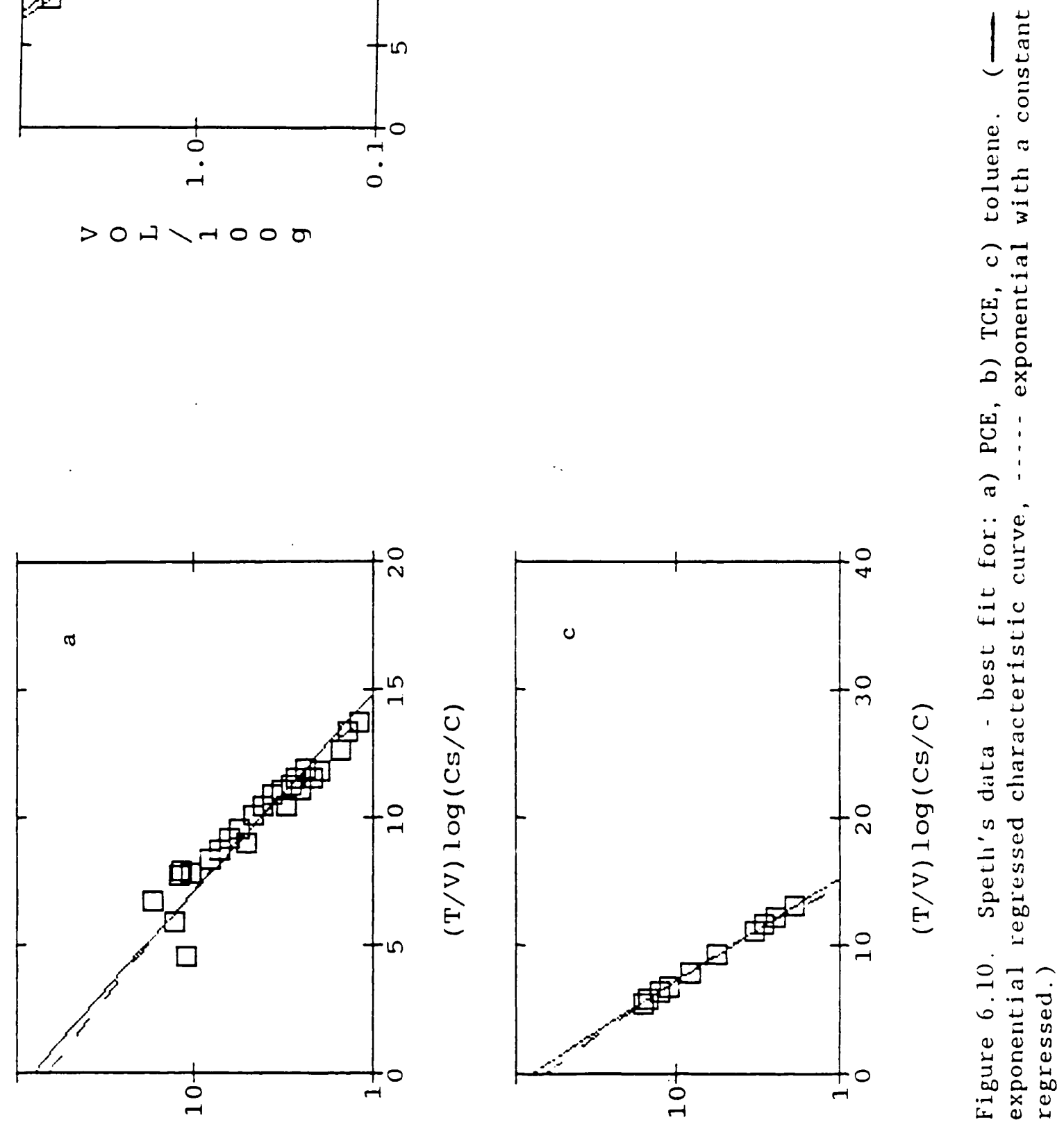

$>0$ フ \}

$>0$ > 


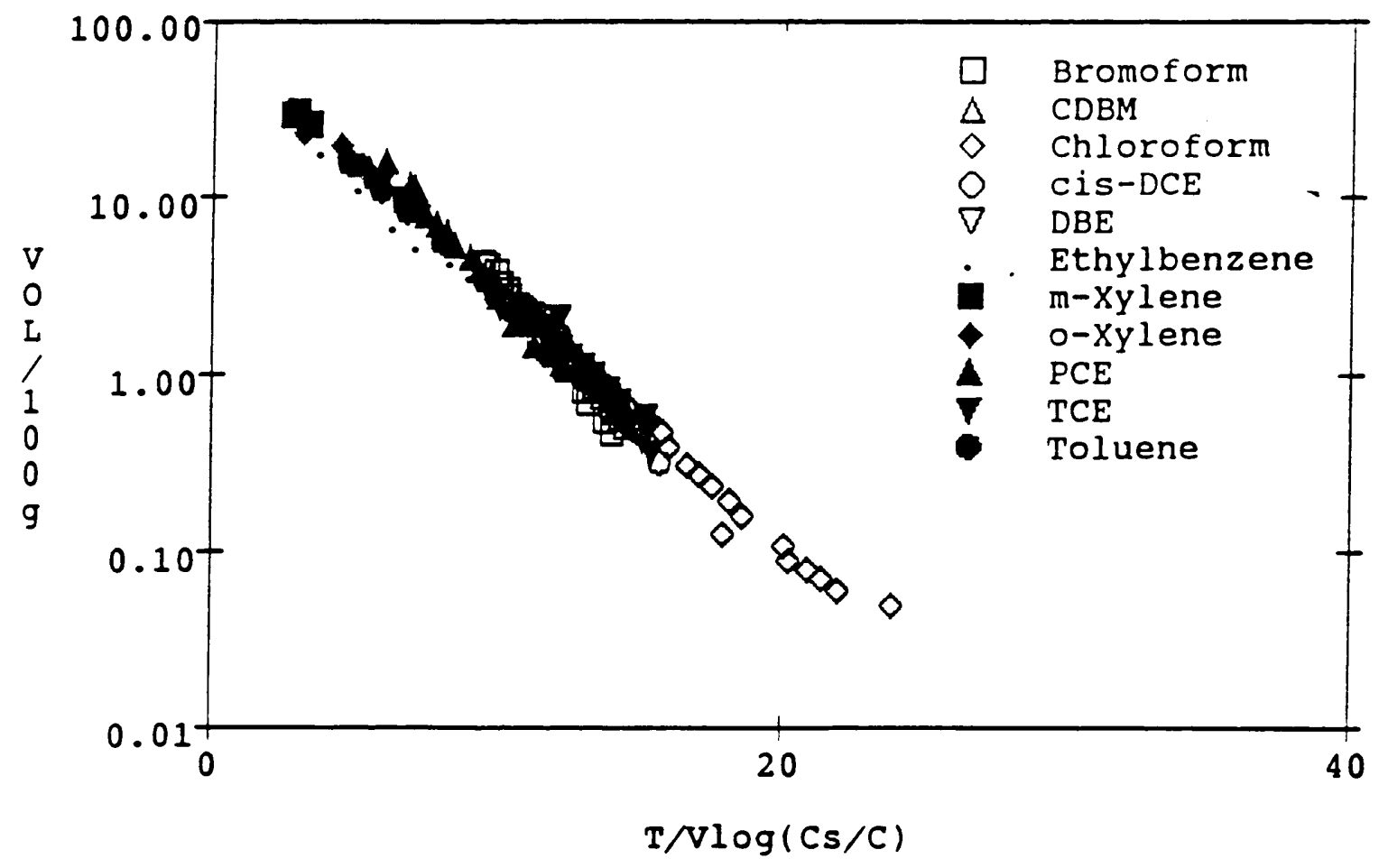

Figure 6.11. Correlation curve of Speth's cuata - adjusted using EDASF (exp).

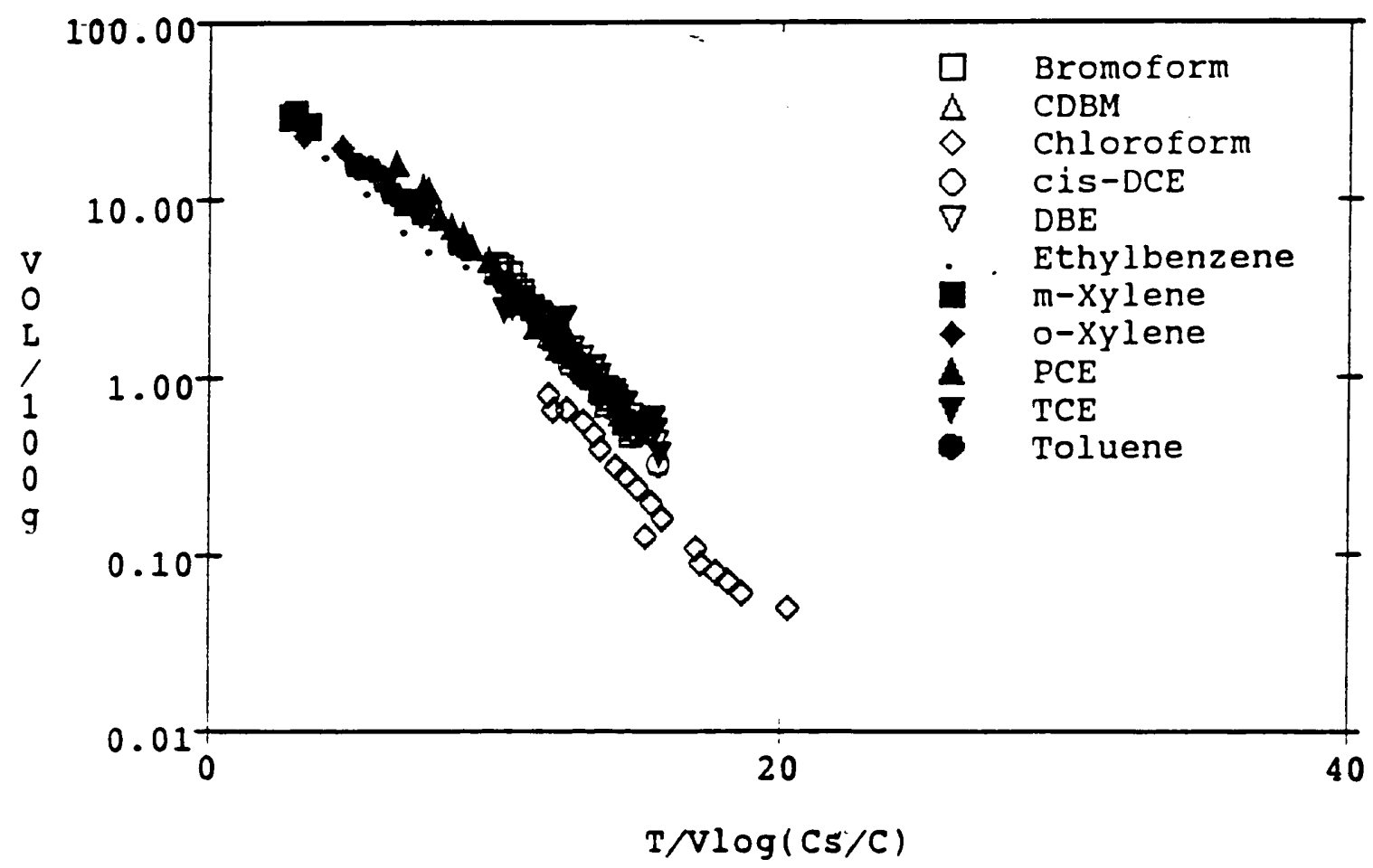

Figure 6.12. Correlation curve of Speth's data

- adjusted using EDASF (exp w/constant). 
improve the curve's fit. The poor fit of chloroform in Figure 6.12 is not unexpected since, as mentioned, this data is not well explained by this type of equation.

The above scale factors were determined from a regression of several data points for each compound. In practice, the reference compound must be well defined but only one data point for each of the other compounds would be required to determine the experimentally determined scale factors. As a test of the effectiveness of scale factors determined from a single point, two of the compounds, bromoform, and PCE, were examined. EDASF were then determined for each data point. As Figure 6.8a demonstrates, bromoform ( $\mathrm{AE}=0.19$ and 0.08 ) is accurately described by both the exponential and the exponential with a constant models. One would expect that since the observed data points all Iie within a narrow range, any point chosen should produce an acceptable scale factor. Figures 6.13 and 6.14 depict the worst case results when the highest and lowest scale factors, determined using individual data points, are applied to the bromoform data. Even using these extreme values, the single point EDASF produces a reasonably good fit $(\mathrm{AE}=0.40,0.27$ using the exponential, $0.28,0.10$ using the exponential with a constant model).

In contrast, several PCE data points do not conform to either model (see Figure 6.10a). Using one of these outliers will result in an inaccurate EDASF. Figures 6.15 and 6.16 depict the results obtained when the worst (high and low) fitting data are used to determine the EDASF. These graphs are indicative of the poor description of data which results when incorrect EDASF are applied (lowest $A E=0.72$ ). In Figures 6.13 thru 6.16 the predictions are somewhat errant at both the 


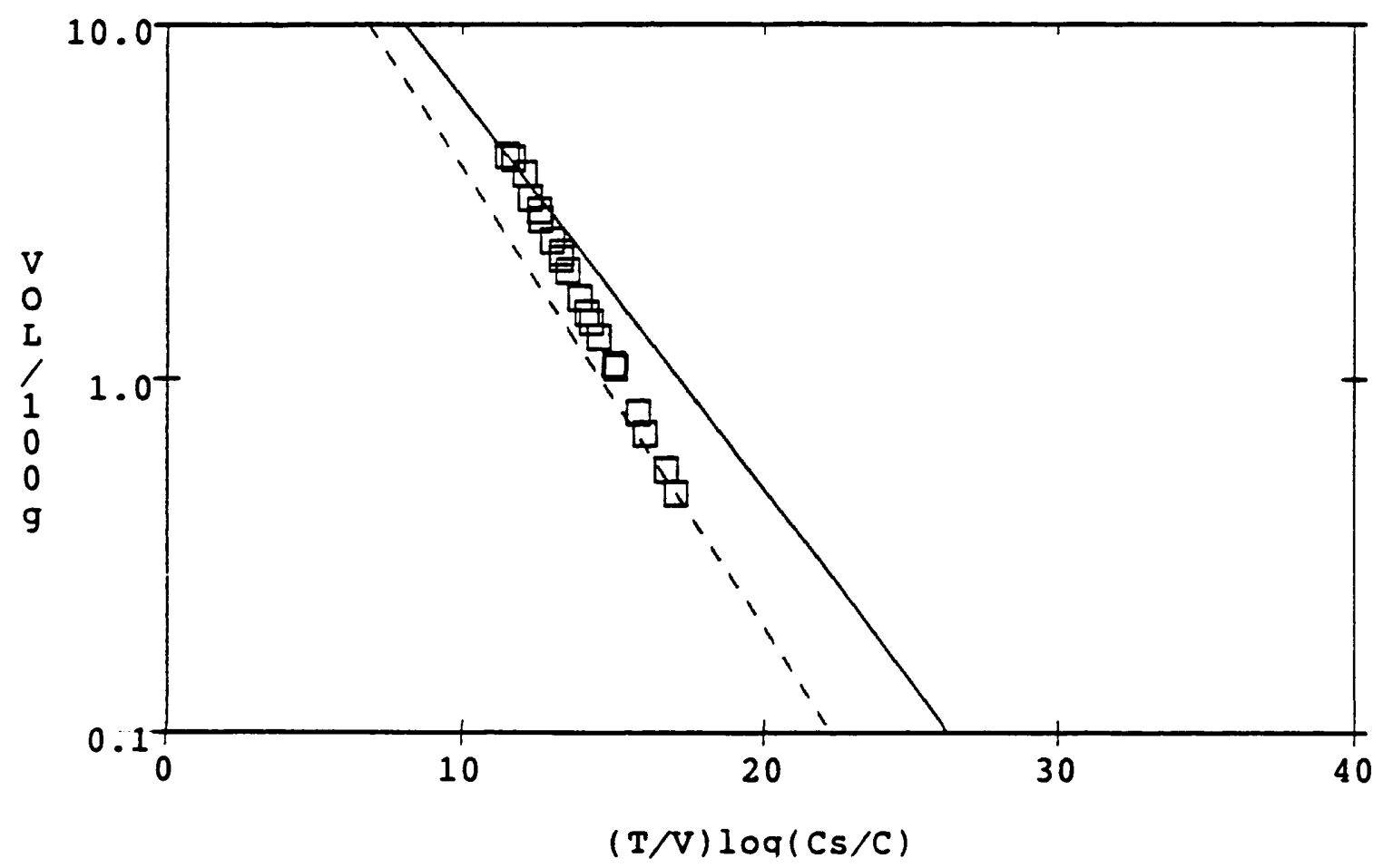

Figure 6.13. Speth's bromoform data - worst case results using single point EDASF (exp).

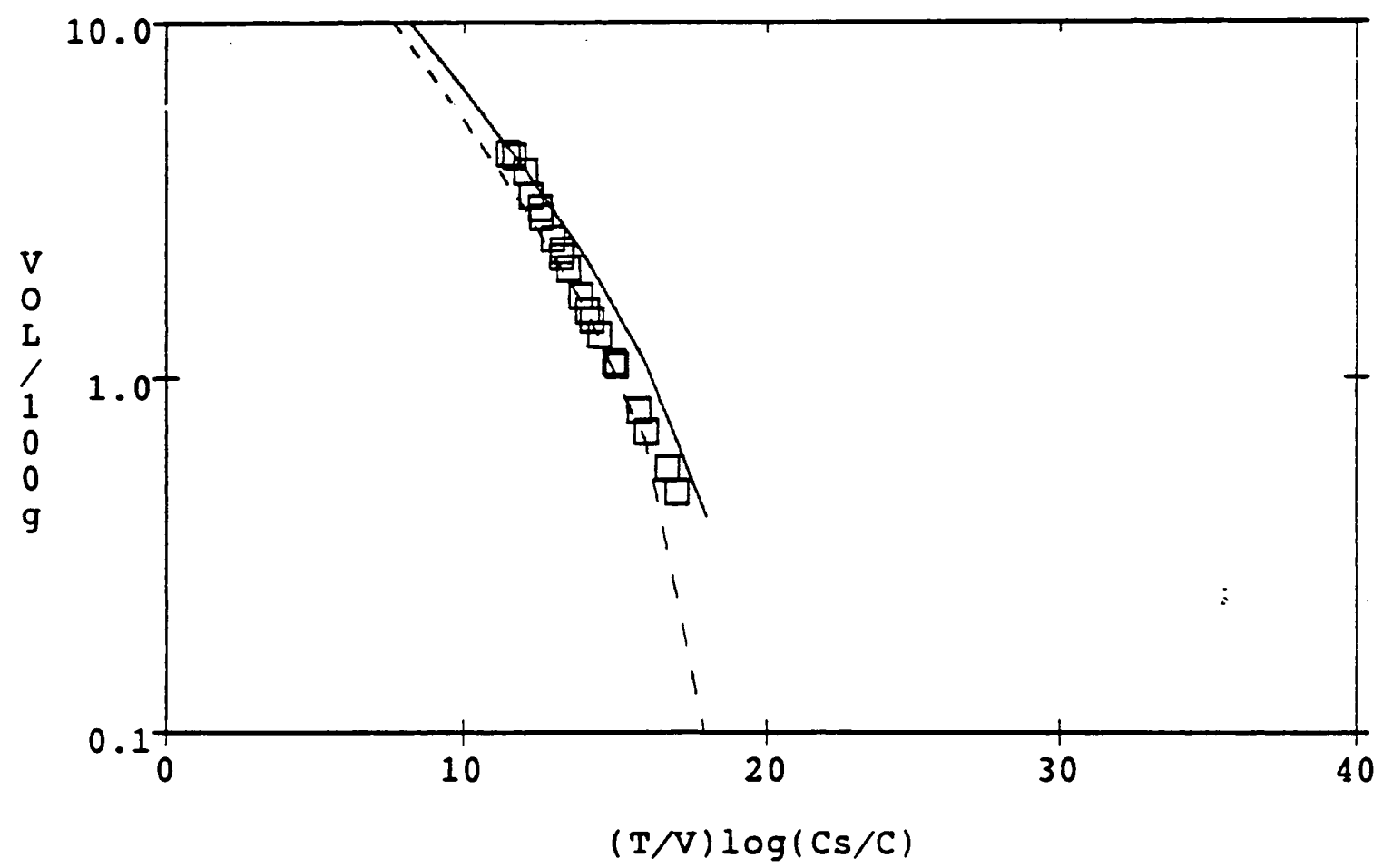

Figure 6.14. Speth's bromoform data - worst case results using single point EDASF (exp $w / k)$. 


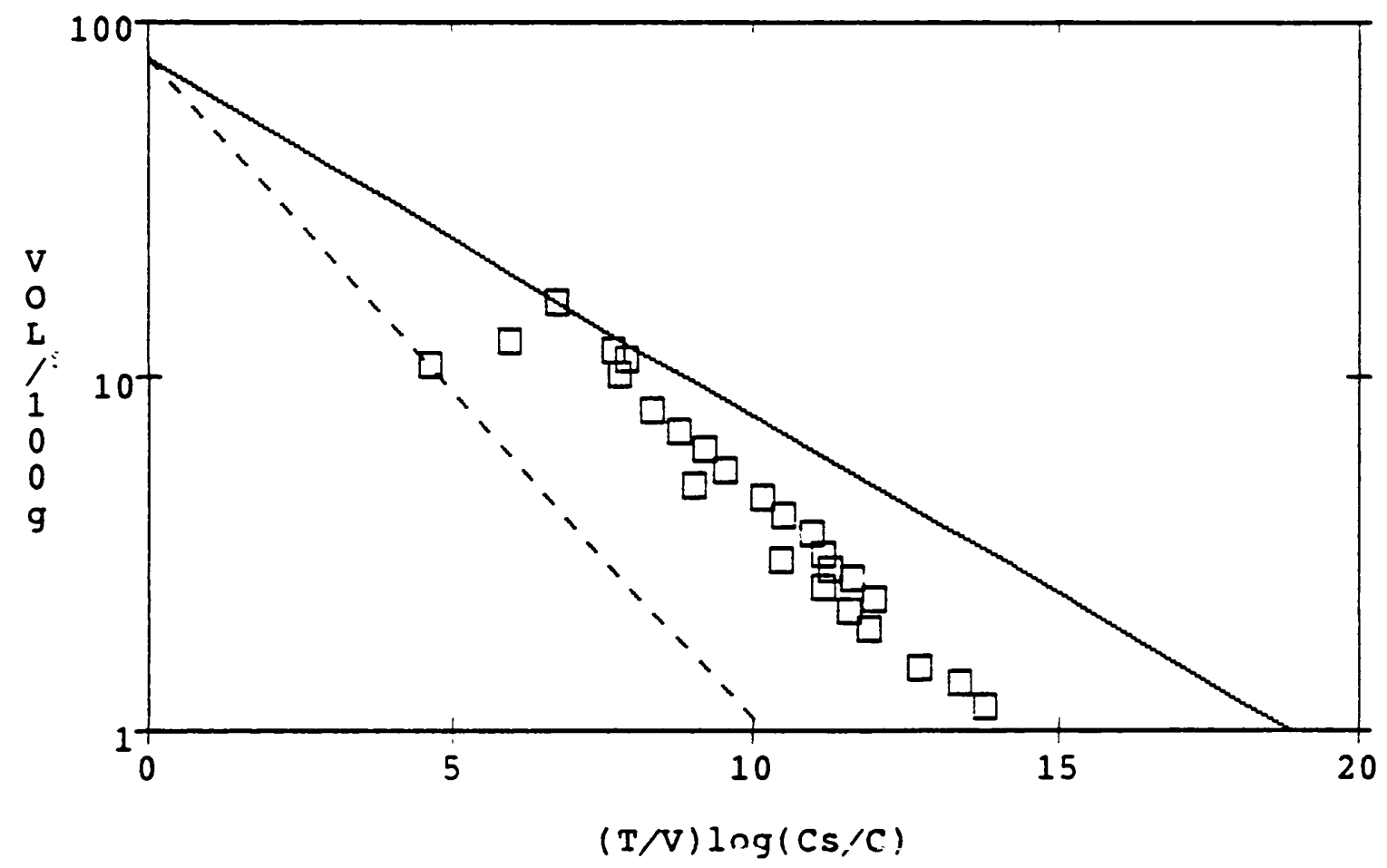

Figure 6.15. Speth's PCE data - worst case results using single point EDAsF (exp).

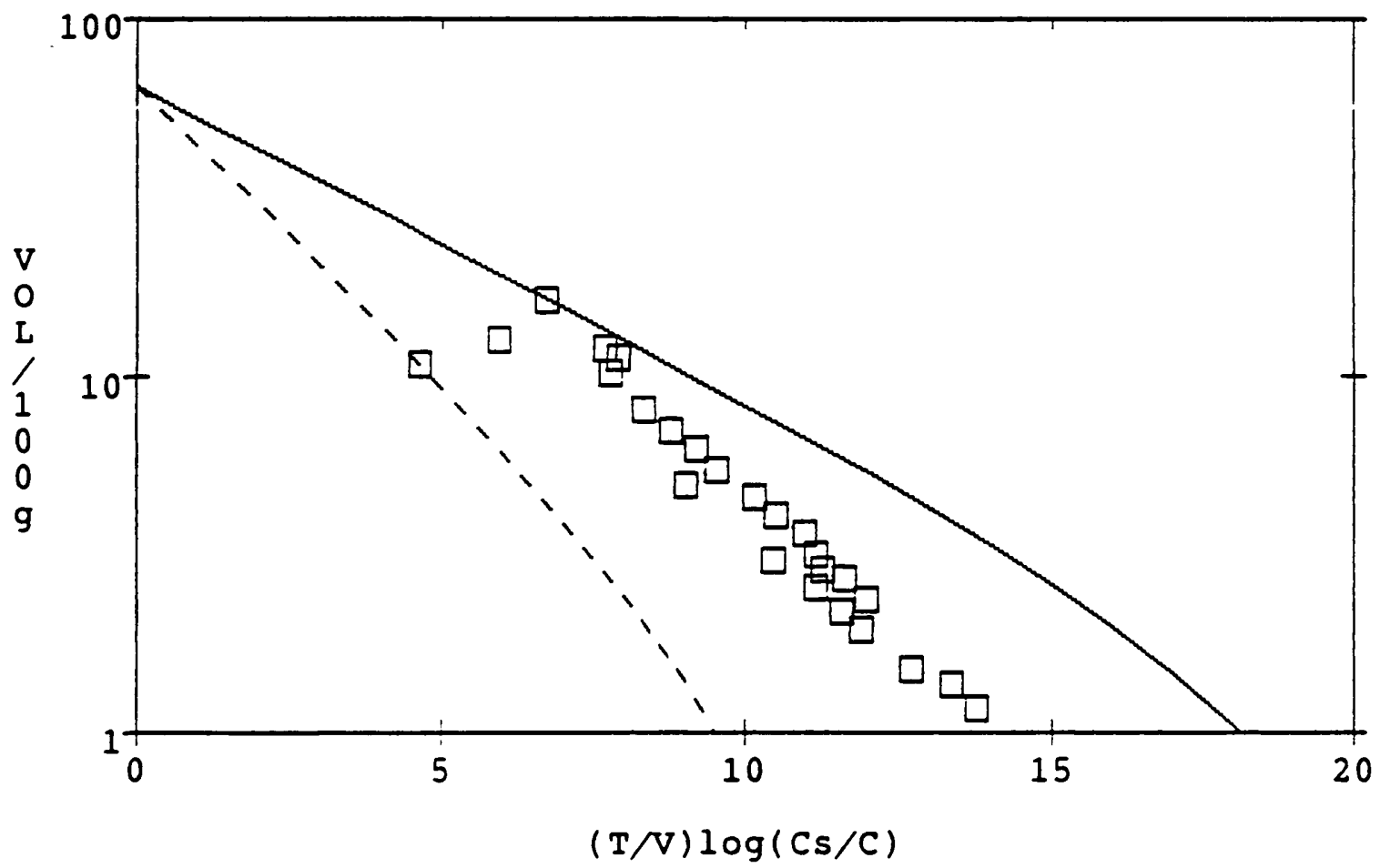

Figure 6.16. Speth's PCE data - worst case results using single point EDASF (exp $w / k)$. 
extreme low and high concentration ranges. The most representative data occurs in the middle ranges. Data in the extreme concentrations is more prone to error. At the low solute concentration range there is greater potential for error because the percent error in the measurement of the solute will increase substantially as the detection limit is approached. Additionally, analytical techniques generally follow a trend of increasing variability with increasing sensitivity. At equilibrium solute concentrations that approach the initial concentration there are also large errors due to the error involved in weighing small carbon doses and the small solute concentration changes. Therefore, single point EDASF should be determined from isotherm data determined using carbon weights greater than $0.02 \mathrm{gm}$, to minimize weighing error. The chosen solute equilibrium concentration should be at least half of the initial concentration but sufficiently high to avoid error in the solute measurement.

The theoretically and experimentally determined scale factors, as well as the differences between them, are presented in Table 6.3. As this data indicates the agreement between observed and predicted is quite good. Only chloroform, with a 12.98 difference using the exponential with a constant, exceeded 10\%. This indicates that polarizability is a good predictor of adsorption. The average difference indicates that the simple exponential model yields results closer to those predicted by polarizability.

The fit is quantified in Table 6.4, which summarizes the average error for each compound using no scale factor and using either experimentally or theoretically determined scale factors. This goodness of fit parameter is mean error defined by equation 5.2. A reasonably 
TABLE 6.3 ABSCISSA SCALE FACTORS THEORETICALLY AND EXPERIMENTALLY DERIVED FROM SPETH'S DATA

\begin{tabular}{|c|c|c|c|c|c|}
\hline COMPOUND & \multicolumn{4}{|c|}{ SCALE FACTORS } & \multirow[b]{3}{*}{ DIFF } \\
\hline & TDASF & & EDASF & & \\
\hline & & $\exp$ & $\& D I F F$ & $\begin{array}{l}\exp \\
w / K\end{array}$ & \\
\hline Bromoform & 0.7869 & 0.8247 & 4.6 & 0.8677 & 9.3 \\
\hline CDBM & 0.8450 & 0.8500 & 0.6 & 0.8651 & 2.3 \\
\hline Chloroform & 1.0040 & 1.0452 & 3.9 & 0.8890 & -12.9 \\
\hline cis-DCE & 1.0000 & 1.0000 & 0.0 & 1.0000 & 0.0 \\
\hline $\mathrm{DBE}$ & 0.8554 & 0.8383 & -2.0 & 0.8682 & 1.5 \\
\hline Ethylbenzene & 0.9178 & 0.9112 & -0.7 & 0.9798 & 6.3 \\
\hline m-Xylene & 0.9150 & 0.8454 & -8.2 & 0.8577 & -6.7 \\
\hline o-Xylene & 0.9030 & 0.9512 & 5.1 & 0.9829 & 8.1 \\
\hline PCE & 0.9018 & 0.8880 & -1.6 & 0.9549 & 5.6 \\
\hline TCE & 0.9502 & 0.9466 & -0.4 & 0.9648 & 1.5 \\
\hline Toluene & 0.9153 & 0.8574 & -6.8 & 0.9233 & 0.9 \\
\hline AVERAGE & & & 3.1 & & 5.0 \\
\hline
\end{tabular}

Note: TDASF = Theoretically Determined Abscissa Scale, factor, $E D A S F=$ Experimentally Determined Abscissa Scale factor, $\exp =$ exponential model, $\exp \mathrm{w} / \mathrm{k}=$ exponential with a constant model, \&Diff $=[($ TDASF-EDASF $) /$ EDASF $] * 100$. 
Table 6.4

Table 6.4 AVERAGE ERROR Of SPETH'S DATA USING NO ADJUSTMENTS, TDASF AND EDASF

COMPOUND

Bromoform

CDBM

Chloroform

cis-DCE

DBE

Ethylbenzene

$\mathrm{m}$-xylene

o-Xylene

PCE

TCE

Toluene

AVERAGE
NO ADJUSTMENT

$\exp$

0.32

0.30

1.00

0.48

0.32

0.10

0.11

0.12

0.19

0.15

0.17

0.30

0.57

0.50

0.30

0.10

0.26

0.15

0.09

0.10

0.09

0.11

0.13

0.07

0.17

0.11

0.19

0.29

0.08

0.12

0.16

0.15

$0.15 \quad 0.60$

0.60

0.15

3.76

1.09

0.13

0.17

0.07

0.11

0.26

0.23

0.03

0.11

0.19

0.10

0.10

0.10

0.10

0.09

0.06

0.14

0.19

0.08

0.02

$\exp$

$\mathrm{w} / \mathrm{K}$
EDASF USING A SINGLE DATA POINT

$$
\text { exp }
$$

low high

$0.40 \quad 0.27$

0.89

0.72 $\exp$

$\mathrm{w} / \mathrm{K}$

Bromoform

PCE

Note $: \exp =$ exponential mode1, $\exp \mathrm{w} / \mathrm{k}=$ exponential with a constant model. 
good fit should yield a value of 0.5 or less. Although this represents an error of 50\%, it is a fairly reasonable cutoff point given the predictive nature of the methodology. When no adjustments are made to the characteristic curve, the overall average error indicates that the exponential model provides a better fit of the data. However, the data from bromoform, CDBM, chloroform and DBE were not used in creating the reference characteristic curve. Excluding these compounds from the calculations demonstrates that the exponential with a constant model provides a slightly more accurate description of the raw data ( $\mathrm{AE}=$ 0.16 ) than the exponential model ( $\mathrm{AE}=0.19)$. When scale factors are applied the simple exponential model is overall more effective. For example, TDASF applied to the exponential with a constant model provide an inaccurate depiction of the cis-DCE ( $\mathrm{AE}=1.09$ ) and bromoform (AE 0.60) data. Chloroform's data, using the exponential with a constant, is poorly described by both the theoretical and the experimental scale factor $(\mathrm{AE}=3.76$ and 2.64 respectively). All other compounds are well described by the theory. 
6.1.4 Summary of Analysis of Speth's Data

The Polanyi Equilibrium seems to be quite effective at predicting adsorption isotherm. Both the theoretically and experimentally determined scale factors, in general, provided, an accurate description of the raw data. Using a simple exponential equation to describe the characteristic curve resulted in good fits of all the solutes tested. However, some problems, particularly with chloroform, were encountered when the exponential with a constant model was used to define this curve. This indicates the importance of the function used to describe the reference curve. The simple exponential model was, in this case, best. As Table 6.4 indicates, even with no adjustments this model yielded an average error of only 0.30 .

Polarizability proved to be an effective indicator of the abscissa scale factors. Only in the case of chloroform, where the EDASF was 12.98 lower than the TDASF, was the difference greater than $10 \%$ (and then only when the exponential with a constant model was used).

As mentioned, when applying scale factors, the reference solution should be well defined over the entire adsorption range. Using the overall data fit as the reference curve was a compromise made necessary by the limited testing range of the individual solutes. It appears that using this overall curve caused no difficulties in applying the theory. In fact, it may point to an advantage of the theory, in that one compound can be used to define the reference curve in the higher concentration range, while another can be used to determine the curve in a lower range, which may be beyond the detection level of the other compound. 
The EDASF were determined by regressing the isotherm data of each compound. The bromoform and PCE data indicate that a single point, if properly selected, can be used to determine these scale factors. 


\subsection{EVALUATION OF THE POLANYI MODEL FOR FUKUCHI'S DATA}

Speth's data demonstrated that Polanyi's theory shows much promise as a predictive tool. As a further test of his theory, data on an wider variety of compounds is required. Application of the theory to compounds which exist as solids above the isotherm temperature has received much attention from Manes and coworkers. The following section describes an analysis of isotherm data obtained from an article written by Kenji Fukuchi, Hideaki Hamaoka and Yasuhiko Arai published in the Memoirs of the Faculty of Engineering at the Kyushu University in Japan. Three of the compounds tested, benzoic acid, p-chlorophenol and phenol, exist as solids at the temperature at which the isotherms were conducted.

Again, the bottle point isotherm technique was used. The equilibrium time used by Fukuchi ( 70 hours) was less than the Speth's 7 days; so, it's possible that true equilibrium was not attained. Also, Fukuchi's article is unclear whether the isotherms were obtained using granular or pulverized carbon. This is important since the required equilibrium time is proportional to the square of the particle diameter (Hand et al, 1983). The F-400 carbon used in this case was separated by filtration instead of centrifugation. The experimental conditions are described in Table 6.5.

TABLE 6.5 EXPERIMENTAL CONDITIONS (Fukuchi)

Author........................................... Hama and

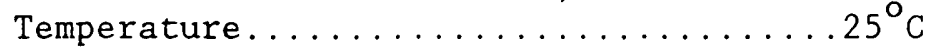

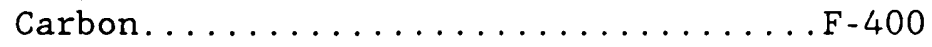

Mesh................12 x 16

Method of Analysis......uv spectrophotometry

Equilibration Time...........70 hours 
The solutes tested were: acetone, benzoic acid, n-butanol, p-chlorophenol (PCP), methyl ethyl ketone (MEK), phenol, pyridine, 2-propanol, propionitrile and vinyl acetate. Relevant information on each of the solutes is presented in Table 6.6 .

\section{TABLE 6.6 CHARACTERISTICS OF SOLUTES (Fukuchi)}

$\begin{array}{lrrrrrc}\text { COMPOUND } & \text { MOL WT } & \begin{array}{c}\text { DEN } \\ (\mathrm{g} / \mathrm{mL})\end{array} & \begin{array}{r}\text { SOL } \\ (\mathrm{mg} / \mathrm{L})\end{array} & \begin{array}{r}\text { MP } \\ (\mathrm{C})\end{array} & \text { INDEX } & \text { P } \\ \text { Acetone } & 58.08 & 0.791 & 280956 & -94 & 1.3585 & 0.2199 \\ \text { Benzoic Acid } & 122.12 & 1.321 & 19211 & 122.4 & 1.5040 & 0.2961 \\ \text { n-Butanol } & 74.12 & 0.810 & 76016 & -90 & 1.3985 & 0.2416 \\ \text { p-Chlorophenol } & 128.56 & 1.306 & 574 & 43.2 & 1.5579 & 0.3223 \\ \text { MEK } & 72.11 & 0.805 & 124923 & -86 & 1.3788 & 0.2310 \\ \text { Phenol } & 94.11 & 1.071 & 6568 & 40.9 & 1.5425 & 0.3150 \\ \text { Pyridine } & 79.10 & 0.978 & 623801 & -42 & 1.5102 & 0.2992 \\ \text { 2-Propanol } & 60.09 & 0.785 & 166135 & -88.5 & 1.3770 & 0.2300 \\ \text { Propionitrile } & 55.08 & 0.772 & 80689 & -91.8 & 1.3660 & 0.2240 \\ \text { Vinyl Acetate } & 86.09 & 0.934 & 10343 & -100 & 1.3954 & 0.2400\end{array}$

Note: MOL WT = molecular weight; $\mathrm{DEN}=$ density; $\mathrm{SOL}=$ solubility; $M P$ = melting point; INDEX = refractive index; $P=$ polarizability

At the isotherm temperature three of the solutes, benzoic acid, p-chlorophenol and phenol, exist as solids. For these compounds corrections for density are necessary in addition to the adjustments for molar volume and polarizability, which apply to all solutes. The UNIFAC (Fredenslund et al, 1975) estimated solubility of several compounds, pyridine and acetone in particular, is very high. With such great solubility one would assume that these solutes will be poorly absorbed (since they must be removed from water for which they have such a strong affinity). However, although acetone's polarizability is low, 
indicating poor adsorption, pyridine's is not; so, these adsorption estimators - solubility and polarizability - seem to be in conflict.

The Polanyi treatment of isotherm data does take both of these parameters into account. The abscissa, which defines adsorption potential, contains the solubility term, $\mathrm{C}_{\mathbf{S}}$, in the denominator (large solubility yields small adsorption potential). The polarizability serves as the predicted abscissa scale factor. 


\subsubsection{Basic Characteristic Curve}

As shown in Figure 6.17, a plot of volume adsorbed vs $(\mathrm{T} / \mathrm{V}) \log \left(\mathrm{C}_{\mathrm{s}} / \mathrm{C}\right)$ for Fukuchi's data does not, as opposed to Speth's data, resemble a single characteristic curve. The $\mathrm{Y}$ intercept is referred to as the limiting adsorbate volume as it refers to the maximum volume of a solute which can be adsorbed. As this figure demonstrates, the $Y$ point corresponding to an abscissa value of 0 ( $Y$ intercept), of the two of the solids, p-chlorophenol and phenol, is obviously lower than that of the other compounds. As previously stated, Rosene and Manes (1976) have hypothesized that the solids, with their more rigid structure, can not fit into the carbon pores as efficiently as liquids. This data seems to support this theory.

Figure 6.17 also points out a rather interesting phenomena in that p-chlorophenol's and, to a lesser degree, phenol's data points extend past the 0 point of the $X$ axis. This is impossible since adsorption cannot increase past the saturation concentration since, by definition, the concentration cannot increase past this point. The most likely explanation is that the UNIFAC solubility for these compounds is underestimated. If any of the assumptions made in the UNIFAC determination are inaccurate or, if other important characteristics are not considered in the estimation, then the resulting value will reflect these deficiencies. Using a solubility value obtained from a reference manual (Lange, 1987), for p-chlorophenol $(27,100 \mathrm{mg} / \mathrm{L}$ ) and phenol $(82,000 \mathrm{mg} / \mathrm{L})$ resulted in characteristic curves which did not extend beyond the $\mathrm{Y}$ intercept. These reference values will therefore be used in the data analysis.

Even if the solids are not considered, it would appear that the 


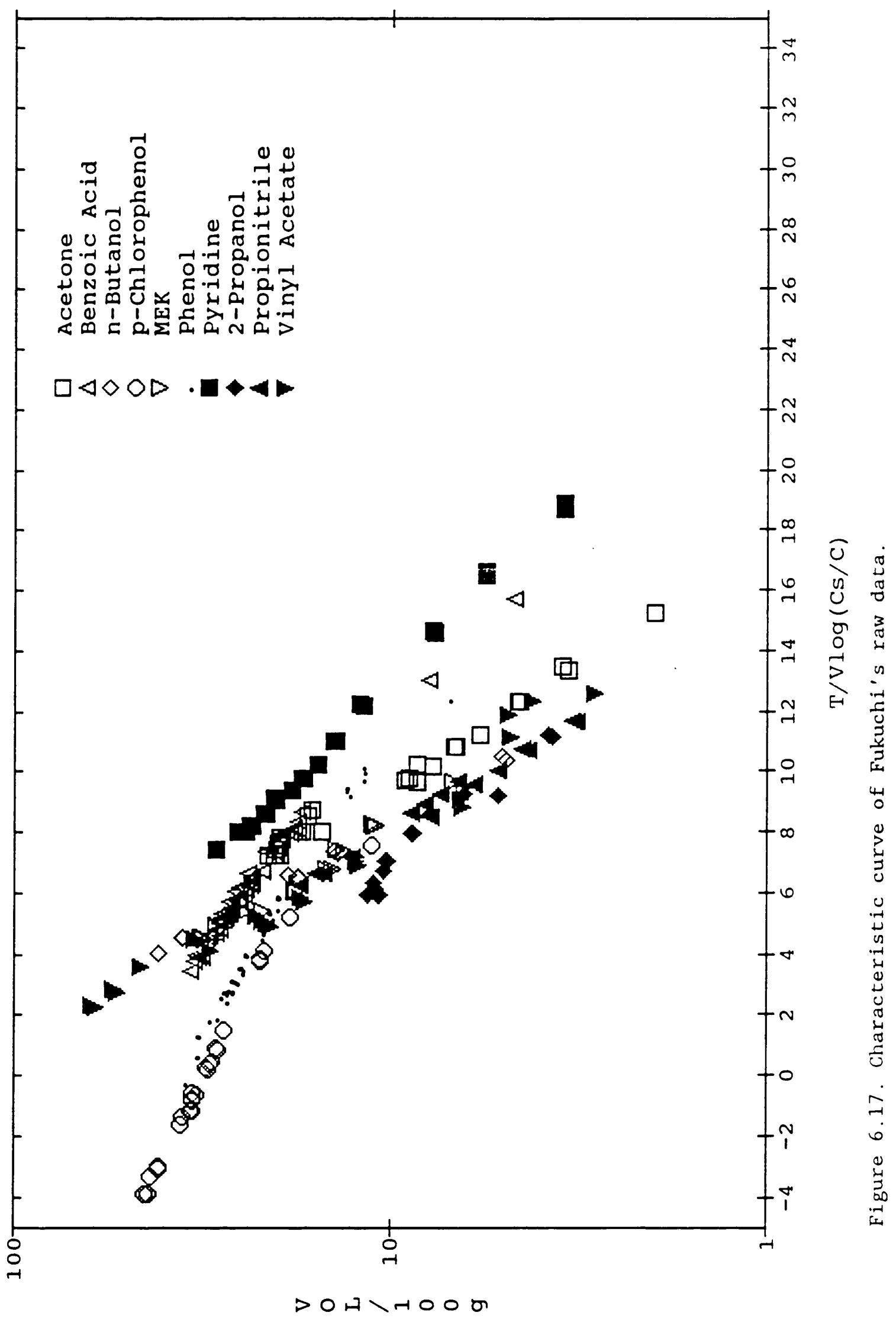


isotherm data of the various compounds is very different. Can all this seemingly unrelated data be derived from one characteristic curve? Before theoretical scale factors can be applied, one compound must be chosen to serve as a reference. Vinyl acetate's data covers a wide concentration range and is therefore a good choice. Using RS/1 to nonlinearly regress this data, it was determined that an accurate fit $(A E=0.13)$ results from the following simple exponential equation:

$$
F(X)=127.6 \times \exp (-0.330494 \times X)
$$

This function defines the reference characteristic curve. (See Figure 6.18.)

\subsubsection{Theoretically Predicted Characteristic Curves}

TDASF were then calculated using equations 2.6 and 2.7 . To predict the characteristic curves of the individual compounds from the reference curve the $B$ term in the equation $(-0.330494)$ is multiplied by each solute's scale factor, while the $A$ term is fixed at 127.6. Figures 6.19 thru 6.21 demonstrate the differences between observed and predicted data for all compounds except those existing as solids above $25^{\circ} \mathrm{C}$. The predictions work well for n-butanol, MEK, and propionitrile ( $\mathrm{AE}=0.14$, 0.21 and 0.29); however, the predicted curves for acetone and pyridine data don't fit the data well $(\mathrm{AE}=0.60$ and 0.51$)$. Although it intercepts the data, the predicted curve of 2-propanol ( $\mathrm{AE}=0.25)$ doesn't seem to match the shape of the data. 


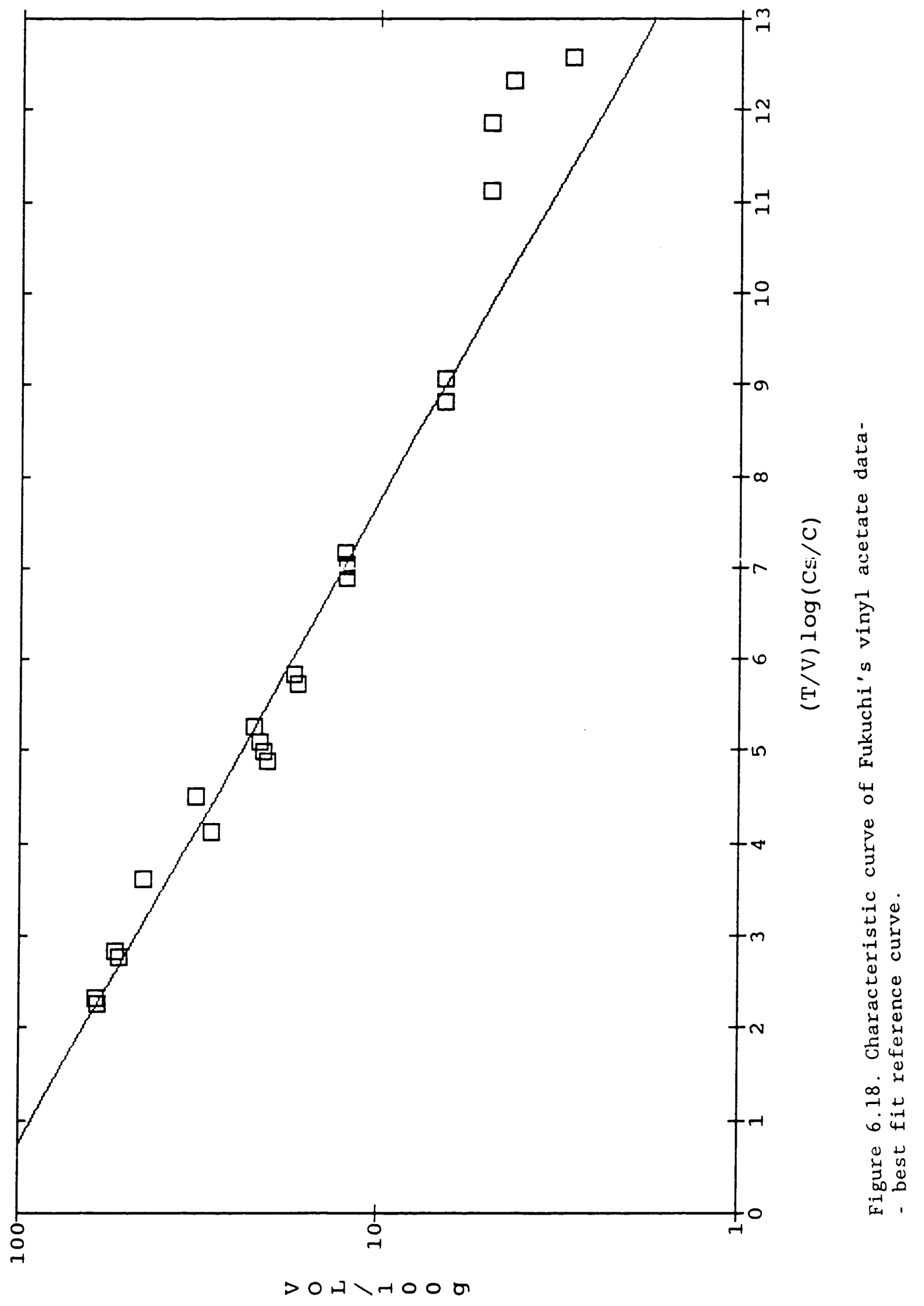



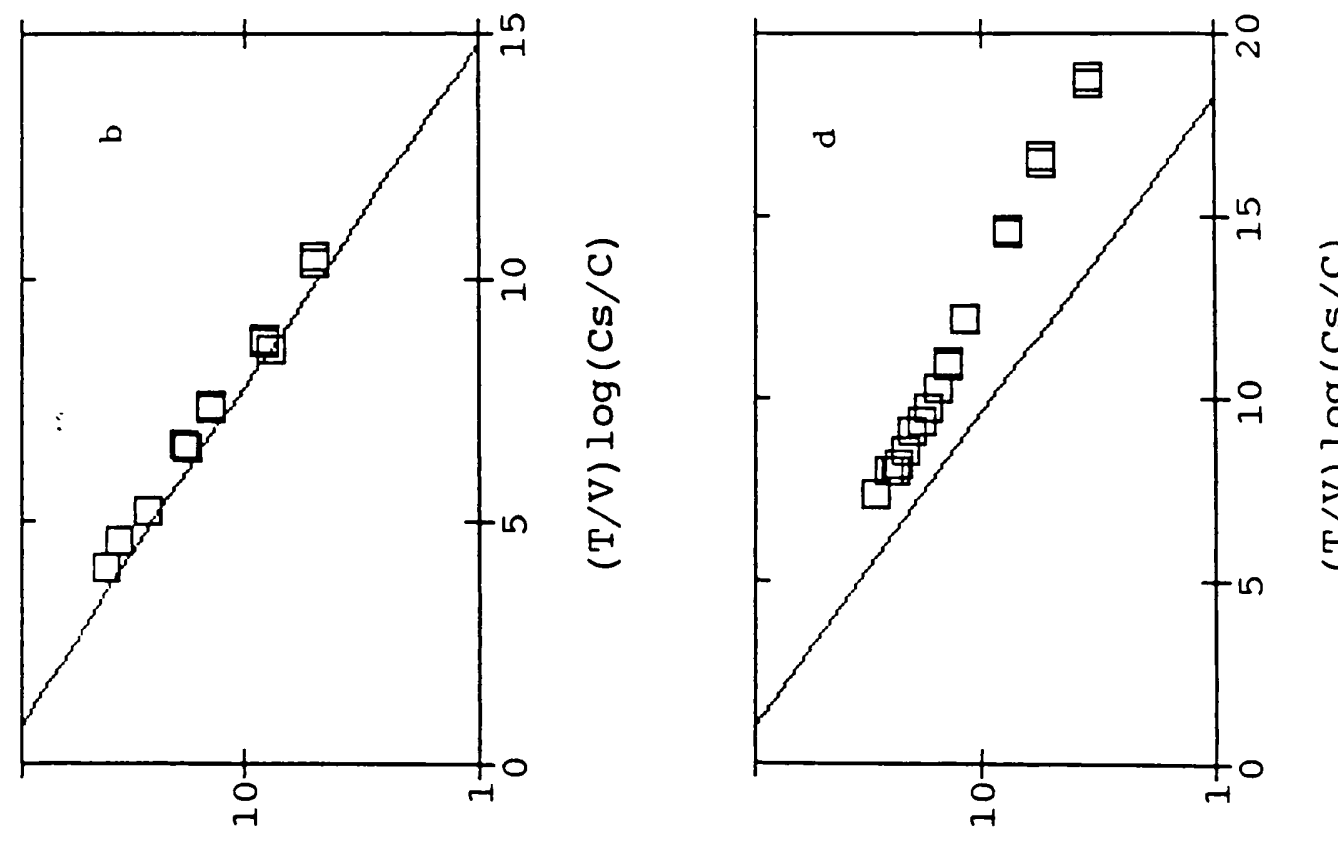

$>0$ a > $>000$
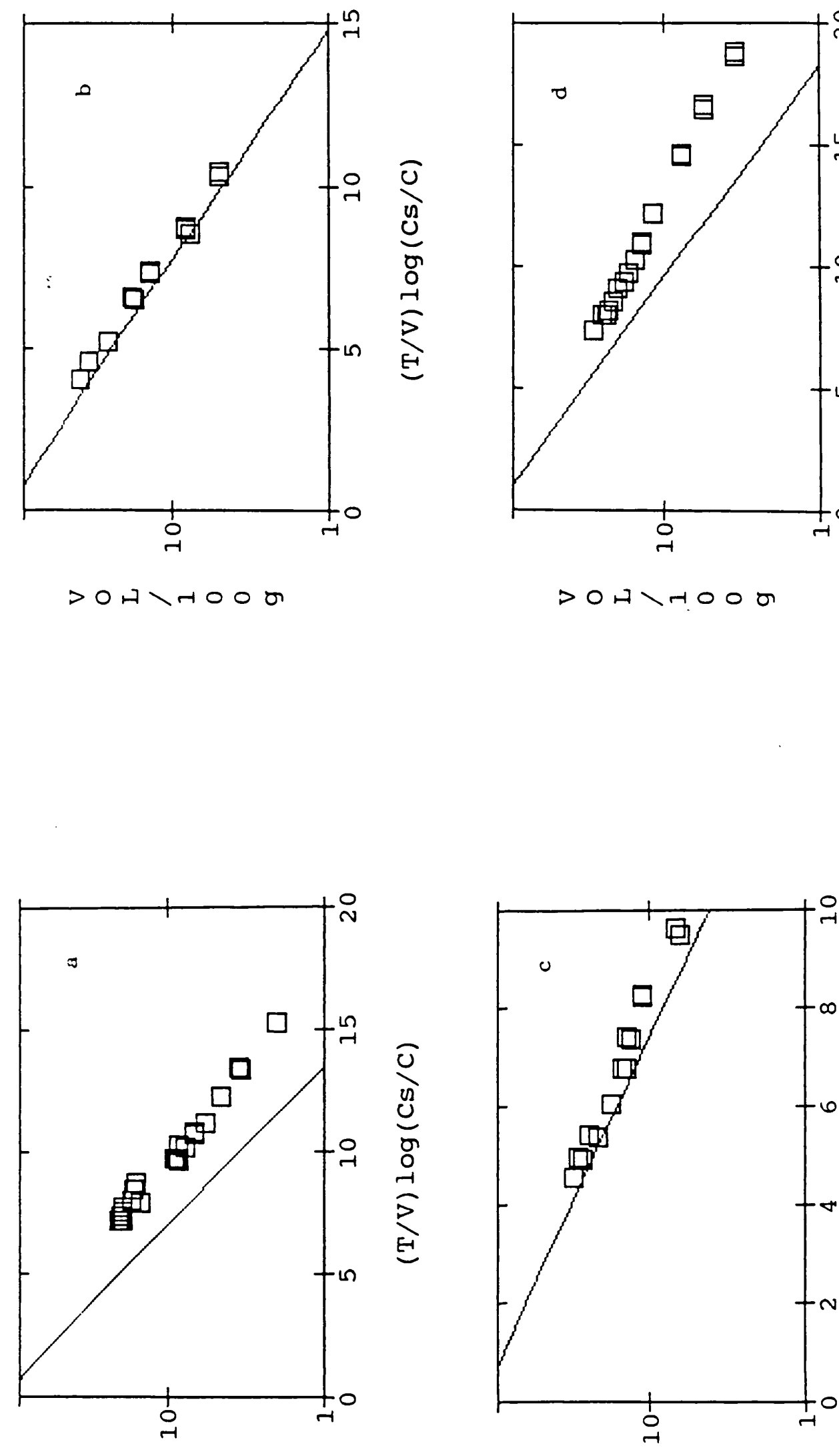

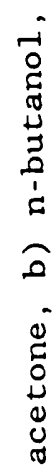

>0n>400

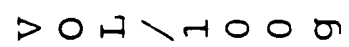




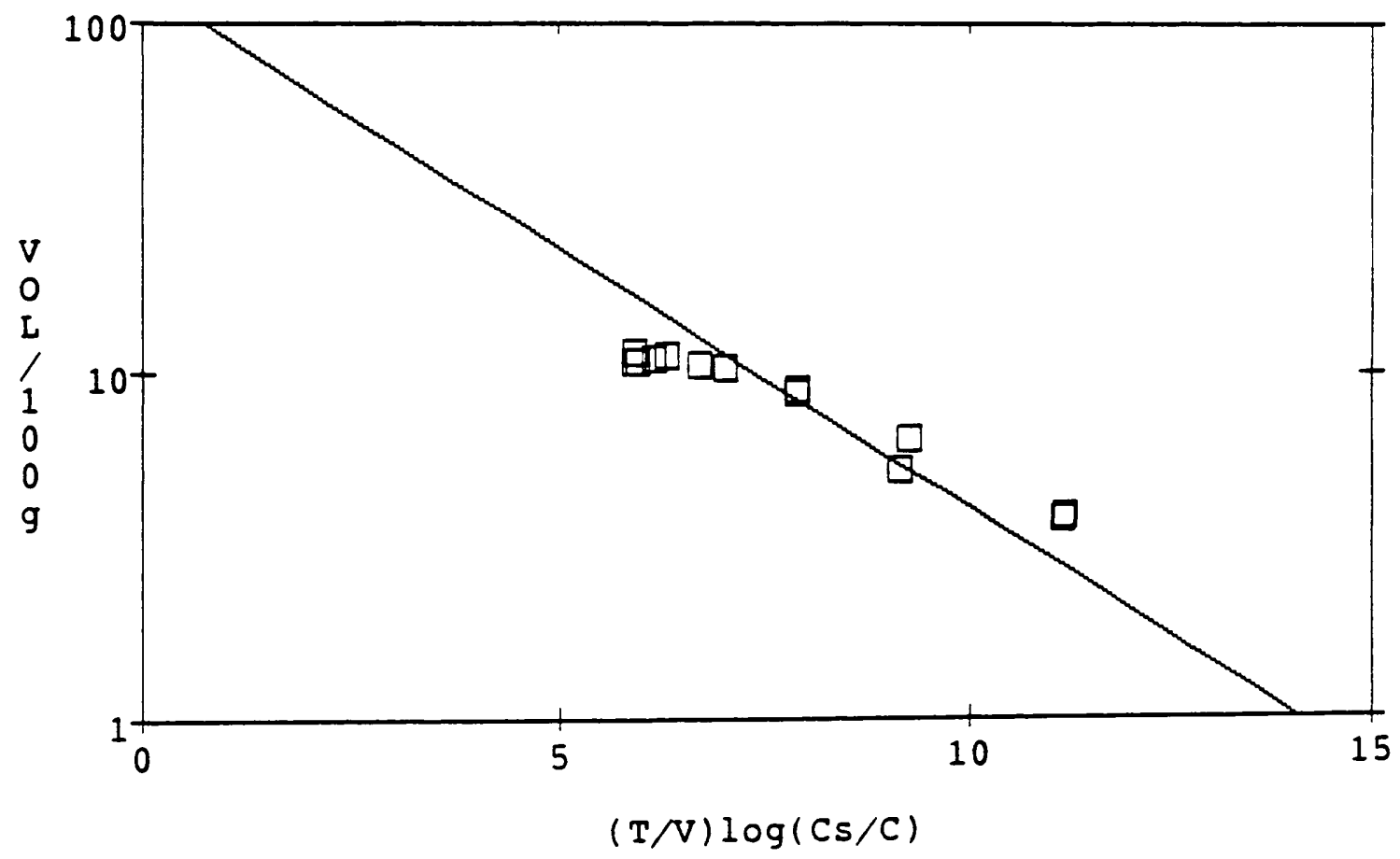

FIGURE 6.20. TDASF PPEDICIION OF FURUCHI'S ? -PROPANOI, DATA

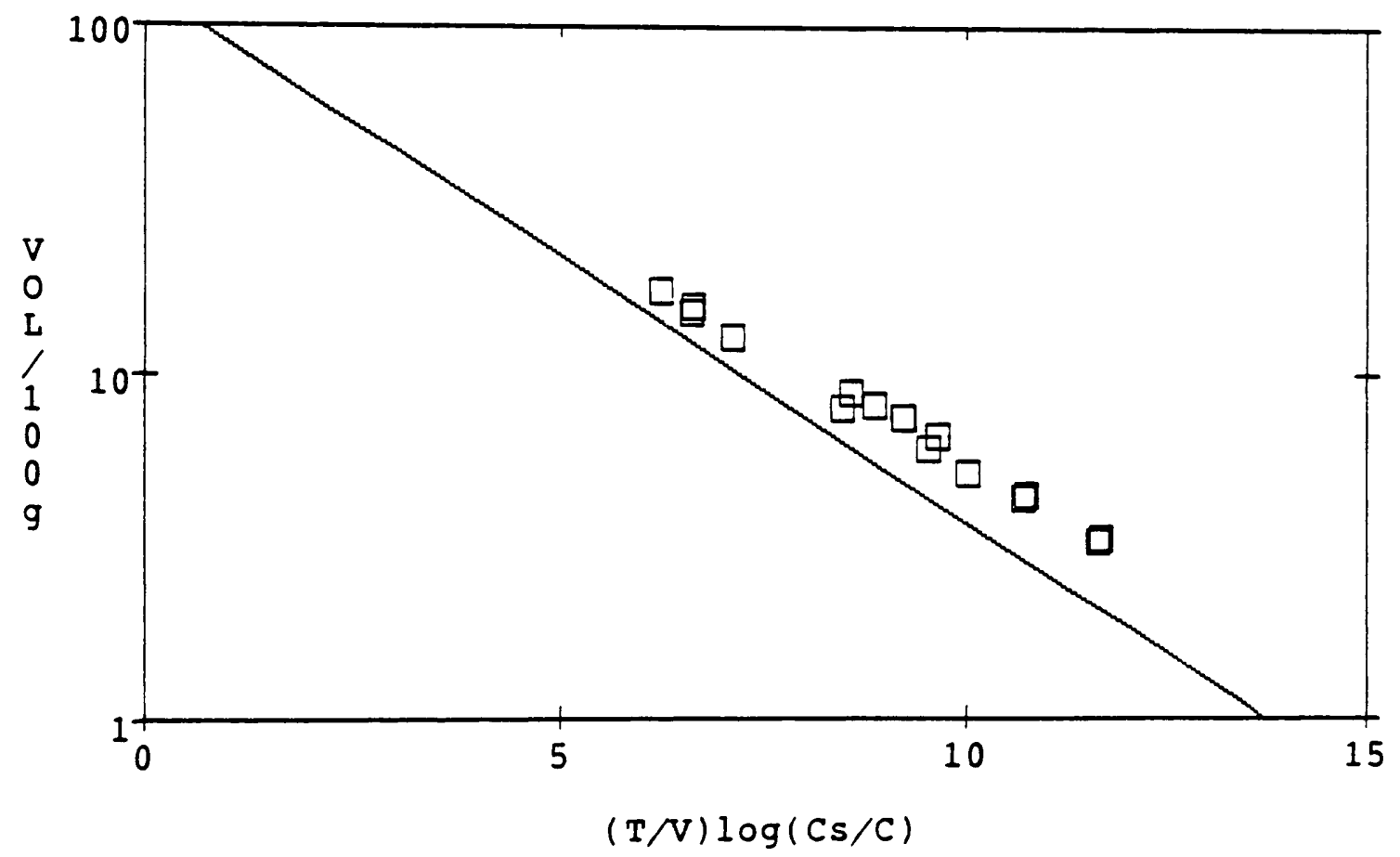

FIGURE 6.21. TDASF PREDICTION OF FURUCHI'S PROPIONITRILE DATA. 


\subsubsection{Density Adjustment for Solids}

As mentioned, due to the suspected inefficient pore packing of solids, Manes and coworkers have suggested that an ordinate density adjustment is required. The ordinate of a characteristic curve reports volume adsorbed per 100 grams of carbon. Isotherm data is normally reported as mass adsorbed per mass of carbon. An assumption of the adsobate's density is thus required to convert the mass adsorbed to volume adsorbed. Normally, the density used for liquids is the room temperature density of the pure solute. Although this is satisfactory for liquids, adjustments are required to make isotherm data for solids fit on the characteristic curve.

These density adjustments were determined by first using $\mathrm{RS} / 1$ to determine the best fit values of both the $A$ and $B$ terms of the equation $\mathrm{F}(\mathrm{X})=A^{*} \exp (B * \mathrm{X})$ for the uncorrected isotherm data of the solid. The density of the solid was then lowered to a value which made the $Y$ intercept value, the $A$ term, of the solid's best fit curve coincide with the $\mathrm{Y}$ intercept of the reference compound. This correction is easily determined by determining the ratio of the solid's $Y$ intercept to that of the reference compound. The adjusted density is then determined by multiplying the solid's density by this value.

Figures 6.22 through 6.27 demonstrate the predicted fit of the solid's isotherm data which results both before and after the ordinate density adjustments, which are required to compensate for the inefficient pore packing, are applied. Although the average error of benzoic acid, $\mathrm{p}$-chlorophenol and phenol is acceptable $(\mathrm{AE}=0.18,0.41$ and 0.28 ), the predicted curve seems to intersect, rather than follow, 


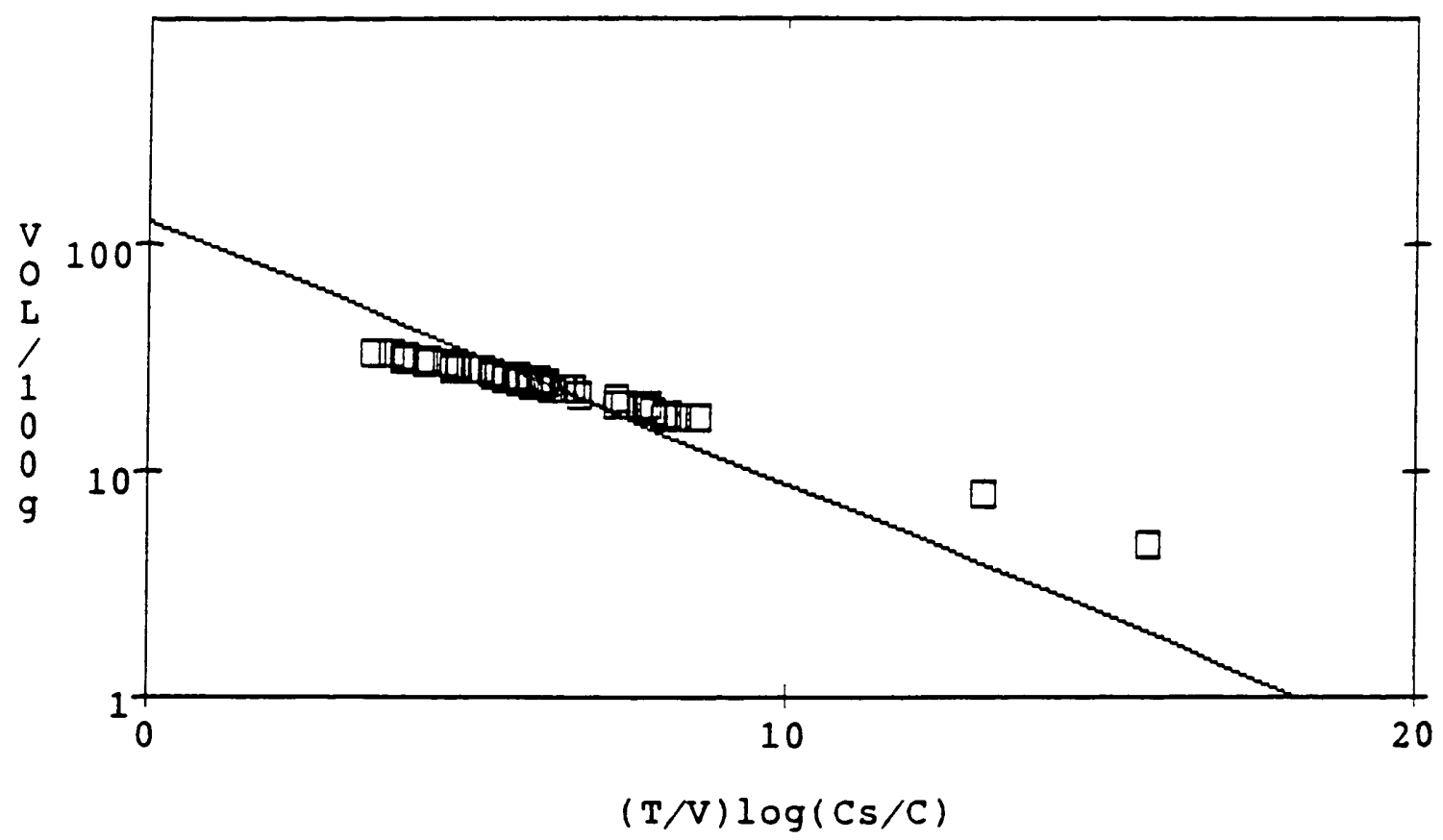

Figure 6.22. TDASF prediction of Fukuchi's benzoic acic data (iso lieisity äjustinent).

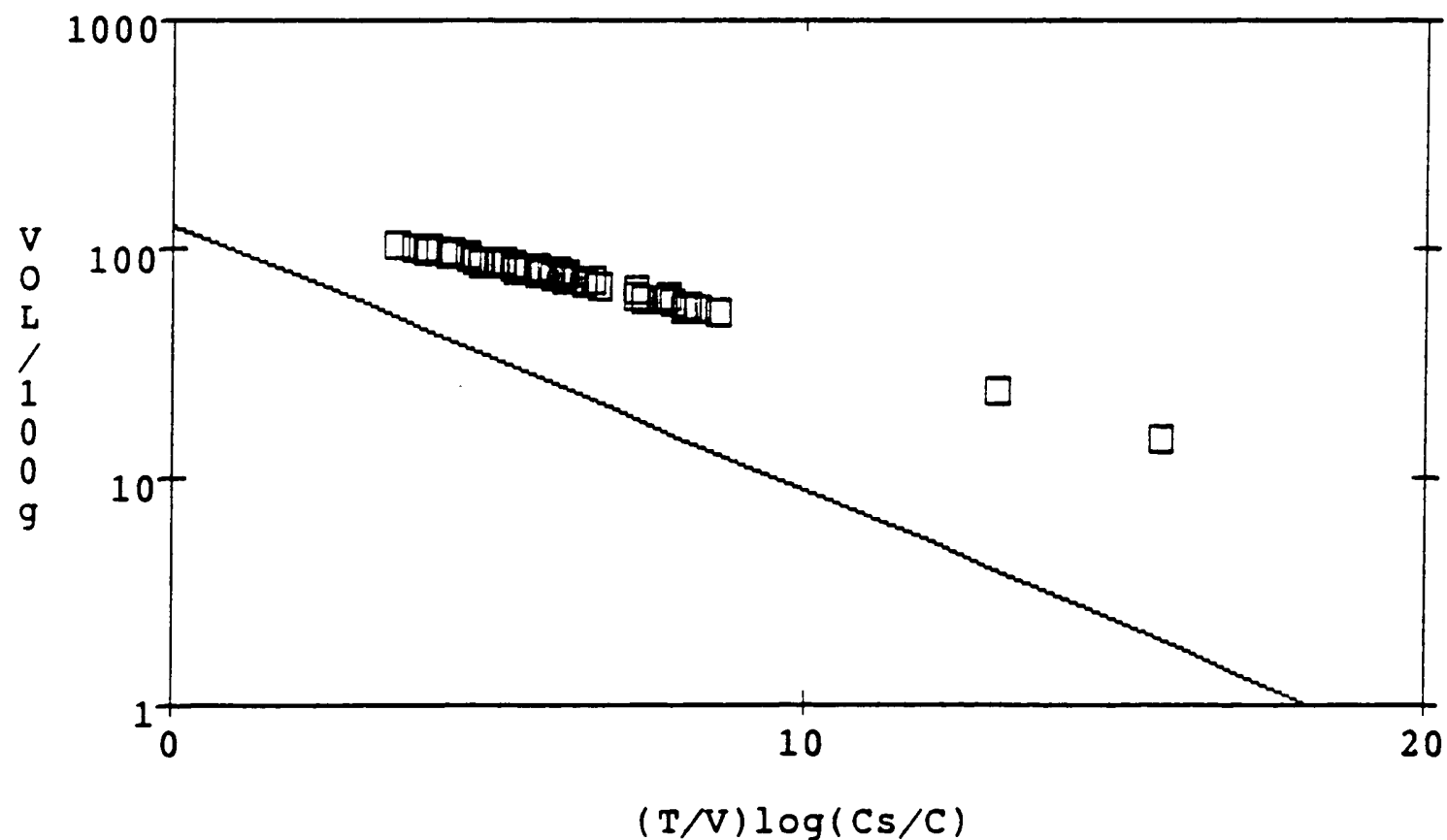

Figure 6.23. TDASF prediction of Fukuchi's benzoic acid data (ordinate density adjusted). 


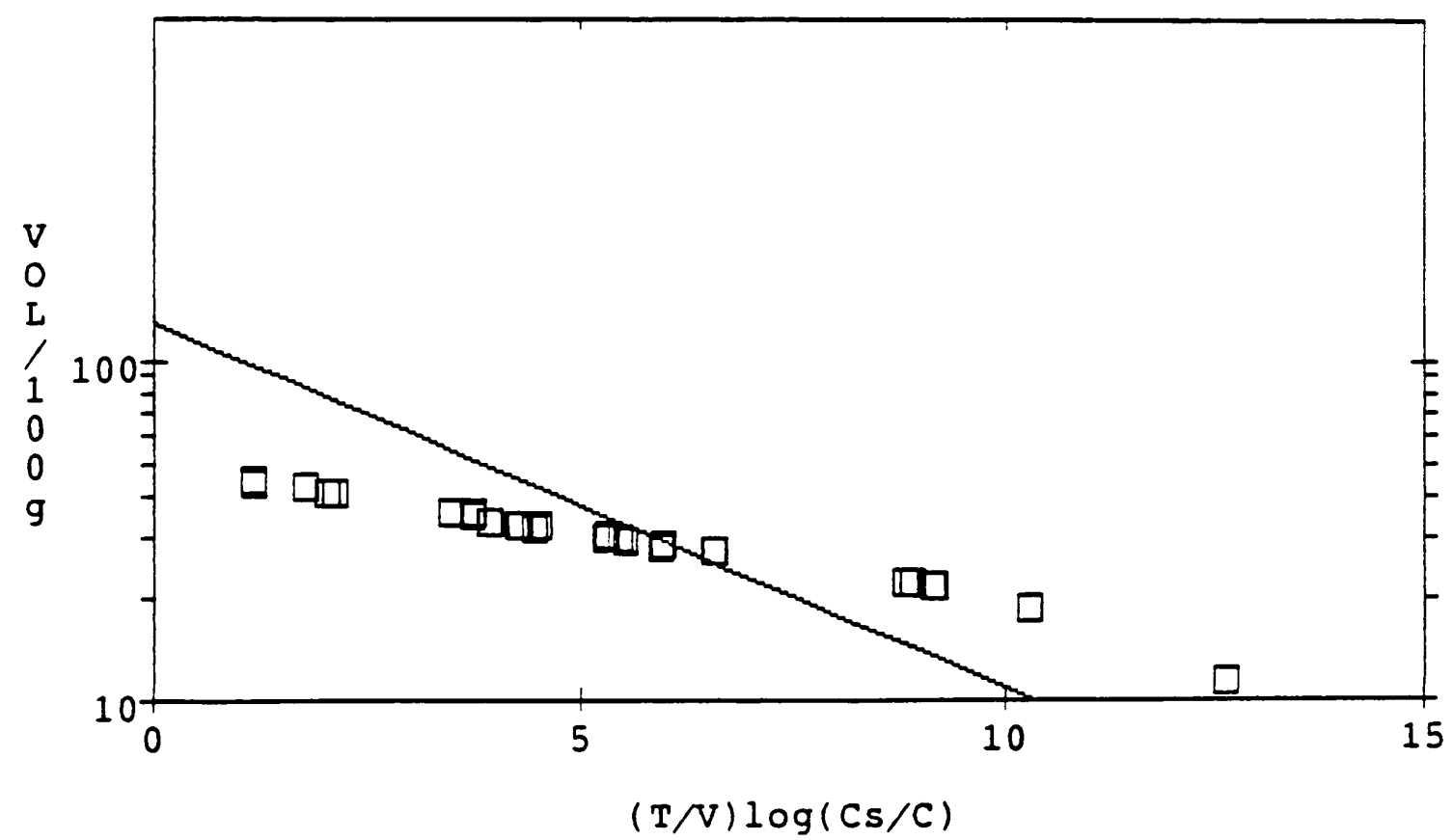

Figure 6.24. TDASF prediction of Fukuchi's p-chlorophenol data (no density adjustment).

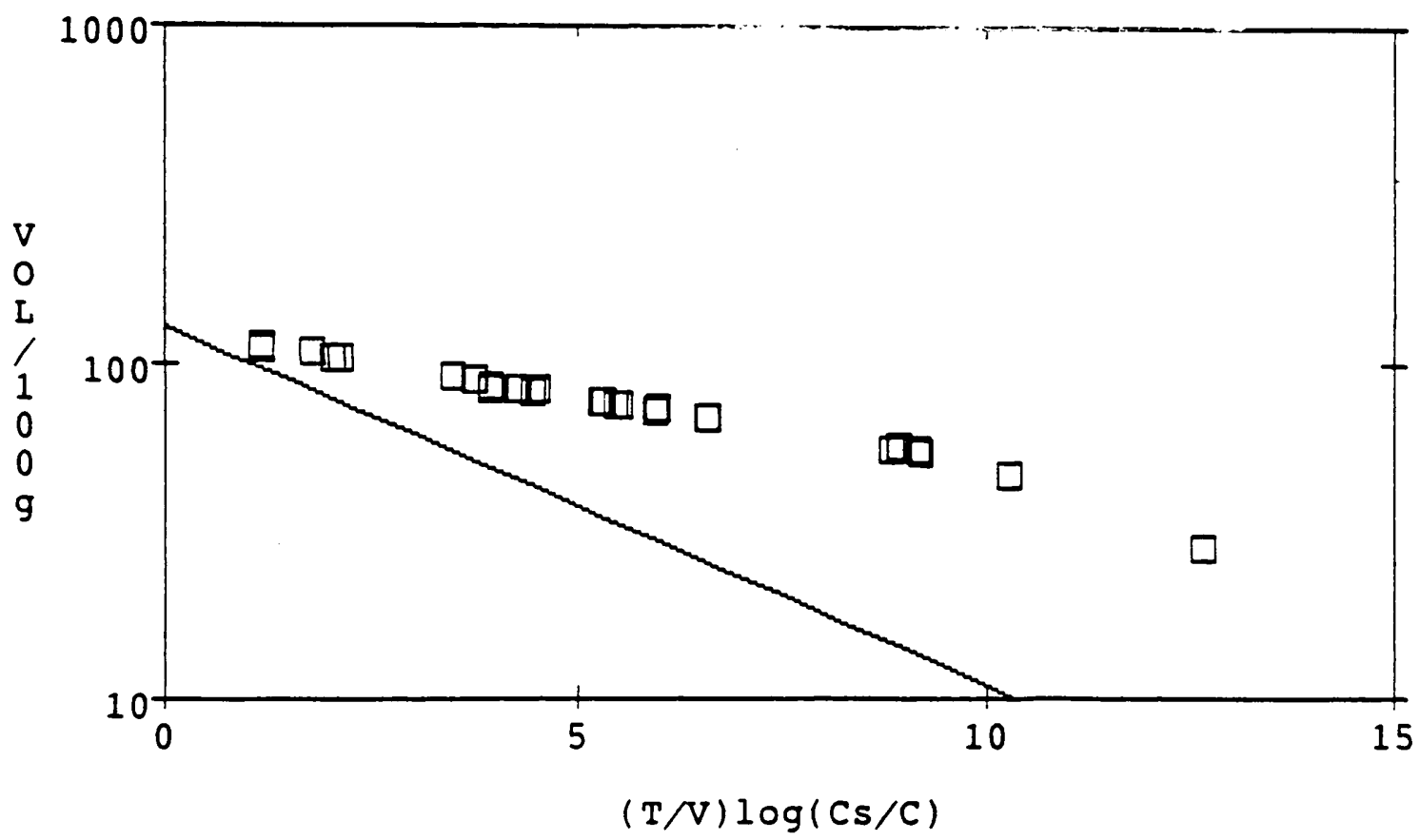

Figure 6.25. TDASF prediction of Fukuchi's p-chlorophenol data (ordinate density adjusted). 


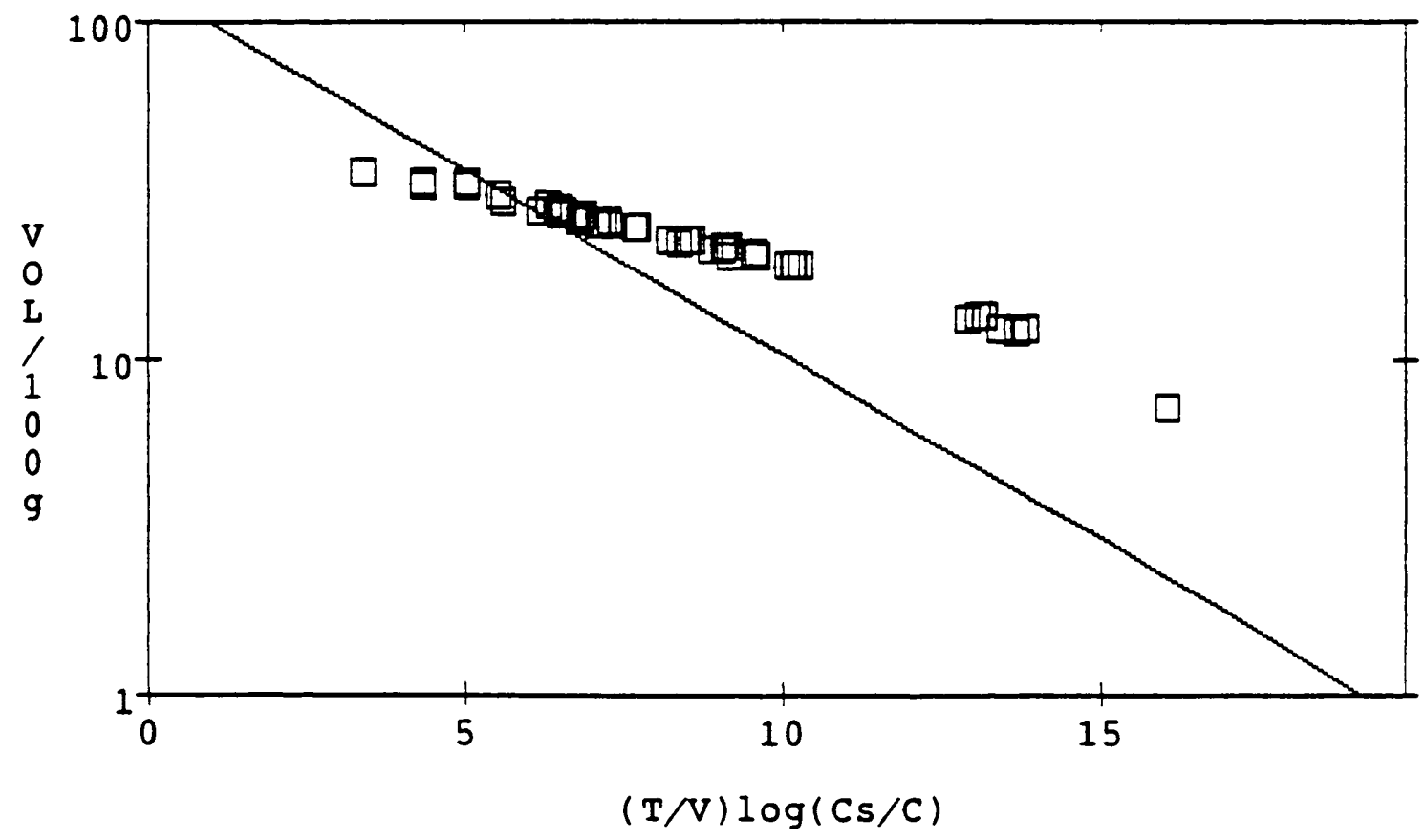

Figure 6.26. TDASF prediction of Fukuchi's phensl data (no density adjustment).

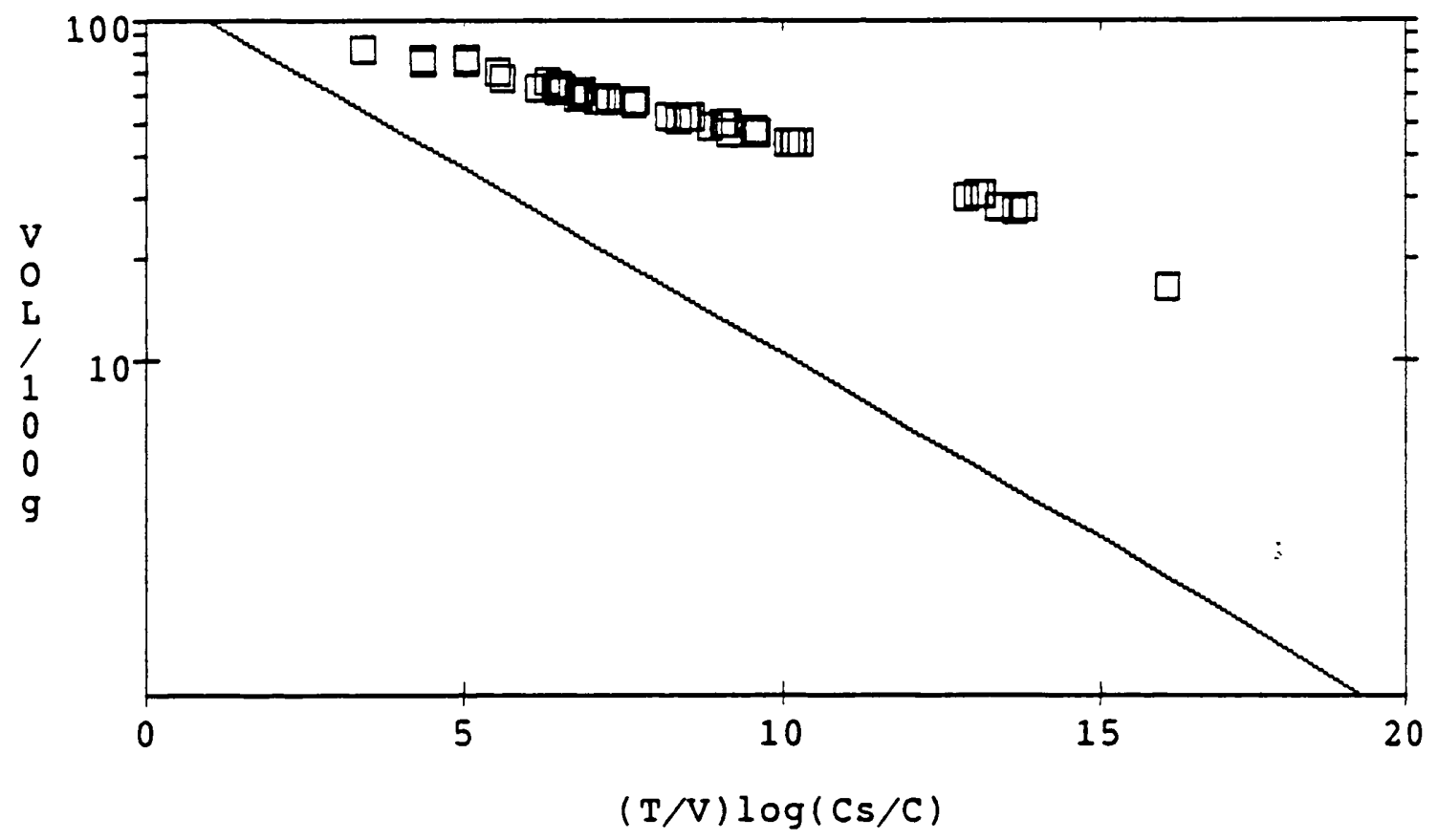

Figure 6.27. TDASF prediction of Fukuchi's phenol data (ordinate density adjusted). 
the data. However, adjusting the ordinate density increases the average error $(\mathrm{AE}=0.66,0.51$ and 0.67 for benzoic acid, p-chlorophenol and pheno1).

Molar volume, which is a term in the abscissa, is also affected by a compound's density since it is defined as:

$$
\text { Molar Volume = molecular weight / density }
$$

However, in following the procedure used by Manes for single solute isotherms, the adjusted density is not used in the calculation of molar volume.

In contrast to the poor fit evident in Figures $6.23,6.25$ and 6.27 when only the ordinate density is adjusted, Figure 6.28 indicates that an excellent fit results $(\mathrm{AE}=0.16,0.03,0.03)$ when the abscissa density is also adjusted. Although Manes does recommend adjusting both ordinate and abscissa densities in competitive adsorption, this data seems to contradict his single solute recommendations.

\subsubsection{Regression Based Characteristic Curves}

As mentioned, TDASF offer the advantage of requiring a minimum of testing. EDASF require additional data (at least one point for each solute) but, if extra precision results, it may be worth the effort. As mentioned, a reference curve is needed before applying either theoretical or experimental scale factors. Vinyl acetate will also be the reference for the experimental scale factors. This reference curve is represented by the following function: 

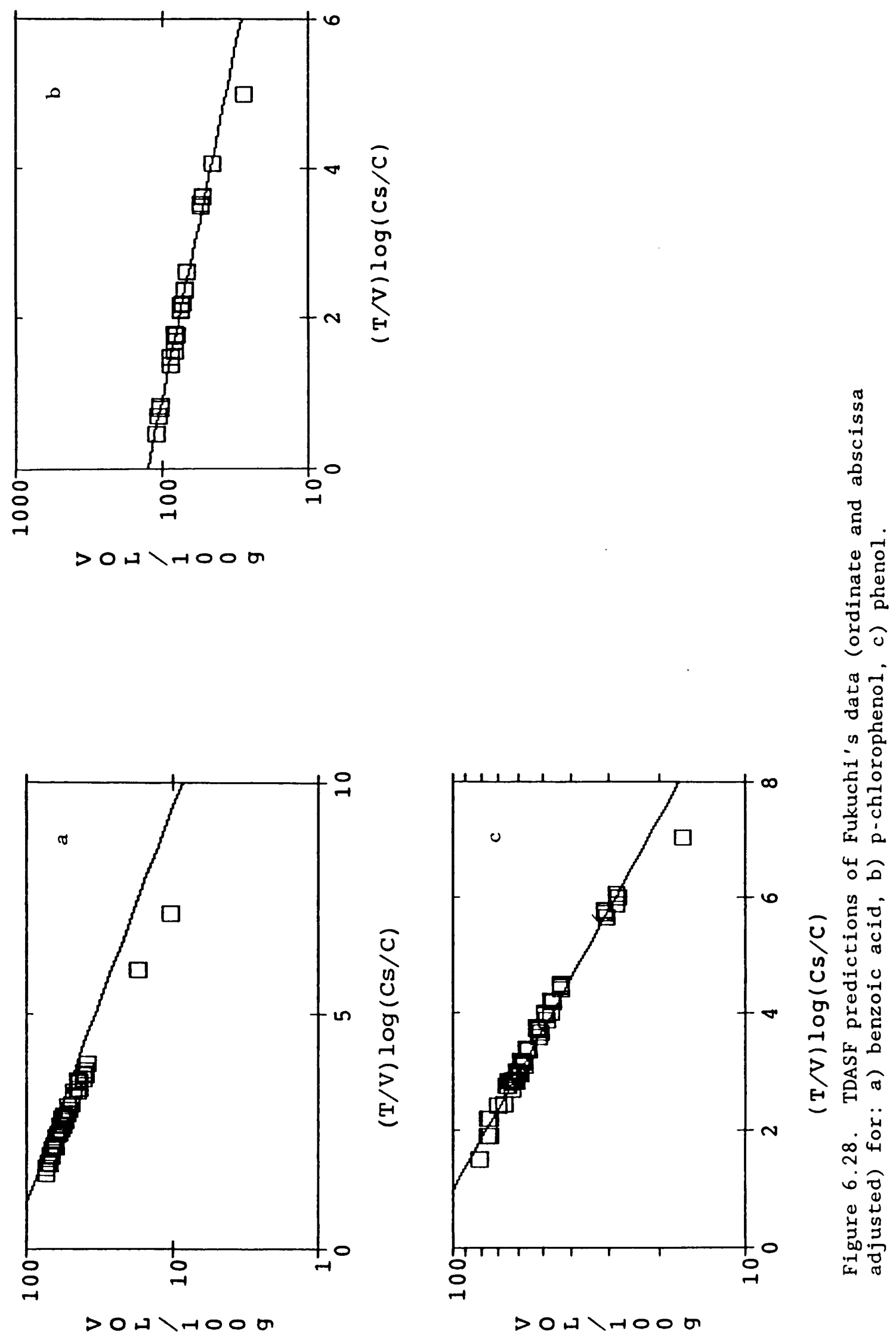


$$
F(X)=127.6 * \exp (-0.330494 * X)
$$

The $\mathrm{Y}$ intercept value of this curve, the $\mathrm{A}$ term, was then fixed at 127.6 and value of $B$ which results in the best fit was then determined for each solute. Figures 6.29 through 6.31 portray the resulting fit for all of the solutes tested which are liquids at $25^{\circ} \mathrm{C}$.

As these graphs indicate, the experimentally determined scale factors provide an excellent description for all the "liquid" solutes (largest $\mathrm{AE}=0.24)$. The only possible concern is that, as in the case of the predicted curve, the model does not follow the data for 2-propanol. But, even in this case, the fit is sufficiently accurate for practical purposes.

Similar regressions conducted for benzoic acid, p-chlorophenol and phenol, the solutes which are solids at $25^{\circ} \mathrm{C}$, are shown in Figures 6.32 thru 6.34 These figures demonstrate that, except for benzoic acid, these simulations provide poor descriptions of the data without the density adjustment $(\mathrm{AE}=0.17,3.20$ and 0.56 for benzoic acid, $\mathrm{PCP}$ and phenol). However, as opposed to the predicted curves, the data is well described after the ordinate density is adjusted $(\mathrm{AE}=0.09,0.03$, 0.03). If both abscissa and ordinate are adjusted for density, an even better simulation results ( $\mathrm{AE}=0.03$ in all cases).

As before, the EDASF is then defined by equation 6.5 .

Theoretically and experimentally derived scale factors, and the difference between them, are listed in Table 6.7. This data indicates that, for the solutes which are liquids at $25^{\circ} \mathrm{C}$, the predictions work well except for acetone and pyridine. Acetone's predicted scale factor 

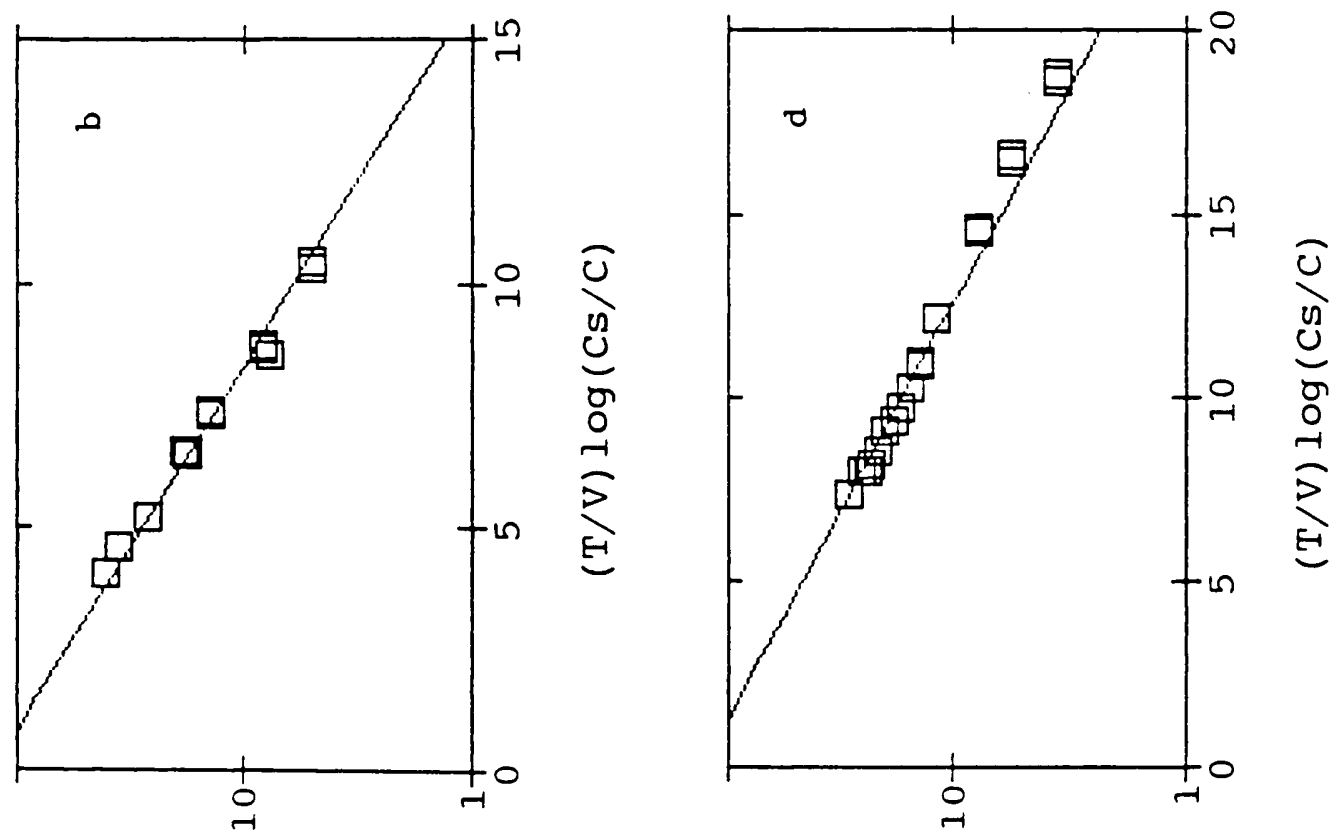

>

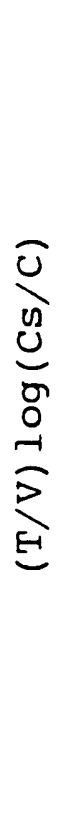

>0n>400

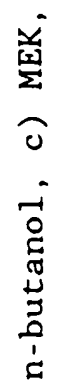
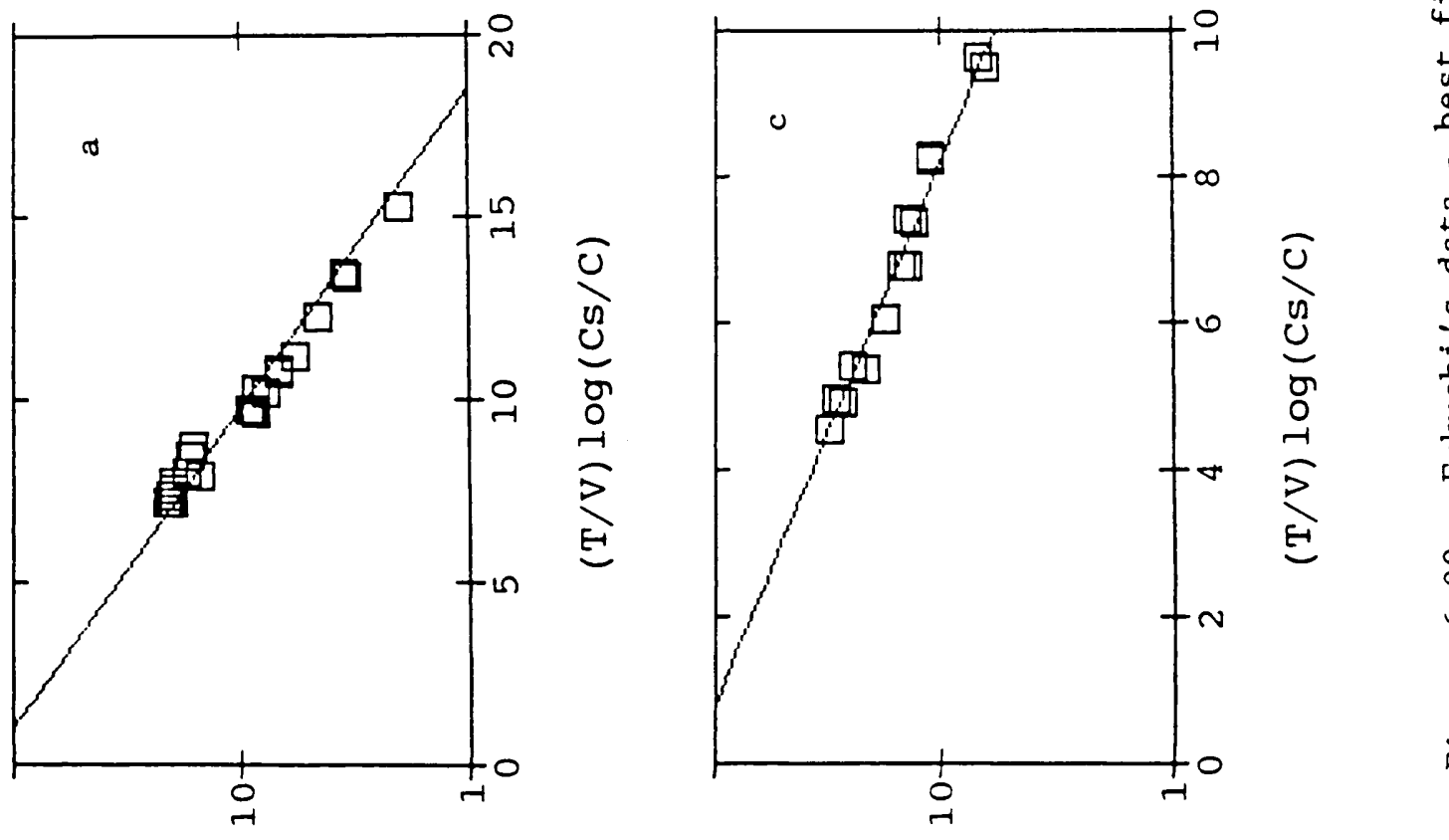

อิ

岂

ช

近

$\stackrel{4}{4}$

㟔

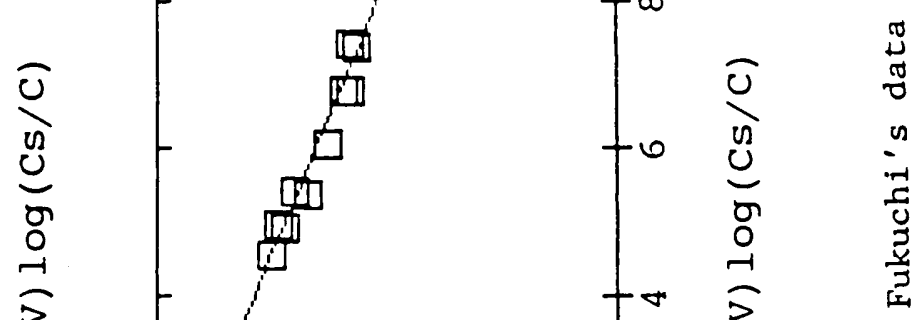

$>0$ म $>$ तO O

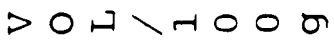




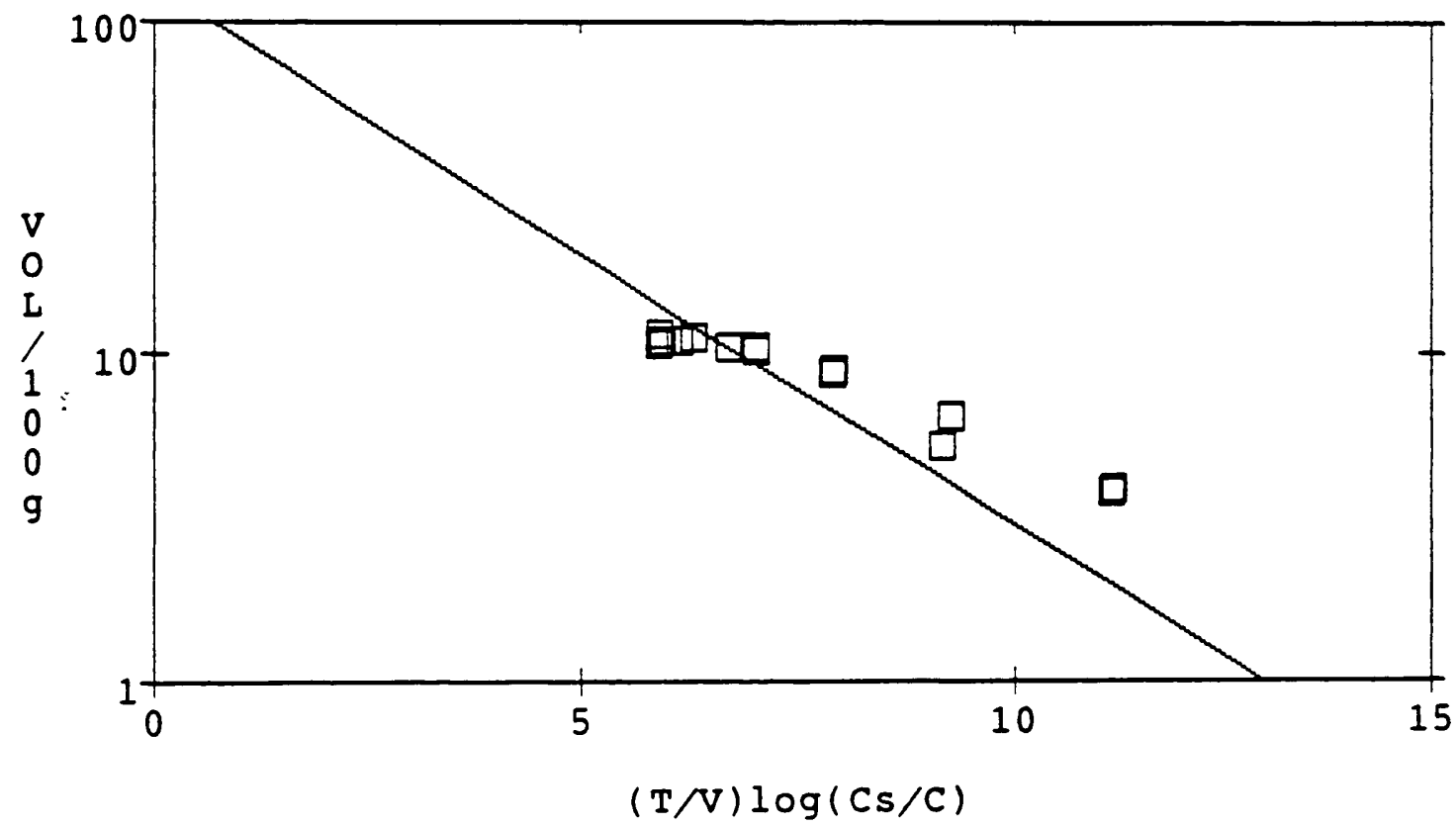

Figure 6.30. Fukuchi's 2-propanol data - best fit.

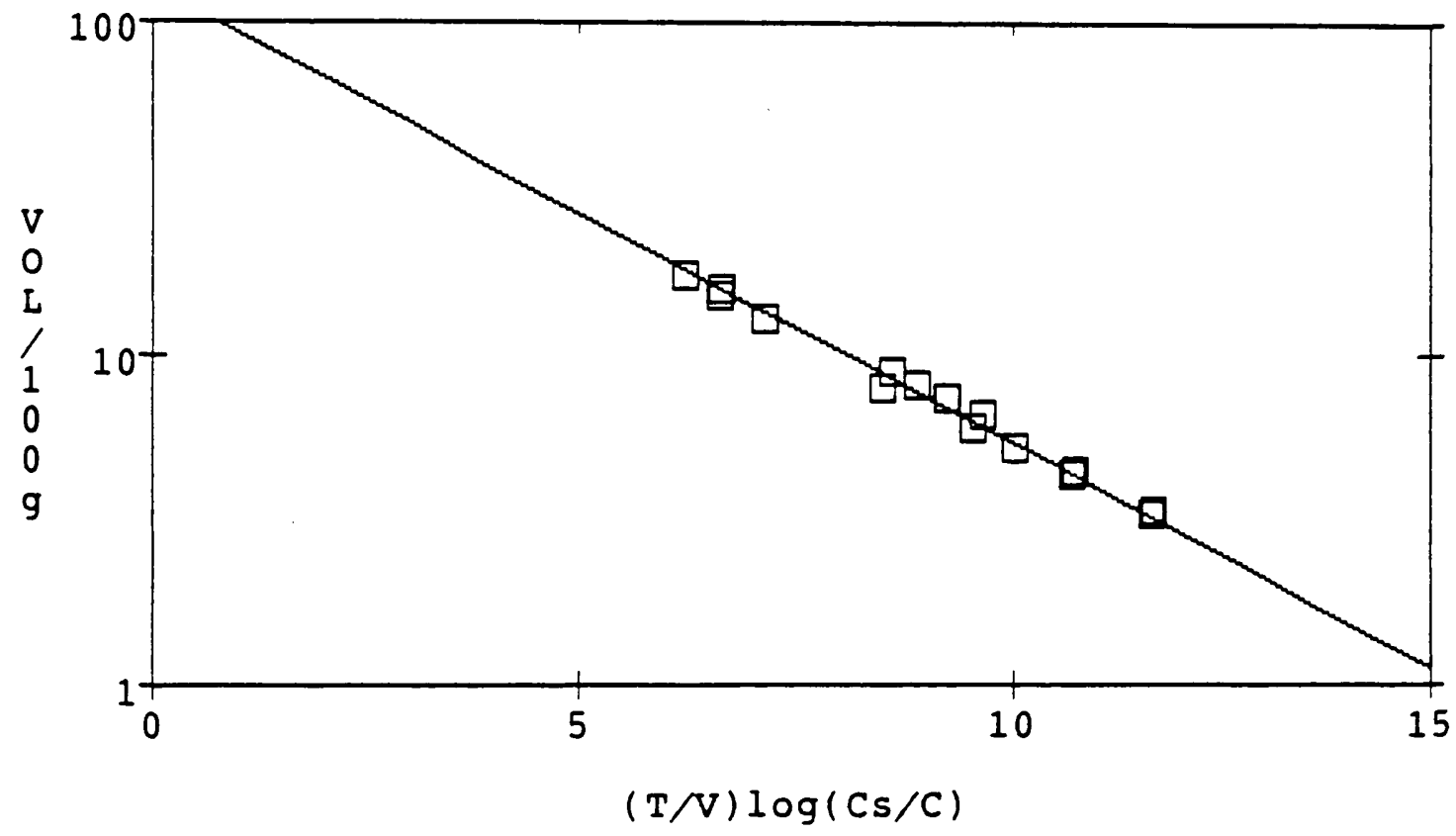

Figure 6.31. Fukuchi's propionitrile data

- best fit. 


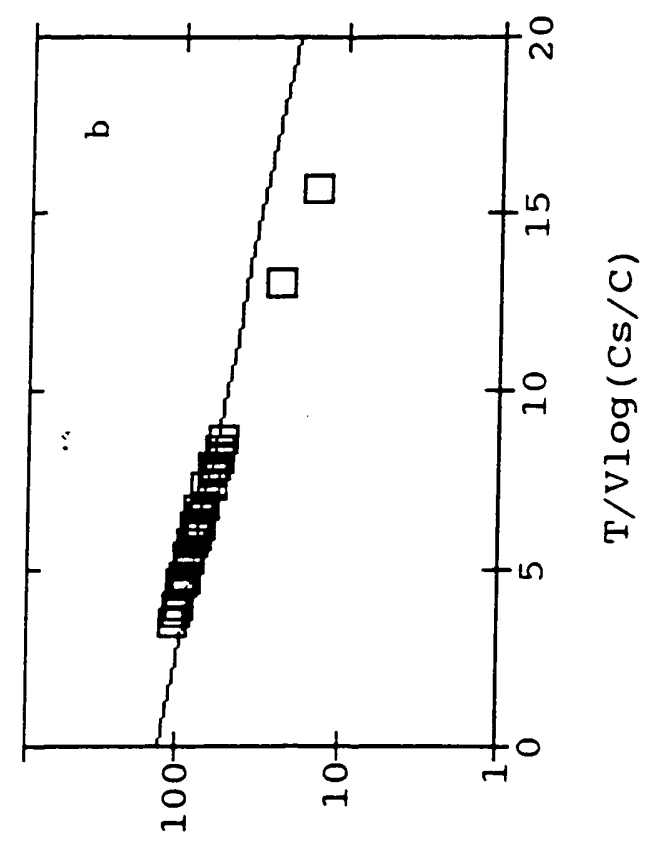

>0ル入

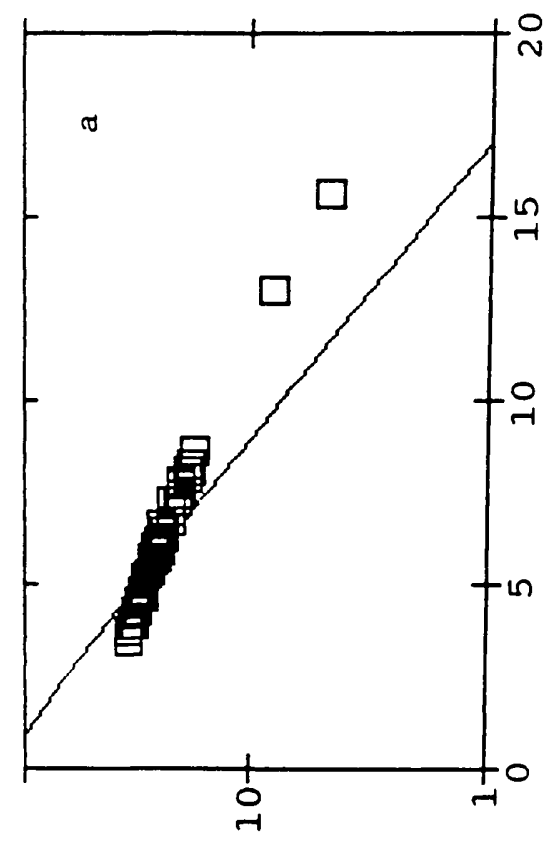

>0月>

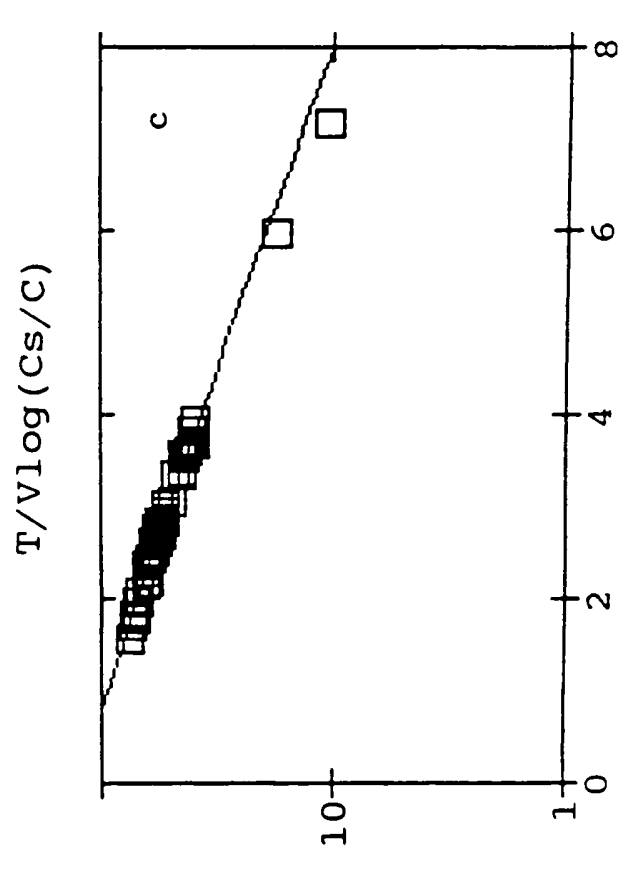

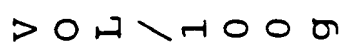

雚

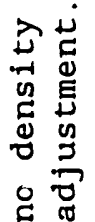

का

ii

$i 0$

車

$+$

岂

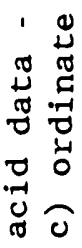

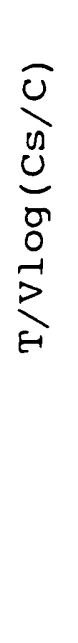

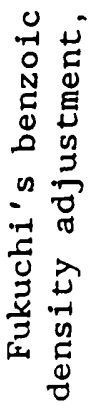

ले

m.

6 .

远

เ 

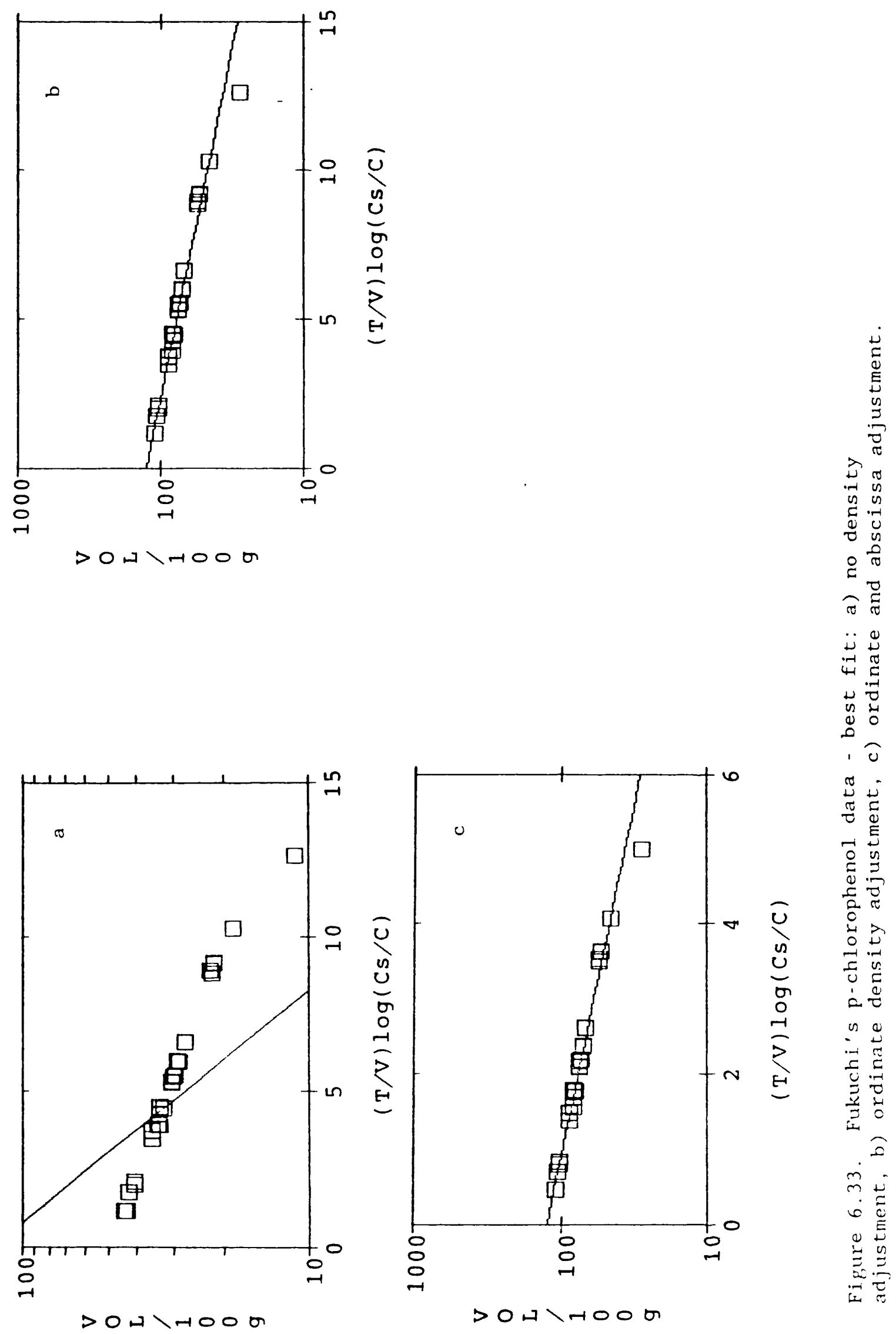

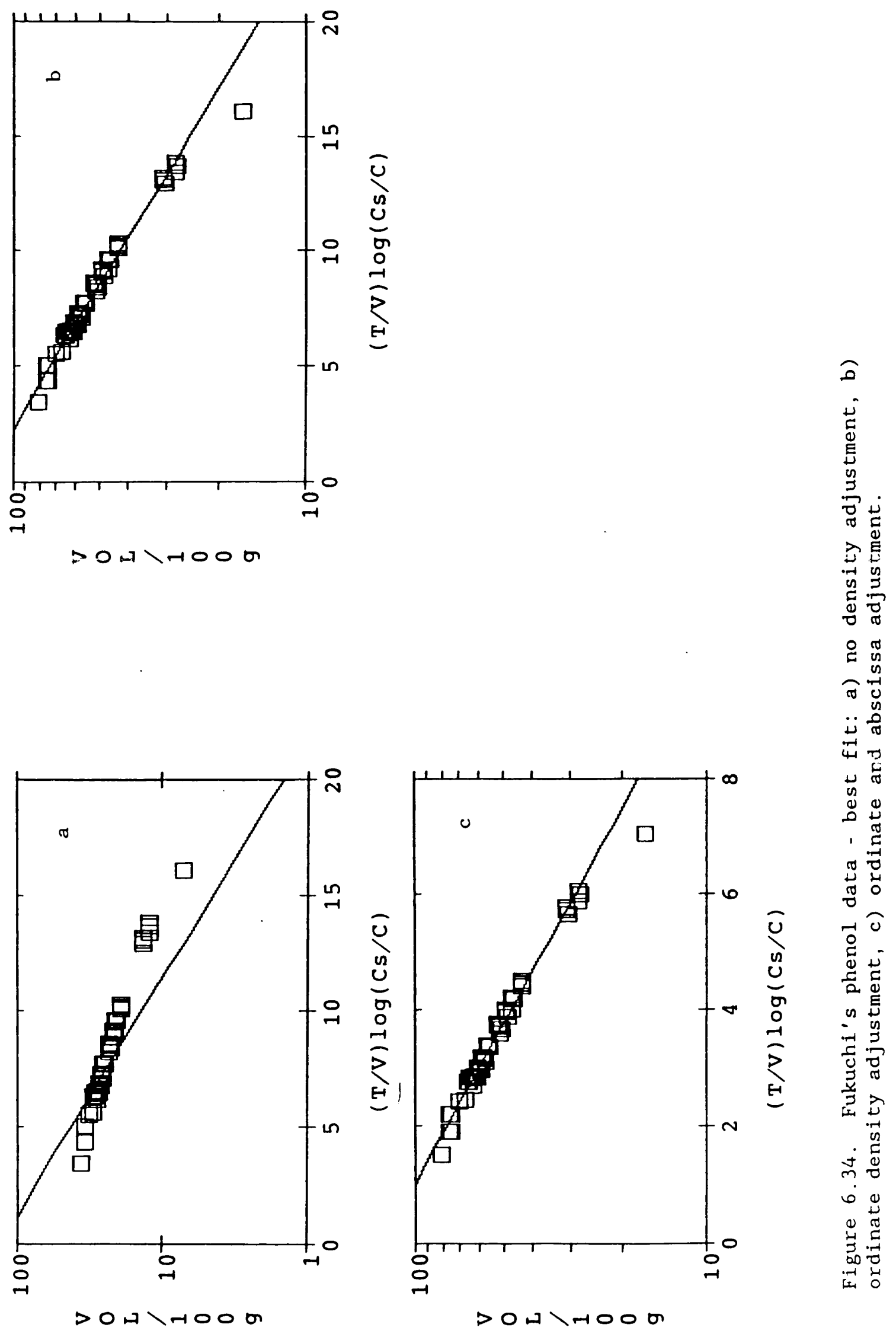
is 388 higher that observed. The scale factors for the other liquids are within 128 of their predicted values.

TABLE 6.7 ABSCISSA SCALE FACTORS THEORETICALLY AND EXPERIMENTALLY DERIVED FROM FUKUCHI'S DATA

\begin{tabular}{lccr} 
COMPOUND & \multicolumn{2}{c}{ SCALE FACTORS } \\
& & EDASF & \\
& & & DIFF \\
Acetone & 1.091 & 0.791 & -38.0 \\
n-Butanol & 0.993 & 0.924 & -7.4 \\
MEK & 1.039 & 0.937 & -10.8 \\
Pyridine & 0.802 & 0.610 & -31.5 \\
2-Propanol & 1.043 & 1.131 & 7.8 \\
Propionitrile & 1.071 & 0.956 & -12.0 \\
Vinyl Acetate & 1.000 & 1.000 & 0.0 \\
& & & 15.3 \\
Benzoic Acid & 0.810 & 0.956 & -189.2 \\
$\quad$ (ordinate adj) & & 0.280 & 15.7 \\
$\quad$ (both axes adj) & & 0.961 & 20.2 \\
p-Chlorophenol & & 0.933 & -150.2 \\
$\quad$ (ordinate adj) & & 0.297 & 1.1 \\
$\quad$ (both axes adj) & & 0.753 & -13.0 \\
Phenol (ordinate adj) & & 0.674 & -131.6 \\
$\quad$ (both axes adj) & & 0.329 & -1.3
\end{tabular}

For the unadjusted solids there is an average difference of $16 \%$ between the TDASF and the EDASF. Adjusting only the ordinate density greatly increases the difference between observed and predicted for benzoic acid and phenol. P-chlorophenol's observed is slightly improved (from 1318 to 1898). Adjusting the density on both axes yields observed values which are virtually identical to those predicted (1.0\% difference) for PCP and phenol and which approximate the predicted scale factor for benzoic acid (168 difference).

These results indicate that the predicted scale factors, in general, provide only a approximation of the abscissa scale factors. 
The predictions for solids are very accurate if both axes are adjusted.

The goodness of fit of both the observed and predicted curves are quantified in Table 6.8, which summarizes the average error, for each compound, using both EDASF and TDASF. As mentioned, a reasonably good fit should yield an average error of 0.5 or less. The data in Table 6.8 substantiates the graphical information previously presented. For example, the data fit to the experimental curves was good for all liquids. The predicted curve for the liquids also worked well. Only acetone, with a value of .60 , produced a poor fit. Table 6.8 also indicates the improved fit to the predicted curve which results when the density adjustments are made. The simulations fit the experimental data well when either one (the ordinate) or both axes were adjusted. The overall average indicates that EDASF perform substantially better than TDASF .

A good indication of the overall effectiveness of the scale factors at predicting adsorption can be obtained by plotting the raw data of each compound adjusted by the scale factor. To force the characteristic curves of the individual compounds to collapse to one correlation curve, each abscissa point is multiplied by the scale factor while the $Y$ values are left unadjusted. Figures 6.35 and 6.36 show the curves which result when the theoretically and experimentally determined (via regression) abscissa scale factors as well as the density adjustments (both axes) for the solids are applied. Whereas the data of the TDASF correlation curve is spread over a wide range, the points of the EDASF curve fall within a narrow range indicating that the Polanyi theory works well using EDASF.

As mentioned, in practice only one point is required for each 
TABLE 6.8 AVERAGE ERROR OF FUKUCHI'S DATA

\begin{tabular}{|c|c|c|}
\hline COMPOUND & TDSF & EDSF \\
\hline Acetone & 0.60 & 0.11 \\
\hline n-Butanol & 0.14 & 0.0 \\
\hline MEK & 0.21 & 0.0 \\
\hline Pyridine & 0.51 & 0.0 \\
\hline 2-Propanol & 0.25 & 0.2 \\
\hline Propionitrile & 0.29 & 0.0 \\
\hline Vinyl Acetate & & 0.1 \\
\hline Benzoic Acid & 0.18 & 0.1 \\
\hline (ordinate adj) & 0.66 & 0.0 \\
\hline (both axes adj) & 0.16 & 0.0 \\
\hline p-Chlorophenol & 0.41 & 0.0 \\
\hline (ordinate adj) & 0.51 & 0.0 \\
\hline (both axes adj) & 0.03 & 0.0 \\
\hline Phenol & 0.28 & 0.2 \\
\hline (ordinate adj) & 0.67 & 0.0 \\
\hline (both axes adj) & 0.03 & 0.0 \\
\hline AVERAGE & 0.33 & 0.0 \\
\hline
\end{tabular}

EDASF BASED ON A SINGLE DATA POINT

MEK

high low

2 - Propanol

$0.10 \quad 0.12$

0.420 .34 


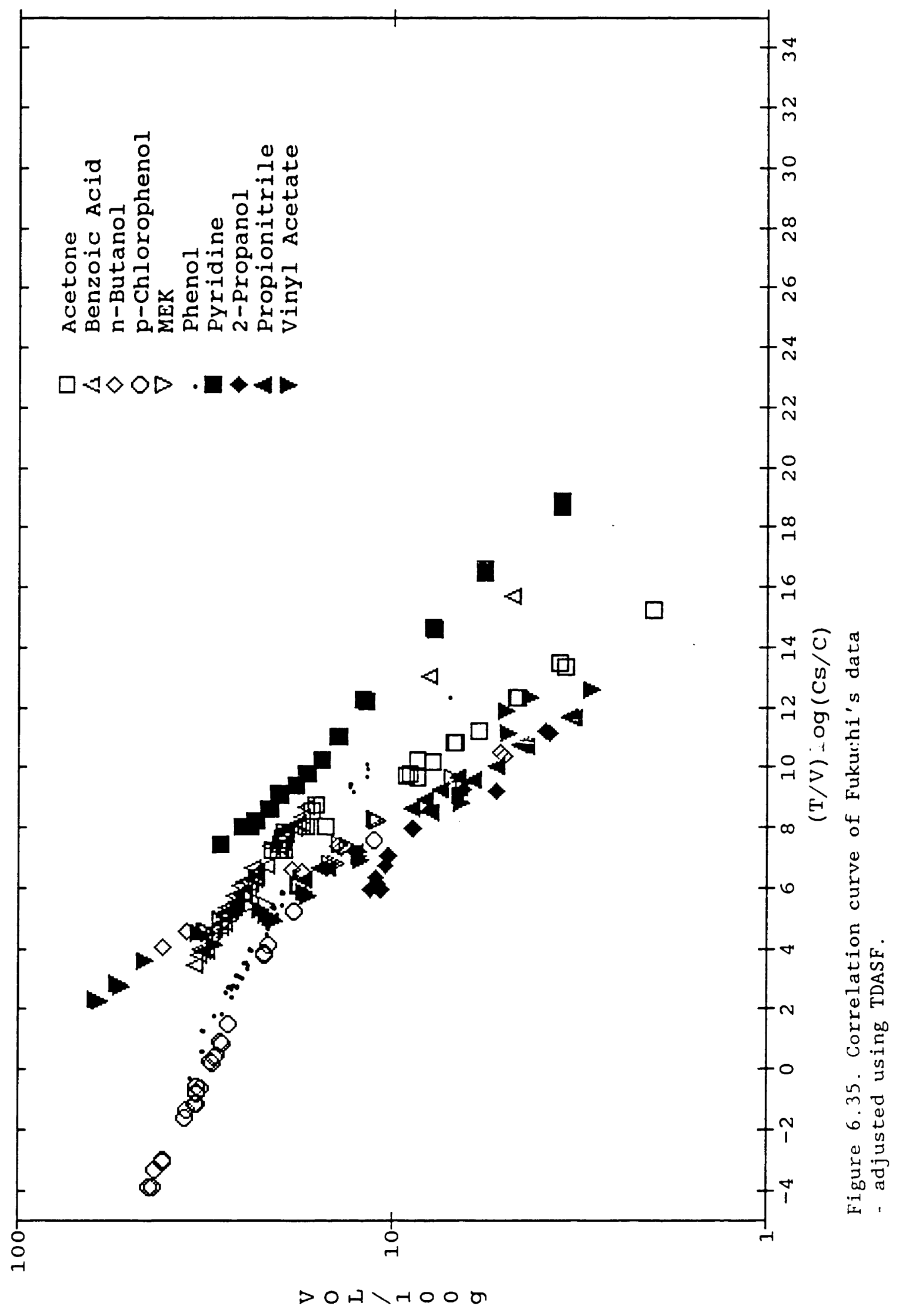




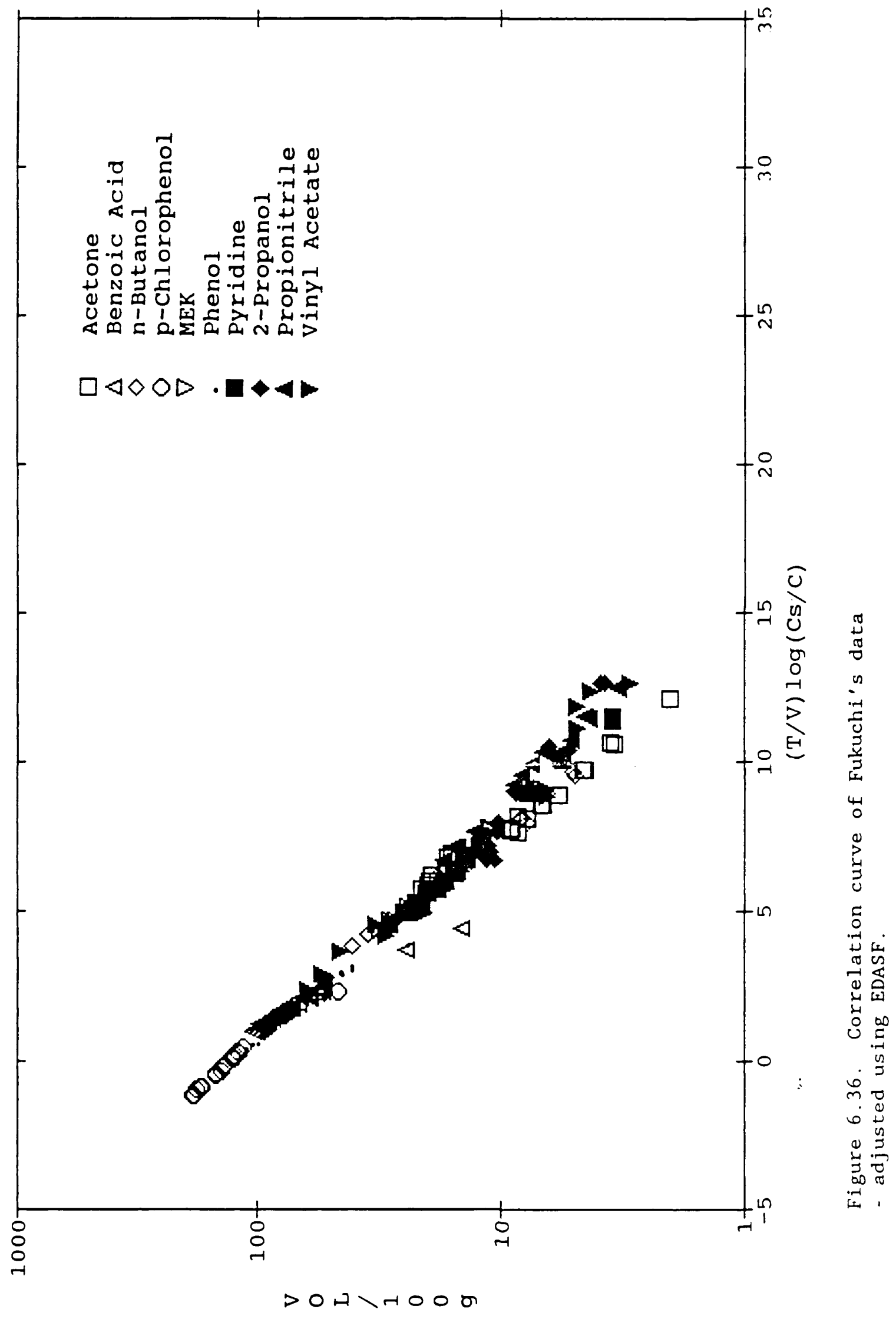


compound to determine these scale factors. The reference solute must still be well defined over the concentration range. Speth's bromoform and PCE data demonstrated that the accuracy of EDASF determined from a single data point is affected by the data point's concentration. The middle concentrations seemed less prone to error. As a further test of the effectiveness of single point EDASF, Fukuchi's MEK and 2-propanol data was examined. Figure 6.37 indicates that even the worst case (highest and lowest) scale factors for MEK, whose data is concentrated in a limited range, are good ( $\mathrm{AE}=0.10,0.12)$. In contrast, the 2-propanol data (figure 6.38), with more spread in the data points, produces less accurate estimates $(\mathrm{AE}=0.42,0.34)$. It appears that even these extreme single point EDASF are acceptable. Obvious1y, data which is well described by the theory (low AE, as in MEK's case) will produce a more accurate single point EDASF. Again, extreme concentrations, which are prone to experimental error, should be avoided. 


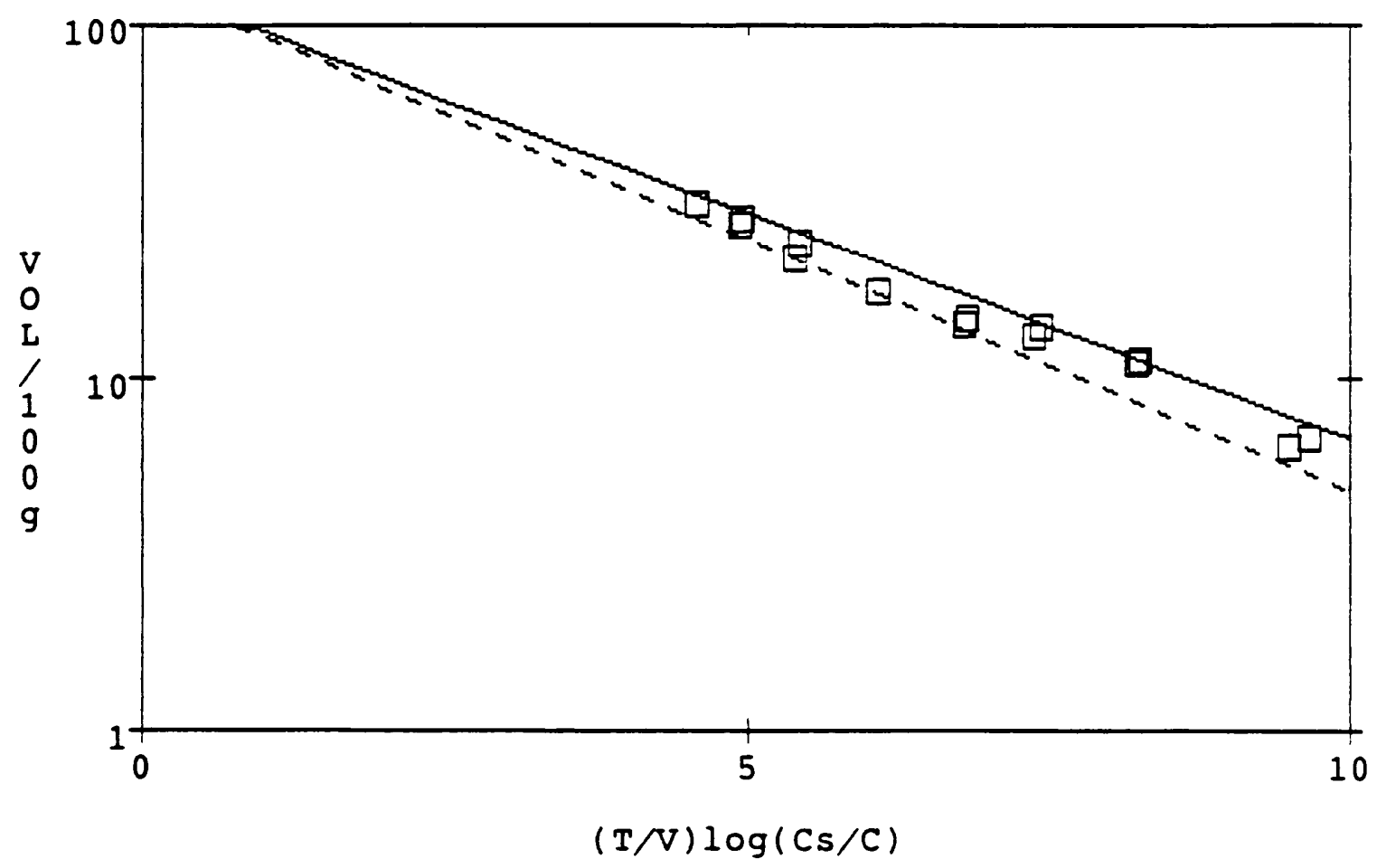

Figure 6.37. Fukuchi's MER data

- worst case results using single point EDASF.

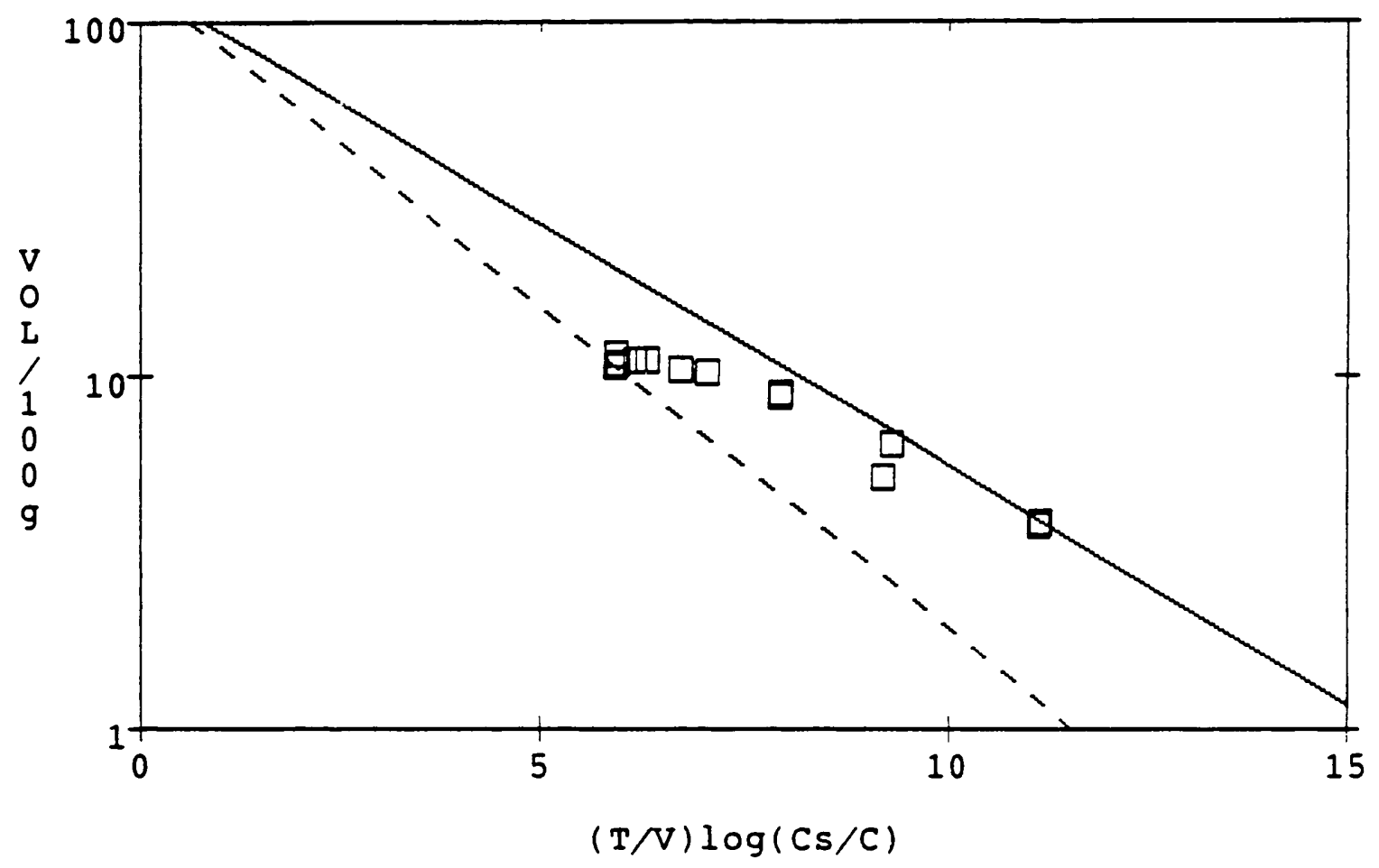

Figure 6.38. Fukuchi's 2-propanol data

- worst case results using single point EDASF. 
6.2.5 Summary of Analysis of Fukuchi's Data

The experimental scale factors, which were determined by regression, worked very well and the Polanyi Equilibrium theory seems to be quite effective when these factors are applied to simulate adsorption isotherm. Both solids, after the appropriate adjustments, and liquids were well explained using these scale factors.

The TDASF provided approximations, after scale factors were applied, of the solid's adsorption data. The liquid's isotherm data, except for acetone, was fairly well predicted.

The ordinate density adjustment recommended by Manes and coworkers seems sufficient to make the data conform to the curve when EDASF are used. However, when the abscissa density is also altered, the curves simulate the data very well using either TDASF or EDASF.

In short, the Polanyi theory has again demonstrated that, with certain adjustments, it is effective at describing adsorption isotherms. 


\subsection{EVALUATION OF THE POLANYI MODEL FOR LUFT'S DATA}

The data from Speth and Fukuchi have demonstrated that the Polanyi Equilibrium Theory effectively describes isotherm data of both liquids and solids. Thus far, the data supports the existence of a characteristic curve which can define adsorption of all compounds on a carbon. However, all of the data examined was obtained on a single carbon, F-400. An important feature of the Polanyi theory is that the experimentally determined scale factors, once determined, should be the same on all carbons.

To test the validity of this claim, isotherm data from the Master's thesis of Paul J. Luft (Luft, 1984) was examined. The thesis list isotherms of three compounds - TCE, bromoform and chlorotorm, obtained on three different carbons - F-400, WV-G and HD-3000. This adsorption data, like Speth's, was generated at Michigan Technological University under the supervision of $\mathrm{Dr}$. John C. Crittenden. The bottle point technique, described in section 6.1, was used under the experimental conditions listed in Table 6.9.

TABLE 6.9 EXPERIMENTAL CONDITIONS (LUFT)

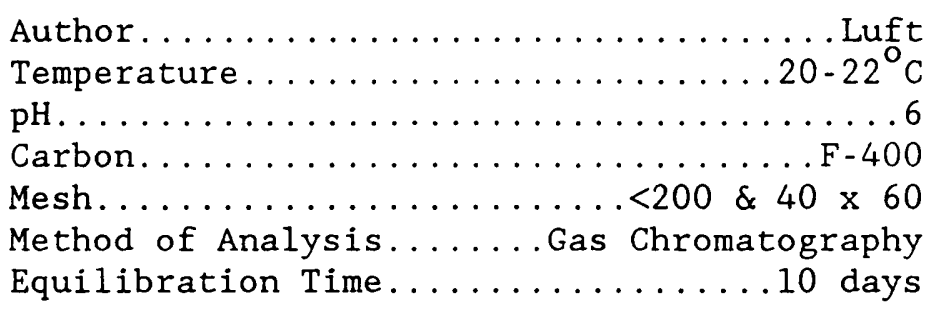

Relevant information on each of the solutes is listed in Table 6.10. Since these solutes exist as liquids under experimental 
conditions, molar volume and polarizability should be the only scale factors which apply.

TABLE 6.10 CHARACTERISTICS OF SOLUTES (LUFT)

\begin{tabular}{lrrrrrr} 
COMPOUND & MOL WT & $\begin{array}{c}\text { DEN } \\
(\mathrm{g} / \mathrm{mL})\end{array}$ & $\begin{array}{c}\text { SOL } \\
(\mathrm{mg} / \mathrm{L})\end{array}$ & \multicolumn{1}{c}{$\begin{array}{c}\text { MP } \\
(\mathrm{C})\end{array}$} & INDEX & POLAR \\
& & & & & & \\
Bromoform & 252.77 & 2.894 & 8229 & 7 & 1.5960 & 0.3403 \\
Chloroform & 119.39 & 1.500 & 7257 & -63 & 1.4460 & 0.2667 \\
TCE & 131.40 & 1.464 & 984 & -85 & 1.4755 & 0.2818
\end{tabular}

Note: $\mathrm{MOL} W \mathrm{WT}=$ molecular weight; $\mathrm{DEN}=$ density; $\mathrm{SOL}=$ solubility; $M P=$ melting point; $\operatorname{INDEX}=$ refractive index; $\mathrm{P}=$ polarizability 


\subsubsection{Basic Characteristic Curve}

Figure 6.39 illustrates the characteristic curves based on the raw data for the three different carbons. The TCE data in Figure 6.39a, the F-400 characteristic curve, contains some outliers. The five points in the upper right don't seem related to the other TCE data. Also, for these five points, the relationship of TCE to the other compounds is inconsistent with the WV-G and HD-3000 data. These values can probably be attributed to experimental error and, consequently, they will not be considered in future data analysis.

The F-400 TCE data serves as an example of the problems which can occur when performing isotherms. As previously mentioned, the experiments are extremely delicate and care must be taken in each step of the procedure. Errors can occur in weighing the carbon, mixing the dilutions with the carbon and in preparing the samples for analysis. The GC measuring process is also quite complex with possible errors existing in the extraction procedure, the dilutions or in column conditioning. In short, an accurate predictive model can not only serve as a timesaver, but it would also help to eliminate many of the potential sources of error present in the isotherm process.

An additional problem which is evident in Figure 6.39 is that a well defined reference curve can't be derived from this data since only the lower concentration range is represented. In practice, when using the Polanyi theory care should be taken to fully define the reference curve by testing all concentration ranges from dilute to saturation. Data in the higher concentration ranges is important because it determines the value of the limiting adsorbate volume, or maximum carbon capacity. However, the researcher's data examined herein was never intended to 

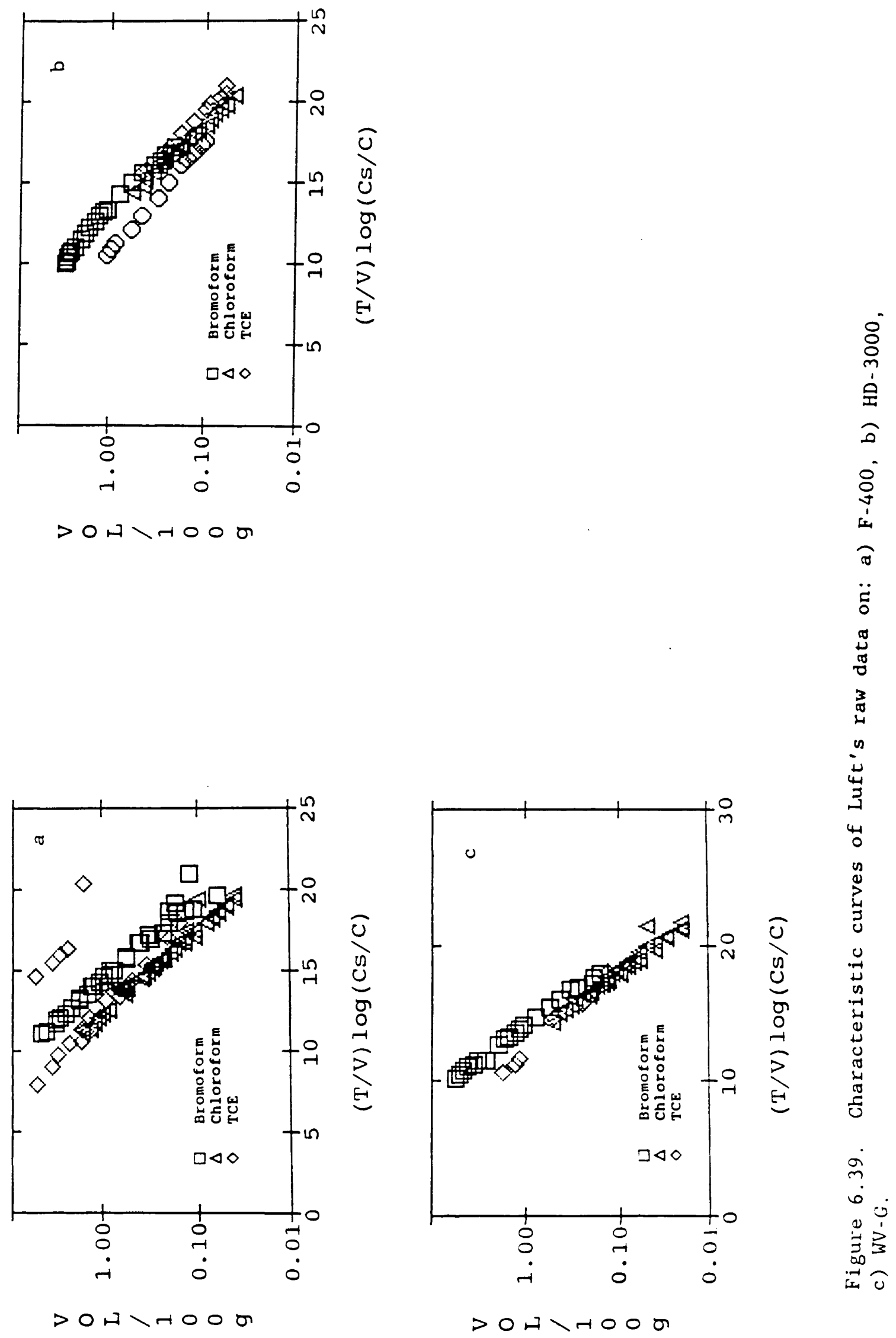
serve as a test of this theory and testing is often restricted to low concentrations since, in most applications, dilute concentrations are treated. Realizing that the validity of the curve is questionable outside of the testing range, the bromoform data was used to generate a reference characteristic curve. The chloroform data could also be used since these compounds cover approximately the same concentration range. Nonlinear regression, using $R S / 1$, was then applied to determine the function which best describes this curve.

Figure 6.40 shows the best fit of the bromoform data on F-400, HD-3000 and WV-G carbons. As in the case of Speth's data, a good fit results when either a simple exponential or an exponential with a constant model is used to describe the characteristic curve. The limiting adsorbate volume, or $\mathrm{Y}$ intercept, reflects the amount of solute which is adsorbed at saturation and, for both F-400 and WV-G, it seems unrealistically high using either equation $(611$ and $609 \mathrm{cc} / 100 \mathrm{gm}$ for F-400; 452 and $349 \mathrm{cc} / 100 \mathrm{gm}$ for WV-G). As mentioned, extrapolating beyond the range of experimental data has some hazards and this is one possible example. In spite of this shortcoming, this plot will be used since the goodness of fit which will only apply to the testing range. Placing importance upon areas outside of this range is unwarranted.

For the simple exponential the best fit function of the WV-G data is:

$$
F(X)=452 * \exp (-.435118 * X)
$$

For this data, the experimental data yields a graph with a Y intercept of 452 and a slope of -0.435118 . 

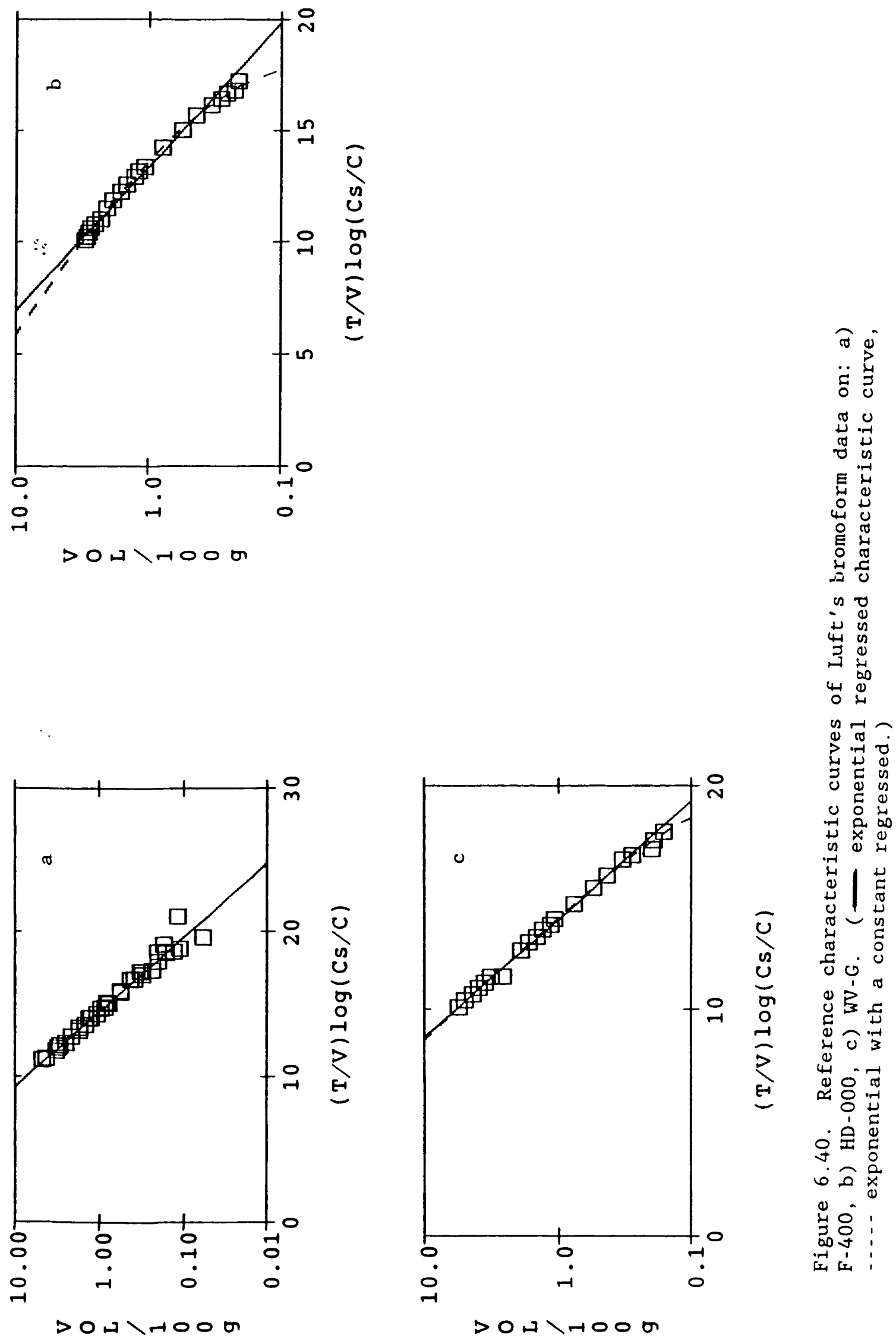
For the exponential with a constant a good representation of the same data resulted with the following function:

$$
F(X)=349 * \exp (-0.410055 * X)-0.067771
$$

This function results in a curve whose $Y$ intercept is 349 and whose slope $=-0.342284(-.410055+0.067771)$. The shape of the curve, as Figure 6.40 demonstrates, will depend upon the function used to describe it.

\subsubsection{Theoretically Predicted Characteristic Curves}

Using these plots of bromoform to deternine the shape of the characteristic curve, TDASF were then applied using equations 2.6 and 2.7. Figures 6.41 and 6.42 demonstrate the differences between observed and predicted for chloroform and TCE using both the exponential and an exponential with a constant model to describe the characteristic curve.

Although TCE data approximates the predicted curve, chloroform demonstrates stronger adsorption than anticipated from its polarizability (figure 6.41). The poor fit of chloroform to the predicted curve is consistent with Speth's results on chloroform. Its worth noting that the data fit, relative to the predicted curve, is about the same, for both solutes, on all three types of carbons. 

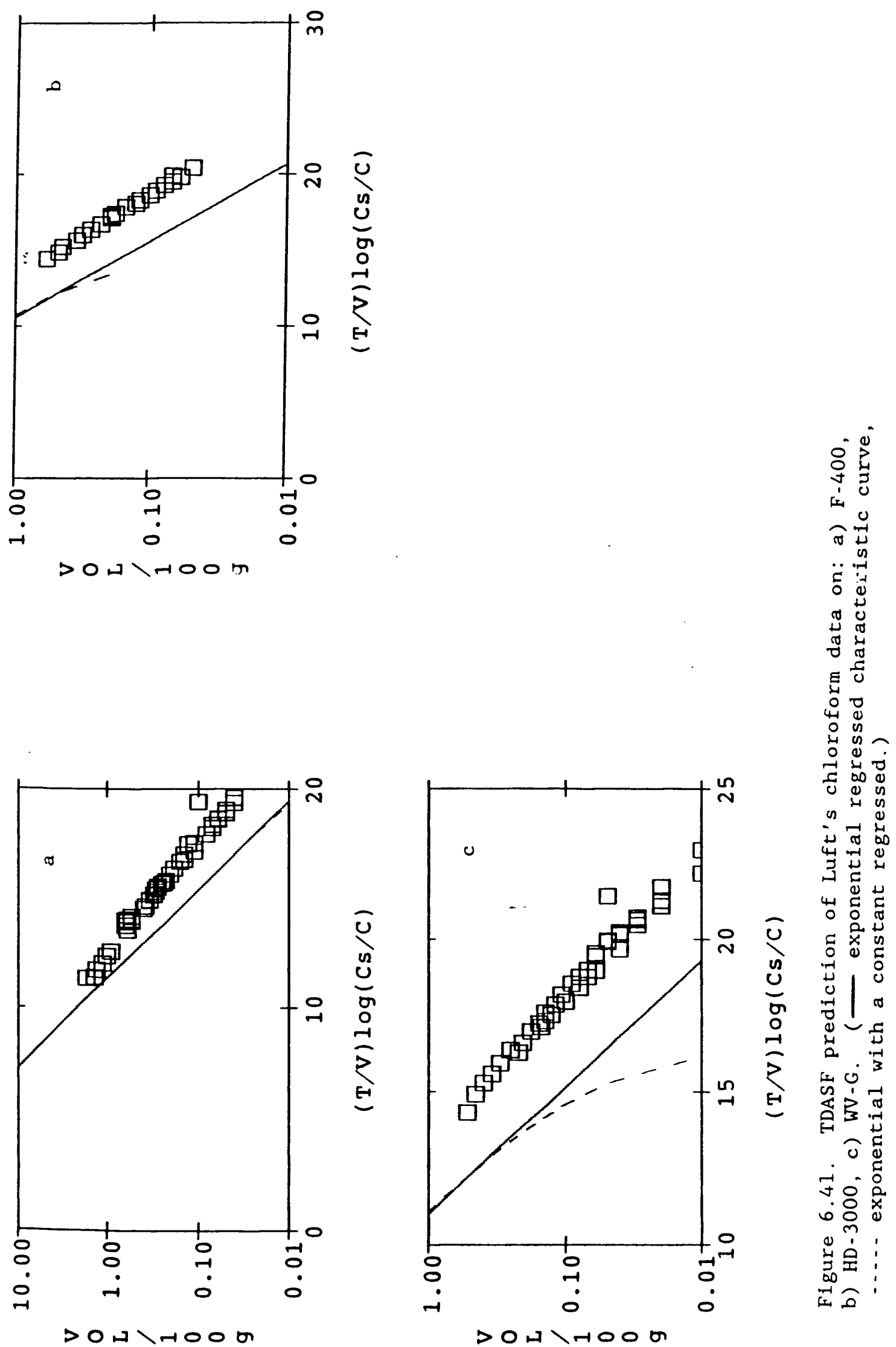

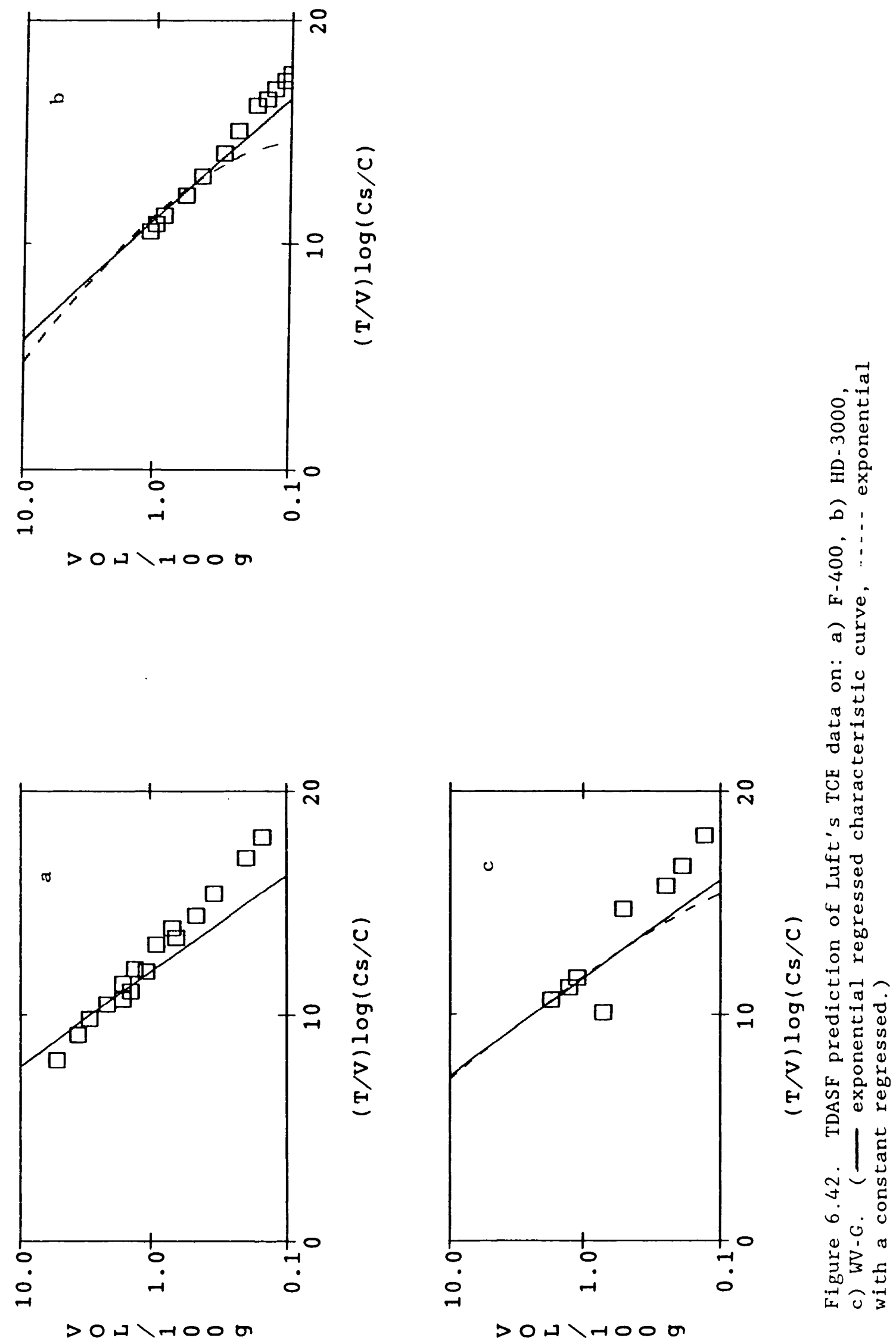


\subsubsection{Regression Based Characteristic Curves}

Figures 6.43 and 6.44 show the characteristic curves obtained when EDASF are applied. For all three carbons the chloroform data is well defined by the simple exponential model $(\mathrm{AE}=0.19,0.07$ and 0.08 for F400, HD-3000 and WV-G). The exponential with a constant model yields a poor fit $(\mathrm{AE}=0.19,0.69,0.85)$. From this data it seems that the extra effort required to determine the experimental scale factors for chloroform would be well spent.

As Figure 6.44 demonstrates TCE is best defined by a simple exponential equation. However, in the low concentration range, the characteristic curve underestimates the amount of adsorption. Since this occurs on all three carbons, one might assume that TCE's characteristic curve is simply different than that of bromoform and chloroform. It's also possible that some aspect of the isotherm process itself creates a positive bias in the low concentration range.

As in the case of the predicted scale factors, the location of the adsorption data relative to that of the characteristic curve was consistent on all three carbons. But can the scale factors determined on F-400 be used to predict isotherm data on HD-3000 and WV-G?

\subsubsection{Comparison Between Different Activated Carbons}

Figure 6.45 shows the fit obtained when F-400 scale factors are applied to HD-3000 and WV-G data. The exponential model provides a good fit of TCE's data on HD-3000 (AE = 0.22), but WV-G's TCE fit is poor (AE $=0.63)$. Chloroform results, using this model are marginal $(\mathrm{AE}=0.43$ 

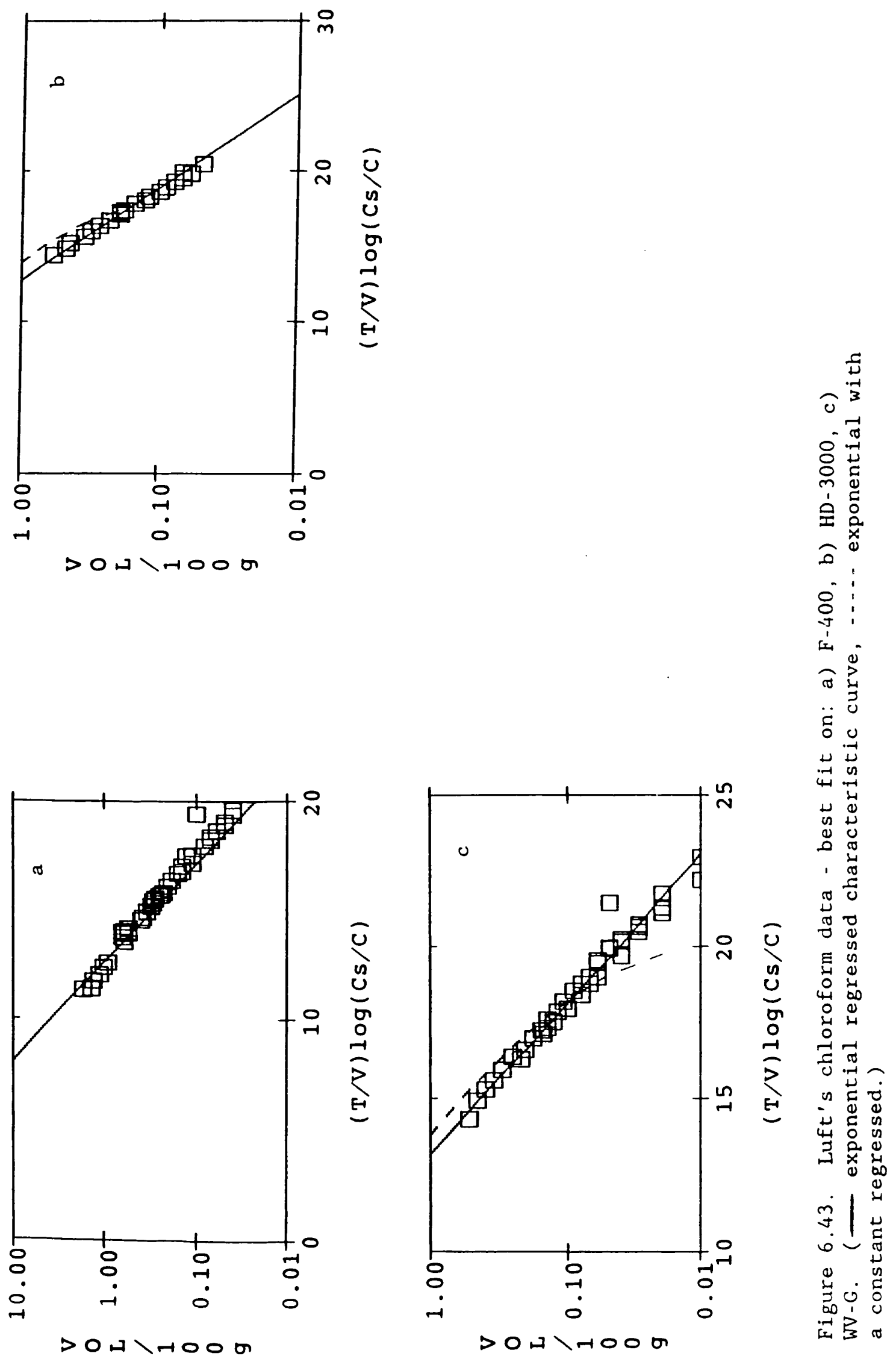

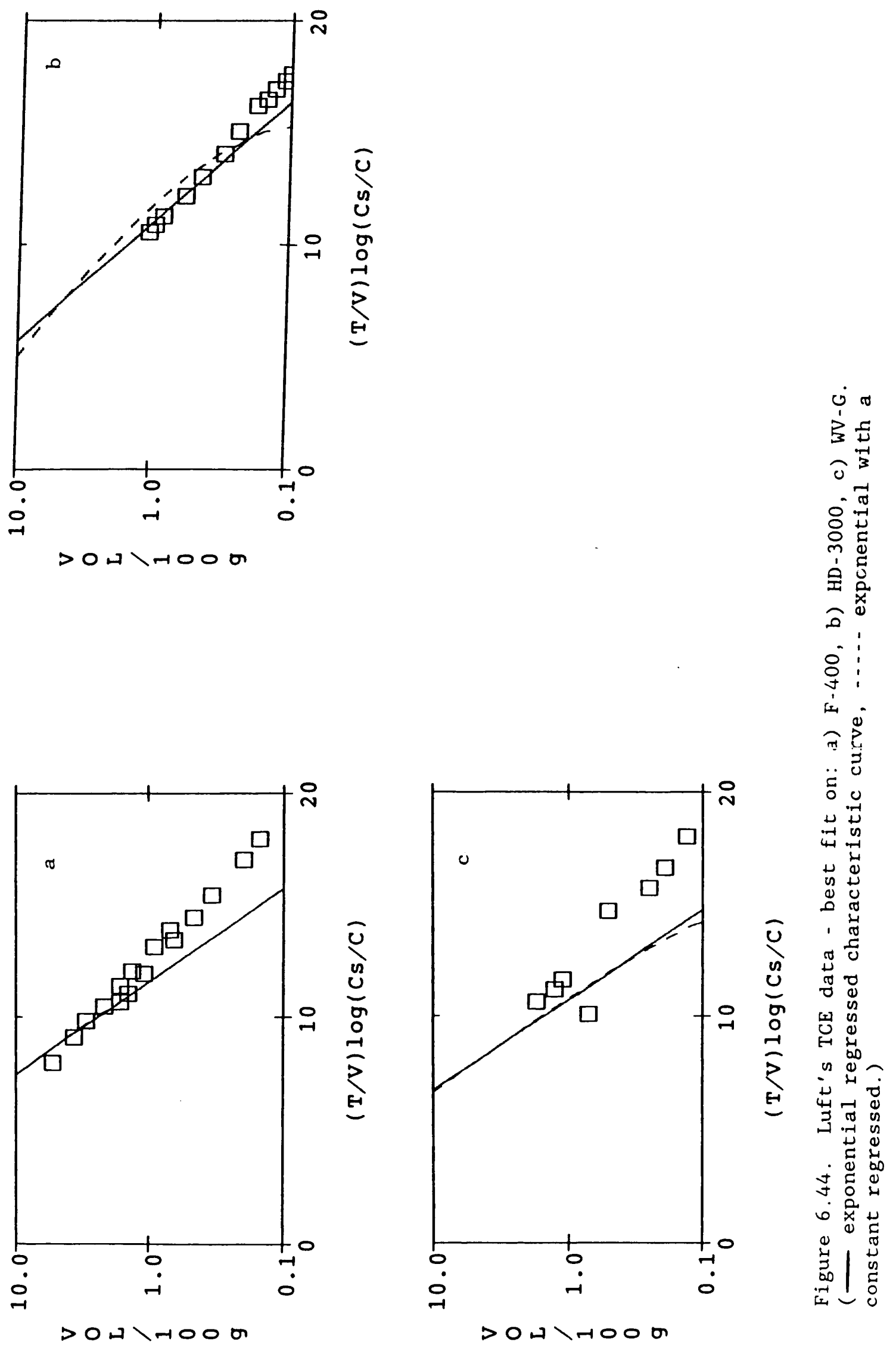

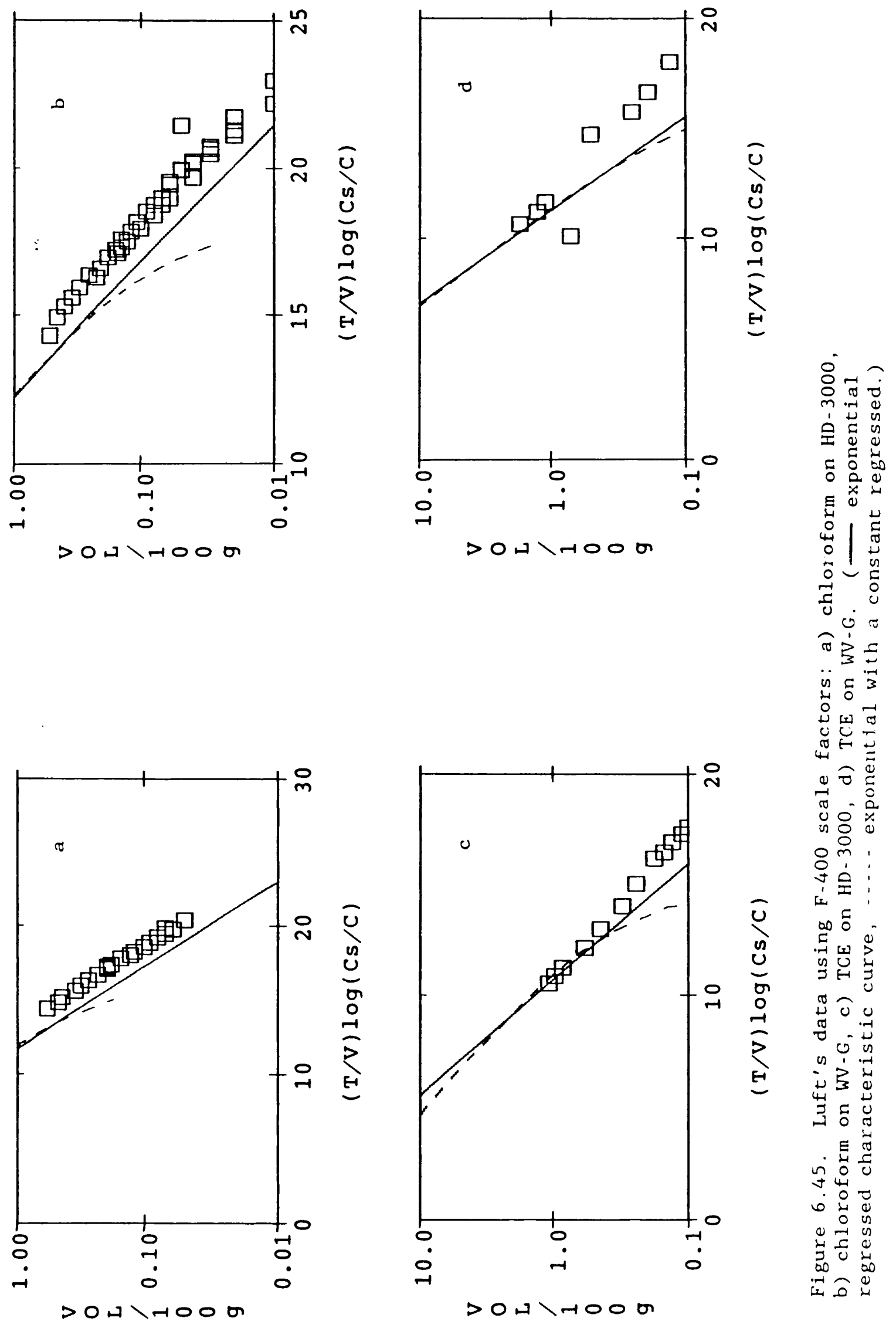
and 0.49 for $H D-3000$ and $W V-G)$. The exponential with a constant model yields poor results on all configurations (smallest $A E=0.75$ ). It appears, from this data, that scale factors determined on one carbon can only approximate adsorption on other carbons. Also, it is important to note that the function used to describe the characteristic curve plays an important role in determining the accuracy of the Polanyi predictions. If the simple exponential is used to describe the characteristic curve, a reasonably good approximation of adsorption results when $\mathrm{F}-400$ scale factors are applied; however, when the exponential with a constant model is used, results are unacceptable. This is consistent with the analysis of Speth's data where the simple exponential model also proved superior overall. In both cases the function which best describes the reference curve (which in both Luft's and Speth's case was an exponential with a constant) is not the optimum model for other compounds, this indicates of a serious flaw in the Polanyi theory. Perhaps a linear model (such as the simple exponential on the log-linear plot) provides the optimum description of Polanyi adsorption data.

TDASF and EDASF and the difference between them, are 1isted in Table 6.11. For comparison, Speth's data, using bromoform instead of cis-DCE as the reference, is also listed. (Although several compounds were utilized in determining the shape of Speth's characteristic curve, one compound, cis-DCE, was chosen to serve as the reference when applying TDASF and EDASF.)

As this data indicates the agreement between EDASF and TDASF is quite good for TCE on all three carbons. This is not, as expected from the graphs, the case for chloroform. With Speth's data, when the simple exponential model is used to describe the characteristic curve, the TDASF 
for chloroform is close to that determined experimentally. In contrast, TCE's predicted and experimental scale factors are very different (38\%). The exponential with a constant model yields results which are more consistent with Luft's data.

TABLE 6.11 ABSCISSA SCALE FACTORS THEORETICALLY AND EXPERIMENTALLY DERIVED FROM SPETH'S AND LUFT'S DATA

\begin{tabular}{|c|c|c|c|c|c|c|c|c|}
\hline & \multicolumn{8}{|c|}{ SCALE FACTORS } \\
\hline & \multirow{3}{*}{\multicolumn{2}{|c|}{ COMPOUND }} & \multicolumn{6}{|c|}{ EDASF } \\
\hline & & & $\exp$ & 8 & DIFF & $\exp$ & 8 & DIFF \\
\hline \multirow[t]{2}{*}{ CARBON } & & & & & & $w / K$ & & \\
\hline & Bromoform & 1.0000 & 1.0000 & & 0.0 & 1.0000 & & \\
\hline \multirow[t]{3}{*}{$F-400$} & Chloroform & 1.2760 & 1.1484 & & -11.1 & 1.1483 & & -11 \\
\hline & TCE & 1.2074 & 1.2463 & & 3.1 & 1.2461 & & \\
\hline & Bromoform & 1.0000 & 1.0000 & & 0.0 & 1.0000 & & \\
\hline \multirow[t]{3}{*}{$\mathrm{HD}-3000$} & Chloroform & 1.2760 & 1.0521 & & -21.3 & 0.9743 & & -31 \\
\hline & TCE & 1.2074 & 1.2158 & & 0.7 & 1.1537 & & -4 \\
\hline & Bromoform & 1.0000 & 1.0000 & & 0.0 & 1.0000 & & \\
\hline \multirow[t]{2}{*}{ WV -G } & Chloroform & 1.2760 & 1.0673 & & -19.5 & 1.0233 & & -24 \\
\hline & TCE & 1.2074 & 1.3009 & & 7.2 & 1.3064 & & 7 \\
\hline
\end{tabular}

SPETH'S DATA

$\begin{array}{lllrrrr} & \text { Bromoform } & 1.0000 & 1.0000 & 0.0 & 1.0000 & 0.0 \\ \text { F-400 Chloroform } & 1.2760 & 1.2673 & -0.7 & 1.0246 & -24.5 \\ & \text { TCE } & 1.2074 & 0.8713 & -38.6 & 1.1119 & -8.6\end{array}$

Note: $\exp =$ exponential model, $\exp \mathrm{w} / \mathrm{k}=$ exponential with a constant model, \&Diff $=($ TDASF-EDASF) $/$ EDASF .

When testing a new carbon, if one decides to utilize scale factors determined using another carbon, it is still necessary to obtain sufficient data on the reference solute to clearly define the characteristic curve. If only a few other solutes are of interest, it would be prudent to determine an isotherm point on each of them for an added measure of confidence. As Speth's bromoform and PCE and 
Fukuchi's MEK and 2-propanol indicated, data points in the moderate concentration ranges, which are less susceptible to experimental error, should be used when determining the EDASF.

The average error of the three solutes on all three carbons is quantified in Table 6.12 using both EDASF and TDASF. This data reinforces the previously shown graphical information. For example, chloroform's fit using the TDASF is poor on all three carbons, but is much worse, on HD-3000 and WV-G, when the exponential with a constant equation is used. With the simple exponential model, EDASF, with the exception of TCE on WV-G carbon, work quite well. One TCE isotherm point on the WV-G was the cause of the high average error. When this point is omitted, a closer fit results (average error $=0.34$ and 0.47 instead of .68 and .80 for the exponential and exponential with a constant). As was the case with the TDASF, the exponential with a constant model does not work as well.

Also, the average error resulting when F-400 scale factors are applied to HD-3000 and WV-G is fairly low. When the simple exponential model is used to describe the curve, only the TCE fit on WV-G is poor $(0.63)$. When one isotherm point is edited, the fit improves to 0.50 . Worth noting is the fact that the EDASF's average error for TCE using F-400 carbon is greater than the AE using TDASF. RS1 finds the best fitting curve by minimizing the square of the error terms. The error is not squared in determining $A E$ (eq 5.2). Although the sum of the squares will usually produce a low AE, the TDASF yields a lower AE in this instance.

Correlation curves, which portray the characteristic curves after the abscissa scale factors are applied, are a good representation of the 
TABLE 6.12 AVERAGE ERROR - LUFT'S DATA

\begin{tabular}{|c|c|c|c|c|c|}
\hline \multirow[t]{2}{*}{ CARBON } & COMPOUND & TDASF & & \multicolumn{2}{|l|}{ EDASF } \\
\hline & & $\exp$ & $\begin{array}{l}\exp \\
w / K\end{array}$ & $\exp$ & $\begin{array}{l}\exp \\
w / K\end{array}$ \\
\hline$\because$ & Bromoform & & & 0.11 & 0.11 \\
\hline \multirow[t]{4}{*}{$F-400$} & Chloroform & 0.64 & 0.64 & 0.19 & 0.19 \\
\hline & TCE & 0.37 & 0.37 & 0.45 & 0.45 \\
\hline & AVERAGE & 0.51 & 0.51 & 0.25 & 0.25 \\
\hline & Bromoform & & & 0.08 & 0.03 \\
\hline \multirow[t]{4}{*}{$\mathrm{HD}-3000$} & Ch1oroform & 0.74 & 2.92 & 0.07 & 0.69 \\
\hline & TCE & 0.22 & 1.00 & 0.23 & 0.87 \\
\hline & AVERAGE & 0.48 & 1.96 & 0.13 & 0.53 \\
\hline & Bromoform & & & 0.06 & 0.04 \\
\hline \multirow[t]{3}{*}{ WV-G } & Chloroform & 0.82 & 2.14 & 0.08 & 0.85 \\
\hline & TCE & 0.59 & 0.70 & 0.68 & 0.80 \\
\hline & AVERAGE & 0.70 & 1.42 & 0.27 & 0.56 \\
\hline
\end{tabular}

\begin{tabular}{|c|c|c|c|}
\hline $\mathrm{HD}-3000$ & Chloroform & 0.43 & 2.21 \\
\hline & TCE & 0.22 & 1.00 \\
\hline & AVERAGE & 0.32 & 1.60 \\
\hline WV-G & Chloroform & 0.49 & 1.73 \\
\hline & TCE & 0.63 & 0.75 \\
\hline & AVERAGE & 0.56 & 1.24 \\
\hline
\end{tabular}


accuracy of the Polanyi predictions. In creating these curves, each abscissa point is multiplied by the scale factor. When accurate scale factors are applied a single curve should result. For example, Figure 6.46 confirms that predicted scale factors are not very effective at describing either the adsorption of chloroform (across the entire range) or low concentrations of TCE. The consistency of this pattern from carbon to carbon creates hope that, once these patterns are established, they can be expected to occur on other carbons. In other words, although the chloroform data deviates from the predicted curve, the deviation appears sufficiently consistent to itself be predicted.

Correlation curves created by applying experimental scale factors provide a reasonably good fit of the chloroform data (figures 6.47 and 6.48). Although overall the fit is fair, these curves demonstrate the poor fit of TCE in the low concentration range. Again, the consistency of this pattern from carbon to carbon is important to note. The above scale factors were determined using several data points for each compound. In practice, the reference compound would be well defined but only one data point for each of the other compounds would be required to determine the experimentally determined scale factors. 


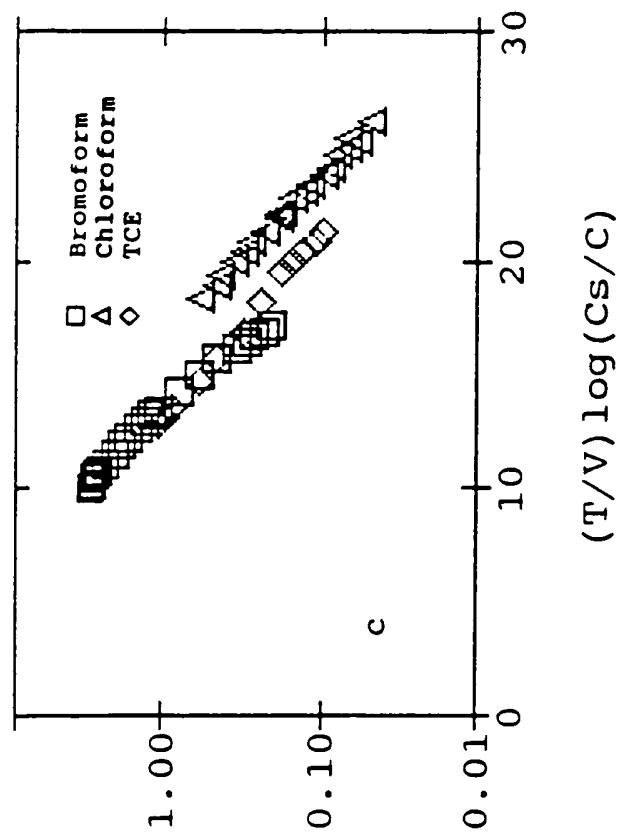

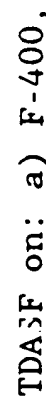
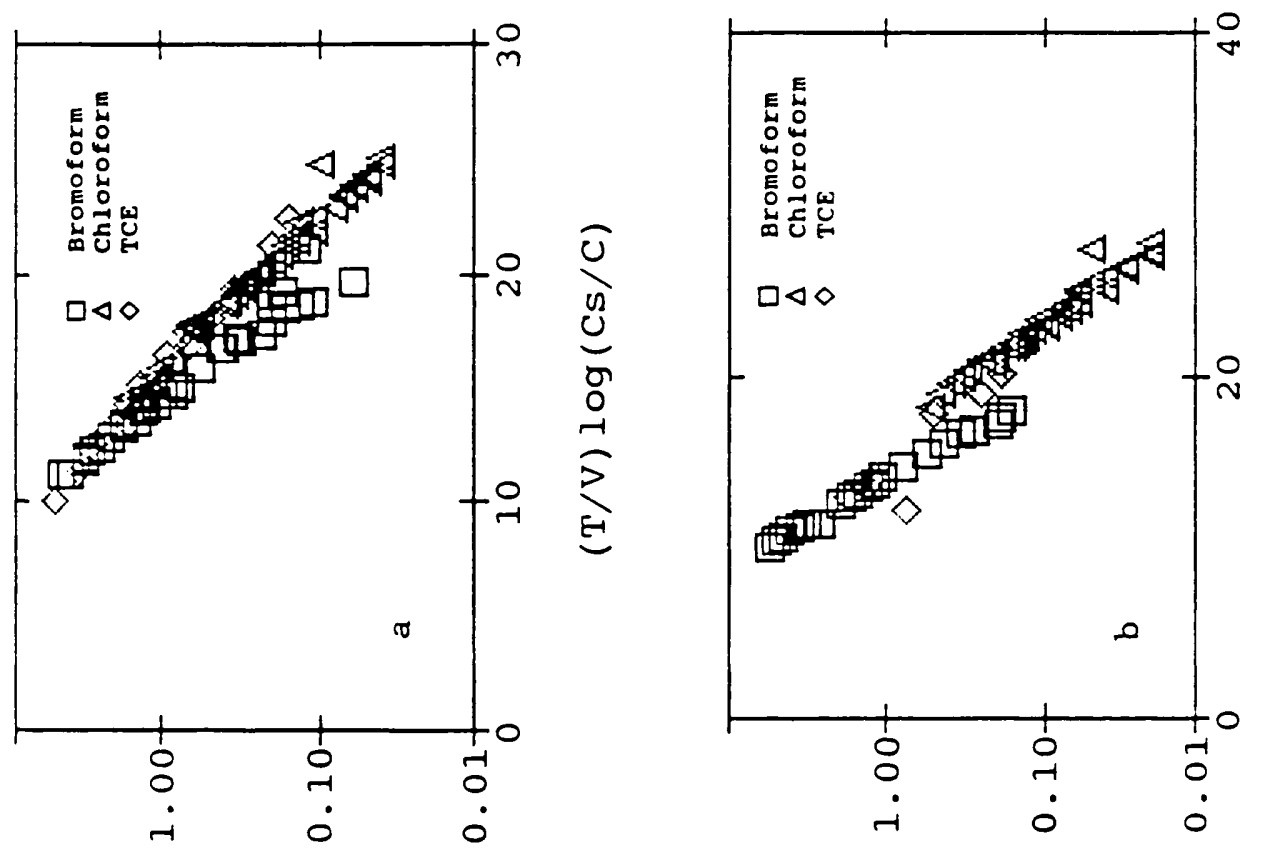

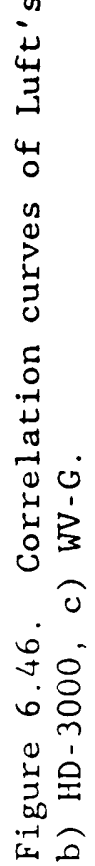

>

$>0$ म $>$ म 0 O 


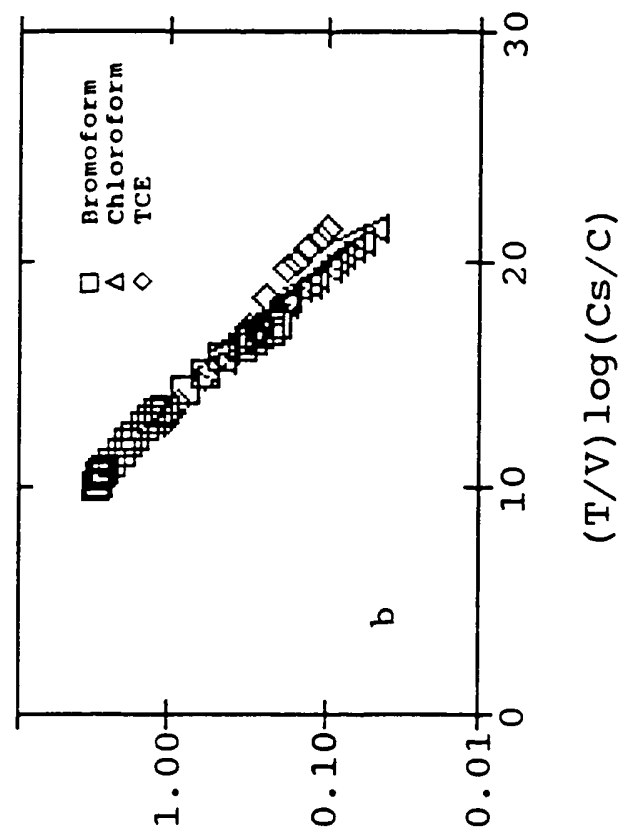

>

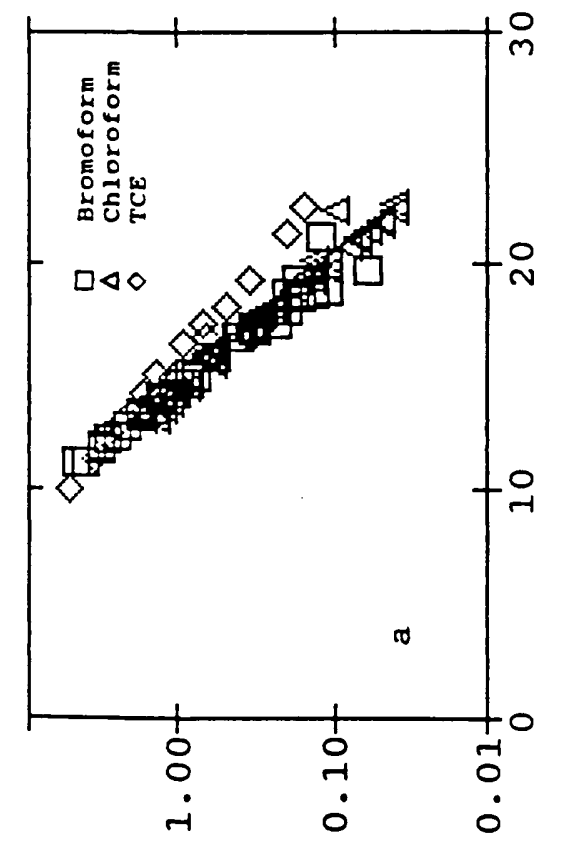

>
>0ル入
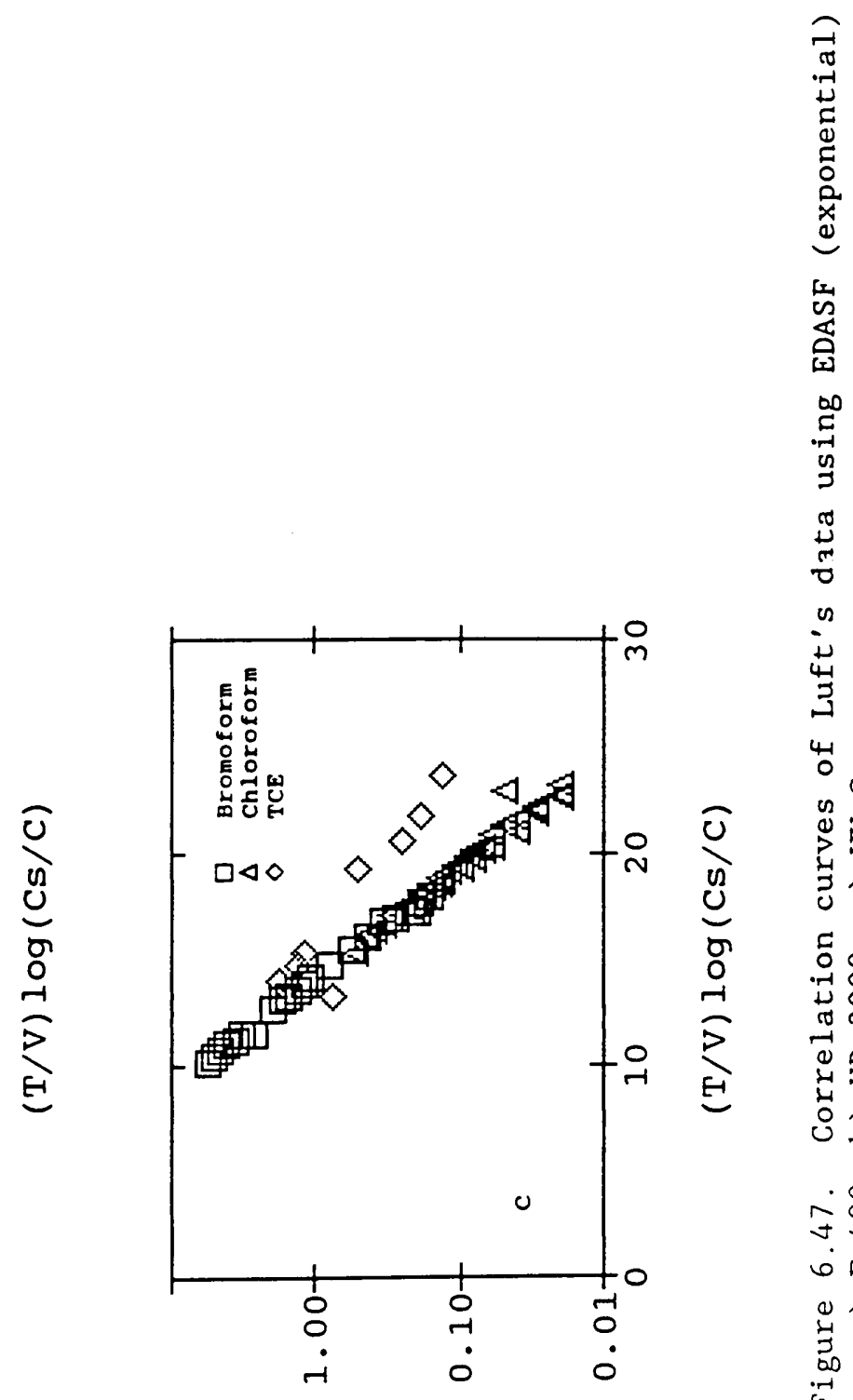

乩

苞

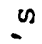

荘

4

U $\quad 0$

ध

б̆ 5.

잉

담

$?$ 它完

E

于̊

का

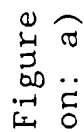




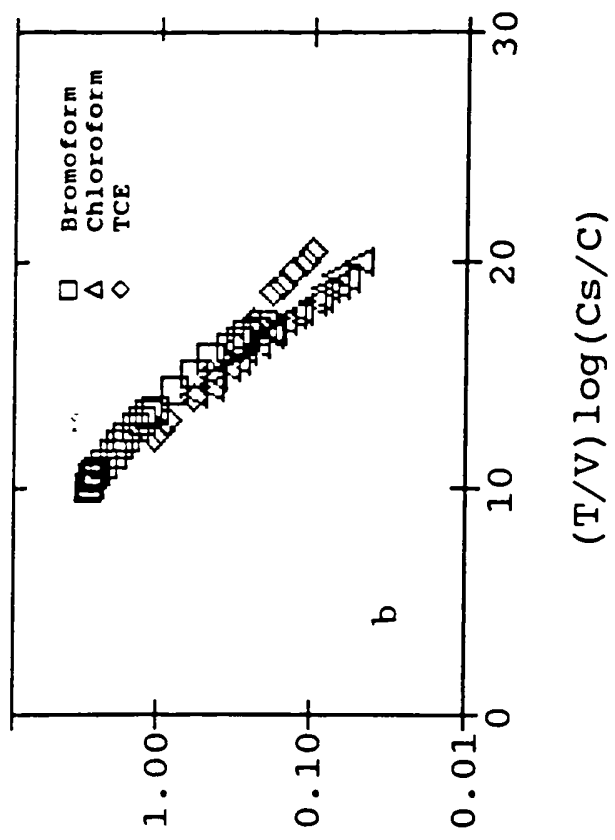

> Oम>
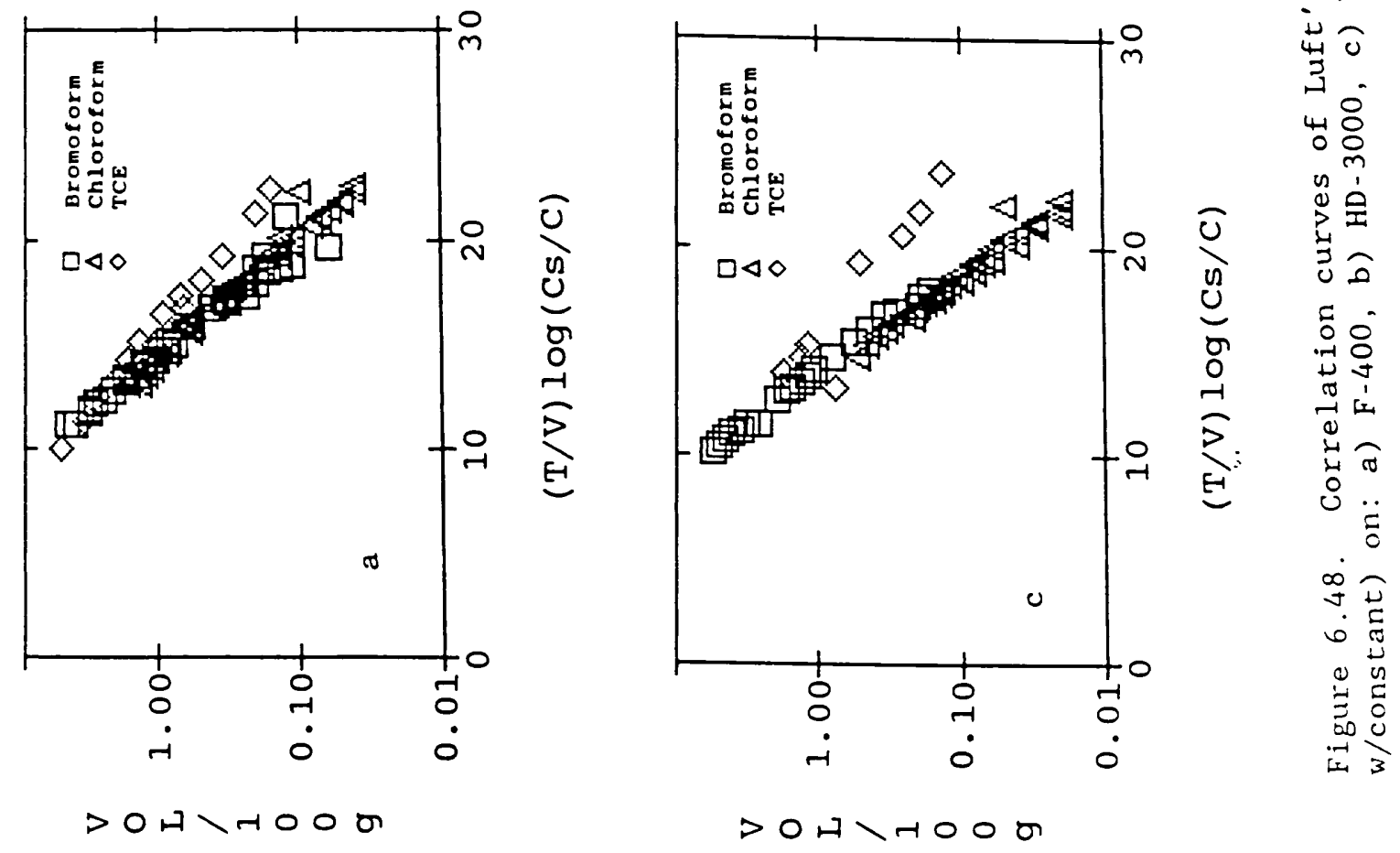
Luft's data gives some support to Polanyi's claim that the abscissa scale factors, once determined, can effectively be applied to all carbons. The scale factors obtained on F-400 are within $15 \%$ of those experimentally derived using the exponential with a constant and within 88 when the simple exponential is used. The average error that results when F-400's scale factors are applied to $\mathrm{HD}-3000$ and $\mathrm{WV}-\mathrm{G}$ are also reasonable (worst case $=0.63$ which improves to 0.50 when one data point is edited).

As was the case with Speth's data, the TDASF do not accurately describe chloroform adsorption. The poor fit is relatively consistent between the three carbons.

EDASF work well except for the low end sorption of TCE. This may indicate that TCE adheres to a different shaped characteristic curve than chloroform and bromoform. Fortunately, the pattern is similar for all carbons tested, so there is hope that once an aberrant behaving compound is identified, the behavior can be expected to occur with some consistency. However, since Speth's TCE data demonstrated no such bias it is more likely a result of experimental error.

Based upon the data evaluated thus far, it seems that experimentally determined scale factors, EDASF, provide fairly accurate simulations of adsorption isotherms. The scale factors determined on one carbon can serve as approximations of those on other carbons.

Some solutes, chloroform in particular, demonstrate adsorption behavior inconsistent with their polarizability. The behavior does however, appear to be fairly consistent on all carbons.

It seems, and Speth's and Fukuchi's data also supports this view, 
that when isotherm data is presented as characteristic curves there is a linear relationship between the solid and liquid phases. 
In this section, published data supplied by B. M. van Vliet (1987, 1988) will be used to challenge further Mane's hypothesis concerning the need for ordinate adjustments when applying the Polanyi theory to solutes which are solids. This data consist of adsorption isotherms of phenol and p-chlorophenol on F-400 and BACM carbons. Testing was performed at the University of Michigan under the guidance of Dr. W. J. Weber Jr. Experimental conditions are listed in Table 6.13.

\section{TABLE 6.13 EXPERIMENTAL CONDITIONS (VAN VLIET)}

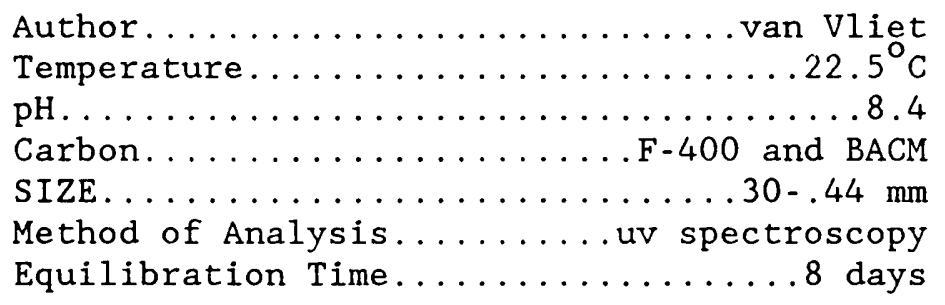

Relevant information on the two solutes is listed in Table 6.14. Consistent with the analysis of Fukuchi's data, the solubility value utilized was obtained from a reference source (Lange, 1987) and is not a UNIFAC estimate.

\begin{tabular}{|c|c|c|c|c|c|c|}
\hline COMPOUND & MOL WT & $\begin{array}{c}\text { DEN } \\
(\mathrm{g} / \mathrm{mL})\end{array}$ & $\begin{array}{c}\text { SOL } \\
(\mathrm{mg} / \mathrm{L})\end{array}$ & $\begin{array}{l}\text { MP } \\
(C)\end{array}$ & INDEX & $\mathrm{P}$ \\
\hline - chlo & 128.56 & 1.306 & 27100 & 43.2 & 1.5579 & 0.3223 \\
\hline phenol & 94.11 & 1.071 & 82000 & 40.85 & 1.5425 & 0.3150 \\
\hline
\end{tabular}

Note: MOL WT = molecular weight; $\mathrm{DEN}=$ density; SOL = solubility; $M P=$ melting point; $\operatorname{INDEX}=\operatorname{refractive}$ index; $\mathrm{P}=$ polarizability 


\subsubsection{Basic Characteristic Curves}

Figures $6.49 \mathrm{a}$ and $\mathrm{b}$ demonstrate the characteristic curves obtained when the van Vliet's raw data, on the two carbons, is plotted. Figure 6.49c shows Fukuchi's data for these two compounds, using F-400. As these figures indicate, the plots of these two compounds are very similar and together they almost form a single curve.

The relationship between the two solutes is about the same on F-400 and BACM. Van Vliet's isotherms on F-400 also closely matches those of Fukuchi. But do the scale factors determined using Fukuchi's data apply to van Vliet's isotherms? Based on Fukuchi's data the corrected densities of p-chlorophenol and phenol are $0.516 \mathrm{~g} / \mathrm{ml}$ and $0.469 \mathrm{~g} / \mathrm{ml}$ respectively. These adjustrents will be applied to both the ordinate and the abscissa since Fukuchi's results demonstrated that adjustments to both axes were required to make accurate predictions of a solid's adsorption.

\subsubsection{Between Carbon Comparison of Scale Factors}

Figures 6.50 and 6.51 show the characteristic curves, on both carbons, which result in the best fit of the phenol data (after the density was adjusted on both axes). The f nction used to describe the F-400 data is:

$$
f(x)=167 * \exp (-0.328 * x)
$$




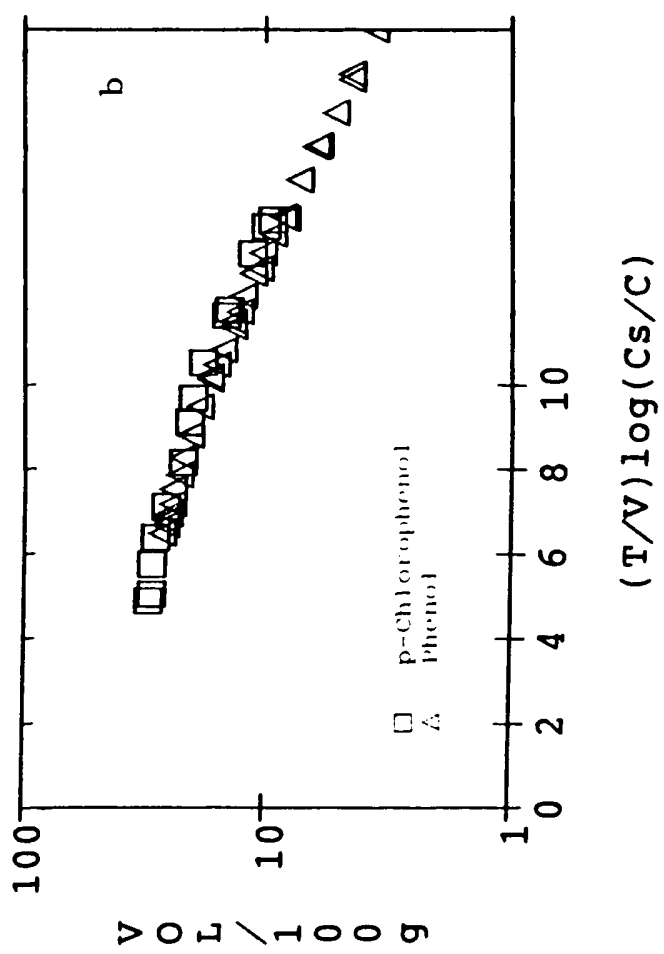

2
0
0
0
0
0
0
0
0
0
0
0
0
0
0
0
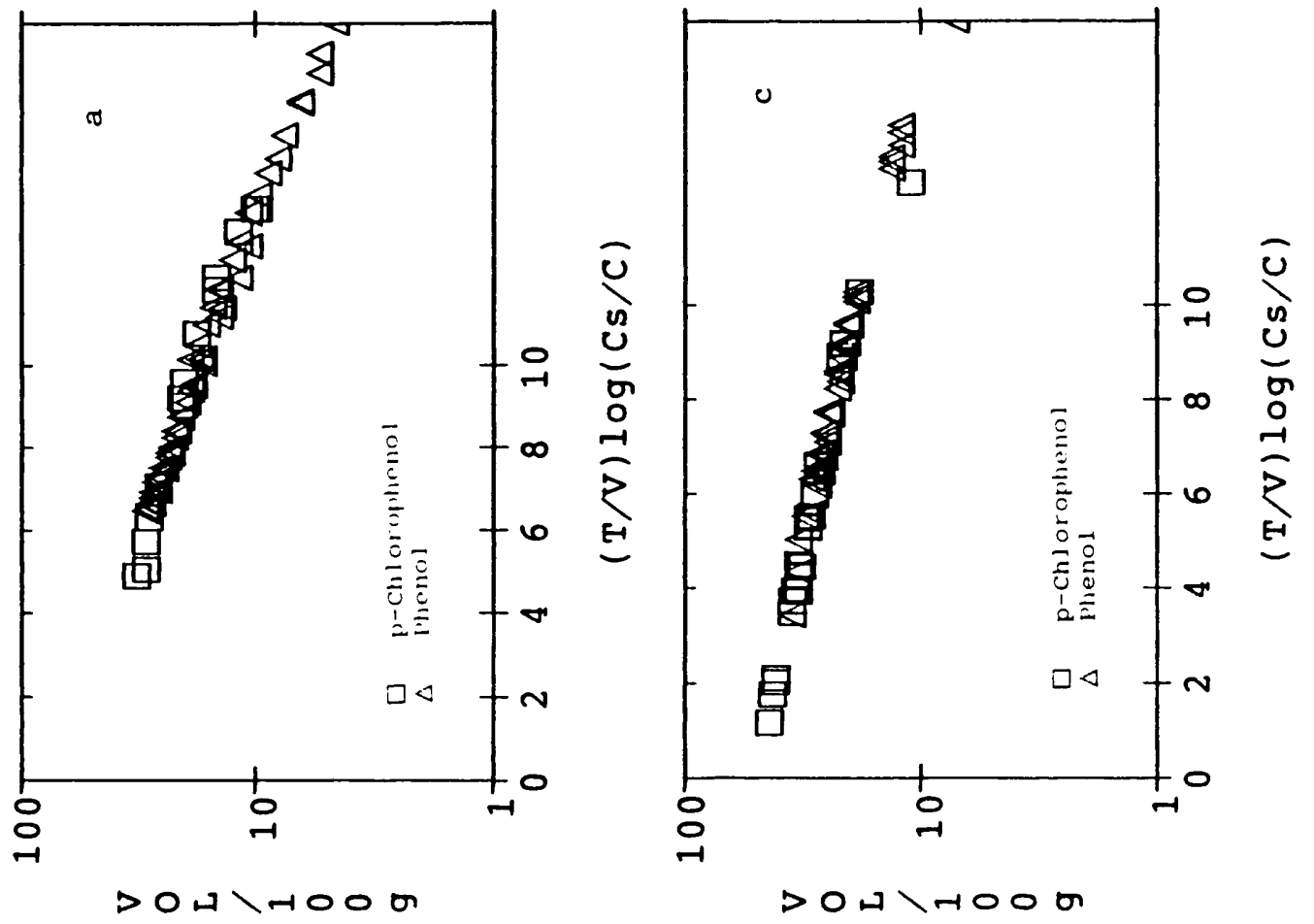

ป

4

ง

$\$$

ट्य i

उ $v$

U 0 us

n

$1 \frac{0}{0}$

$\stackrel{4}{-1}$

4)

0

(5)

党

an us

$\checkmark$ it

60

i)

का

in $\rightarrow$ 


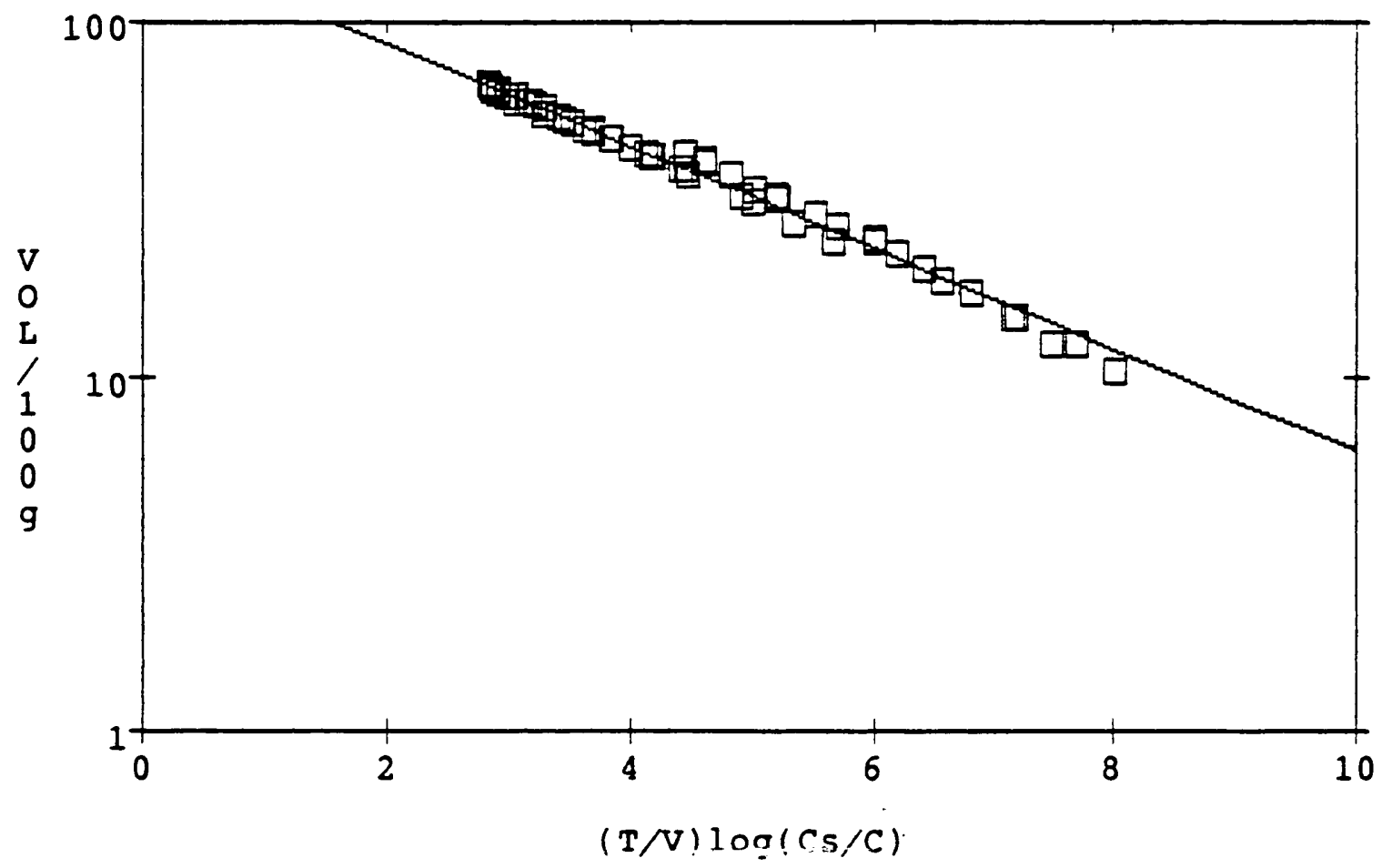

Figure 6.50. Characteristic curve of van vliet's phenol data - best fit F-400 reference curve.

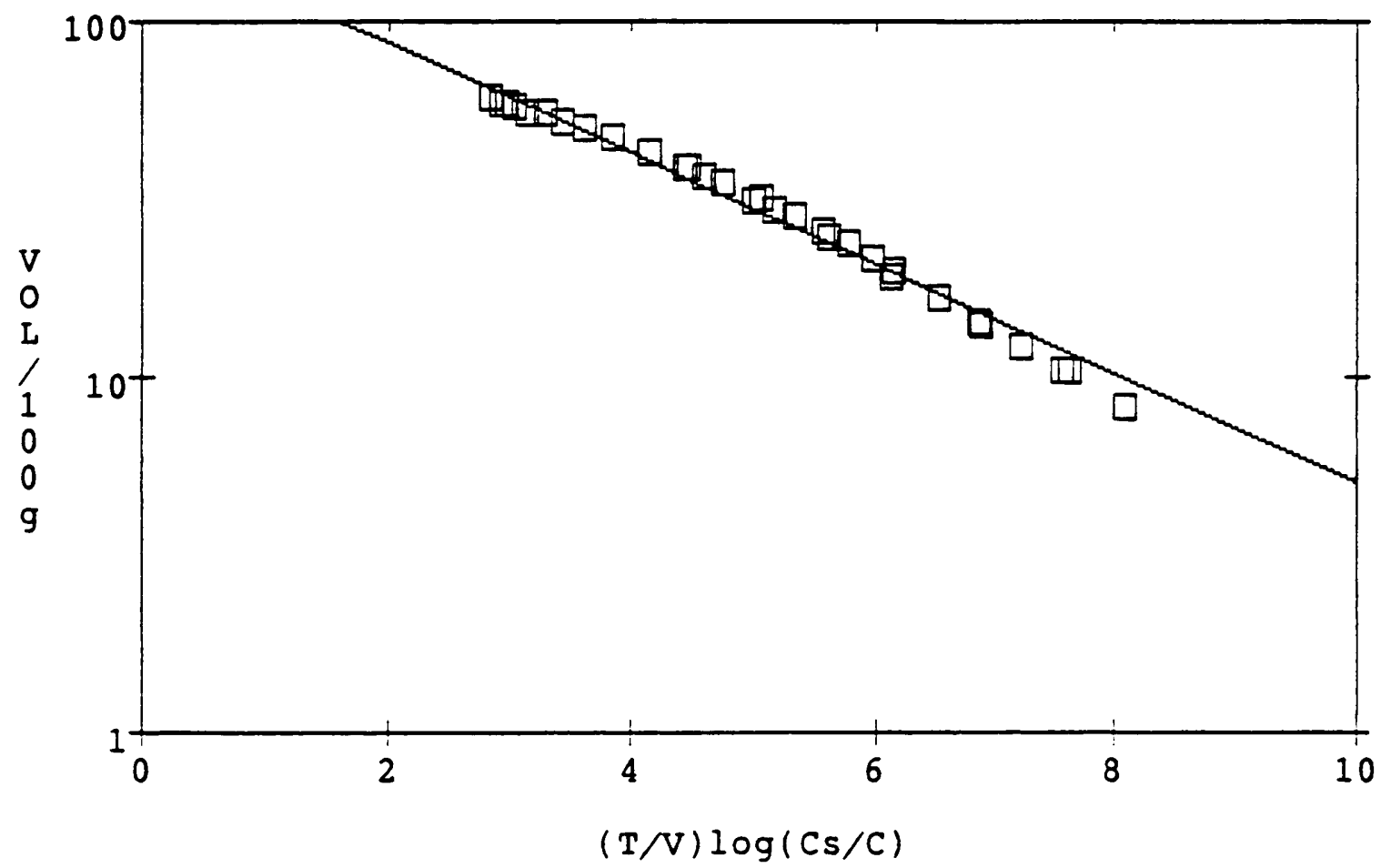

Figure 6.51. Characteristic Curve of van vliet's phenol data - best fit BACB reference curve. 


$$
f(x)=175 * \exp (-0.3543 * x)
$$

From these reference characteristic curves, the p-chlorophenol data was predicted by applying the TDASF of 0.977 . This scale factor is simply the ratio of the polarizability of phenol, the reference solute, to that of $\mathrm{p}$-chlorophenol. The predicted curve is the same as the reference curve except that the slope term $(-0.328$ and -0.3543 is altered by multiplying it by the scale factor. As Figure $6.52 \mathrm{a}$ and $\mathrm{b}$ indicate, the predicted curve fits the $\mathrm{p}$-chlorophenol data quite well $(\mathrm{AE}=0.07$ and 0.06 for $F-400$ and BACM)).

When the EDASF, based on Fukuchi's data, are applied to van Vliet's p-chlorophenol data an accurate fit $(\mathrm{AE}=0.06,0.07)$ also results (figure $6.52 \mathrm{c}$ and d). Van Vliet's data thus supports Manes' contention that the abscissa scale factors as well as the density adjustments, determined on one carbon, can successfully be used on other carbons.

TDASF and EDASF, and the difference between them, are listed in Table 6.15. The experimental scale factors were obtained from Fukuchi's data.

TABLE 6.15 ABSCISSA SCALE FACTORS THEORETICALLY AND EXPERIMENTALLY DERIVED FROM AND FUKUCHI'S DATA

$\begin{array}{lccr} & \begin{array}{c}\text { SCALE FACTORS } \\ \text { TDASF }\end{array} & \text { EDASF } & \text { \& DIFF } \\ \text { COMPOUND } & & & \\ \text { p-chlorophenol } & 0.977 & 0.999 & 2.2\end{array}$

The average error of the two solutes on both carbons is quantifies 

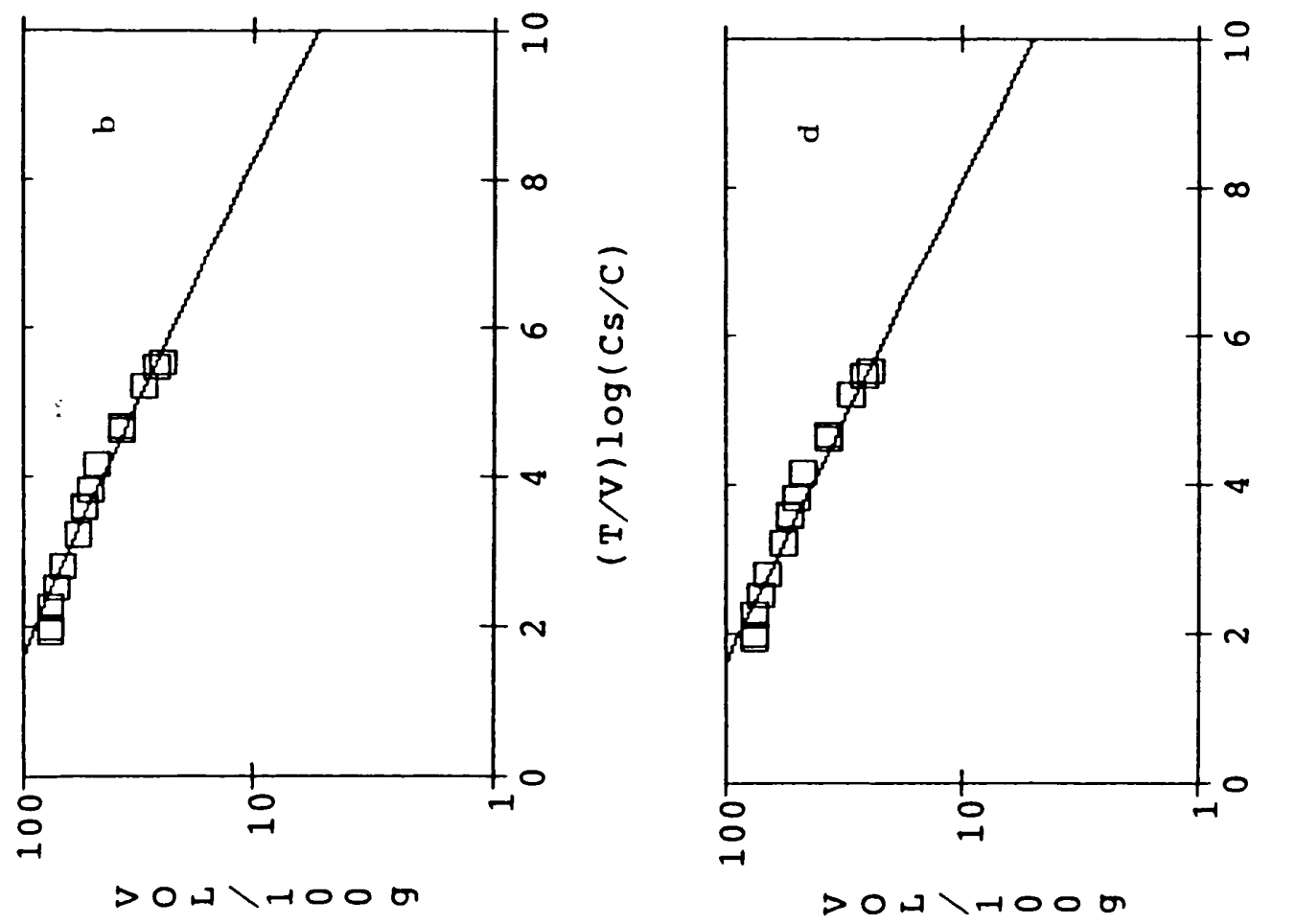

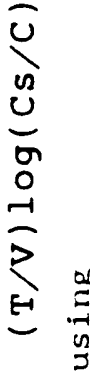
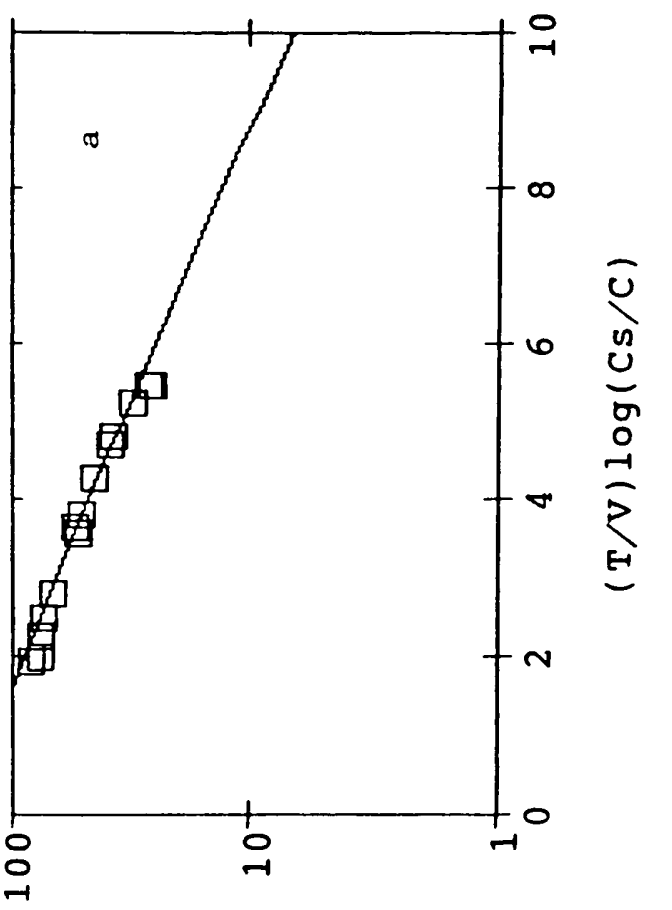

$>0$ >

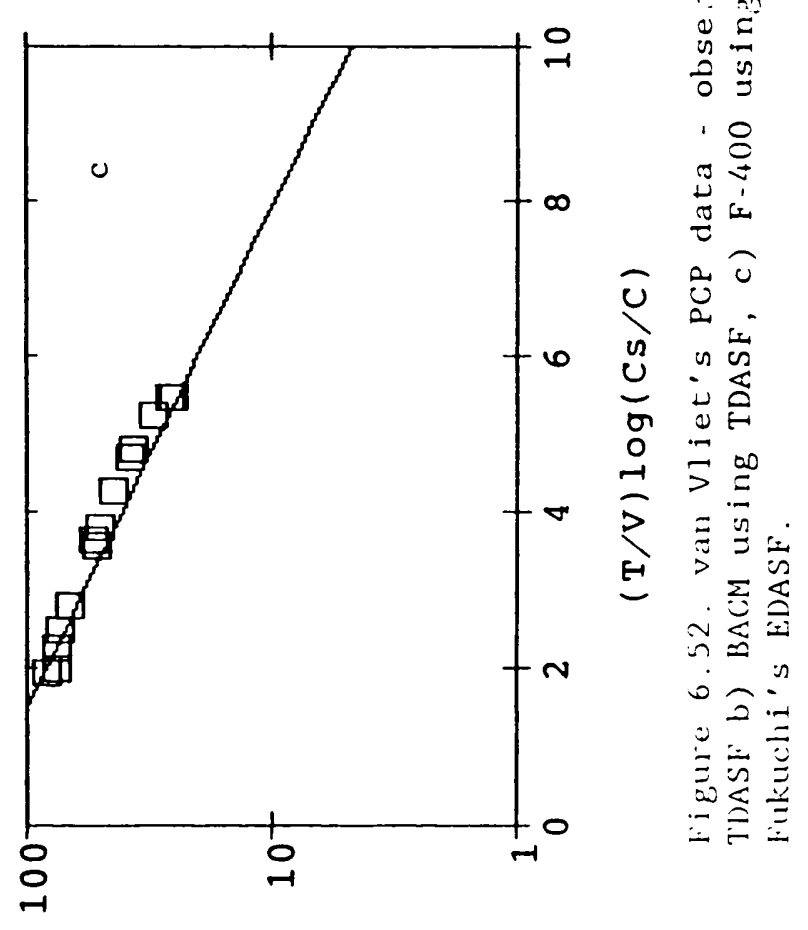

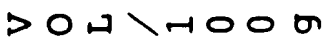

$\bigcirc_{0}^{\infty} \stackrel{\infty}{a}$

$x^{1}=$

为它

ฮิ

D

$د \&$

考部

ช。

ㄴ.

$\rightarrow \frac{0}{3}$

- 혹

d) 结

$?$

i

$\div$ 今

18

ชู

$\widehat{0}$

O

ये का एक

- i

$\stackrel{\rightarrow}{\rightarrow} \stackrel{\infty}{=}$

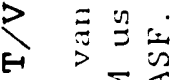

$N \underset{n}{n}$

in

$2=$

$\Xi \dot{\vec{n}}$

二三 
in Table 6.16, for each compound, using both experimentally and theoretically determined scale factors. As mentioned, a reasonably good fit should yield a value of 0.5 or less. The lower the value the better the fit.

TABLE 6.16 GOODNESS OF FIT - VAN VLIET'S DATA

$\begin{array}{llcr} & \text { COMPOUND } & \text { TDASF } & \text { EDASF } \\ \text { F-400 } & \begin{array}{l}\text { p-chlorophenol } \\ \text { phenol }\end{array} & 0.07 & 0.07 \\ \text { BACM } & \begin{array}{l}\text { p-chlorophenol } \\ \text { phenol }\end{array} & 0.06 & 0.02 \\ & & & 0.06 \\ & & 0.05\end{array}$

Table 6.16 reflects the accuracy of the fit obtained using either the TDASF or the EDASF derived from Fukuchi's data. Fukuchi's abscissa scale factors, as well as the density adjustments seem to apply to van Vliet's isotherm results.

As previously stated, correlation curves, which portray the characteristic curves after the scale factors are applied, are a good representation of the effectiveness of the Polanyi predictions. In creating these curves, each abscissa point is multiplied by the scale factor. When accurate scale factors are applied a single curve should result. Figure $6.53 \mathrm{a}$ and $\mathrm{b}$ demonstrates that the predicted scale factors provide an accurate description of adsorption on both types of carbon.

Correlation curves created by applying Fukuchi's experimental scale factors provide an even better fit of the data (figure $6.53 \mathrm{c}$ and $\mathrm{d}$ ). Again, the good fit applies to both F-400 and BACM. 

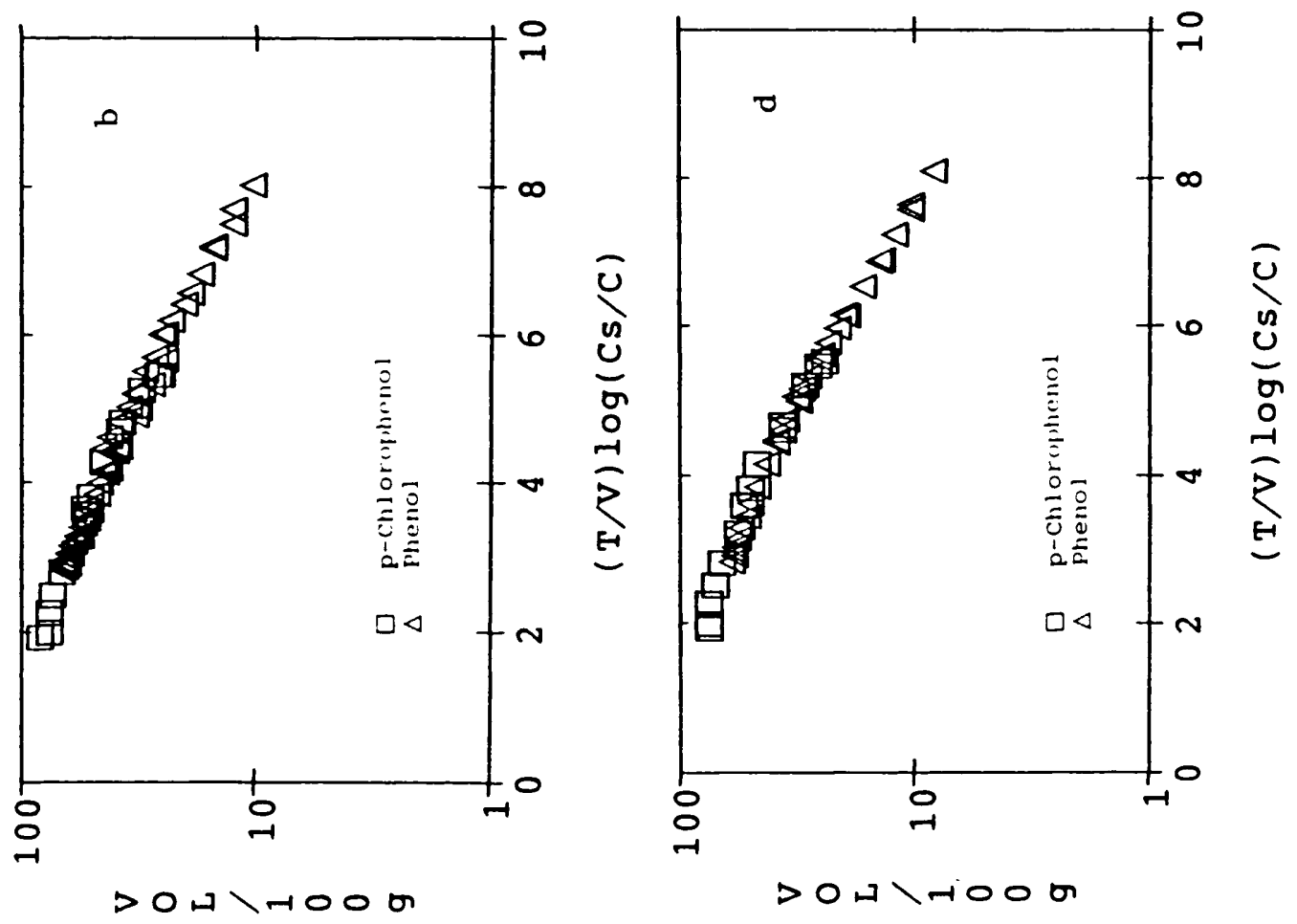

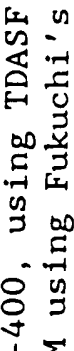

ज

क嵒

.. ช

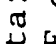

कृ

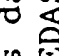

오
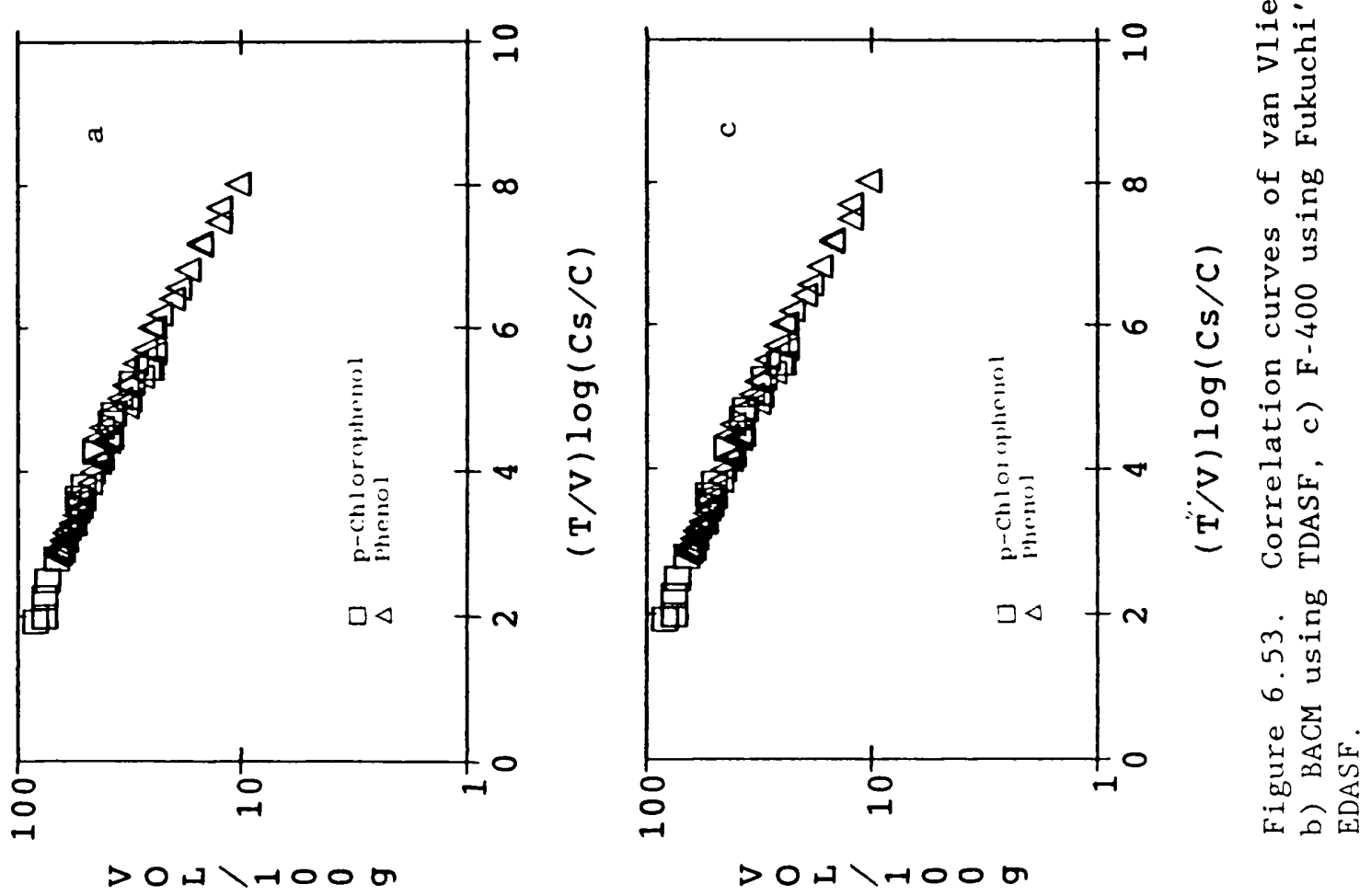
Summary of the Analysis of van Vliet's data

Van Vliet's results add support to the claim that scale factors of solid solutes (solutes which exist as solids at the isotherm temperature), derived on one carbon, can effectively be applied to other carbons. The average error that results when Fukuchi's F-400 scale factors, including density adjustments, are applied to van Vliet's F-400 and BACM data on p-chlorophenol are excellent (worst case $=0.07$ ).

The small amount of deviation observed in the correlation curves of the phenol and p-chlorophenol data is further testimony to the existence of a single curve which describes the adsorption of all compounds. Although the data base examined in this chapter is too small to serve as absolute proof (only 2 solutes and 2 types of carbon were tested), it does provide further support of the effectiveness of the Polanyi theory's predictive capacity. 
6.5 EVALUATION OF THE POLANYI MODEL FOR KONG'S DATA

As a further challenge to the Polanyi theory's predictive abilities, data from the Master's thesis of Emory Kong (1984) was examined. This thesis reports on the adsorption isotherms of carbon tetrachloride, tetrachloroethylene (PCE), and trichloroethylene (TCE) which were performed at the University of North Carolina under the guidance of Dr. Francis DiGiano. Again, the standard bottle point isotherm technique was employed. Experimental conditions are described in Table 6.17 .

TABLE 6.17 EXPERIMENTAL CONDITIONS (KONG)

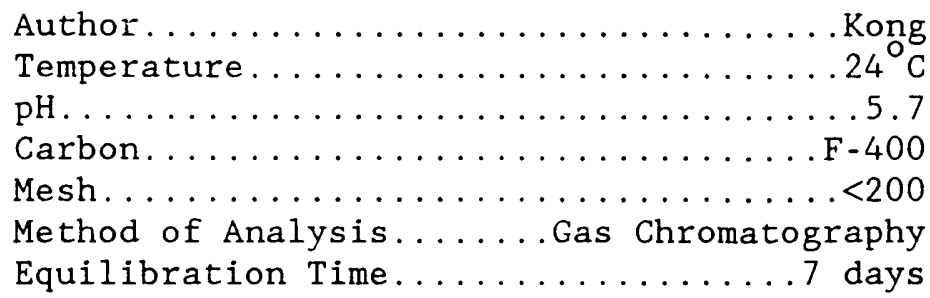

Relevant information on each of the solutes is listed in Table 6.18. Since these solutes exist as liquids under experimental conditions, molar volume and polarizability should be the only scale factors which apply.

TABLE 6.18 CHARACTERISTICS OF SOLUTES (KONG)

COMPOUND

$\begin{array}{cccc}\text { MOL WT } & \text { DEN } & \text { SOL } & \text { MP } \\ & (\mathrm{g} / \mathrm{mL}) & (\mathrm{mg} / \mathrm{L}) & (\mathrm{C})\end{array}$

INDEX

$P$

$\begin{array}{lrrrrrr}\text { Carbon Tetrachloride } & 153.8 & 1.594 & 807 & -23 & 1.4595 & 0.2736 \\ \text { TCE } & 131.4 & 1.464 & 1047 & -85 & 1.4755 & 0.2818 \\ \text { PCE } & 165.9 & 1.623 & 420 & -22 & 1.5056 & 0.2969\end{array}$

Note: MOL WT $=$ molecular weight $;$ DEN = density; SOL = solubility; $M P=$ melting point; INDEX = refractive index; $\mathrm{P}=$ polarizability 


\subsubsection{BASIC CHARACTERISTIC CURVE}

Figure 6.54 shows the characteristic curve of Kong's raw data. As was the case with Luft's isotherms, there is no good candidate to serve as a reference solute since only the lower concentration ranges are defined by the data. PCE was selected as the reference compound because its data covers the widest concentration range. Figure 6.55 demonstrates the fit obtained when the following simple exponential equation is used to describe the PCE data:

$$
V=490 * \exp (-0.5200 * X)
$$

where $\mathrm{V}=$ volume adsorbed $/ 100$ gm carbon

The limiting adsorbate volume, $Y$ intercept, is again, unrealistically high (490); nevertheless, this curve will serve as the reference characteristic curve with the understanding that the curve is valid only within the experimental testing range.

\subsubsection{Theoretically Predicted Characteristic Curves}

Using this plot of PCE to determine the shape of the characteristic curve, TDASF were applied. To predict the characteristic curves of the individual compounds from the reference curve the slope term, -0.5200 , of the reference curve is multiplied by this scale factor. Figures 6.56 and 6.57 present the observed loadings for carbon tetrachloride and TCE and their predictions using 


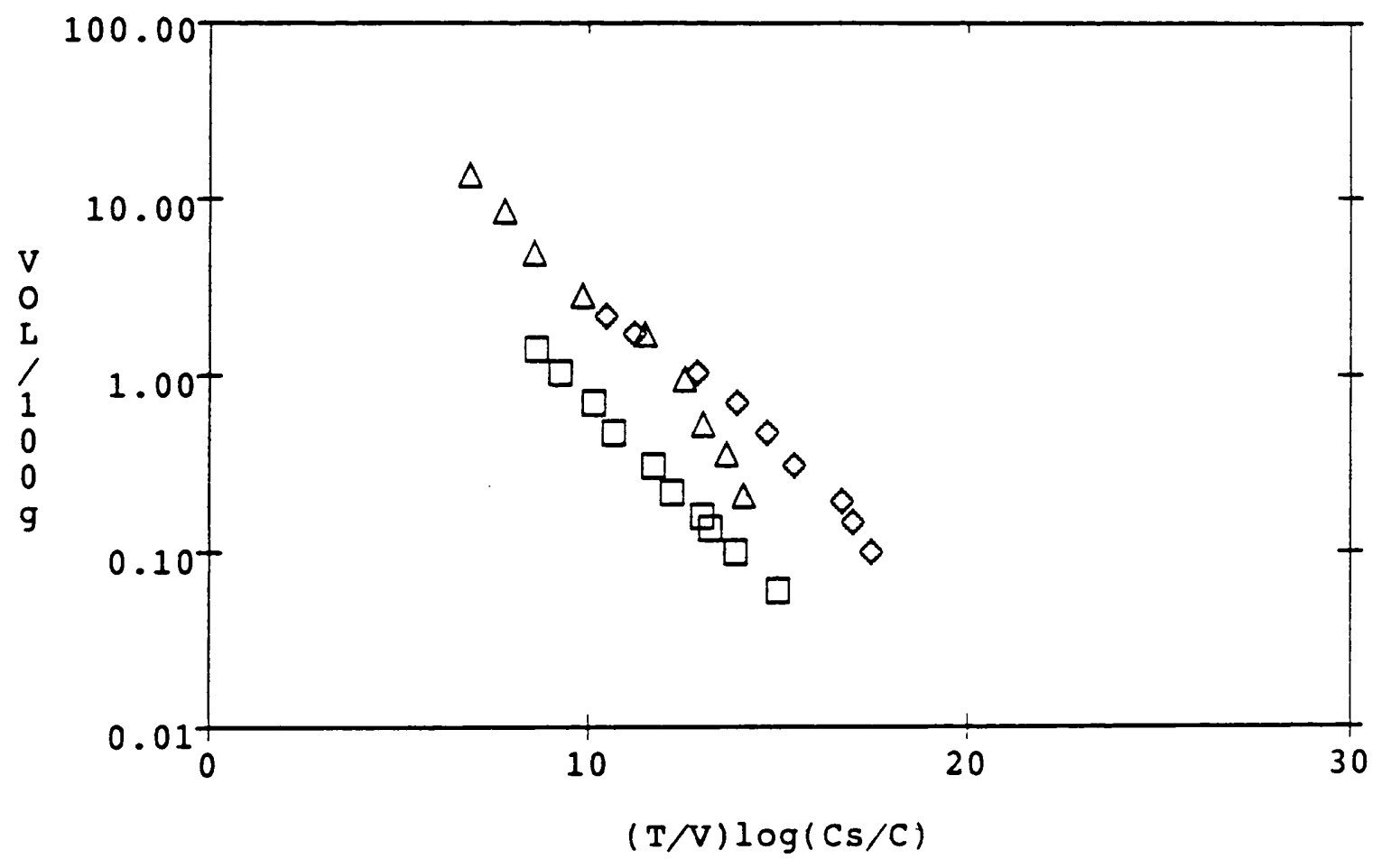

Figure 6.54. Characteristic curve

- Kong's raw data.

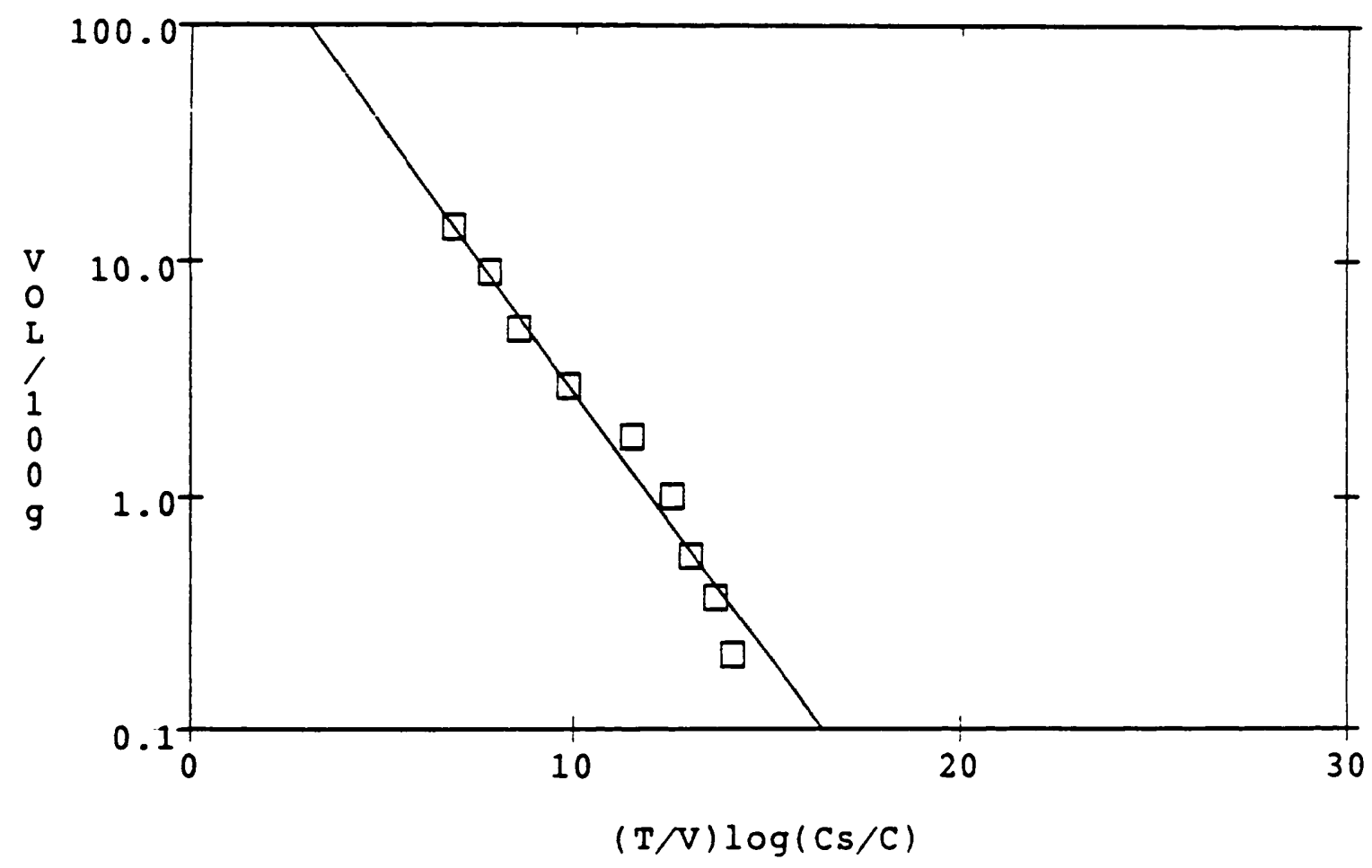

Figure 6.55. Characteristic curve of Kong's PCE data - best fit reference curve. 


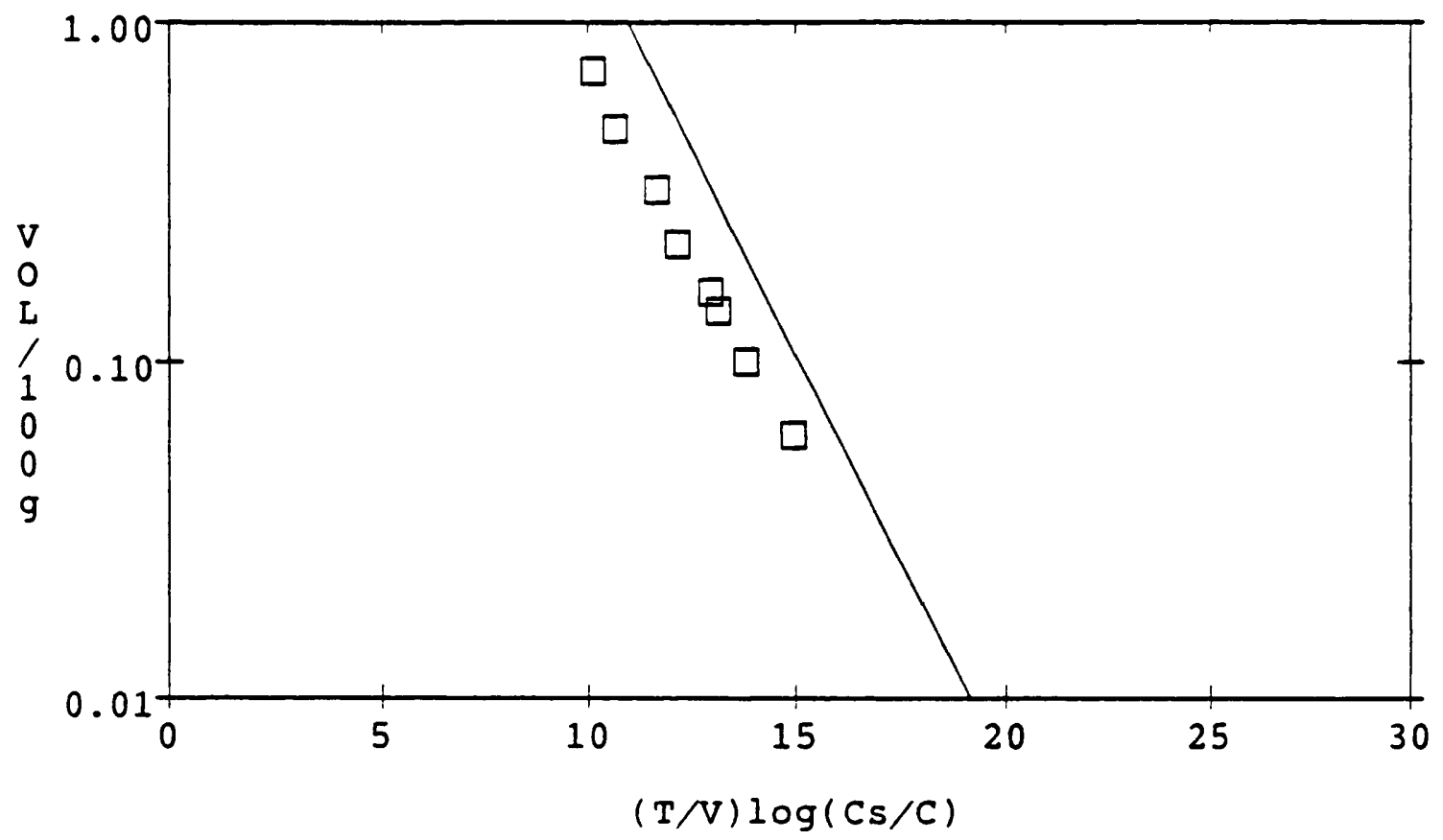

Figure 6.56. TDASF prediction of Kong's carbon tetrachloride data.

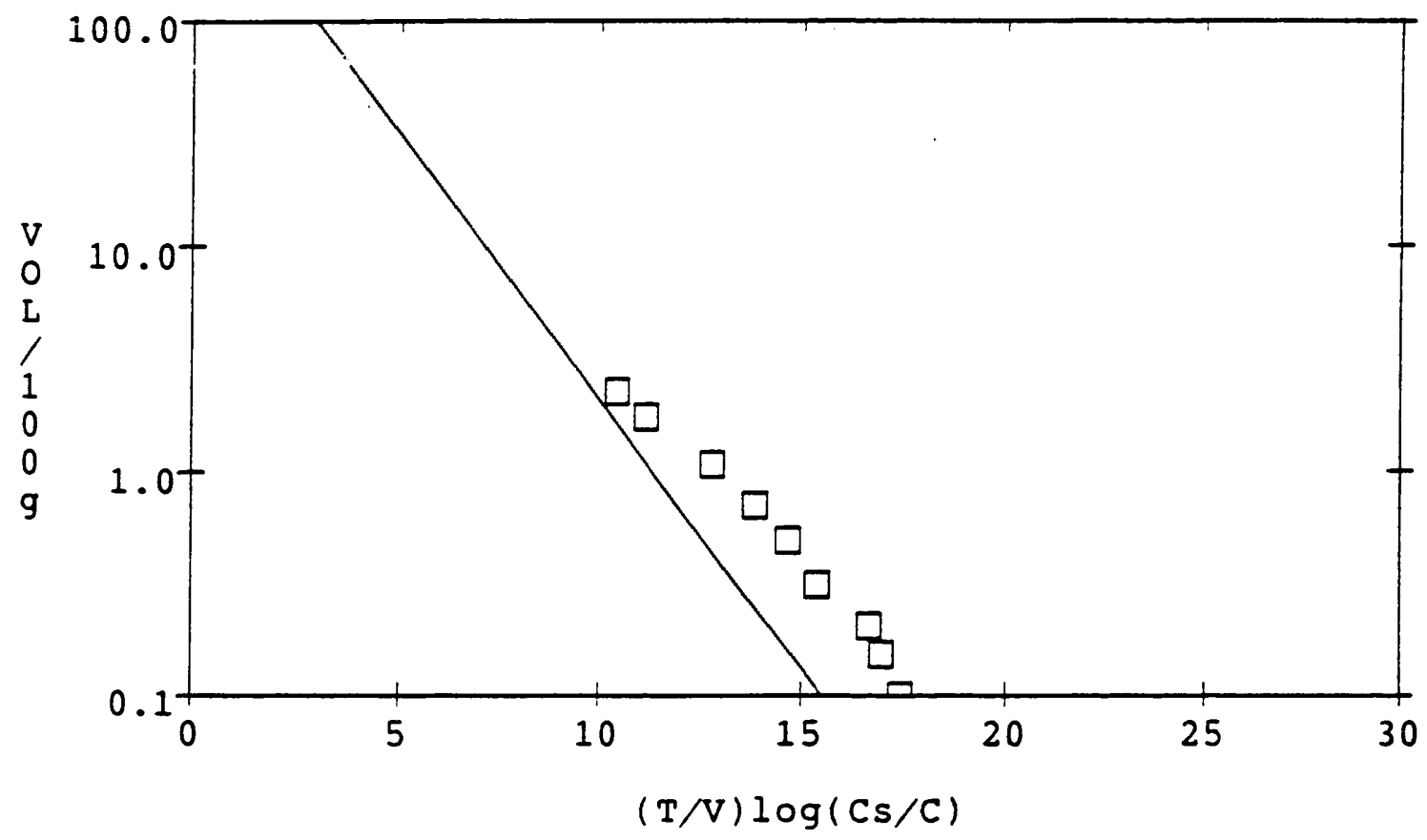

Figure 6.57 . TDASF prediction of Rong's TCE data. 
the theoretical (polarizability) scale factors. The substantial differences between the two $(\mathrm{AE}=1.21$ and 0.60$)$ indicates that this prediction method yields rather poor results in these instances.

\subsubsection{Regression Based Simulations}

In contrast, the fit depicted in Figure $6.58 \mathrm{a}$ and $\mathrm{b}$, in which experimental scale factors are applied, is fairly good $(A E=0.27$ and 0.24). So, as was the case with chloroform, it would be worthwhile to obtain at least one isotherm point for both carbon tetrachloride and PCE in addition to the data required to define the reference curve. The extra data points are required to employ experimental scale factors.

PCE and TCE adsorption isotherms were also included in the analysis of Speth's data. Figure $6.58 \mathrm{c}$ depicts the poor fit $(\mathrm{AE}=$ 0.63) obtained using Speth's scale factors on Kong's data. Since both Speth and Kong used F-400 carbon, the differences must be due to either batch to batch variability in carbon or differences in experimental technique.

Theoretically and experimentally derived scale factors, and the difference between them, are listed in Table 6.19. For comparison, Speth's data, using PCE instead of vinyl acetate as the reference, is also 1 isted.

As this data indicates, for Speth's data, the agreement between observed and predicted is very good for TCE (18 difference). Kong's experimental scale factors, on the other hand, are 10 and 148 from the predicted values. The differences are most likely due to 


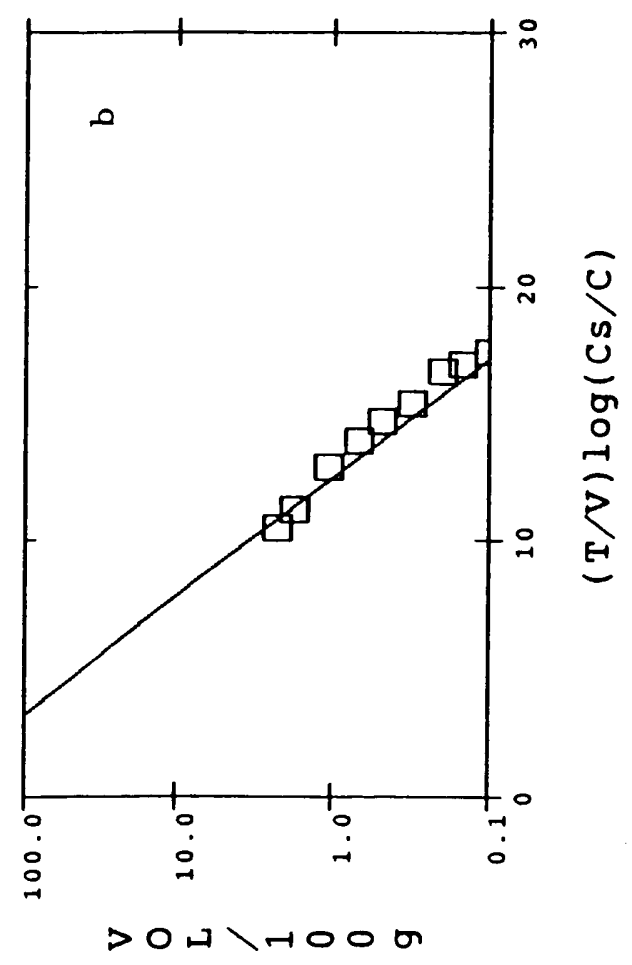

된

o

㸃

อิ

تٓ
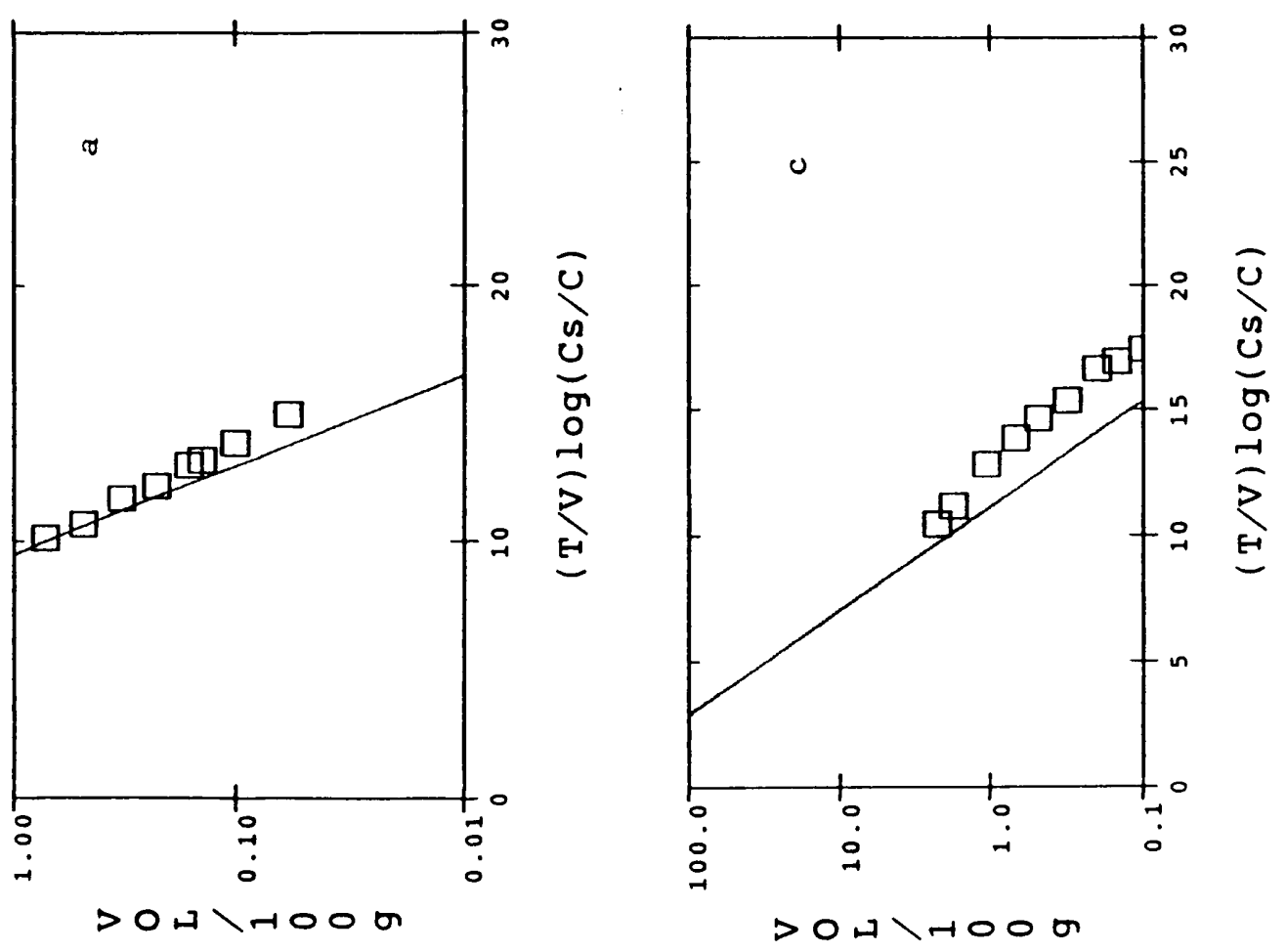

芩

$\pi$

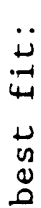

,

$\underbrace{\pi}_{0}$

站皆

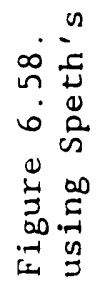


differences in experimental technique or variability in the carbon.

TABLE 6.19 ABSCISSA SCALE FACTORS THEORETICALLY AND EXPERIMENTALLY
DERIVED FROM SPETH'S AND KONG'S DATA

The goodness of fit is quantified in Table 6.20, which summarizes the average error.

TABLE 6.20 AVERAGE ERROR - KONG'S DATA

$\begin{array}{lrr} & \text { TDASF } & \text { EDASF } \\ \text { Carbon Tetrachloride } & 1.21 & 0.27 \\ \text { TCE } & 0.60 & 0.24 \\ \text { PCE } & & 0.16\end{array}$

Using Speth's scale factors

TCE

0.63

As indicated by the graphs, neither the theoretical nor speth's scale factors, produce accurate fits. The experimentally determined (via regression) scale factors work well.

As previously mentioned, correlation curves, which portray the characteristic curves after the abscissa scale factors are applied, are a good representation of the accuracy of the Polanyi predictions. If accurate scale factors are applied, a single curve should result. Figure 6.59 shows the poor results obtained when theoretical scale factors are applied. In contrast, the correlation curve created by 
applying experimental scale factors, Figure 6.60 , simulates a single curve. 


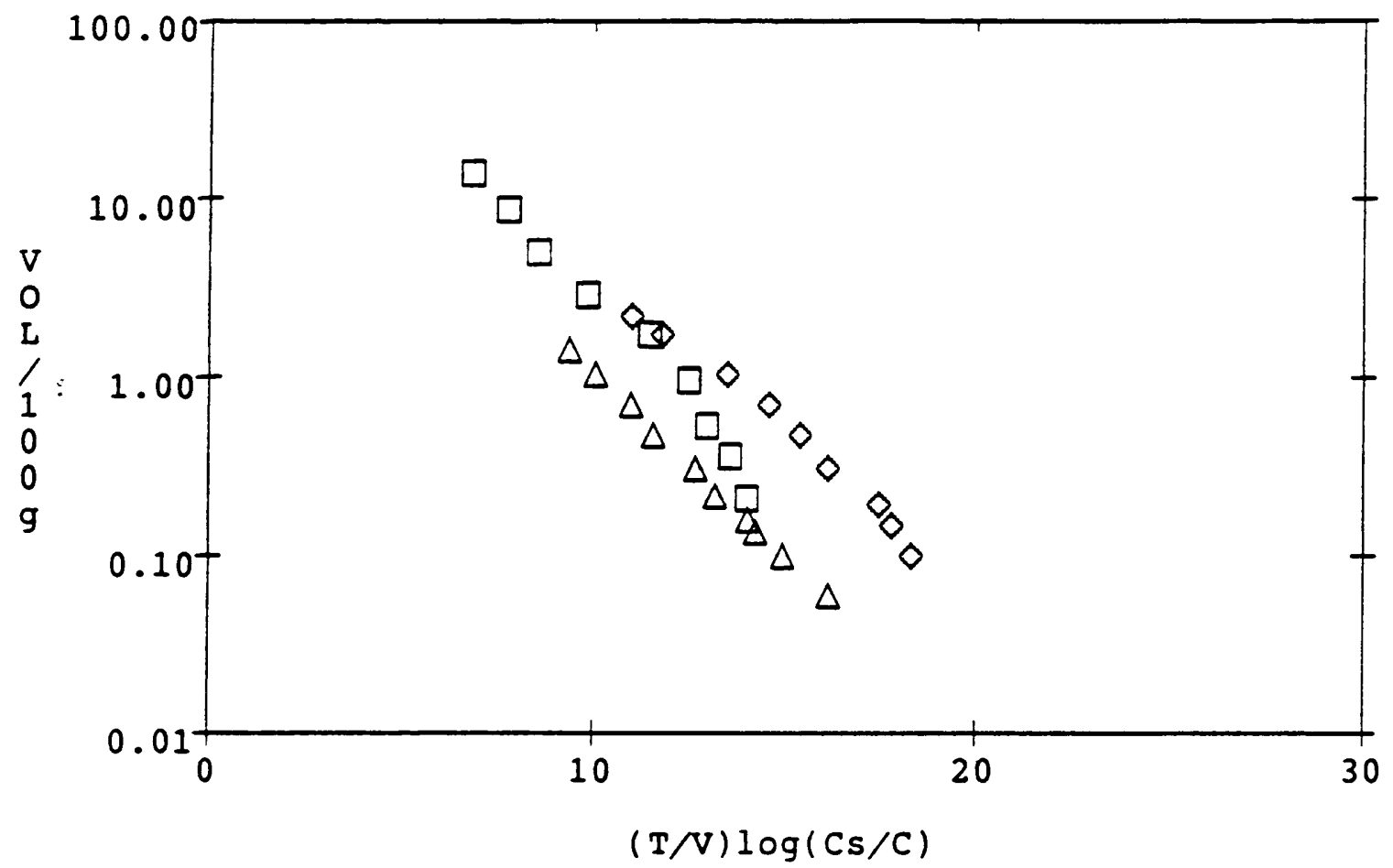

Figure 6.59. Correlation curve of Rong's data - adjusted using TDASF.

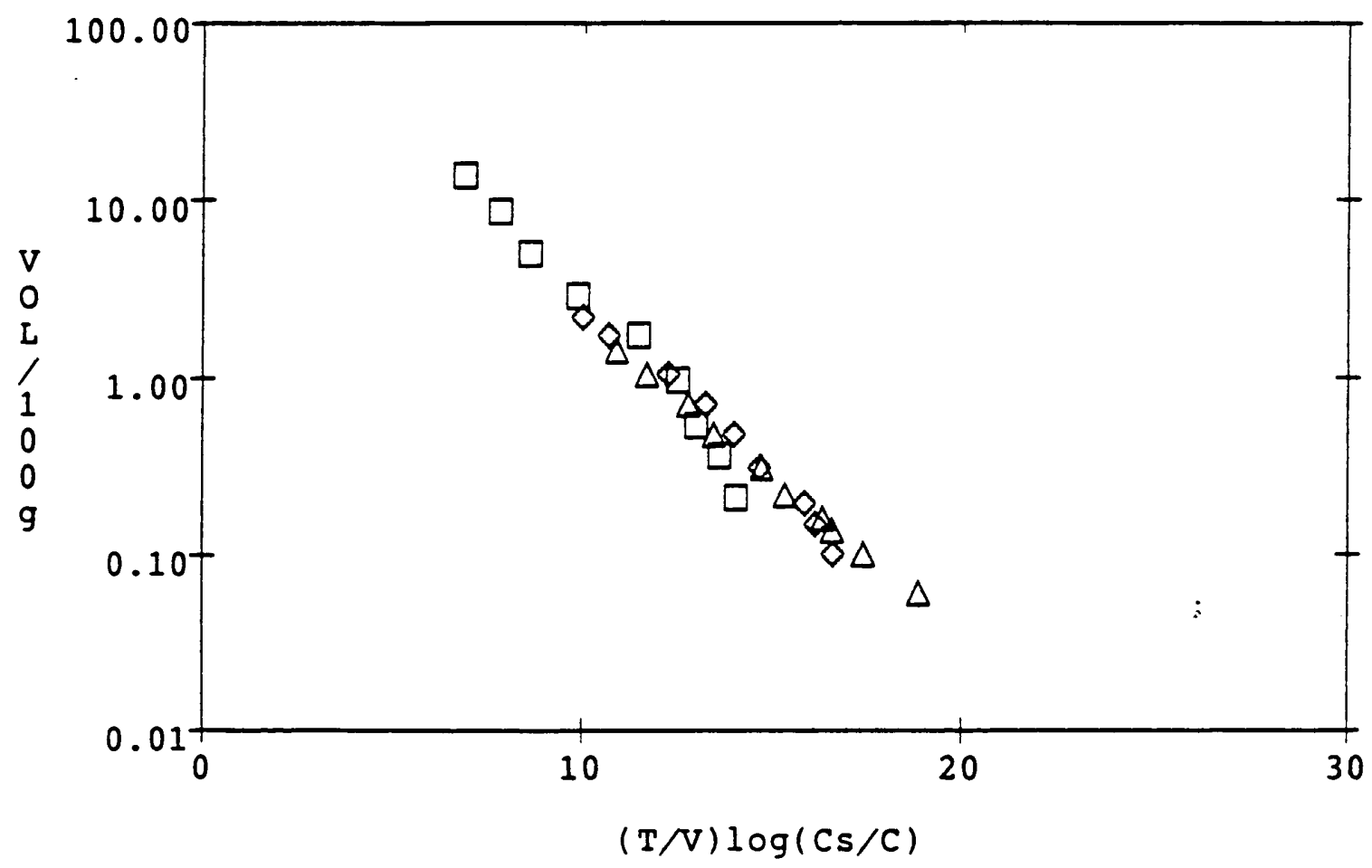

Figure 6.60. Correlation curve of Kong's data - adjusted using EDASF. 
6.6.4 Summary of the Analysis of Kong's Data

Kong's data supports earlier results which demonstrated the existence of a single curve, the characteristic curve, which, with the application of the proper scale factors, describes adsorption of all solutes on a carbon. As was the case in several previous instances, the TDASF yield a rather poor fit of the adsorption data.

In contrast, the EDASF once again proved quite effective at creating, after their application, a single correlation curve. So far, isotherm data from Speth, Fukuchi, Luft, van Vliet and now Kong has demonstrated the usefulness of these experimental (via regression) scale factors. 
6.6 EVALUATION OF THE POLANYI MODEL FOR NARBAITZ'S DATA

The purpose of this study was to assess the effectiveness of the Polanyi theory by examining adsorption isotherm data from a wide variety of sources. The final application of the theory will pertain to isotherm results of $\mathrm{Dr}$. Roberto Narbaitz on trichloroethylene and carbon tetrachloride.

This data, which was published in the Journal of the American Water Works Association (Amy at al, 1987), was obtained at Florida International University. The bottle point isotherm technique was, once again, employed. Experimental conditions are described in Table 6.21 .

TABLE 6.21 EXPERIMENTAL CONDITIONS (NARBAITZ)

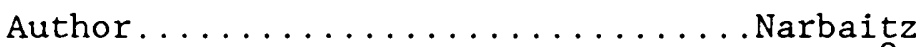

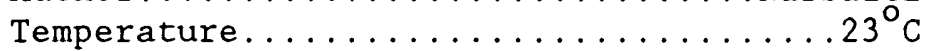

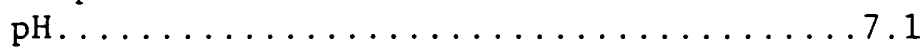
Carbon....................... -400 Mesh..................... Method of Analysis........Gas Chromatography Equilibration Time.............14 days

Relevant information on the two solutes is listed in Table 6.22.

TABLE 6.22 CHARACTERISTICS OF SOLUTES (NARBAITZ) COMPOUND MOL WT $\begin{array}{cc}\mathrm{DEN} & \mathrm{SOL} \\ (\mathrm{g} / \mathrm{mL}) & (\mathrm{mg} / \mathrm{L})\end{array}$ MP (C)

$\begin{array}{lrrrrrr}\text { Carbon Tetrachloride } & 153.84 & 1.594 & 807 & -23 & 1.4595 & 0.2736 \\ \text { TCE } & 131.40 & 1.464 & 1047 & -85 & 1.4755 & 0.2818\end{array}$

Note: MOL $W T=$ molecular weight $;$ DEN = density; SOL = solubility; $M P=$ melting point; INDEX = refractive index; $\mathrm{P}=$ polarizability. 


\subsubsection{Basic Characteristic Curve}

The characteristic curve of Narbaitz's raw data can be seen in Figure 6.61. Again, there is no good candidate to serve as a reference solute since only the lower concentration ranges are defined by the data. Since TCE covers a slightly wider range, it will be utilized as the reference compound. Figure 6.62 demonstrates the fit obtained when the following simple function is used to describe the TCE data:

$$
F(X)=157 * \exp (-0.4158 * X)
$$

Because the isotherm data covers such a limited range, the validity of the equation at higher concentrations is questionable.

\subsubsection{Theoretically Predicted Characteristic Curves}

Using this graph of TCE to determine the shape of the characteristic curve (within the experimental testing range), TDASF were then applied. To predict the characteristic curve of carbon tetrachloride from TCE's curve the slope term, -0.4158, of the reference curve is multiplied by this scale factor. Figure 6.63a demonstrates the difference between observed and predicted for carbon tetrachloride. As indicated, the theoretical scale factor provides a poor estimate of adsorption $(A E=3.96)$. 


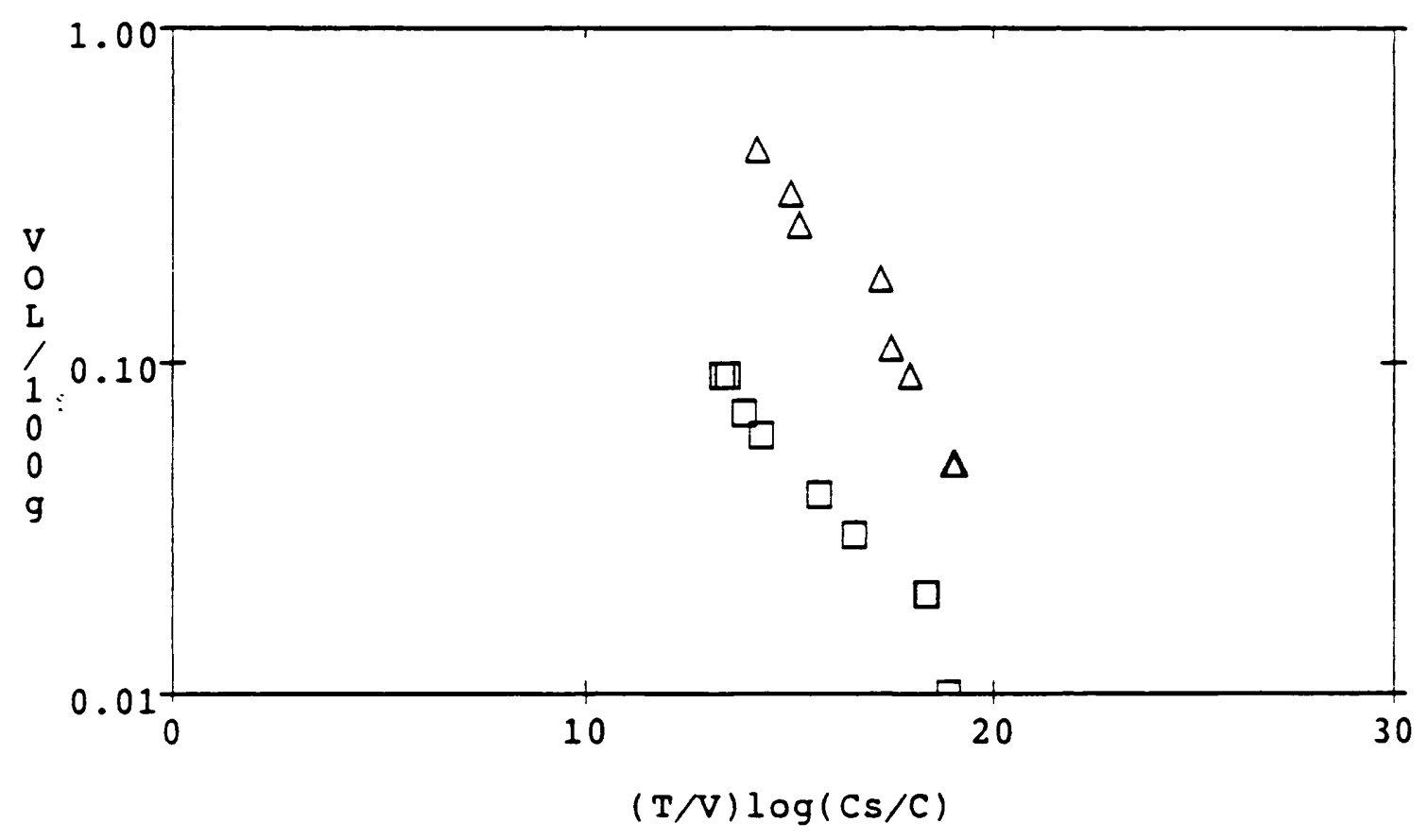

Figure 6.61. Characteristic curve

- Narbaitz'z raw data.

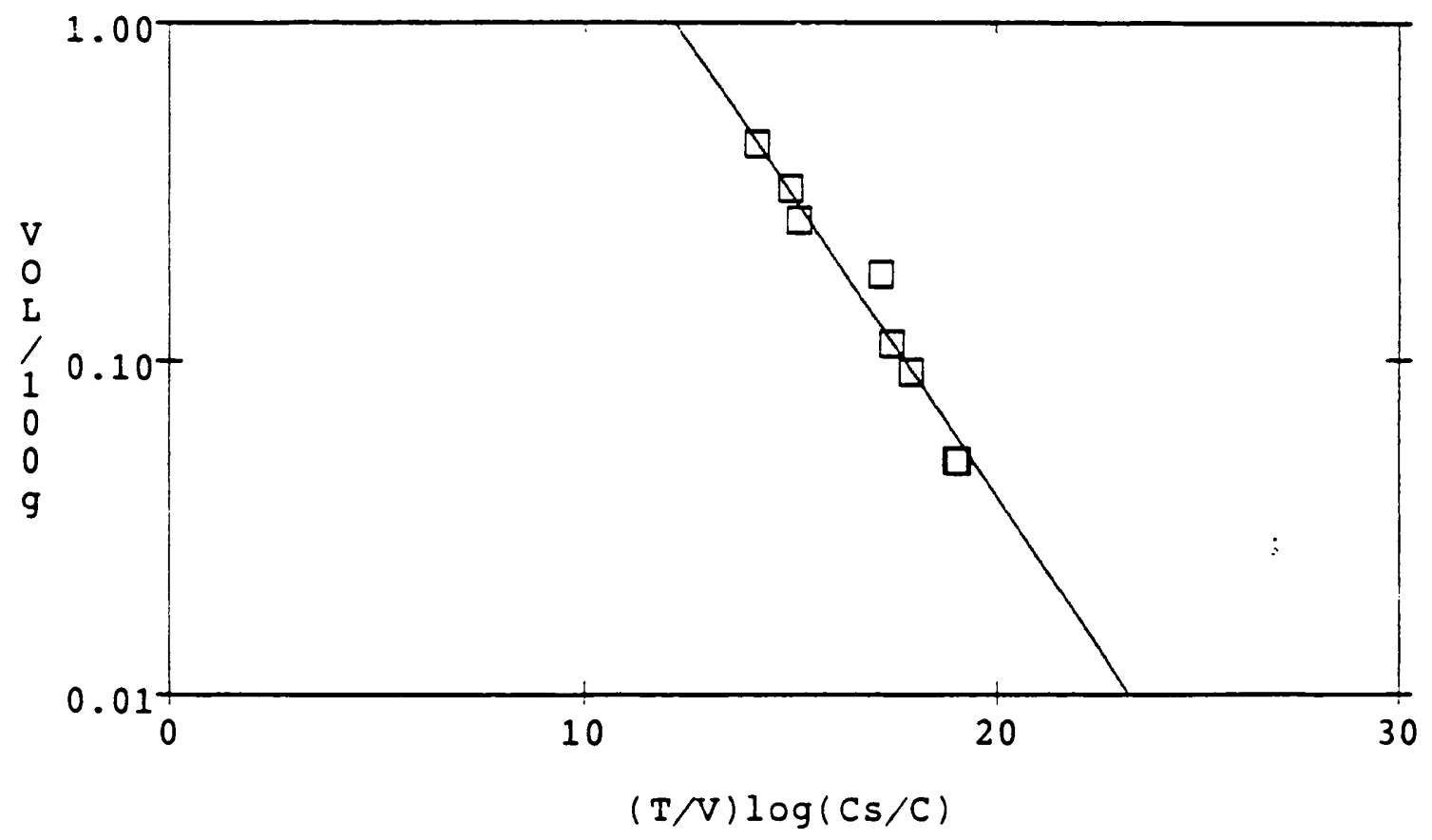

Figure 6.62. Narbaitz'a TCE data

- best fit reference curve. 

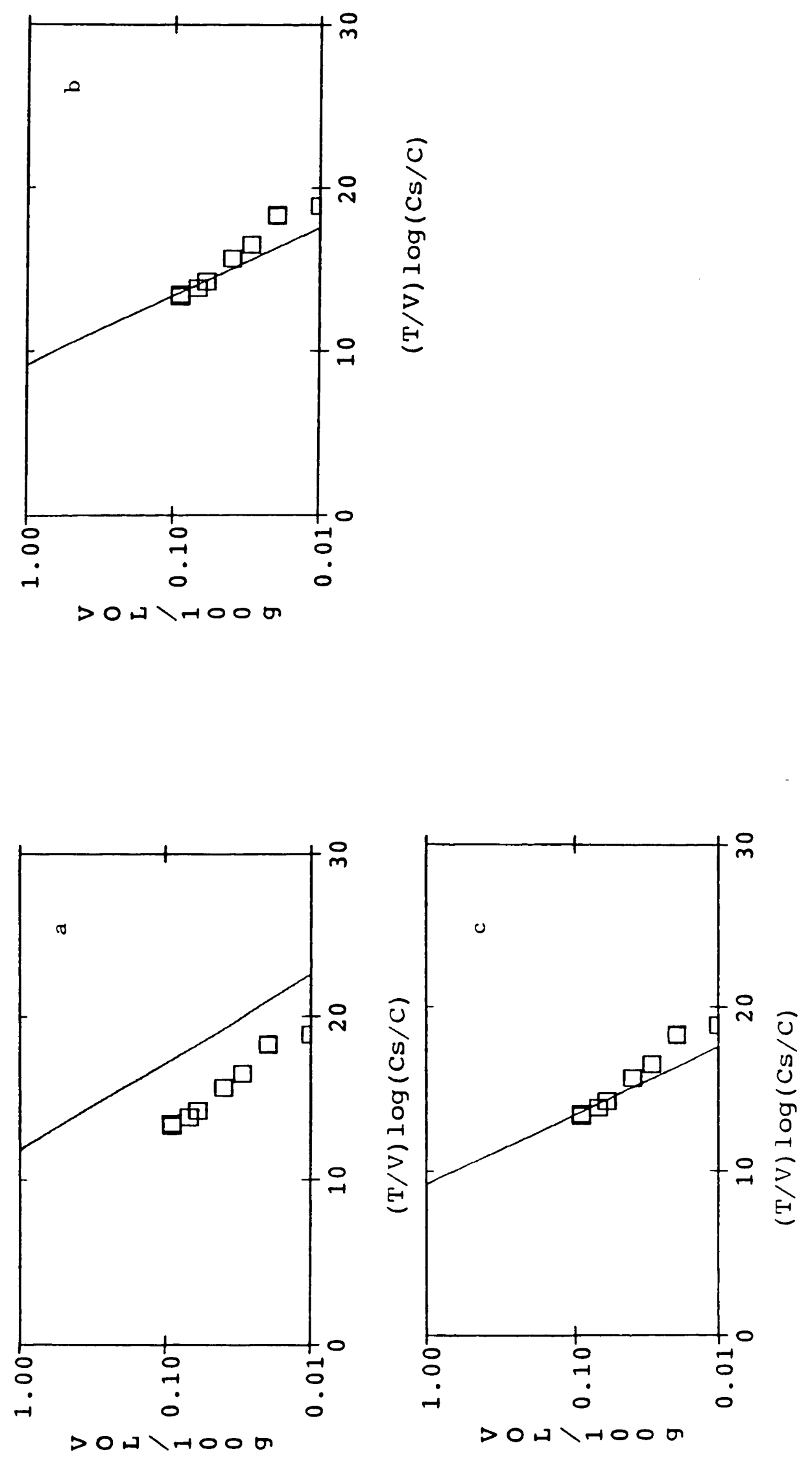

稌

as

ه

త్ర

항 क्ञ

委

넝

o

i do

도은

?

ชิ 0

a

iN

.

要

䓀

z

ลิ

m

ชै ह

०.

(1) 0

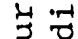

on 8

被范 


\subsubsection{Regression Based Characteristic Curve}

In contrast, Figure $6.63 \mathrm{~b}$ shows that a good simulation $(\mathrm{AE}=$ 0.34 ) is possible when the EDASF (obtained by regression) is employed, although the model slightly overestimates adsorption at the lower concentrations. So, as was the case with chloroform, it would seem worthwhile to obtain at least one isotherm point on carbon tetrachloride in addition to that required to define the reference curve. The extra data point would be used to determine the EDASF.

Carbon tetrachloride and TCE adsorption isotherms were also performed by Kong. Figure $6.63 \mathrm{c}$ depicts the fit obtained when Kong's scale factor is applied to Narbaitz's carbon tetrachloride data. The similarity between Figures $6.63 \mathrm{~b}$ and $\mathrm{c}$ testify to the similarity of technique used by both authors. Also, the carbon, which in both cases was F-400, had to demonstrate little batch to batch variability.

Theoretically and experimentally derived scale factors, and the difference between them, are listed in Table 6.23. For comparison, Kong's data, using TCE instead of PCE as the reference, is also listed. These figures point out the shortcomings associated with the use of theoretical scale factors as a predictor of adsorption of carbon tetrachloride.

The average error is listed in Table 6.24. These figures confirm the poor fit of carbon tetrachloride which results with the TDASF $(A E=3.96)$. The TCE fit is excellent $(\mathrm{AE}=0.09)$ indicating that the simple exponential function describes well the sorption of TCE. The value associated with carbon tetrachloride's fit, 0.34 , reflects the underestimation of the degree of adsorption which occurs 
TABLE 6.23 ABSCISSA SCALE FACTORS THEORETICALLY AND EXPERIMENTALLY DERIVED FROM KONG'S AND NARBAITZ'S DATA

SCALE FACTORS

TDASF EDASF
1.030
1.323
22.19

KONG's Results

Carbon Tetrachloride

$1.030 \quad 1.321$

22.06

\& Diff

TABLE 6.24 AVERAGE ERROR - NARBAITZ'S DATA

COMPOUND

Carbon Tetrachloride

TCE

Using KONG's scale factors TDASF

3.957

1.000
EDASF

0.335

0.087

0.337

Carbon Tetrachloride 
in the low concentration range. The fact that Kong's scale factor produces the same average error emphasizes the similarity between Kong's and Narbaitz's data.

The correlation curves, which portray the characteristic curves after the abscissa scale factors are applied, should result in a single curve, with little variability if accurate scale factors are applied. Figure 6.64 shows the poor results obtained when theoretical scale factors are applied. In contrast, the data in Figure 6.65 , the correlation curve created by applying EDASF, is concentrated in a narrow range. 


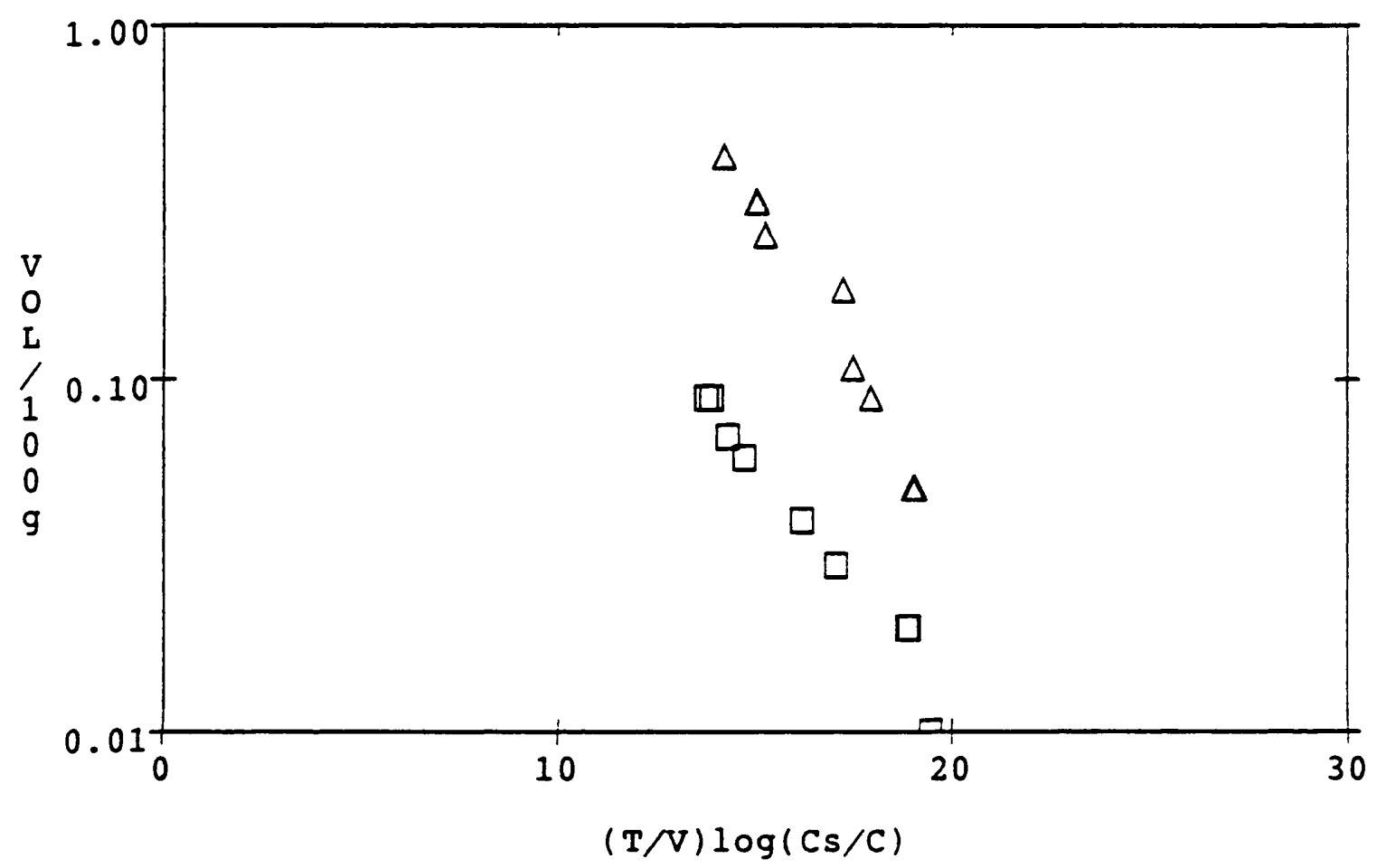

Figure 6.64. Correlation curve of Narbaitz's data - adiusted usinq TDASF.

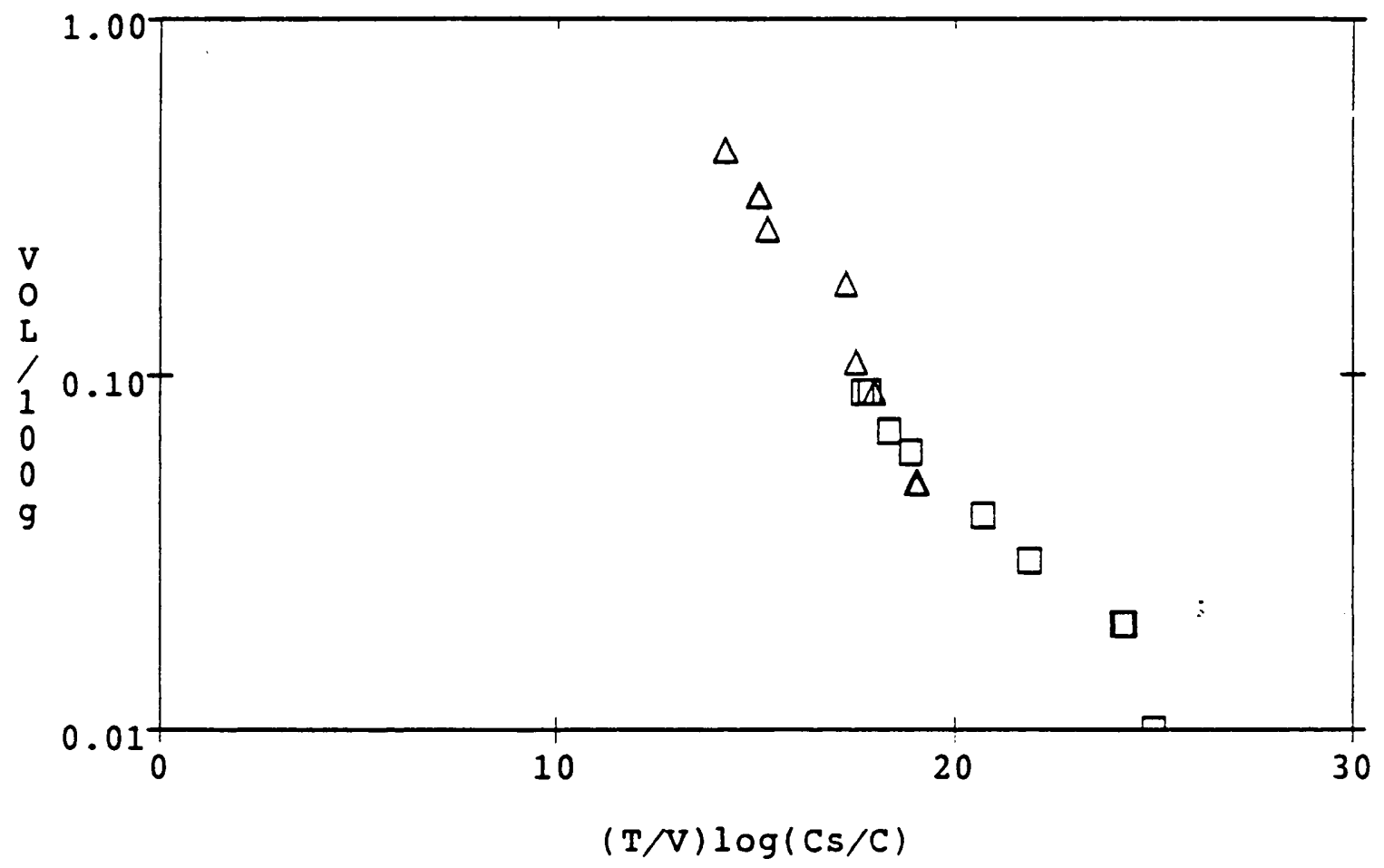

Figure 6.65. Correlation curve of Narbaitz's data

- adjusted using EDASF. 
6.6.4 Summary of the Analysis of Narbaitz's Data

Narbaitz's isotherm results add further support to the existence of a characteristic curve. Experimental scale factors worked fairly well; however, the use of theoretically determined scale factors, as was the case in several previous instances, resulted in a rather poor fit of the experimental data.

A simple exponential model simulated the TCE data well, although the low concentration ranges are slightly underestimated for carbon tetrachloride. The fit is sufficiently accurate for practical purposes. Narbaitz's isotherm results are consistent with those of Kong. Since both authors used F-400 carbon this isn't unexpected. However when, as reported in section 6.5 , Kong's results and those of Speth on PCE and TCE were quite different. As mentioned, batch to batch variability in carbon, or differences in experimental technique could be the cause of the differences between Speth's and Kong's data. 


\subsection{SUMMARY OF EVALUATIONS}

Table 6.25 contains a list of all solutes analyzed in this study. Although 22 different solutes were examined, this number pales in comparison to the number of pollutants which are candidates for carbon adsorption. Analysis of all of these chemicals is not only beyond the scope of this study but is virtually impossible. Hopefully, sufficient data was analyzed to determine if the Polanyi theory is worthy of greater consideration as an alternative to laboratory batch experiments.)

TABLE 6.25 SOLUTES ANALYZED

COMPOUND

Acetone

Benzoic Acid

Bromoform

n-Butanol

Carbon Tetrachloride

CDBM

Chloroform

p-Chlorophenol

cis-DCE

DBE

Ethylbenzene

MEK

PCE

Phenol

2 - Propanol

Propionitrile

Pyridine

TCE

Toluene

Vinyl Acetate

m-Xylene

o-Xylene
Fukuchi (F-400)

Fukuchi (F-400)

Speth (F-400) Luft (F-400, HD-3000,WV-G)

Fukuchi (F-400)

Narbaitz (F-400) Kong (F-400)

Speth $(F-400)$

Speth (F-400) Luft (F-400, HD-3000,WV-G)

Fukuchi (F-400) van Vliet (F-400, BACM)

Speth $(F-400)$

Speth $(F-400)$

Speth $(F-400)$

Fukuchi (F-400)

Speth (F-400) Kong (F-400)

Fukuchi (F-400) van Vliet (F-400,BACM)

Fukuchi (F-400)

Fukuchi (F-400)

Fukuchi (F-400)

Speth (F-400) Luft (F-400, HD-3000, WV-G)

Kong (F-400) Narbaitz (F-400)

Speth $(F-400)$

Fukuchi (F-400)

Speth $(F-400)$

Speth $(F-400)$

The first step in applying the Polanyi theory is choosing a 
reference solute. Since this reference curve defines the shape of the characteristic curve, it should be well defined with data points covering the entire concentration range. A problem commonly encountered in this study was finding a suitable candidate to serve in this capacity. Typically, an experimenter only tests the lower concentration levels when performing adsorption isotherms since contaminants are usually present in these dilute concentrations. A compromise was reached, wherein the solute which covered the widest range was chosen as the reference. This is acceptable as long as extrapolation outside of the data range is avoided. As it turned out, data for the other solutes was generally within the same range of the reference curve; so, the predicted curves validity was not jeopardized.

Speth's adsorption data was unique in that, although no one compound covered the entire concentration range, a well defined reference curve was created by simply plotting the characteristic curve of all compounds. This phenomena is not unexpected if the compounds in question are not too varied in their physical properties. This reference characteristic curve created by Speth's overall data performed quite well.

After the reference solute is chosen, it was defined by a mathematical function. Although earlier applications of the Polanyi theory used a third degree polynomial to describe the data (Wohleher, 1970), this function proved ineffective in this analysis. Rather a simple exponential equation generally yielded a good fit to the data. This is in agreement with earlier reports (Gu and Manes, 1982) which suggest that adsorption is linear in dilute 
concentrations. In most cases, in this study, the fit was indeed based upon the low concentration data available, although the equation also worked well for concentrated solutions.

However, there were instances where an exponential with a constant provided a better fit of the experimental data. Table 6.26 list the average error which resulted when both the simple exponential and the exponential with a constant models were used to describe the data. As this table indicates, when experimental scale factors are utilized the exponential with a constant model yielded a better fit for some compounds (Speth's bromoform $\mathrm{AE}=0.08$ ). However, the fit was very poor for other solutes (Speth's chloroform $\mathrm{AE}=2.64)$

TABLE 6.26 COMPARISON OF AE WHEN BOTH SIMPLE EXPONENTIAL AND EXPONENTIAL WITH CONSTANT MODELS WERE USED

\begin{tabular}{|c|c|c|c|c|c|}
\hline \multirow[b]{2}{*}{ COMPOUND } & \multirow[b]{2}{*}{ AUTHOR } & \multicolumn{2}{|c|}{ TDASF } & \multicolumn{2}{|c|}{ EDASF } \\
\hline & & $\exp$ & $\begin{array}{l}\exp w / \\
\text { const }\end{array}$ & $\exp$ & $\begin{array}{l}\exp w / \\
\text { const }\end{array}$ \\
\hline Bromoform & Speth $(F-400)$ & 0.30 & 0.60 & 0.19 & 0.08 \\
\hline Bromoform & Luft $(F-400)$ & 0.11 & 0.11 & 0.11 & 0.11 \\
\hline Bromoform & Luft (HD-3000) & 0.08 & 0.03 & 0.08 & 0.03 \\
\hline Bromoform & Luft $(W V-G)$ & 0.06 & 0.04 & 0.06 & 0.04 \\
\hline CDBM & Speth $(F-400)$ & 0.10 & 0.15 & 0.10 & 0.07 \\
\hline Chloroform & Speth $(F-400)$ & 0.26 & 3.76 & 0.10 & 2.64 \\
\hline Chloroform & Luft $(F-400)$ & 0.64 & 0.64 & 0.19 & 0.19 \\
\hline Chloroform & Luft (HD-3000) & 0.74 & 2.92 & 0.07 & 0.69 \\
\hline Chloroform & Luft $(W V-G)$ & 0.82 & 2.14 & 0.08 & 0.85 \\
\hline cis-DCE & Speth $(F-400)$ & 0.15 & 1.09 & 0.10 & 0.11 \\
\hline $\mathrm{DBE}$ & Speth $(F-400)$ & 0.09 & 0.13 & 0.10 & 0.13 \\
\hline Ethylbenzene & Speth $(F-400)$ & 0.09 & 0.17 & 0.09 & 0.09 \\
\hline PCE & Speth $(F-400)$ & 0.19 & 0.26 & 0.19 & 0.17 \\
\hline TCE & Speth $(F-400)$ & 0.08 & 0.23 & 0.08 & 0.28 \\
\hline TCE & Luft $(F-400)$ & 0.37 & 0.37 & 0.45 & 0.45 \\
\hline TCE & Luft (HD-3000) & 0.22 & 1.00 & 0.23 & 0.87 \\
\hline TCE & Luft $(W V-G)$ & 0.59 & 0.70 & 0.68 & 0.80 \\
\hline Toluene & Speth $(F-400)$ & 0.16 & 0.03 & 0.02 & 0.03 \\
\hline m-Xylene & Speth $(F-400)$ & 0.11 & 0.07 & 0.06 & 0.03 \\
\hline o-Xylene & Speth $(F-400)$ & 0.11 & 0.11 & 0.14 & 0.08 \\
\hline AVERAGE & & 0.26 & 0.73 & 0.16 & 0.39 \\
\hline
\end{tabular}


When theoretical scale factors are used the problems encountered when using the exponential with a constant model were even more pronounced. For example, Speth's chloroform and cis-DCE, as well as Luft's chloroform and TCE all demonstrated a much better fit when the simple exponential was used when applying the theoretical scale factors. It seems that adding a constant to the exponential equation makes its shape more inflexible and less able to fit the experimental data. The simple exponential model seems preferable.

The data examined in this study seems to indicate that, although theoretical abscissa scale factors work well for many solutes, their performance is quite poor on others. In contrast, the experimental scale factors performed well on all compounds except TCE. Table 6.27 list the average error of several solutes (excluding solids) whose theoretical predictions provided a poor fit to the actual data. The corresponding results using experimental scale factors are also listed. As this data indicates, theoretical scale factors encountered difficulty with five of the twenty two solutes analyzed in this project. Perhaps the incidence of inaccurate predictions is too high to allow use of the theoretical abscissa scale factors. EDASF, on the other hand performed very well. Speth's bromoform and PCE data, as well as Fukuchi's MEK and 2-propanol, indicate single data points, if properly selected, will yield accurate EDASF.

Luft's TCE data, on three different carbons, did not seem to fit the reference characteristic curve in the low concentration range. This could indicate that TCE does not conform to the 
characteristic curve of the other compounds, or, more likely, it may be an artifact of experimental technique. Results of Speth, Kong and Narbaitz support the latter explanation in that their data did not demonstrate this problem. Overall, the effectiveness of the experimental scale factors supports the existence of a characteristic curve which does indeed describe adsorption of all compounds on a carbon.

TABLE 6.27 AVERAGE ERROR IN INSTANCES WHERE SCALE FACTORS PERFORMED POORLY

COMPOUND

Acetone
Carbon Tetr
Carbon Tetr
Chloroform
Chloroform
Chloroform
Pyridine
TCE
TCE
TCE

AVERAGE
TDASF

EDASF

Fukuchi (F-400)

0.60

1. 21

3.96

0.64

0.74

0.82

0.51

0.37

0.59

0.60

1.00

0.25

For compounds which exist as solids at the isotherm temperature, the abscissa scale factors alone will not force the characteristic curves to coincide with the correlation curve. In such cases, an additional adjustment is required to compensate for the inefficient pore packing of these solids. This density adjustment must be empirically derived. This study tested three such solids - benzoic acid, p-chlorophenol and phenol. The analysis 
of Fukuchi's isotherm data indicated that, after the density adjustments are applied, these solutes do indeed fall on the correlation curve. Additionally, when the density adjustment is applied to both axes, the isotherm data comes quite close to the curve predicted by theoretical scale factors. Van Vliet's data on p-chlorophenol and phenol, using F-400 and BACM carbons, provides hope that density adjustments, determined on one carbon, are valid on other carbons.

To assess the effectiveness of the Polanyi theory, one need only examine the correlation curves obtained after the abscissa scale factors have been applied. If a single curve is created, the scale factors are effective and the characteristic curve concept is validated. The correlation curves obtained on the various researcher's isotherm data using EDASF attest to the effectiveness of the Polanyi theory at describing adsorption.

It should be mentioned that the Polanyi equilibrium theory ascribes adsorption to physical, or van der Waals, forces whose primary influence exist within the pores of the carbon. Chemical adsorption, which is primarily caused by a solute's reaction with functional groups present at the edges of the carbon planes, may not be accurately depicted by the theory. Studies indicate that these functional groups may be carbonyl and carboxyl groups (Mattson, 1969) which react by donating electrons. A compound such as phenol, whose ring would act as the recipient of such electrons, is a likely candidate for chemical adsorption.

However, since its adsorption can be accurately described by the Polanyi theory, either the density adjustments applied 
compensate for of the chemisorption, or phenol must also be subject to physical adsorption. If the latter is true, the effects of physical should far outweigh those of chemical adsorption because available physical adsorption sites far outnumber the functional groups. In cases where only chemical adsorption occurs, the Polanyi plot would most likely result in a low $Y$ intercept (limiting adsorbate volume).

Further, if steric hindrance, caused by a molecule's size and/or orientation, prevents access to the smaller pores, which contain the majority of a carbon's surface area, adsorption will be less than expected and the maximum adsorbate volume, for that solute, should not match that of smaller molecules. Neither chemical adsorption nor steric hindrance seemed to pose problems with the solutes analyzed in this study.

In conclusion, the evidence examined herein generally supports the existence of a characteristic curve which, after the application of certain scale factors, describes the adsorption of all compounds on a carbon. Although the predicted scale factors demonstrated some difficulty with certain solutes, the empirically derived scale factors performed quite well. The purpose of this study was to assess the Polanyi theory's predictive abilities and, in terms of its potential as a predictive model, and, although EDASF described the adsorption data we11, TDASF, which would make the model truly predictive, proved inadequate in several instances. Although the data of Speth, Fukuchi, Luft, van Vliet, Kong and Narbaitz seems to support the underlying principles of the theory, further study, on more compounds, is required before an absolute determination on the 
theory's effectiveness can be realized. 


\section{CHAPTER 7}

CONCLUSION

1. The fact that the correlation curves created using EDASF simulate a single curve supports the existence of a characteristic curve which describes the adsorption of all compounds on a carbon.

2. The basic Polanyi model, using only molar volume as a scale factor, yielded relatively poor predictions of most data sets. Only in the case of Speth's data, which compared fairly similar compounds, were good predictions possible.

3. The curves predicted using polarizability, although effective for many solutes, did not, in several instances, accurately describe the data. The Polanyi model thus has severe limitations as a predictive model.

4. In contrast, the curves resulting from scale factors obtained by regressing the experimental data provided good fits to this data. The analysis of Speth's bromoform and PCE, as well as Fukuchi's MEK and 2-propanol indicates that a single point from each solute could be used to determine these scale factors thus saving considerable time; however, as Speth's PCE data demonstrated, the choice of data point can drastically affect the EDASF's accuracy in cases where there are large deviations from the regression curve.

5. For the solutes which are present as solids under the experimental conditions, it was found that the regression based density adjustment of 
the abscissa, proposed by Manes (1974), improved the Polanyi model's simulations; however, the author found substantially better simulations were possible if the density was adjusted on both the ordinate and the abscissa.

6. The analysis of Luft's and van Vliet's data indicates that scale factors determined on one carbon may be useful on others. This adds greatly to the model's usefulness.

7. Analysis of data from different researchers has certain hazards. Differences in technique (and carbons) can greatly affect results, although there were cases where the data matched very well. 


\section{CHAPTER 8}

\section{ENGINEERING APPLICATIONS}

The preceding analysis of the Polanyi Equilibrium Theory has demonstrated that the theory can effectively describe adsorption isotherm data. Since the Polanyi model attributes adsorption to van dex Waals forces, the accuracy of the data simulations contained herein supports the claim that physical forces are, in fact, the primary mechanism of adsorption. This knowledge, although academically important, does not, in itself, yield practical engineering significance. Further, the failure, in several instances, of TDASF to predict adsorption considerably limits its abilities as a truly predictive model.

However, the application of EDASF did, as opposed to TDASF, yield results consistent with the experimental data. If these scale factors can be estimated from a single data point of each solute, a considerable reduction in the amount of time, and money, spent on laboratory testing will result. The analysis of Speth's bromofrom and PCE, as well as Fukuchi's MEK and 2-propanol, data generally supports this claim.

Once determined these EDASF can be utilized to generate the isotherm data required to estimate the minimum carbon requirements in a particular application. The data can also be combined with predictive kinetic models to provide information on the size and configuration of the carbon columns. In many smaller applications, the plant size does not economically warrant extensive testing to determine the optimum configuration. In such cases adsorbers are often designed, with a safety factor, using equilibrium models.

The theory's usefulness is greatly enhanced if, as Luft's data 
demonstrated, the information obtained on one carbon can successfully be applied to others. The proper choice of carbon can then be determined by performing a complete Polanyi analysis on one carbon (a well defined reference curve and one data point on each solute), and then obtaining isotherm data points (as few as two) on the reference compound using the other carbons. 
APPENDIX A

SAMPLE CALCULATIONS 
Compound

Index of Refraction, $n$

Molecular Weight, mw

Density (den)

Solubility, Cs

Equilibrium Concentration, C

Temperatuure, $\mathrm{T}$

Best Fit of Regression Equation

$\mathrm{Y}=\mathrm{a} * \exp (\mathrm{b} * \mathrm{X})$

Reference Compouund

Index of Refraction, $\mathrm{n}$

Best Fit of Regression Equation

$Y=a * \exp (b * X)$ bromoform

1.596

252.77

$2.894 \mathrm{~g} / \mathrm{mL}$

$6934 \mathrm{mg} / \mathrm{L}$

$3400 \mathrm{mg} / \mathrm{L}$

298 K

chloroform

1.446

$\mathrm{Y}=127.6 * \exp (-.3452 * \mathrm{X})$

1) To determine Polarizability, P:

$$
\begin{aligned}
& P=\left(n^{2}-1\right) /\left(n^{2}+2\right) \\
& P_{i}=\left(1.596^{2}-1\right) /\left(1.596^{2}+2\right) \\
& P_{i}=.3403 \\
& P_{r}=\left(1.446^{2}-1\right) /\left(1.442^{2}+2\right) \\
& P_{r}=0.267
\end{aligned}
$$


2) To determine TDASF:

$$
\begin{aligned}
& \text { TDASF }=P_{r} / P_{i} \\
& \text { TDASF }=0.267 / 0.3403 \\
& \text { TDASF }=0.785
\end{aligned}
$$

3) To determine EDASF:

$$
\begin{aligned}
& \text { EDASF }=B_{i} / B_{r} \\
& \text { EDASF }=-0.2723 /-0.3452 \\
& \text { EDASF }=0.789
\end{aligned}
$$

4) To predict the bromoform curve from chloroform data multiply the b value of the reference curve by TDASF:

$$
\begin{aligned}
& \mathrm{b}_{\text {pred }}=\text { TDASF } * \mathrm{~b}_{\text {ref }} \\
& \mathrm{b}_{\text {pred }}=0.785 *(-0.3452) \\
& \mathrm{b}_{\text {pred }}=-.271
\end{aligned}
$$

Predicted Curve $=127.6 * \exp (-.271 * \mathrm{X})$ 
APPENDIX B ISOTHERM DATA 
APPENDIX B

ISOTHERM DATA

$\begin{array}{cc}\begin{array}{l}\text { Isotherm - } \\ \text { Experimenter } \\ \text { Carbon - }\end{array} & \begin{array}{l}\text { Bromoform } \\ \text { Speth } \\ \text { F-400 }\end{array} \\ \text { Ce } & \text { qe } \\ \text { (ug/L) } & \text { (ug/g) } \\ 1971 & 123200 \\ 1720 & 121300 \\ 1320 & 110100 \\ 949 & 87690 \\ 1160 & 94400 \\ 917 & 82540 \\ 702 & 71080 \\ 565 & 66480 \\ 575 & 63320 \\ 488 & 58870 \\ 368 & 49120 \\ 315 & 44940 \\ 285 & 42670 \\ 166 & 32320 \\ 238 & 38250 \\ 157 & 31300 \\ 92 & 23850 \\ 79 & 20560 \\ 48 & 16340 \\ 38 & 13880 \\ & \end{array}$


Isotherm -

Experimenter -

Carbon -

$\begin{array}{rl}\begin{array}{l}\text { Ce } \\ (\mathrm{ug} / \mathrm{L})\end{array} & \begin{array}{l}\mathrm{qe} \\ (\mathrm{ug} / \mathrm{g})\end{array} \\ 1971 & 123200 \\ \mathrm{~s} & 121300 \\ 1720 & 110100 \\ 1320 & 87690 \\ 949 & 94400 \\ 1160 & 82540 \\ 917 & 71080 \\ 702 & 66480 \\ 565 & 63320 \\ 575 & 58870 \\ 488 & 49120 \\ 368 & 44940 \\ 315 & 42670 \\ 285 & 32320 \\ 166 & 38250 \\ 238 & 31300 \\ 157 & 23850 \\ 92 & 20560 \\ 79 & 16340 \\ 48 & 13880\end{array}$

Bromoform

Speth

F-400 
Isotherm -

Experimenter Carbon -

$\begin{array}{rl}\begin{array}{l}\text { Ce } \\ (\mathrm{ug} / \mathrm{L})\end{array} & \begin{array}{l}\mathrm{qe} \\ (\mathrm{ug} / \mathrm{g})\end{array} \\ 1094 & 43580 \\ 695 & 44020 \\ 480 & 32330 \\ 787 & 39610 \\ 599 & 37140 \\ 509 & 32040 \\ 441 & 31000 \\ 383 & 28250 \\ 361 & 26120 \\ 299 & 25050 \\ 334 & 25010 \\ 260 & 22790 \\ 260 & 21090 \\ 237 & 20670 \\ 205 & 18730 \\ 209 & 19140 \\ 159 & 16780 \\ 145 & 15470 \\ 124 & 14190 \\ 106 & 12780\end{array}$

Chlorodibromome thane

Speth

F- 400

$\begin{array}{cc}\begin{array}{c}\text { Ce } \\ (\mathrm{ug} / \mathrm{L})\end{array} & \begin{array}{c}\mathrm{qe} \\ (\mathrm{ug} / \mathrm{g})\end{array} \\ 1829 & 78500 \\ 1818 & 54670 \\ 1667 & 49600 \\ 1300 & 52850 \\ 1096 & 48300 \\ 925 & 43690 \\ 894 & 38680 \\ 751 & 38530 \\ 537 & 34090 \\ 554 & 31770 \\ 470 & 30970 \\ 378 & 28380 \\ 277 & 24160 \\ 222 & 21890 \\ 203 & 19820 \\ 157 & 17430 \\ 160 & 16880 \\ 133 & 15370 \\ 104 & 14330 \\ 92 & 12310\end{array}$




$\begin{array}{cc}\begin{array}{c}\text { Isotherm - } \\ \text { Experimenter } \\ \text { Carbon - }\end{array} & \begin{array}{l}\text { Chloroform } \\ \text { Speth } \\ \text { F-400 }\end{array} \\ \begin{array}{c}\text { Ce } \\ \text { (ug/L) }\end{array} & \begin{array}{c}\text { qe } \\ \text { (ug/g) }\end{array} \\ 1180 & 11850 \\ 1050 & 9920 \\ 725 & 9890 \\ 478 & 8400 \\ 357 & 7300 \\ 308 & 6020 \\ 203 & 4750 \\ 156 & 4240 \\ 116 & 3600 \\ 82 & 3020 \\ 61 & 2460 \\ 94 & 2000 \\ 26 & 1710 \\ 23 & 1410 \\ 15 & 1210 \\ 11 & 1010 \\ 8 & 865 \\ 3 & 718\end{array}$


Isotherm -

Experimenter -

Carbon -

$\begin{array}{rr}\begin{array}{l}\text { Ce } \\ (\mathrm{ug} / \mathrm{L})\end{array} & \begin{array}{c}\mathrm{qe} \\ (\mathrm{ug} / \mathrm{g})\end{array} \\ 1260 & 24800 \\ 1100 & 21800 \\ 973 & 18100 \\ 866 & 15500 \\ 819 & 16300 \\ 640 & 14700 \\ 610 & 13800 \\ 504 & 12400 \\ 436 & 11400 \\ 415 & 10500 \\ 349 & 9580 \\ 342 & 9460 \\ 300 & 8390 \\ 294 & 8090 \\ 276 & 7620 \\ 238 & 7090 \\ 214 & 6700 \\ 197 & 6450 \\ 187 & 6120 \\ 121 & 4200\end{array}$

cis 1,2 Dichloroethene

Speth

F-400 
Isotherm -

Experimenter Carbon -

\begin{tabular}{|c|c|}
\hline $\begin{array}{c}\mathrm{Ce} \\
(\mathrm{ug} / \mathrm{L})\end{array}$ & $\begin{array}{c}\text { qe } \\
(u g / g)\end{array}$ \\
\hline 2068 & 54690 \\
\hline 1748 & 61340 \\
\hline 1203 & 51430 \\
\hline 891 & 49260 \\
\hline 786 & 46400 \\
\hline 663 & 41590 \\
\hline 621 & 38490 \\
\hline 374 & 31080 \\
\hline 282 & 27810 \\
\hline 196 & 24660 \\
\hline 202 & 23740 \\
\hline 177 & 20560 \\
\hline 133 & 18970 \\
\hline 102 & 16470 \\
\hline 85 & 15050 \\
\hline 67 & 13510 \\
\hline 55 & 11750 \\
\hline 39 & 10520 \\
\hline 32 & 9390 \\
\hline
\end{tabular}

1,2 Dibromoethane Speth

F-400 


\begin{tabular}{|c|c|c|}
\hline $\begin{array}{l}\text { Isotherm - } \\
\text { Experimenter - } \\
\text { Carbon - }\end{array}$ & & $\begin{array}{l}\text { Ethyl Benzene } \\
\text { Speth } \\
\text { F-400 }\end{array}$ \\
\hline $\begin{array}{c}\mathrm{Ce} \\
(\mathrm{ug} / \mathrm{L})\end{array}$ & $\begin{array}{c}\text { qe } \\
(u g / g)\end{array}$ & \\
\hline 2824 & 193866 & \\
\hline 1317 & 189407 & \\
\hline 892 & 150868 & \\
\hline 665 & 121458 & \\
\hline 261 & 107763 & \\
\hline 180 & 73894 & \\
\hline 74 & 57119 & \\
\hline 20 & 46927 & \\
\hline 10 & 39071 & \\
\hline 4 & 28878 & \\
\hline
\end{tabular}




\begin{tabular}{|c|c|c|}
\hline $\begin{array}{l}\text { Isotherm - } \\
\text { Experimenter } \\
\text { Carbon - }\end{array}$ & & $\begin{array}{l}\text { m-Xylene } \\
\text { Speth } \\
\text { F-400 }\end{array}$ \\
\hline $\begin{array}{c}\mathrm{Ce} \\
(\mathrm{ug} / \mathrm{L})\end{array}$ & $\begin{array}{c}\text { qe } \\
(\mathrm{ug} / \mathrm{g})\end{array}$ & \\
\hline 3790 & 256058 & \\
\hline 3047 & 263383 & \\
\hline 1794 & 223998 & \\
\hline 39 & 86096 & \\
\hline
\end{tabular}


Isotherm -

Experimenter -

o-Xylene

Carbon -

Speth

F-400

\begin{tabular}{rr}
\multicolumn{1}{c}{$\begin{array}{l}\mathrm{Ce} \\
(\mathrm{ug} / \mathrm{L})\end{array}$} & $\begin{array}{c}\mathrm{qe} \\
(\mathrm{ug} / \mathrm{g})\end{array}$ \\
4384 & 242682 \\
3535 & 202553 \\
907 & 170387 \\
216 & 116882 \\
53 & 77284
\end{tabular}


Isotherm -

Experimenter -

Carbon -

$\begin{array}{rr}\begin{array}{l}\text { Ce } \\ \text { (ug/L) }\end{array} & \begin{array}{c}\text { qe } \\ \text { (ug/g) }\end{array} \\ & \\ 1169 & 266800 \\ \therefore \quad & 167500 \\ 488 & 194700 \\ 532 & 130800 \\ 310 & 184400 \\ 442 & 116100 \\ 217 & 89020 \\ 116 & 102100 \\ 153 & 74770 \\ 69 & 65890 \\ 53 & 59280 \\ 36 & 52000 \\ 31 & 46480 \\ 28 & 44200 \\ 21 & 38600 \\ 16 & 31890 \\ 17 & 24730 \\ 9 & 22190 \\ 5 & 19200\end{array}$

Tetrachloroethene

Speth

F-400

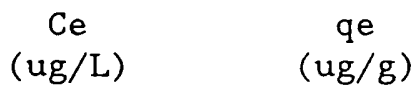

7827

175282

2604

211

206624

66

81091

49417

41458

27

35322 
Isotherm -

Experimenter -

Carbon -

\begin{tabular}{|c|c|}
\hline $\begin{array}{c}\mathrm{Ce} \\
(\mathrm{ug} / \mathrm{L})\end{array}$ & $\begin{array}{c}\text { qe } \\
(u g / g)\end{array}$ \\
\hline 359 & 34540 \\
\hline 166 & 28750 \\
\hline 112 & 25330 \\
\hline 71 & 31030 \\
\hline 28 & 14800 \\
\hline 19 & 12300 \\
\hline 18 & 11200 \\
\hline 14 & 10500 \\
\hline 7 & 8590 \\
\hline 10 & 8090 \\
\hline 6 & 7280 \\
\hline 6 & 5420 \\
\hline
\end{tabular}

Trichloroe thene

Speth

F-400
$\begin{array}{cc}\mathrm{Ce} & \mathrm{qe} \\ (\mathrm{ug} / \mathrm{L}) & (\mathrm{ug} / \mathrm{g})\end{array}$

3101

$876 \quad 59130$

$428 \quad 41785$

$42 \quad 15899$

$22 \quad 11195$

$15 \quad 9960$ 
Isotherm -

Experimenter -

Carbon -

\begin{tabular}{|c|c|}
\hline $\begin{array}{c}\mathrm{Ce} \\
(\mathrm{ug} / \mathrm{L})\end{array}$ & $\begin{array}{c}\text { qe } \\
(u g / g)\end{array}$ \\
\hline 3456 & 138225 \\
\hline 2212 & 129563 \\
\hline 1456 & 110396 \\
\hline 1113 & 96665 \\
\hline 431 & 72614 \\
\hline 127 & 49577 \\
\hline 28 & 29396 \\
\hline 17 & 25618 \\
\hline 11 & 21747 \\
\hline 5 & 16863 \\
\hline
\end{tabular}

Toluene

Speth

F-400 
Isotherm -

Experimenter Carbon -

$\begin{array}{ll}\begin{array}{c}\mathrm{Ce} \\ (\mathrm{ug} / \mathrm{L})\end{array} & \begin{array}{l}\mathrm{qe} \\ (\mathrm{ug} / \mathrm{g})\end{array} \\ 4646400 & 159720 \\ 4628976 & 153912 \\ 4617360 & 166690 \\ 4245648 & 157978 \\ 3897168 & 156235 \\ 3891360 & 156816 \\ 3380256 & 153912 \\ 3031776 & 120226 \\ 2956272 & 135326 \\ 2247696 & 131261 \\ 1986336 & 127776 \\ 1167408 & 67373 \\ 1138368 & 72600 \\ 1115136 & 70858 \\ 871200 & 61565 \\ 836352 & 67373 \\ 621456 & 53143 \\ 609840 & 54014 \\ 491938 & 45883 \\ 265426 & 36010 \\ 261941 & 36358 \\ 145200 & 27123 \\ 134746 & 28169 \\ 48787 & 15914\end{array}$

Acetone

Fukuchi

F-400 
Isotherm -

Experimenter -

Carbon - qe

(ug/g)

1611984

1318896

1156476

1147928

1139380

1125946

903688

874379

722950

720508

667996

664333

625254

616706

523895

522674

483595

478710

438411

432305

431084

428641

420093

402996

371245

370024

328503

322397

321176

319954

317512

312627

274770

255231

241798

239355

230807

222258

214931

213710

190507

188065

169747
Benzoic Acid

Fukuchi

F-400
442074

434747

411544

423756

412766

426199

402996

416429

398111

395669

377351

381014

368802

381014

368802

371245

371245

373687

357812

361475

362696

365139

348042

352927

343157

343157

334609

349263

348042

334609

329724

333388

319954

338272

316291

317512

328503

310185

307742

306521

305300

306521

312627
$\begin{array}{cc}\mathrm{Ce} & \mathrm{qe} \\ (\mathrm{ug} / \mathrm{L}) & (\mathrm{ug} / \mathrm{g})\end{array}$

$157535 \quad 288203$

$103069 \quad 263779$

$102581 \quad 282097$

$94277 \quad 257673$

$76569 \quad 256452$

$73760 \quad 260116$

$73760 \quad 256452$

$70463 \quad 261337$

$67777 \quad 244240$

$59961 \quad 232028$

$58984 \quad 238134$

$56542 \quad 238134$

$50436 \quad 233249$

$40300 \quad 227143$

$1746 \quad 104413$

$264 \quad 62770$ 
Isotherm -

Experimenter -

Carbon -

$\begin{array}{ll}\begin{array}{l}\mathrm{Ce} \\ (\mathrm{ug} / \mathrm{L})\end{array} & \begin{array}{l}\mathrm{qe} \\ (\mathrm{ug} / \mathrm{g})\end{array} \\ 4291548 & 329834 \\ 3024096 & 286103 \\ 1919708 & 210501 \\ 770848 & 141569 \\ 727117 & 150464 \\ 429155 & 111921 \\ 415072 & 114145 \\ 177888 & 63224 \\ 161582 & 66560 \\ 161582 & 66486 \\ 157134 & 67301 \\ 51069 & 40321 \\ 46992 & 41137\end{array}$

n-Butanol

Fukuchi

F-400 


\begin{tabular}{ll}
$\begin{array}{l}\text { Isotherm - } \\
\text { Experimenter }- \\
\text { Carbon - }\end{array}$ & \multicolumn{1}{c}{$\begin{array}{l}\text { Methyl Ethyl Keytone } \\
\text { Fukuchi } \\
\text { F-400 }\end{array}$} \\
Ce & $\begin{array}{c}\text { qe } \\
\text { (ug/L) }\end{array}$ \\
& \\
5242397 & 253827 \\
5242397 & 252385 \\
4117481 & 217772 \\
4052582 & 230752 \\
3021409 & 175948 \\
2927666 & 196139 \\
1889282 & 142778 \\
1882071 & 144220 \\
1153760 & 114655 \\
1132127 & 119703 \\
764366 & 107444 \\
735522 & 112492 \\
422565 & 88695 \\
418238 & 89416 \\
418238 & 89416 \\
410306 & 90859 \\
175227 & 51414 \\
155758 & 55308
\end{tabular}




$\begin{array}{cc}\begin{array}{c}\text { Isotherm } \\ \text { Experimenter }\end{array} & \text { p-Chlorophenol } \\ \text { Carbon - } & \text { Fukuchi } \\ \text { Ce } & \text { F-400 } \\ \text { (ug/L) } & \text { (ug/g) } \\ \text { 11210432 } & 565664 \\ 11197576 & 577234 \\ 7083656 & 555379 \\ 5875192 & 530953 \\ 5489512 & 532238 \\ 1928400 & 465387 \\ 1594144 & 460245 \\ 1581288 & 462816 \\ 1375592 & 434533 \\ 1362736 & 439675 \\ 1069619 & 431962 \\ 1049050 & 431962 \\ 917918 & 421677 \\ 885778 & 431962 \\ 487242 & 393394 \\ 485957 & 393394 \\ 483386 & 393394 \\ 475672 & 397250 \\ 422962 & 388251 \\ 407535 & 383109 \\ 294402 & 370253 \\ 286689 & 375395 \\ 181270 & 356111 \\ 178698 & 356111 \\ 32911 & 286689 \\ 30597 & 287974 \\ 25712 & 282832 \\ 25069 & 281546 \\ 10863 & 241693 \\ 1838 & 146558 \\ \end{array}$




\begin{tabular}{|c|c|c|c|c|}
\hline $\begin{array}{l}\text { Isotherm - } \\
\text { Experimenter } \\
\text { Carbon - }\end{array}$ & & $\begin{array}{l}\text { Phenol } \\
\text { Fukuchi } \\
\text { F-400 }\end{array}$ & & \\
\hline $\begin{array}{c}\mathrm{Ce} \\
(\mathrm{ug} / \mathrm{L})\end{array}$ & $\begin{array}{c}\text { qe } \\
(u g / g)\end{array}$ & & $\begin{array}{c}\mathrm{Ce} \\
(\mathrm{ug} / \mathrm{L})\end{array}$ & $\begin{array}{c}\text { qe } \\
(\mathrm{ug} / \mathrm{g})\end{array}$ \\
\hline 7961706 & 383028 & & 175045 & 229628 \\
\hline 4282005 & 353854 & & 174104 & 231511 \\
\hline 4272594 & 356677 & & 169398 & 230570 \\
\hline 2719779 & 352913 & & 162810 & 219276 \\
\hline 2710368 & 351971 & & 162810 & 231511 \\
\hline 2700957 & 355736 & & 124225 & 220217 \\
\hline 1929255 & 330326 & & 124225 & 220217 \\
\hline 1929255 & 330326 & & 124225 & 217394 \\
\hline 1929255 & 330326 & & 120461 & 219276 \\
\hline 1844556 & 314327 & & 87899 & 202337 \\
\hline 1261074 & 296447 & & 83476 & 204219 \\
\hline 1261074 & 297388 & & 81593 & 204219 \\
\hline 1148142 & 306799 & & 76511 & 204219 \\
\hline 1129320 & 308681 & & 12799 & 142106 \\
\hline 1054032 & 297388 & & 11481 & 144929 \\
\hline 1035210 & 297388 & & 10729 & 144929 \\
\hline 1025799 & 287977 & & 10634 & 143988 \\
\hline 1016388 & 303975 & & 9082 & 130813 \\
\hline 1006977 & 303034 & & 7585 & 129872 \\
\hline 997566 & 287036 & & 6832 & 130813 \\
\hline 988155 & 297388 & & 1496 & 77170 \\
\hline 969333 & 293623 & & & \\
\hline 835697 & 278566 & & & \\
\hline 808405 & 282330 & & & \\
\hline 785819 & 286094 & & & \\
\hline 778290 & 287977 & & & \\
\hline 773584 & 288918 & & & \\
\hline 674769 & 270096 & & & \\
\hline 665358 & 271037 & & & \\
\hline 623949 & 269155 & & & \\
\hline 594775 & 272919 & & & \\
\hline 588188 & 276683 & & & \\
\hline 584423 & 272919 & & & \\
\hline 449846 & 263508 & & & \\
\hline 441376 & 267272 & & & \\
\hline 436670 & 267272 & & & \\
\hline 431024 & 267272 & & & \\
\hline 311504 & 240922 & & & \\
\hline 279507 & 239039 & & & \\
\hline 258803 & 239981 & & & \\
\hline 251274 & 243745 & & & \\
\hline 240922 & 243745 & & & \\
\hline 200454 & 225864 & & & \\
\hline
\end{tabular}




$\begin{array}{ll}\begin{array}{l}\text { Isotherm - } \\ \text { Experimenter - } \\ \text { Carbon - }\end{array} & \begin{array}{l}\text { 2-Propanol } \\ \text { Fukuchi } \\ \text { F-400 }\end{array} \\ \text { Ce } & \text { qe } \\ (\mathrm{ug} / \mathrm{L}) & (\mathrm{ug} / \mathrm{g}) \\ & \\ 5047560 & 84126 \\ 5023524 & 90135 \\ 4909353 & 85328 \\ 4374552 & 86530 \\ 3977958 & 87731 \\ 3148716 & 82323 \\ 2595888 & 81122 \\ 2595888 & 80521 \\ 1544313 & 68503 \\ 1538304 & 69704 \\ 739107 & 40921 \\ 691035 & 50055 \\ 228943 & 29504 \\ 224737 & 30285\end{array}$


Isotherm -

Experimenter -

Carbon -
Propionitrile

Fukuchi

F-400

$\begin{array}{cc}\begin{array}{l}\mathrm{Ce} \\ (\mathrm{ug} / \mathrm{L})\end{array} & \begin{array}{c}\mathrm{qe} \\ (\mathrm{ug} / \mathrm{g})\end{array} \\ 2599776 & 133844 \\ 2093040 & 116219 \\ 2071008 & 121176 \\ 1580796 & 98593 \\ 749088 & 60588 \\ 705024 & 68299 \\ 600372 & 62791 \\ 497372 & 57283 \\ 495169 & 57283 \\ 419159 & 46543 \\ 394924 & 51224 \\ 321116 & 40098 \\ 222523 & 33819 \\ 218117 & 34645 \\ 133294 & 25337 \\ 131090 & 25777\end{array}$




\begin{tabular}{ll}
$\begin{array}{l}\text { Isotherm - } \\
\text { Experimenter }-\end{array}$ & \multicolumn{1}{c}{$\begin{array}{l}\text { Pyridine } \\
\text { Fukuchi } \\
\text { Carbon - }\end{array}$} \\
Ce & qe \\
(ug/L) & (ug/g) \\
& \\
6082790 & 281596 \\
4176480 & 235718 \\
4121110 & 246001 \\
3765160 & 227808 \\
3757250 & 228599 \\
2966250 & 210406 \\
2966250 & 208824 \\
2135700 & 196168 \\
2127790 & 198541 \\
1779750 & 178766 \\
1392160 & 166110 \\
1384250 & 168483 \\
1028300 & 152663 \\
1028300 & 151872 \\
656530 & 136052 \\
649411 & 137634 \\
312445 & 115486 \\
300580 & 117859 \\
68738 & 74829 \\
65811 & 75620 \\
20962 & 54579 \\
19221 & 55054 \\
5316 & 34092 \\
4738 & 34329 \\
&
\end{tabular}




\begin{tabular}{ll}
$\begin{array}{l}\text { Isotherm - } \\
\text { Experimenter - } \\
\text { Carbon - }\end{array}$ & \multicolumn{1}{l}{$\begin{array}{l}\text { Vinyl Acetate } \\
\text { Fukuchi } \\
\text { Fe }\end{array}$} \\
$\begin{array}{c}\text { qe } \\
\text { (ug/L) }\end{array}$ & (ug/g) \\
2057551 & 560446 \\
1988679 & 573359 \\
1446312 & 488130 \\
1368831 & 502766 \\
791167 & 424424 \\
548393 & 278071 \\
417537 & 304759 \\
318533 & 194563 \\
296150 & 198868 \\
273766 & 204033 \\
243635 & 210060 \\
175624 & 158406 \\
161849 & 161849 \\
75673 & 114500 \\
70422 & 115361 \\
59130 & 115361 \\
62501 & 116222 \\
19284 & 60607 \\
16271 & 61210 \\
3771 & 45542 \\
2238 & 45886 \\
1584 & 39687 \\
1326 & 27463
\end{tabular}




\begin{tabular}{|c|c|c|c|c|}
\hline $\begin{array}{l}\text { Isotherm - } \\
\text { Experimenter } \\
\text { Carbon - }\end{array}$ & & $\begin{array}{l}\text { Bromoform } \\
\text { Luft } \\
\text { F- } 400\end{array}$ & & \\
\hline $\begin{array}{c}\mathrm{Ce} \\
(\mathrm{ug} / \mathrm{L})\end{array}$ & $\begin{array}{c}\text { qe } \\
(\mathrm{ug} / \mathrm{g})\end{array}$ & & $\begin{array}{c}\mathrm{Ce} \\
(\mathrm{ug} / \mathrm{L})\end{array}$ & $\begin{array}{c}\text { qe } \\
(\mathrm{ug} / \mathrm{g})\end{array}$ \\
\hline 3870 & 131744 & & 3698 & 118903 \\
\hline 2548 & 90997 & & 2234 & 88470 \\
\hline 2010 & 81594 & & 857 & 49138 \\
\hline 1759 & 69562 & & 549 & 37208 \\
\hline 1309 & 60286 & & 348 & 27906 \\
\hline 996 & 49467 & & 264 & 23616 \\
\hline 746 & 41277 & & 151 & 16309 \\
\hline 546 & 35084 & & 88 & 12057 \\
\hline 450 & 30535 & & 61 & 9196 \\
\hline 349 & 27097 & & 23 & 5723 \\
\hline 334 & 24145 & & 16 & 4856 \\
\hline 273 & 21933 & & 4 & 3554 \\
\hline 160 & 15970 & & & \\
\hline 85 & 11291 & & & \\
\hline 69 & 8688 & & & \\
\hline 56 & 6696 & & & \\
\hline 37 & 5702 & & & \\
\hline 25 & 4547 & & & \\
\hline 23 & 3789 & & & \\
\hline 20 & 3248 & & & \\
\hline 12 & 1839 & & & \\
\hline
\end{tabular}


Isotherm -

Experimenter -

Carbon -

\begin{tabular}{|c|c|}
\hline $\begin{array}{c}\mathrm{Ce} \\
(\mathrm{ug} / \mathrm{L})\end{array}$ & $\begin{array}{c}\text { qe } \\
(u g / g)\end{array}$ \\
\hline 8321 & 86725 \\
\hline 7469 & 83667 \\
\hline 6534 & 81670 \\
\hline 5672 & 78485 \\
\hline 5045 & 73859 \\
\hline 4297 & 66276 \\
\hline 3056 & 59249 \\
\hline 2384 & 53132 \\
\hline 1850 & 46484 \\
\hline 1461 & 41909 \\
\hline 1156 & 37536 \\
\hline 984 & 34301 \\
\hline 856 & 31040 \\
\hline 469 & 23118 \\
\hline 275 & 16589 \\
\hline 174 & 12889 \\
\hline 127 & 9901 \\
\hline 105 & 8475 \\
\hline 88 & 7507 \\
\hline 81 & 6789 \\
\hline 61 & 6163 \\
\hline
\end{tabular}

Bromoform

Luft

HD -3000 


$\begin{array}{cc}\begin{array}{l}\text { Isotherm - } \\ \text { Experimenter - } \\ \text { Carbon - }\end{array} & \begin{array}{l}\text { Bromoform } \\ \text { Luft } \\ \text { WV-W }\end{array} \\ \text { Ce } & \text { qe } \\ \text { (ug/L) } & \text { (ug/g) } \\ & \\ 8094 & 159018 \\ 6481 & 144888 \\ 5414 & 127522 \\ 4464 & 114707 \\ 3852 & 101538 \\ 3208 & 92489 \\ 3167 & 75427 \\ 1435 & 56545 \\ 1098 & 48709 \\ 938 & 42137 \\ 747 & 37789 \\ 641 & 33896 \\ 534 & 30914 \\ 334 & 22497 \\ 206 & 15960 \\ 141 & 12358 \\ 86 & 9502 \\ 75 & 8086 \\ 63 & 5887 \\ 48 & 5424 \\ 37 & 4643 \\ & \end{array}$




\begin{tabular}{|c|c|c|}
\hline $\begin{array}{l}\text { Isotherm - } \\
\text { Experimenter } \\
\text { Carbon - }\end{array}$ & & $\begin{array}{l}\text { Chlorodibromomethane } \\
\text { Luft } \\
\text { HD }-3000\end{array}$ \\
\hline $\begin{array}{c}\mathrm{Ce} \\
(\mathrm{ug} / \mathrm{L})\end{array}$ & $\begin{array}{c}\text { qe } \\
(\mathrm{ug} / \mathrm{g})\end{array}$ & \\
\hline 508 & 10977 & \\
\hline 421 & 10290 & \\
\hline 265 & 7519 & \\
\hline 172 & 5770 & \\
\hline 100 & 4312 & \\
\hline 61 & 3208 & \\
\hline 38 & 2479 & \\
\hline 30 & 2145 & \\
\hline 23 & 1737 & \\
\hline 19 & 1560 & \\
\hline 14 & 1408 & \\
\hline
\end{tabular}




\begin{tabular}{|c|c|c|c|}
\hline $\begin{array}{l}\text { Isotherm - } \\
\text { Experimenter - } \\
\text { Carbon - }\end{array}$ & & & \\
\hline $\begin{array}{c}\mathrm{Ce} \\
(\mathrm{ug} / \mathrm{L})\end{array}$ & $\begin{array}{c}\text { qe } \\
(\mathrm{ug} / \mathrm{g})\end{array}$ & $\begin{array}{c}\mathrm{Ce} \\
(\mathrm{ug} / \mathrm{L})\end{array}$ & $\begin{array}{c}\text { qe } \\
(\mathrm{ug} / \mathrm{g})\end{array}$ \\
\hline 1324 & 9605 & 5873 & 24200 \\
\hline 1202 & 9484 & 5732 & 20105 \\
\hline 1179 & 8133 & 4645 & 18792 \\
\hline 1147 & 9167 & 3847 & 16213 \\
\hline 1123 & 8281 & 3142 & 15019 \\
\hline 1104 & 8940 & 2738 & 13193 \\
\hline 1027 & 8146 & 1495 & 8674 \\
\hline 978 & 7667 & 626 & 5041 \\
\hline 997 & 7001 & 394 & 3588 \\
\hline 1004 & 6829 & 202 & 2149 \\
\hline 881 & 7413 & 129 & 1958 \\
\hline 827 & 6509 & 39 & 1452 \\
\hline 813 & 6059 & & \\
\hline 760 & 5476 & & \\
\hline 648 & 5066 & & \\
\hline 557 & 4710 & & \\
\hline 544 & 4691 & & \\
\hline 468 & 4379 & & \\
\hline 502 & 4291 & & \\
\hline 437 & 4020 & & \\
\hline 451 & 3996 & & \\
\hline 408 & 3688 & & \\
\hline 375 & 3432 & & \\
\hline 310 & 3023 & & \\
\hline 262 & 2705 & & \\
\hline 215 & 2356 & & \\
\hline 175 & 2032 & & \\
\hline 159 & 1700 & & \\
\hline 126 & 1624 & & \\
\hline 97 & 1270 & & \\
\hline 81 & 1092 & & \\
\hline 74 & 977 & & \\
\hline 64 & 885 & & \\
\hline 54 & 811 & & \\
\hline 62 & 886 & & \\
\hline 53 & 812 & & \\
\hline 49 & 746 & & \\
\hline 40 & 644 & & \\
\hline 35 & 589 & & \\
\hline
\end{tabular}


Isotherm -

Experimenter -

Carbon -

$\begin{array}{lr}\begin{array}{c}\text { Ce } \\ \text { (ug/L) }\end{array} \\ 888 \\ \text { (ug/g) } \\ 681 & 8663 \\ 550 & 6846 \\ 421 & 6526 \\ 335 & 5246 \\ 264 & 4678 \\ 210 & 4078 \\ 164 & 3422 \\ 160 & 2800 \\ 159 & 2806 \\ 149 & 2831 \\ 138 & 2795 \\ 106 & 2636 \\ 91 & 2206 \\ 79 & 1981 \\ 64 & 1728 \\ 54 & 1545 \\ 43 & 1342 \\ 37 & 1178 \\ 31 & 1063 \\ 29 & 908 \\ 21 & 1027 \\ & 705\end{array}$

Chloroform

Luft

HD - 3000 


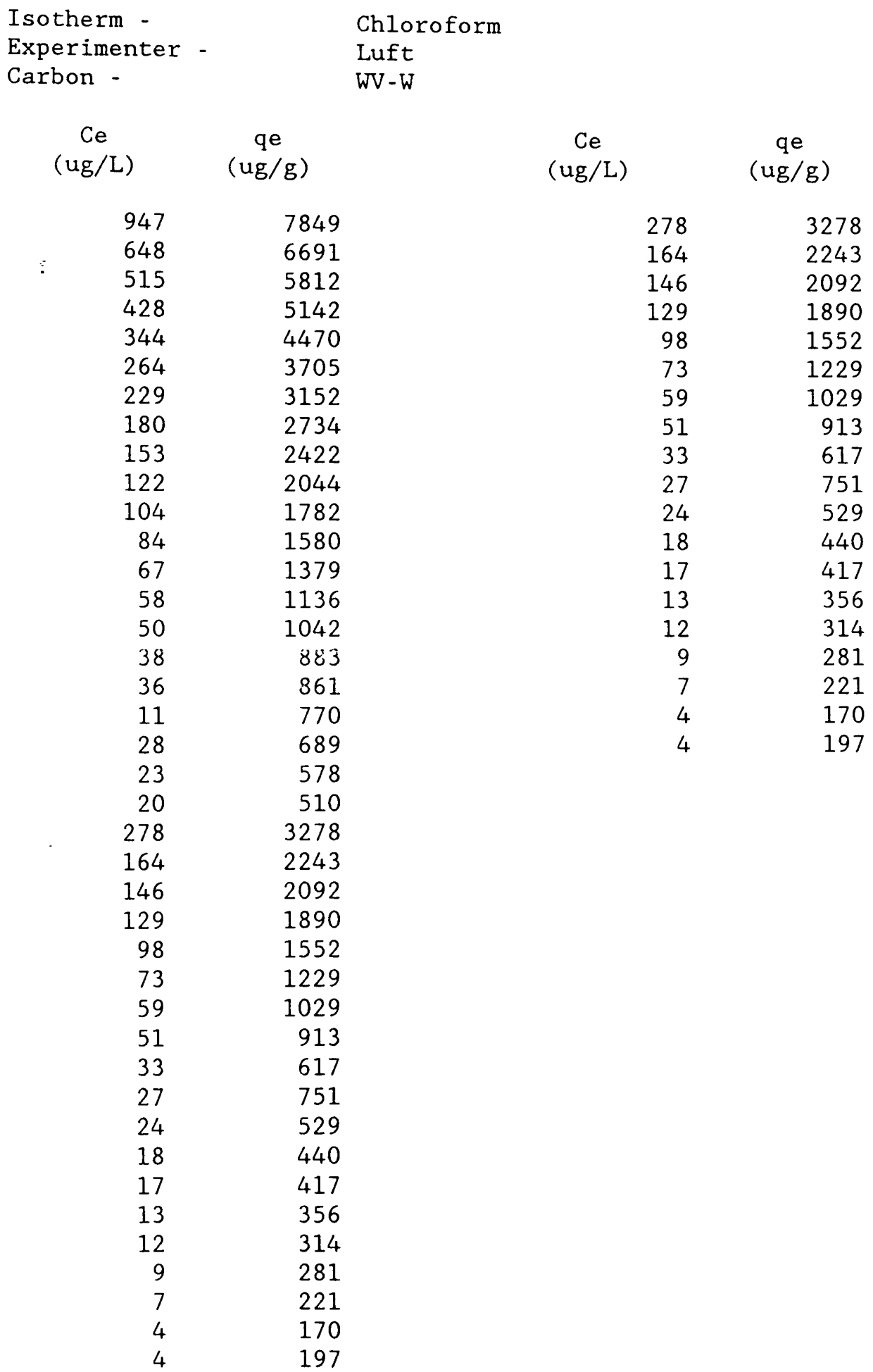


Isotherm -

Experimenter Carbon -

$\begin{array}{rl}\begin{array}{c}\text { Ce } \\ (\mathrm{ug} / \mathrm{L})\end{array} & \begin{array}{l}\mathrm{qe} \\ (\mathrm{ug} / \mathrm{g})\end{array} \\ 3533 & 76646 \\ 1594 & 51601 \\ 950 & 42639 \\ 598 & 31602 \\ 315 & 23928 \\ 196 & 19276 \\ 91 & 13390 \\ 54 & 10134 \\ 32 & 78998 \\ 17 & 51469 \\ 13 & 41036 \\ 10 & 34125 \\ 1 & 22496\end{array}$

Trichloroethene

Luft

F-400

\begin{tabular}{|c|c|}
\hline $\begin{array}{c}\mathrm{Ce} \\
(\mathrm{ug} / \mathrm{L})\end{array}$ & $\begin{array}{c}q e \\
(u g / g)\end{array}$ \\
\hline 528 & 23941 \\
\hline 401 & 21024 \\
\hline 214 & 15663 \\
\hline 74 & 9481 \\
\hline 37 & 6845 \\
\hline 18 & 4942 \\
\hline 6 & 2929 \\
\hline 3 & 2158 \\
\hline
\end{tabular}


Isotherm -

Experimenter -

Carbon -

\begin{tabular}{|c|c|}
\hline $\begin{array}{c}\mathrm{Ce} \\
(\mathrm{ug} / \mathrm{L})\end{array}$ & $\begin{array}{c}\text { qe } \\
(u g / g)\end{array}$ \\
\hline 585 & 15715 \\
\hline 461 & 14178 \\
\hline 355 & 12561 \\
\hline 190 & 8555 \\
\hline 103 & 6554 \\
\hline 50 & 4556 \\
\hline 25 & 3578 \\
\hline 11 & 2628 \\
\hline 9 & 2234 \\
\hline 7 & 1830 \\
\hline 5 & 1625 \\
\hline 4 & 1464 \\
\hline
\end{tabular}

Trichloroethene

Luft

HD - 3000 
Isotherm -

Experimenter -

Carbon -

$\begin{array}{cc}\mathrm{Ce} & \text { qe } \\ (\mathrm{ug} / \mathrm{L}) & (\mathrm{ug} / \mathrm{g})\end{array}$

537

368

270

790

31

15

8

3
Trichloroethene

Luft

WV - W

25413

19027

16648

10749

7428

3733

2734

1895 


\begin{tabular}{|c|c|c|}
\hline $\begin{array}{l}\text { Isotherm - } \\
\text { Experimenter } \\
\text { Carbon - }\end{array}$ & & $\begin{array}{l}\text { p-Chlorophenol } \\
\text { VLIET } \\
\text { F- } 400\end{array}$ \\
\hline $\begin{array}{c}\mathrm{Ce} \\
(\mathrm{ug} / \mathrm{L})\end{array}$ & $\begin{array}{c}\text { qe } \\
(\mathrm{ug} / \mathrm{g})\end{array}$ & \\
\hline 564000 & 383800 & \\
\hline 118800 & 337700 & \\
\hline 17090 & 259100 & \\
\hline 26570 & 264600 & \\
\hline 2990 & 191300 & \\
\hline 680 & 131300 & \\
\hline 631500 & 416800 & \\
\hline 333300 & 383200 & \\
\hline 212800 & 367900 & \\
\hline 23240 & 271000 & \\
\hline 6840 & 229800 & \\
\hline 2390 & 190100 & \\
\hline 1030 & 155800 & \\
\hline 680 & 129400 & \\
\hline
\end{tabular}


Isotherm -

Experimenter -

Carbon -

$\begin{array}{rl}\begin{array}{l}\text { Ce } \\ \text { ug/L) }\end{array} & \begin{array}{l}\text { qe } \\ \text { (ug/g) }\end{array} \\ 564800 & 382400 \\ 116200 & 339000 \\ 16240 & 259300 \\ 24950 & 272700 \\ 3500 & 190000 \\ 680 & 131300 \\ 642600 & 388600 \\ 328900 & 387000 \\ 203400 & 367000 \\ 52120 & 291900 \\ 25640 & 272600 \\ 8550 & 238700 \\ 3160 & 188700 \\ 1110 & 150600 \\ 600 & 124300\end{array}$

p-Chlorophenol

VLIET

BACM 


\begin{tabular}{|c|c|c|c|c|}
\hline $\begin{array}{l}\text { Isotherm - } \\
\text { Experimenter } \\
\text { Carbon - }\end{array}$ & & $\begin{array}{l}\text { Phenol } \\
\text { VLIET } \\
\text { F- } 400\end{array}$ & & \\
\hline $\begin{array}{c}\mathrm{Ce} \\
(\mathrm{ug} / \mathrm{L})\end{array}$ & $\begin{array}{c}\text { qe } \\
(u g / g)\end{array}$ & & $\begin{array}{c}\mathrm{Ce} \\
(\mathrm{ug} / \mathrm{L})\end{array}$ & $\begin{array}{c}\text { qe } \\
(u g / g)\end{array}$ \\
\hline 964700 & 309300 & & 78440 & 202500 \\
\hline 870000 & 294400 & & 61330 & 190900 \\
\hline 787700 & 293400 & & 43470 & 173600 \\
\hline 706600 & 290600 & & 32290 & 160200 \\
\hline 580900 & 277600 & & 23860 & 150800 \\
\hline 484000 & 256700 & & 14880 & 135900 \\
\hline 370500 & 247900 & & 11050 & 126600 \\
\hline 287200 & 236500 & & 6775 & 114000 \\
\hline 201600 & 221600 & & 5089 & 106000 \\
\hline 130200 & 201000 & & 3566 & 95190 \\
\hline 78050 & 183000 & & 1912 & 81360 \\
\hline 32800 & 148100 & & 1070 & 70460 \\
\hline 11800 & 114700 & & 486 & 58260 \\
\hline 976300 & 311700 & & 292 & 49170 \\
\hline 863500 & 301900 & & 61360 & 191500 \\
\hline $716 \% 00$ & 291600 & & 24540 & 151300 \\
\hline 701500 & 277300 & & 6840 & 116200 \\
\hline 608100 & 281400 & & 2807 & 87610 \\
\hline 544600 & 272700 & & 1128 & 70360 \\
\hline 475200 & 267000 & & 674 & 58180 \\
\hline 404500 & 252000 & & & \\
\hline 334500 & 241800 & & & \\
\hline 256200 & 235200 & & & \\
\hline 206700 & 221900 & & & \\
\hline 158400 & 210600 & & & \\
\hline 118000 & 195400 & & & \\
\hline 75720 & 176600 & & & \\
\hline 38380 & 152700 & & & \\
\hline 19710 & 127200 & & & \\
\hline 933600 & 299700 & & & \\
\hline 693700 & 288400 & & & \\
\hline 492700 & 260400 & & & \\
\hline 374700 & 246500 & & & \\
\hline 257500 & 231800 & & & \\
\hline 122700 & 198400 & & & \\
\hline 84020 & 181300 & & & \\
\hline
\end{tabular}


Isotherm -

Experimenter -

Carbon -

$\mathrm{Ce}$

(ug/L)

966600

853200

788300

716400

606800

474900

381200

286500

200300

125300

75850

30300

12740

5640

1686

528

80260

62750

49400

33580

19970

25870

13710

9789

7196

5446

2982

1750

1005

583

259
Phenol

VLIET

BACM qe

(ug/g)

283200

274300

273300

270000

260700

257700

242600

233500

220700

202200

182200

148700

115700

90560

65290

48840

181500

170600

163400

147700

132800

139500

121000

110800

100900

93150

78090

67130

57130

48890

39040 
Isotherm -

Experimenter -

Carbon -

\begin{tabular}{|c|c|}
\hline $\begin{array}{c}\mathrm{Ce} \\
(\mathrm{ug} / \mathrm{L})\end{array}$ & $\begin{array}{c}\text { qe } \\
(u g / g)\end{array}$ \\
\hline 1257 & 22560 \\
\hline 788 & 16900 \\
\hline 413 & 1128 \\
\hline 277 & 7690 \\
\hline 129 & 518 \\
\hline 90 & 349 \\
\hline 49 & 250 \\
\hline 43 & 231 \\
\hline 26 & 156 \\
\hline 11 & 100 \\
\hline
\end{tabular}

Carbon Tetrachloride

Kong

F-400 


\begin{tabular}{|c|c|c|}
\hline $\begin{array}{l}\text { Isotherm - } \\
\text { Experimenter - } \\
\text { Carbon - }\end{array}$ & & $\begin{array}{l}\text { Tetrachloroe thene } \\
\text { Kong } \\
\text { F- } 400\end{array}$ \\
\hline $\begin{array}{c}\mathrm{Ce} \\
(\mathrm{ug} / \mathrm{L})\end{array}$ & $\begin{array}{c}\text { qe } \\
\text { (ug/g) }\end{array}$ & \\
\hline 1800 & 222700 & \\
\hline 868 & 143600 & \\
\hline 471 & 83500 & \\
\hline 174 & 47200 & \\
\hline 48 & 28500 & \\
\hline 21 & 16000 & \\
\hline 14 & 8900 & \\
\hline 9 & 5800 & \\
\hline 6 & 3400 & \\
\hline
\end{tabular}




\begin{tabular}{|c|c|c|}
\hline $\begin{array}{l}\text { Isotherm - } \\
\text { Experimenter } \\
\text { Carbon - }\end{array}$ & & $\begin{array}{l}\text { Trichloroe thene } \\
\text { Kong } \\
\text { F- } 400\end{array}$ \\
\hline $\begin{array}{c}\mathrm{Ce} \\
(\mathrm{ug} / \mathrm{L})\end{array}$ & $\begin{array}{c}\text { qe } \\
(u g / g)\end{array}$ & \\
\hline 725 & 33000 & \\
\hline 434 & 25600 & \\
\hline 139 & 15600 & \\
\hline 67 & 10200 & \\
\hline 39 & 7100 & \\
\hline 24 & 4600 & \\
\hline 10 & 3000 & \\
\hline 8 & 2200 & \\
\hline 6 & 1500 & \\
\hline
\end{tabular}


Isotherm -

Experimenter -

Carbon -

\begin{tabular}{|c|c|}
\hline $\begin{array}{c}\mathrm{Ce} \\
(\mathrm{ug} / \mathrm{L})\end{array}$ & $\begin{array}{c}\text { qe } \\
(u g / g)\end{array}$ \\
\hline 38 & 1388 \\
\hline 35 & 1360 \\
\hline 26 & 1151 \\
\hline 19 & 897 \\
\hline 6.6 & 592 \\
\hline 3.5 & 471 \\
\hline 0.9 & 270 \\
\hline 0.9 & 271 \\
\hline 0.6 & 217 \\
\hline
\end{tabular}

Carbon Tetrachloride

Narbaitz

F-400

217 
Isotherm -

Experimenter -

Carbon -

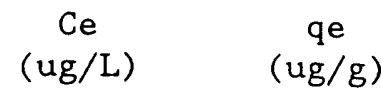

55.3

31.2

31.3

26.9

6.9

5.6

4.1

1.9

1.8

Trichloroe thene

Narbaitz

F-400

\section{8}

4653

4651

3758

2643

1672

1324

754

749 


\section{References}

1. Amy, Gary L.; Narbaitz, Roberto M.; Cooper, William J. Removing VOC's from Groundwater Containing Humic Substances by Means of Coupled Air Stripping and Adsorption. J. AWWA. 49- 54; 1987.

2. Arbuckle, W.B. Estimating Equilibrium Adsorption of Organic Compounds on Activated Carbon from Aqueous Solution. Environ Sci Technol. 15: 812-819; 1981

3. Belfort, G. Selective Adsorption of Organic Homoloques onto Activated Carbon from Dilute Aqueous Solution. Solvophobic Interaction Approach and Correlations of Molar Adsorptivity with Physiochemical Parameters. Environ. Sci and Tech. 13: 939-946; 1979

4. Belfort, G. Adsorption on Carbon: theoretical considerations. Eng. Sci. and Tech. 14: 910-914; 1980

5. Brunauer, S.; Emmett, P.H.; Teller, E. Adsorption of Gases in Multimolecular Layers. J. Amer. Chem. Soc. 60: 309-319; 1938.

6. Butler; Ockrent. Studies in Electrocapillarity III. J. Phy. Chem. 34: 2841-2858; 1930.

7. Chiou, Cary C.T.; Manes, Milton; Application of the Polanyi Adsorption Potential Theory to Adsorption from Solution on Activated Carbo. IV. Steric Factors, as Illustrated by the Adsorption of Planar and Octahedral Metal Acetylacetonates. J. Phys. Chem. 77: 809-813; 1972.

8. Chiou, Cary C.T.; Manes, Milton; Application of the Polanyi Adsorption Potential Theory to Adsorption from Solution on Activated Carbo. V. Adsorption from Water of Some Solids and Their Melts, and a Comparison of Bulk and Adsorbate Melting Points. J. Phys. Chem. 77: 622-626; 1973.

9. Chitra, S.P.; Govind, Rakesh. Application of a Group Contribution Method for Predicting Adsorbability on Activated Carbon. A. I. Ch. E. 32: $167-169 ; 1986$.

10 Cookson, John T., Adsorption Mechanisms: The Chemistry of Organic Adsorption on Activated Carbon, CARBON ADSORPTION HANDBOOK. Ann Arbor Sci. Pub.: Ann Arbor, Mich. Cheremisinoff, P.N.; Ellerbusch, F. eds. 131-132; 1978 .

11. DiGiano, F.A.; Baldauf, G.; Frick, B.; Sontheimer, H.A. Simplified Competitive Equilibrium Adsorption Mode1. Chem. Eng. Sci. 33: $1667-1673$; 1987.

12. Dyksen, J.E.; Hess, A.F. Alternatives for Controlling Organics in Groundwater Supplies. J. AWWA. 150: 394-403; 1982

13. Faust, Samue1 D., Aly, Osman M. Adsorption Models. Ch 2 in 
ADSORPTION PROCESSES FOR WATER TREATMENT. Butterworth pub.

Stoneham, Ma 1987 33-34; 1987

14. Fredenslund, Aage; Jones, Russell L.; Prausnitz, John M.

Group-Contribution Estimation of Activity Coefficients in Nonideal

Liquid Mixtures. AIchE. 21: 1086-1099; 1975.

15. Freundlich, H. Uber die Adsorption in Losungen. Z. Phys. Chem. 57: 385-470; 1906.

16. Fritz, W.; Schlunder, E.U. Competitive Adsorption of Two Dissolved Organics onto Activated Carbon - 1. Adsorption Equilibrium. Chem Eng. Sci. 36: 721-730; 1981.

17. Fukuchi, Kenji; Hamaoka, Hideaki; Arai, Yasuhiko. Adsorption Equilibria of Organic Solutes from Dilute Aqueous Solutions on Activated Carbon. Memoirs of the Faculty of Engineering.

Kyushu University. 40:107-118; 1980

18. Gu, Tiren; Manes, M. Multicomponent Adsorption from Water onto Activated Carbon. Trace Liquids and a dominant Component. J. Phys. Chem. 85: 4221-4223; 1982 .

19. Hansen, Robert S.; Fackler, Walter V. Jr. A Generalization of the Polanyi Theory of Adsorption from Solution. J. Phys. Chem. 57: $634-637 ; 1953$.

20. Hand, D.; Crittenden, J.C.; Thacker, W.E. User-Oriented Batch Reactor Solutions to the Homogeneous Surface Diffusion Model. J. Environ. Eng. 109: 82-101; 1983.

21. Jossens, L; Prausnitz, J.M.; Fritz, W.; Schlunder, E.U.; Myers, A.L. Thermodynamics of Multi-Solute Adsorption from Dilute Aqueous Solutions. Chem. Eng. Sci. 33: 1097-1106; 1978

22. Kincannon, D.F.; Stover, E.L. Treatment of Groundwater. Ch 5 in GROUND WATER POLLUTION CONTROL. Lewis Pub. Chlsea, Mich. Canter, L.W. ; Knox, R.C. eds. 89-125; 1985.

23. Kong, Emery J. Competitive Adsorption of Carbon Tetrachloride, Trichloroethylene, and Tetrachloroethylene on Filtasiob-400 Activated Carbon and XE-340 Carbonaceous Resin. Master's Thesis. University of North Carolina. 1984

24. Kuennen, Roy W., Van Dyke, Karl, Crittenden, John C. and Hand, David W. Predicting the Multicomponent Removal of Surrogate Compounds by Fixed-Bed Adsorber. J AWWA. 81: 46-58; 1989

25. Langmuir, I. The Adsorption of Gases on Plane Surfaces of Glass, Mica and Platinum. J. Amer. Chem. Soc. 40: 1361-1403; 1918.

26. Lang's Handbook of Chemistry. 12th ed. John A. Dean, ed. McGraw Hill. New York: 1987. 
27. Luft, Paul J. Modeling of Multicomponent Adsorption onto Granular Activated Carbon in Mixtures of Known and Unknown Composition.

Master's Thesis. Michigan Technological University. 1984.

28. Lyman, M.; Hofer, J.E. Application of Carbon Adsorption to the Treatment of Hazardous Industrial Waste. CARBON ADSORPTION HANDBOOK. Ann Arbor Sci. Pub.: Ann Arbor, Mich. Cheremisinoff, P.N.; E1lerbusch, F. eds. 131-132; 1978.

29. Manes, M.; Hofer, J.E. Application of the Polanyi Adsorption Potential Theory to Adsorption of Solution on Activated Carbon. J. Phy. Chem. 73: 584-590; 1969.

30. Manes, M. The Polanyi Adsorption Potential Theory and its Applications to Adsorption from Water Solution onto Activated Carbo Ch 2 in ACTIVATED CARBON ADSORPTION OF ORGANICS FROM THE AQUEOUS PHASE. VOL. 1. Ann Arbor Sci. Pub.: Ann Arbor, Mich. McGuire, M.J.; Suffet, I.H. eds. 43-63; 1980.

31. Mattson, J. S., Mark, H.R., Infrared Internal Reflectance Spectroscopic Determination of Surface Functional Groups on Carbon. $\mathrm{J}$. of Col1. and Int. Sci., 31: 131, 1969.

32. McGuire, H.J.; Suffet, I.H. The Calculated Net Adsorption Energy Concept. Ch 4 in ACTIVATED CARBON ADSORPTION OF ORGANICS FROM THE AQUEOUS PHASE. VOL. 1. Ann Arbor Sci. Pub.: Ann Arbor, Mich. McGuire, M.J.; Suffet, I.H. eds. 91-115; 1980.

33. Montogomery, A. WATER TREATMENT PRINCIPLES AND DESIGN. New York: Wiley-interscience; 1985

34. Myers, A.L.; Sincar, S. Theory of Correspondence for Adsorption from Dilute Solutions on Heterogeneous Adsorbents. Ch 4 in TREATMENT OF WATER BY GRANULAR ACTIVATED CARBON. Ann Arbor Sci. Pub.: Ann Arbor, Mich. McGuire, M.J.; Suffet, I.H. 63-76; 1983.

35. Niralakhandan, Nagamany; Speece, Richard E. Adsorption from Aqueous Phase by Activated Carbon: A Simplified Application of the Solvophobic Theory. Environ. Sci. Technol. 24: 575-580; 1990.

36. O'Brien, R.P.; Fisher, J.L. There is an Answer to Groundwater Contamination. Water/Eng. and Man. 5 30-36; 1983.

37. Polanyi, M. Adsorption of Gases by a Solid Nonvolatile Adsorbent Verh. Deut. Physik. Ges. 18: 55-61; 1916.

38. Polanyi, M. Adsorption from Solutions of Substances of Limited Solubility. Z. Physik. 2: 111; 1920.

39. Radke, C.J.; Prausnitz, J.M. Thermodynamics of Multisolute Adsorption of Dilute Liquid Solutions. J. AIChE. 18: $761-766 ; 1972$.

40. Redlich, 0.; Peterson, D.L. A Useful Adsorption Isotherm. J. 
Phys. Chem. 63: 1024; 1959.

41. Rosene, Miichael R.; Ozcan, Mustafa; Manes, Milton. Application of the Polanyi Adsorption Potential Theory to Adsorption from Solution on Activated Carbon. 8. Ideal, Nonideal, and Competitive Adsorption of Some Solids from Water Solution. J. Phys. Chem. 80: $2586-2589 ; 1976$.

42. Schuliger, W.G. Purification of Industrial Liquids with Granular Activated Carbon: Techniques for Obtaining and Interpreting Data and Selecting the Type of Commercial System. Ch 7 in CARBON ADSORPTION HANDBOOK. Ann Arbor Sci. Pub.: Ann Arbor, Mich. Chermisinoff, P.N.; Ellerbusch, F. eds. $55-83 ; 1978$.

43. Singer, P.C.; Yen, C.Y. Adsorption of Alkylphenols by Activated Carbon. Ch 7 in ACTIVATED CARBON ADSORPTION OF ORGANICS FROM THE AQUEOUS PHASE VOL. 1. Ann Arbor Sci. Pub.: Ann Arbor, Mich. McGuire, M.J.; Suffet, I.H. eds. 43-63; 1980.

44. Sontheimer, Crittenden and Summers. Description of Adsorption Equilibria. Ch 3 in ACTIVATED CARBON FOR WATER TREATMENT. Druckerei G. Braun Gmbh: Karlsruhe, FRG. 107; 1988.

45. Speth, T.F. Predicting Equilibria For Single Solute and Multicomponent Aqueous-Phase Adsorption Onto Activated Carbon. Master's Thesis. Michigan Technological University. 1986.

46. Stover, E.L.; Kincannon, D.F. Contaminated Groundwater Treatability - A Case Study. J. AWWA. 6: 292-298; 1983.

47. Toth, J. Gas-Adsorption an Festen Oberflachen Inhomogener Aktivitaten. Acta Chimica Hungarica. 30-31; 1962.

48. US Environmental Protection Agency. The Occurrence of Volatile Organics in Drinking Water. Briefing Paper. Office of Drinking Water. 1980

49. US Environmental Protection Agency. Safe Drinking Water Act 1986 Amendments. EPA-570-9-86-002. 1986.

50. van Vliet, Ben M; Young, Bruce D. Particle Surface Roughness Effects on the Interfacial Mass Transfer Dynamics of Microporous Adsorbents. Chem. Eng. Comm. 68: 165-176; 1988.

51. van Vliet, Ben $M$; Young, Bruce D. The Use of Fractal Dimension To Quantify the Effect of Surface Roughness on Film Mass Transfer Enhancement. Chem. Eng. Comm. 69: 81-94; 1988.

52. van Vliet, B.M.; Weber, W.J.; Hozumi, H. Modeling and Prediction of Specific Adsorption by Activated Carbon and Synthetic Adsorbents Water Research. 14: 1719-1728; 1980.

53. Wohleber, D. A.; Manes, M. Application of the Polanyi Adsorption 
Potential Theory to Adsorption from Solution on Activated Carbon II. Adsorption of Partially Miscible Organic Liquids from Water Solution. J. Phy. Chem. 75: 61-64; 1971 .

54. Wohleber, D. A.; Manes, Milton. Application of the Polanyi Adsorption Potential Theory to Adsorption from Solution on Activated Carbon. III. Adsorption of Miscible Organic Liquids from Water Solution. J. Phy. Chem. 75: 3720-3723; 1971.

55. Wohleber, D. A. Application of the Polanyi Adsorption Potential Theory to Adsorption of Organic Liquids from Water Solution onto Activated Carbon. Doctoral Dissertation. Kent State University. 1970. 